\title{
DEFINITION OF PROMINENT THERMAL MECHANISMS ASSOCIATED WITH THE BUOYANCY-INDUCED TRANSPORT OF HAFNIUM-CARBIDE WITHIN A SOLIDIFYING URANIUM-HAFNIUM ALLOY
}

Michael J. Taylor

Gail Mackiewicz-Ludtka 
This report has been reproduced directly from the begt available copy.

Available to DOE and DOE contractors from the Office of Scientific and Technical Information, P.O. Box 62, Oak Ridge, TN 37831; prices available from (615) 576-8401, FTS 626-8401.

This report was prepared as an account of work sponsored by an agency of the United States Government. Neither the United States Government nor any agency thereof, nor any of their employees, makes any warranty, express or implied, or assumes any legal liability or responsibility for the accuracy, completeness, or usefulness of any information, apparatus, product, or process disclosed, or represents that its use would not intringe privately owned rights. Reference herein to any specitic commercial product, process, or service by trade name, trademark, manufacturer, or otherwise, does not necessarily constitute or imply its endorsement, recommendation, or favoring by the United States Government or any agency thereot. The views and opinions of authors expressed herein do not necessarily state or reflect those of the United States Government or any agency thereof. 


\title{
DEFINITION OF PROMINENT THERMAL MECHANISMS ASSOCIATED WITH THE BUOYANCY-INDUCED TRANSPORT OF HAFNIUM-CARBIDE WITHIN A SOLIDIFYING URANIUM-HAFNIUM ALLOY
}

\author{
Michael J. Taylor \\ Computing and Telecommunications Division \\ at \\ Oak Ridge K-25 Site \\ Post Office Box 2003 \\ Oak Ridge, Tennessee 37831-7039 \\ Gail Mackiewicz-Ludtka \\ Y-12 Development Division \\ Oak Ridge Y-12 Plant \\ Post Office Box 2009 \\ Oak Ridge, Tennessee 37831-7039
}

Manuscript Completed - May 1992

Date Published - December 1992

Martin Marietta Energy Systems, Inc. managing the

Oak Ridge National Laboratory

Oak Ridge K-25 Site

Oak Ridge Y-12 Plant

for the

U.S. DEPARTMENT OF ENERGY

under contract DE-AC05-84OR21400

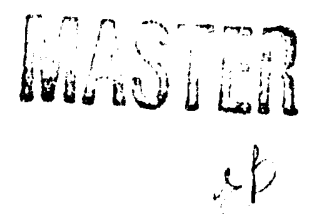




\section{NTENTS}

Page

LIST OF FIGURES $\ldots \ldots \ldots \ldots \ldots \ldots \ldots \ldots \ldots \ldots \ldots \ldots \ldots \ldots \ldots \ldots \ldots \ldots \ldots$

NOMENCLATURE $\ldots \ldots \ldots \ldots \ldots \ldots \ldots \ldots \ldots \ldots \ldots \ldots \ldots \ldots \ldots \ldots \ldots$ vii

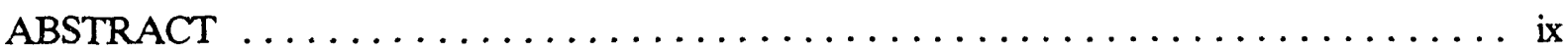

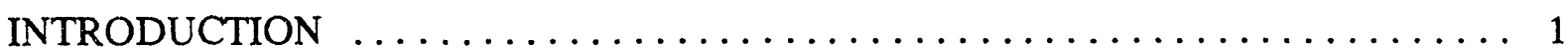

BACKGROUND AND GENERAL PROBLEM STATEMENT $\ldots \ldots \ldots \ldots \ldots$.

CASTING SYSTEM DESCRIPTION $\ldots \ldots \ldots \ldots \ldots \ldots \ldots \ldots \ldots \ldots \ldots \ldots$

DETAILED PROBLEM STATEMENT $\ldots \ldots \ldots \ldots \ldots \ldots \ldots \ldots \ldots \ldots \ldots$

DEVELOPMENT OF THE BASE-CASE MODEL $\ldots \ldots \ldots \ldots \ldots \ldots \ldots \ldots \ldots$

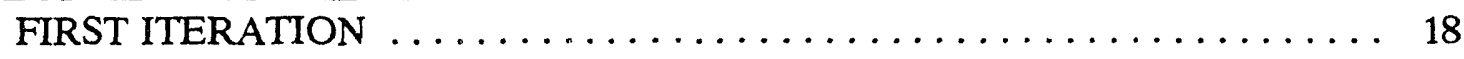

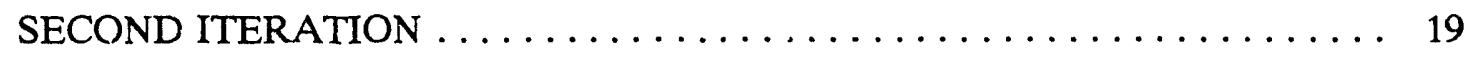

SENSITTVITY STUDIES $\ldots \ldots \ldots \ldots \ldots \ldots \ldots \ldots \ldots \ldots \ldots \ldots \ldots \ldots \ldots$

THERMAL MODEL MACROSCOPIC PERFORMANCE . . . . . . . . . . 59

PHYSICAL MODEL SIMPLIFICATION $\ldots \ldots \ldots \ldots \ldots \ldots \ldots \ldots \ldots \ldots \ldots$

CONCLUSIONS AND RECOMMENDATIONS $\ldots \ldots \ldots \ldots \ldots \ldots \ldots \ldots \ldots$

ACKNOWLEDGMENTS $\ldots \ldots \ldots \ldots \ldots \ldots \ldots \ldots \ldots \ldots \ldots \ldots \ldots \ldots \ldots$

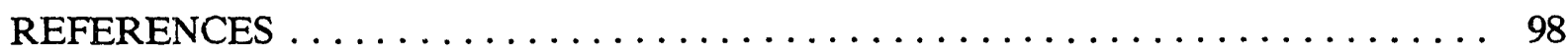

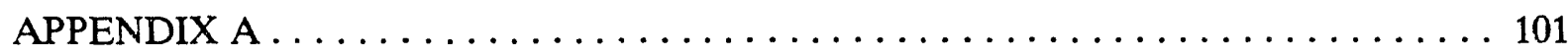




\section{LIST OF FIGURES}

\section{Figure}

1. Engineering drawings showing top, front, and cross-sectional views of the crucible with dimensions in millimeters $\quad \ldots \ldots \ldots \ldots \ldots \ldots \ldots \ldots \ldots \ldots \ldots \ldots$

2. Engineering drawing showing the top, front, and side views of the assembled bookmold with dimensions in millimeters $\ldots \ldots \ldots \ldots \ldots \ldots \ldots \ldots \ldots \ldots$

3. Engineering drawing showing the top and side cross-sectional views of assembled bookmold with dimensions in millimeters $\ldots \ldots \ldots \ldots \ldots \ldots \ldots \ldots \ldots$

4. Engineering drawing showing the top, front, side and cross-sectional views of typical end cap with dimensions in millimeters $\ldots \ldots \ldots \ldots \ldots \ldots \ldots \ldots$

5. Unassembled casting assembly components showing yttrium-oxide coatings . . . . . 7

6. Assembled casting assembly components showing thermocouple placement $\ldots \ldots 8$

7. Schematic illustration of induction heater design $\ldots \ldots \ldots \ldots \ldots \ldots \ldots \ldots$

8. Interior of vacuum-caster pressure vessel $\ldots \ldots \ldots \ldots \ldots \ldots \ldots \ldots \ldots \ldots \ldots \ldots$

9. Exterior of pressure vessel showing diffusion and holding pumps $\ldots \ldots \ldots \ldots \ldots 11$

10. Interior of pressure vessel showing casting assembly and $\mathrm{Al}_{2} \mathrm{O}_{3}$ shield positioned

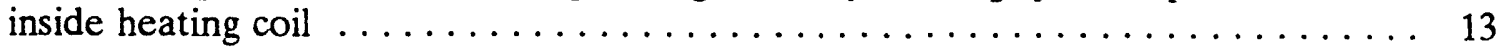

11. Typical experimental temperature data showing transient response of casting assembly

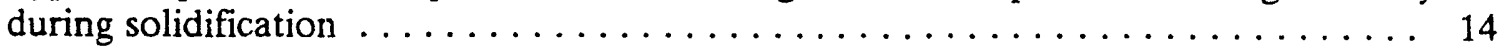

12. Discretized geometry used to represent casting assembly during the initial

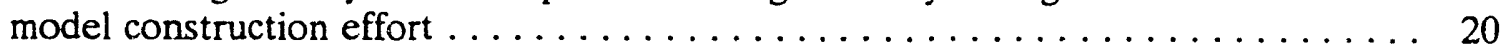

13. Schematic illustration of bookmold/end-cap portion of discretized casting assembly

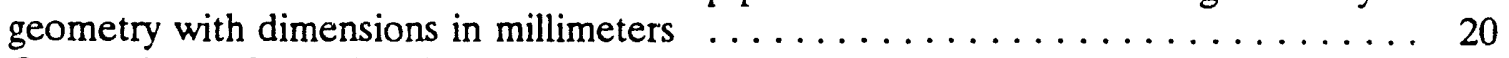

14. Comparison of calculated and experimental bookmold temperatures for the first

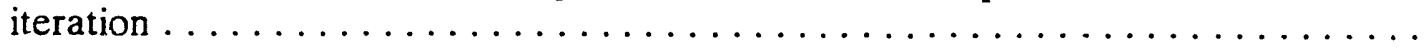

15. Engineering drawing of the approximated upper end cap with dimensions in

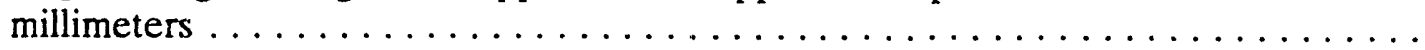

16. Engineering drawing of the approximated lower end cap with dimensions in millimeters . . . . . . . . . . . . . . . . . . 22

17. Engineering drawing of the approximated bookmold with dimensions in millimeters . 23

18. Engineering drawing of the approximated crucible and its top with dimensions in

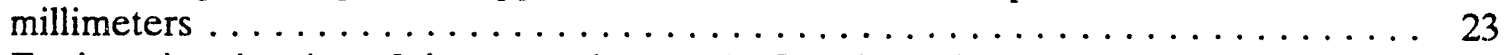

19. Engineering drawing of the approximated $\mathrm{Al}_{2} \mathrm{O}_{3}$ shield with dimensions in millimeters . . . . . . . . . . . . . . . . . . 24

20. Engineering drawing of one pair of plates used to approximate the induction heat coils

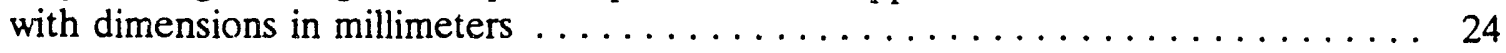

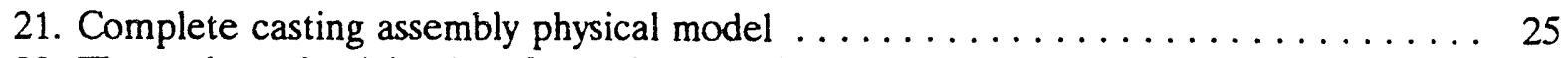

22. Thermal conductivity data for carbon, $\mathrm{Al}_{2} \mathrm{O}_{3}$, copper, solid and liquid uranium,

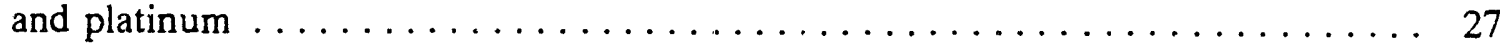

23. Specific heat data for carbon, $\mathrm{Al}_{2} \mathrm{O}_{3}$, copper, solid uranium, and platinum . . . . 27

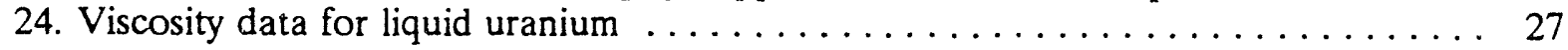

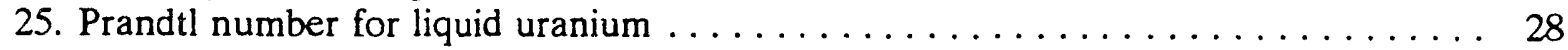

26. Volume coefficient of expansion for liquid uranium $\ldots \ldots \ldots \ldots \ldots \ldots \ldots$

27. Temperature dependent normal total emittance for $\mathrm{Al}_{2} \mathrm{O}_{3} \ldots \ldots \ldots \ldots \ldots \ldots$

28. Temperature dependent normal total emittance for copper . . . . . . . . . . . 29

29. Generic magnetic field radial and axial attenuation for short coils $\ldots \ldots \ldots . \ldots 32$ 


\section{LIST OF FIGURES (continued)}

30. Base-case HEATING model thermocouple agreement . . . . . . . . . . 40

31. Model agreement for the cases where the vertical and horizontal thermal contact resistances (Rth) were increased and decreased by a factor of $5 \ldots \ldots \ldots$

32. Model agreement for the cases where the vertical thermal contact resistances were

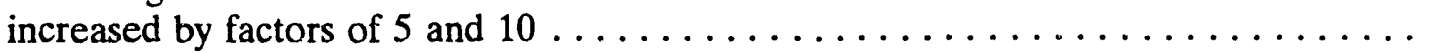

33. Model agreement for the cases where the heating coil cooling-water flow rate was

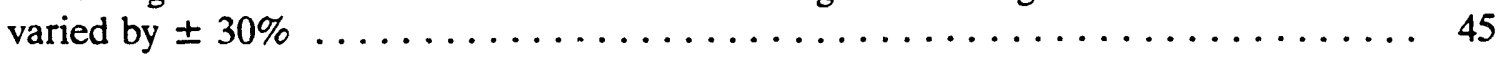

34. Model agreement for the cases where the pressure-vessel wall temperature was varied

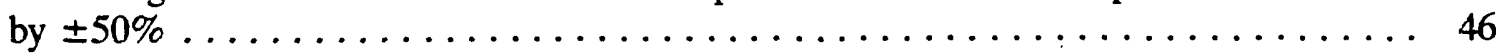

35. Model agreement for the cases where the liquid uranium natural convection heat transfer coefficients were varied by $\pm 50 \% \ldots \ldots \ldots \ldots \ldots \ldots \ldots \ldots$

36. Model agreement for the case where enclosure radiation approximation was

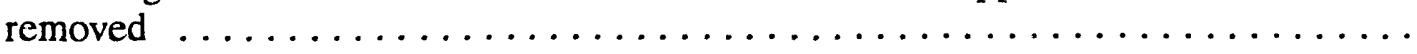

37. Model agreement for the cases where the solidified uranium-bookmold interfacial gap conductance was equal to the base-case liquid uranium natural convectior: heat transfer coefficient and thermal contact resistance $\ldots \ldots \ldots \ldots \ldots \ldots$

38. Model agreement for the cases where the magnetic field axial direction attenuation was varied by $\pm 10 \%$ and where there was no internal heat generation during the

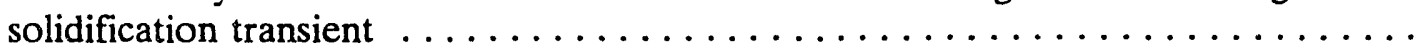

39. Model agreement for the cases where the radiation heat transfer coefficient between the vertical crucible walls and the $\mathrm{Al}_{2} \mathrm{O}_{3}$ shield was increased by factors of 100

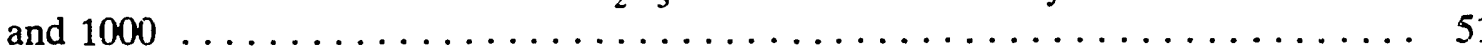

40. Model agreement for the cases where the heating coil current was varied by $\pm 10 \%$. 52

41. Model agreement for the cases where the induced power distribution had an

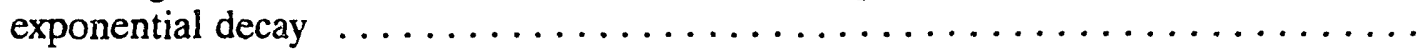

42. Typical model agreement from the earlier sensitivity study for the middle thermocouple location for several combinations of pressure vessel wall temperature, contact resistance, water flow rate, and water inlet temperature . . . . . .

43. Thermocouple locations relative to the casting assembly geometry ...........

44. Base-case model agreement for the complete time period covered by experimental run 892

45. Uranium melt behavior at the beginning of the base-case solidification transient

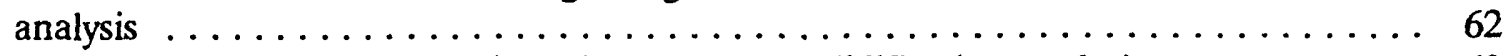

46. Uranium melt behavior $60 \mathrm{~s}$ into the base-case solidification analysis $\ldots \ldots \ldots \ldots 63$

47. Uranium melt behavior $120 \mathrm{~s}$ into the base-case solidification analysis $\ldots \ldots \ldots \ldots 4$

48. Uranium melt behavior $180 \mathrm{~s}$ into the base-case solidification analysis $\ldots \ldots \ldots \ldots 6$

49. Uranium melt behavior $240 \mathrm{~s}$ into the base-case solidification analysis $\ldots \ldots \ldots 66$

50. Uranium melt behavior $300 \mathrm{~s}$ into the base-case solidification analysis $\ldots \ldots \ldots 67$

51. Uranium melt behavior $360 \mathrm{~s}$ into the base-case- solidification analysis . . . . . . 68

52. Uranium melt behavior $420 \mathrm{~s}$ into the base-case- solidification analysis . . . . . . . 69

53. Casting assembly temperature distribution at the beginning of the base-case

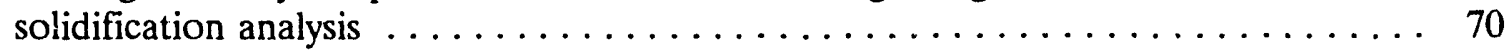

54. Casting assembly temperature distribution $60 \mathrm{~s}$ into the base-case solidification

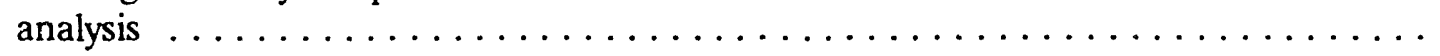




\section{LIST OF FIGURES (continued)}

Figure

$\underline{\text { Page }}$

55. Casting assembly temperature distribution $120 \mathrm{~s}$ into the base-case solidification

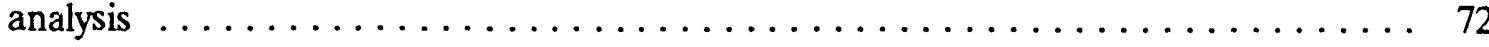

56. Casting assembly temperature distribution $180 \mathrm{~s}$ into the base-case solidification

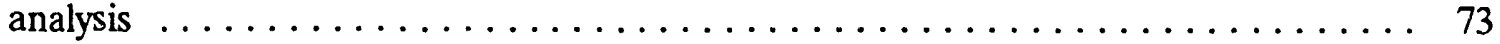

57. Casting assembly temperature distribution $240 \mathrm{~s}$ into the base-case solidification

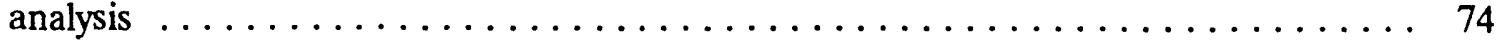

58. Casting assembly temperature distribution $300 \mathrm{~s}$ into the base-case solidification

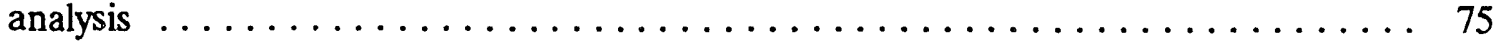

59. Casting assembly temperature distribution $360 \mathrm{~s}$ into the base-case solidification

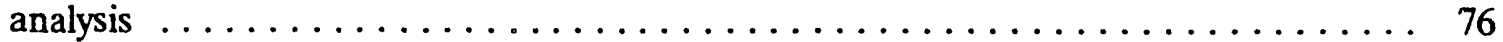

60. Casting assembly temperature distribution $420 \mathrm{~s}$ into the base-case solidification

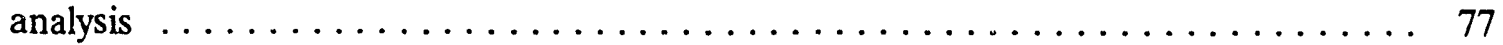

61. The set of $X-Z$ plane monitored locations $\ldots \ldots \ldots \ldots \ldots \ldots \ldots \ldots \ldots \ldots$

62. Temperature history of selected nodes at the base of the lower end cap . . . . . . 79

63. Temperature history of selected nodes at $5.5 \mathrm{~cm}$ into the firebrick base $\ldots \ldots \ldots 79$

64. Temperature history of selected nodes at $15.5 \mathrm{~cm}$ into the firebrick base $\ldots \ldots \ldots 80$

65. Temperature history of selected nodes at $25.5 \mathrm{~cm}$ into the firebrick base $\ldots \ldots \ldots 80$

66. Model agreement for the thermocouple and flat plate simplification scenarios . . . 82

67. Schematic illustration showing recommended thermocouple locations for upper end

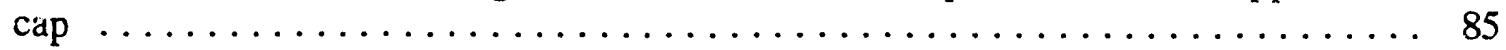

68. Schematic illustration showing recommended thermocouple locations for the lower end

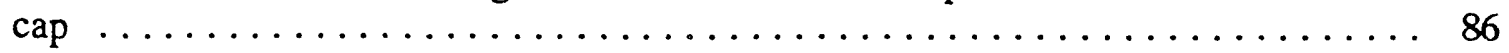

69. Schematic illustration showing recommended thermocouple locations for the bookmold

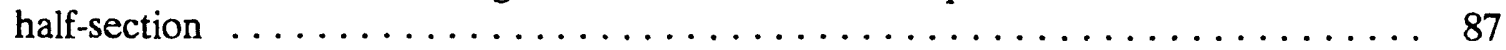

70. Simplified buoyancy driven flow system showing velocity and thermal boundary

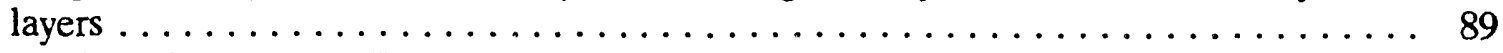

A1. Listing of base-case HEATING steady-state input file $\ldots \ldots \ldots \ldots \ldots \ldots \ldots \ldots$

A2. Listing of base-case HEATING transient input file $\ldots \ldots \ldots \ldots \ldots \ldots \ldots \ldots \ldots$

A3. Listing of base-case HEATING user supplied subroutines $\ldots \ldots \ldots \ldots \ldots \ldots \ldots$ 


\section{NOMENCLATURE}

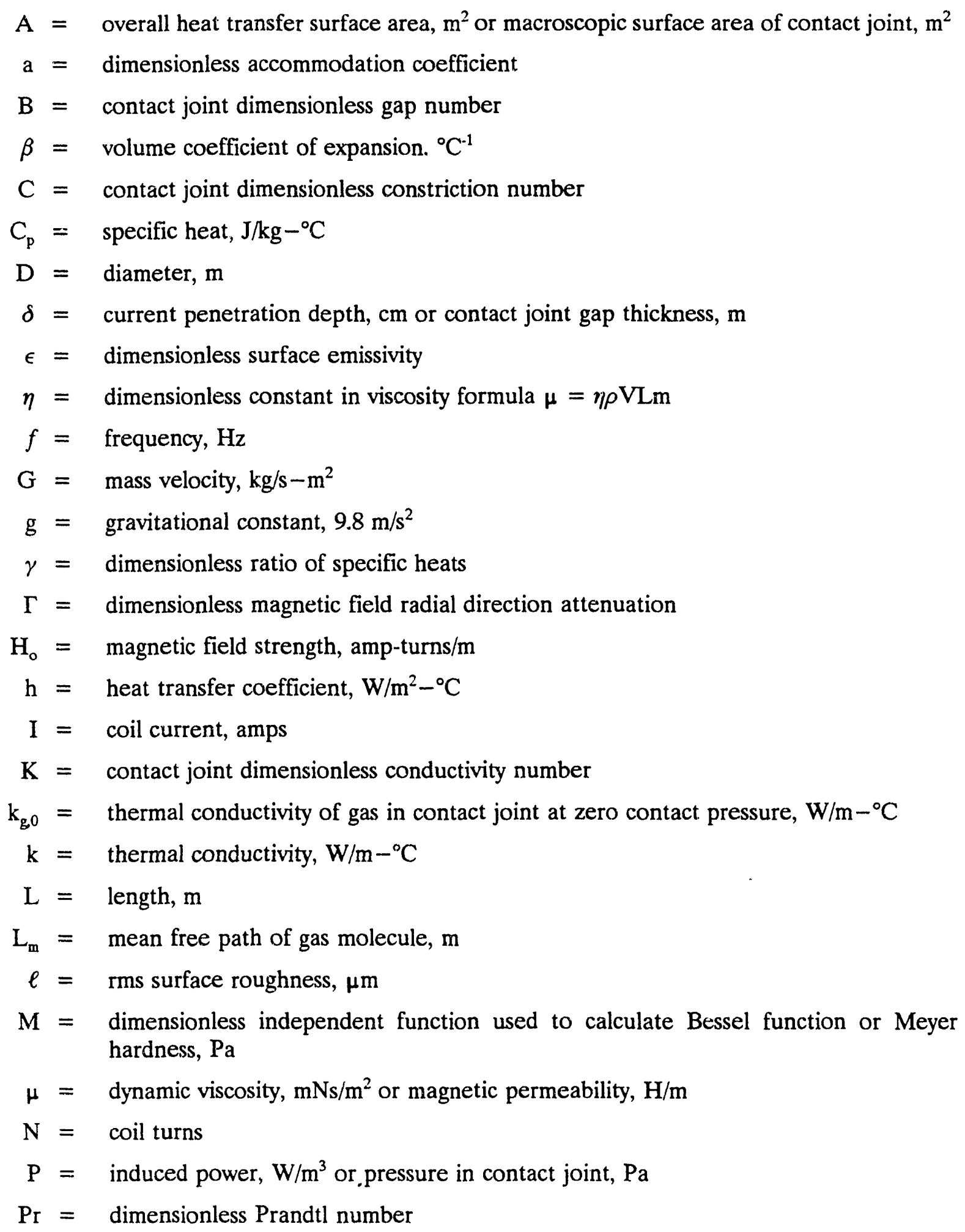




\section{NOMENCLATURE (continued)}

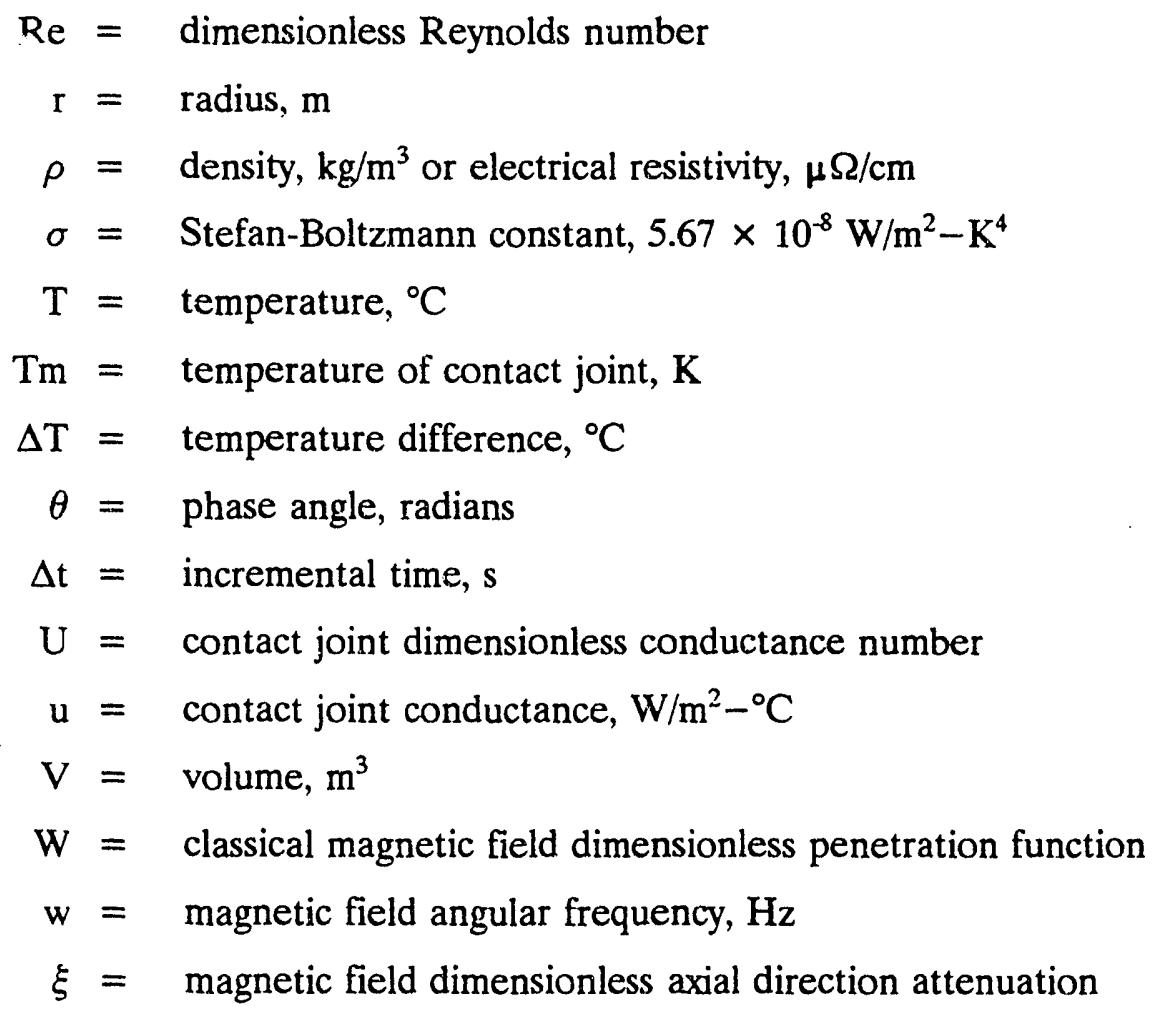

subscripts

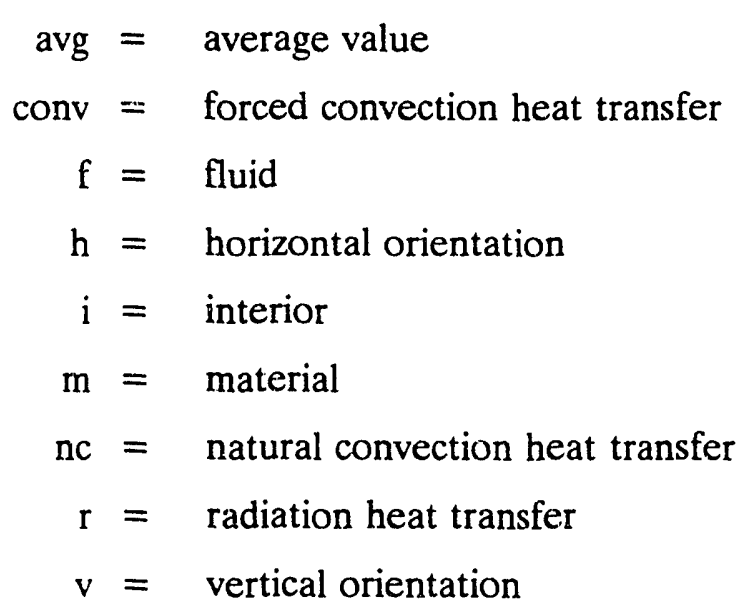




\begin{abstract}
Increased environmental concerns over the handling of uranium wastes have generated interest in using existing uranium stockpiles as feed materials. One obstacle to extensive recycling is that it causes an accumulation of carbon that can degrade as-cast mechanical properties. A program was begun to develop a casting procedure capable of reducing the carbon content in components made from recycled uranium to levels comparable with virgin feed stock. Trace amounts of hafnium are added to form low-density hafnium-carbide, which floats to the top of the casting. This procedure effectively relocates the carbon, where it can be removed at a later time. Developing this procedure requires modeling carbide transport within solidifying uranium, and this necessitates solving a coupled, nonlinear fluid dynamics, heat transfer, and solution thermodynamics problem. Because of the large number of technical and numerical uncertainties associated with this calculation, it was necessary to initially study the problem elements separately and the heat transfer facet was addressed first. The steady-state and transient thermal performance of a laboratory-scale casting assembly was characterized to identify those mechanisms that have a prominent influence on modeling uranium melt solidification. The analysis showed that (1) at least first-order accurate definitions for all thermal mechanisms were required to obtain meaningful agreement with experimental data; (2) prominent mechanisms were thermal contact resistances, liquid uranium natural convection, and internal heat generation; and (3) accurately modeling assembly geometry and enclosure radiation heat transfer would also improve agreement. It was recommende that a second-generation thermal model should be constructed which would include each of thise elements.
\end{abstract}




\section{INTRODUCTION}

\section{BACKGROUND AND GENERAL PROBLEM STATEMENT}

The Oak Ridge Y-12 Plant produces uranium (U) castings using carbon (C) molds as a part of its production activities. In response to increased environmental concerns over the handling and storage of uranium wastes, the use of recycled uranium as a feed material is becoming increasingly attractive. One obstacle to extensive recycling is that repeated casting causes an accumulation of unacceptable carbon levels - on the order of hundreds of parts per million (ppm). This additional carbon results in an increased number of carbide inclusions that have a deleterious effect on as-cast mechanical properties. In CY 1985 the Materials Engineering Department of the Y-12 Development Division tregan a program to develop a casting procedure capable of reducing the carbon conten $t$ in recycled uranium products to levels comparable with virgin feed stock. The procedure chosen for development takes advantage of two characteristics of carbon chemistry: it can easily form compounds with certain elements, and these compounds are less dense than liquid uranium. Conceptually, trace amounts of an alloying element are added to the uranium to combine with the carbon, forming a relatively low-density compound. Buoyancy forces would then tend to transport this compound toward the top of the casting. This procedure effectively relocates the carbon contaminants, where, after solidification, they can be removed and the remainder of the billet used as needed. ${ }^{1}$ After a study of the reaction kinetics of several candidate elements, hafnium (Hf) was chosen for its large free energy of formation and relatively low density, $12.6 \mathrm{~g} / \mathrm{cm}^{3}$ for HfC compared with $17.7 \mathrm{~g} / \mathrm{cm}^{3}$ for uranium.

Developing an optimum uranium-hafnium (U-Hf) composition and production-scale casting assembly design requires predicting carbide motion within solidifying uranium. This transport is controlled by buoyancy forces that result from uranium-hafnium-carbide (U/HFC) and thermally induced density differences. Fluid convective currents, in turn, are dependent on heat transfer out of the casting assembly. Predicting carbide transport then requires solving three coupled, nonlinear problems: a fluid dynamics calculation to define pouring, carbide transport, and solidification; a heat transfer calculation to define the transport of thermal energy away from the fluid; and a solution thermodynamics calculation to define carbide formation. These calculations require a considerable numerical analysis effort, with as many computational uncertainties as there are HfC formation and transport unknowns. Accordingly, an integrated experimental-numerical execution sequence was impleniented so both elements could mature simultaneously. The current focus of this joint effort are laboratory-scale casting experiments designed to quantify basic system performance. Uranium billets are produced to define macroscopic carbide behavior, and casting assembly temperature data are supplied to support numerical studies that are currently aimed at defining thermal-hydraulic cause and effect. The focus of this report is the numerical studies.

The macroscopic objective of these studies is to characterize the thermal, hydraulic, and metallurgical behavior of a U-Hf alloy and its U/HfC component as it melts then solidifies within a carbon casting assembly. Modeling tasks will be defined to support this goal within the context of a research and development (R\&D) environment:

1. coordinating with experimental studies to characterize carbide transport as a function of prominent thermal, hydraulic, and metallurgical mechanisms for a given casting assembly geometry; 
2. providing guidance for scale-up of assembly geometry where the recommendations have been constrained by the current level of technical uncertainties; and

3. repeating the analyses/scale-up sequence until the uncertainties have been reduced to an acceptable level and a mature production-scale technology exists.

\section{CASTING SYSTEM DESCRIPTION}

Experimental studies are conducted using a laboratory-scale vacuum-induction casting system located in the Y-12 Development Foundry. It consists of a casting assembly, a watercooled induction heater, a vacuum-caster, which is a type of pressure vessel that permits the casting process to take place under evacuated conditions, as well as process control and data recording instrumentation.

The casting assembly is designed to mold approximately $18 \mathrm{~kg}$ of U-Hf alloy into a rectangular billet $3.97 \mathrm{~cm}$ thick, $13 \mathrm{~cm}$ wide, and $18.73 \mathrm{~cm}$ long. It consists of five components: a crucible, upper end cap, two bookmold halves, and a lower end cap. The crucible contains the liquid uranium prior to pour, the end caps restrain the bookmold halves, and the bookmold contains the uranium as it solidifies. Scale drawings (dimensions in millimeters) of the crucible, bookmold, and a nominal end cap are shown in Figs. 1, 2, 3, anc 4 respectively. The individual components are shown in Fig. 5, and the assembled pieces are hown in Fig. 6. All components are fabricated in-house from ATJ grade graphite, and those surfaces that might come in contact with liquid uranium are coated with yttrium-oxide. In addition, three platinum $-90 \%$ platinum$110 \%$ rhodium thermocouples with aluminum-oxide $\left(\mathrm{Al}_{2} \mathrm{O}_{3}\right)$ insulating sheaths are installed along the height of one of the bookmold halves. They are positioned halfway into the width and thickness of the piece at distances of $5.08 \mathrm{~cm}, 11.75 \mathrm{~cm}$, and $18.42 \mathrm{~cm}$ from the top of the bookmold. Figure 6 illustrates this thermocouple configuration. As Fig. 6 also shows, the components are assembled by simply stacking them; no mechanical fasteners or other external constraints are used. From a numerical analysis uncertainty perspective, there are two noteworthy aspects of the stacking process.

1. The radial clearances between the bookmold and endcaps are such that a great deal of mechanical force is required to seat the bookmolsi. This results in larger contact pressures and, conceptually, smaller thermal contact resistances in the radial direction than in the axial direction.

2. The radial clearances between the crucible and the $\mathrm{Al}_{2} \mathrm{O}_{3}$ shield are such that there is the possibility of direct contact between the components at high temperatures. Even though there is no question that radiation exchange is the only heat transfer mechanism between the assembly and shield below the crucible, there is considerable uncertainty as to the mechanism(s) and their magnitude between the crucible and the shield.

The induction heater is a $15-\mathrm{kW}, 10,000-\mathrm{Hz}$, digitally controlled, solid-state (i.e., silicon controlled rectifier (SCR) based invertor) unit originally manufactured by Industrial Electric Heating, Inc. It is designed to deliver a constant power level to the casting assembly and consists of four basic subsystems: a high-frequency power supply, an isolation transformer, work coil, and the casting assembly. Electrically, these components function as a series of transformer windings, with the heating coil and casting assembly comprising the final pair. The primary winding of the isolation transformer is placed across the high-frequency power supply, and the secondary is the work coil. The work coil, in turn, represents the primary of the heating coil, and the casting assembly functions as the secondary, once it is placed inside the heating coil. This basic design 


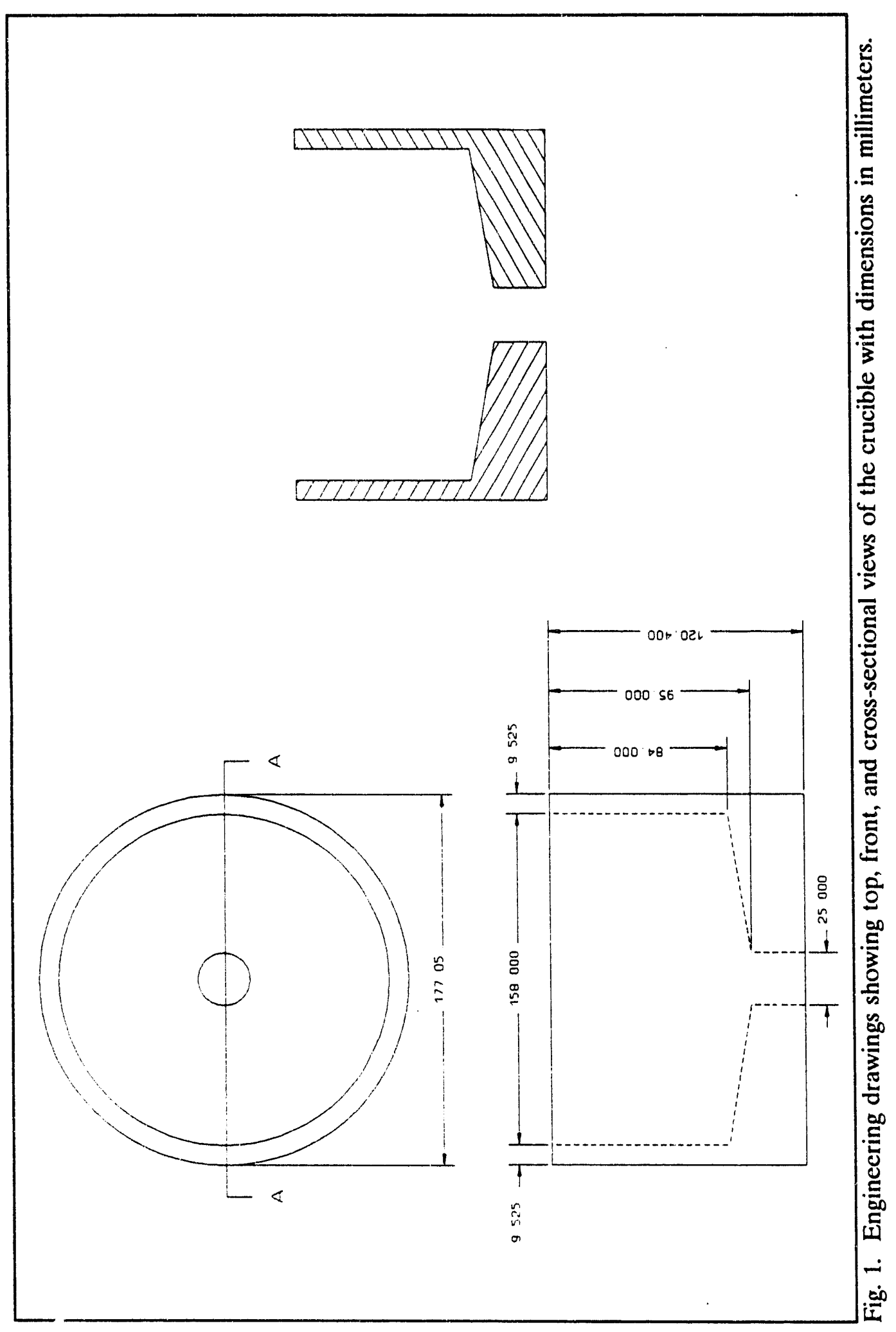



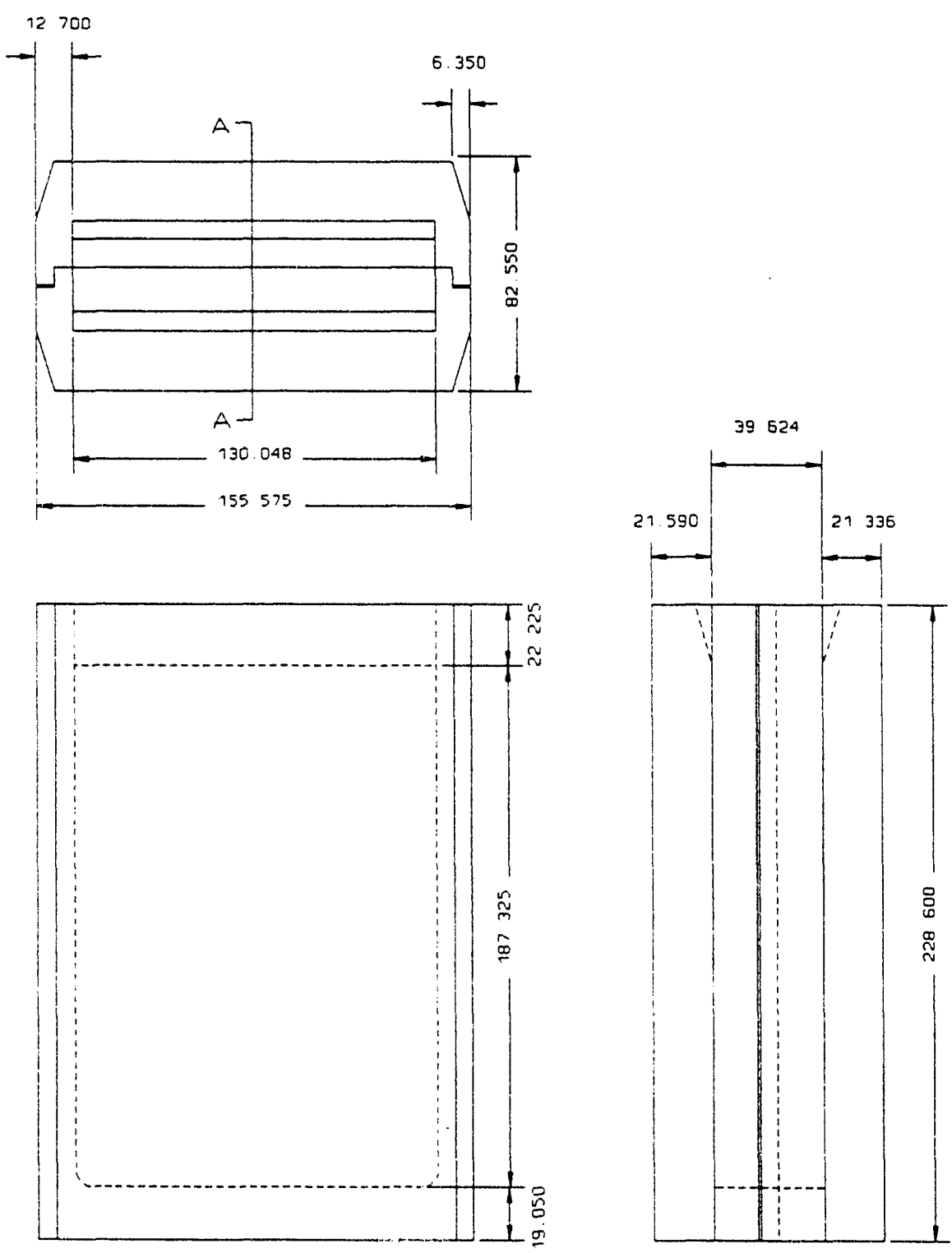

Fig. 2. Engineering drawing showing the top, front, and side views of the assembled bookmold with dimensions in millimeters. 


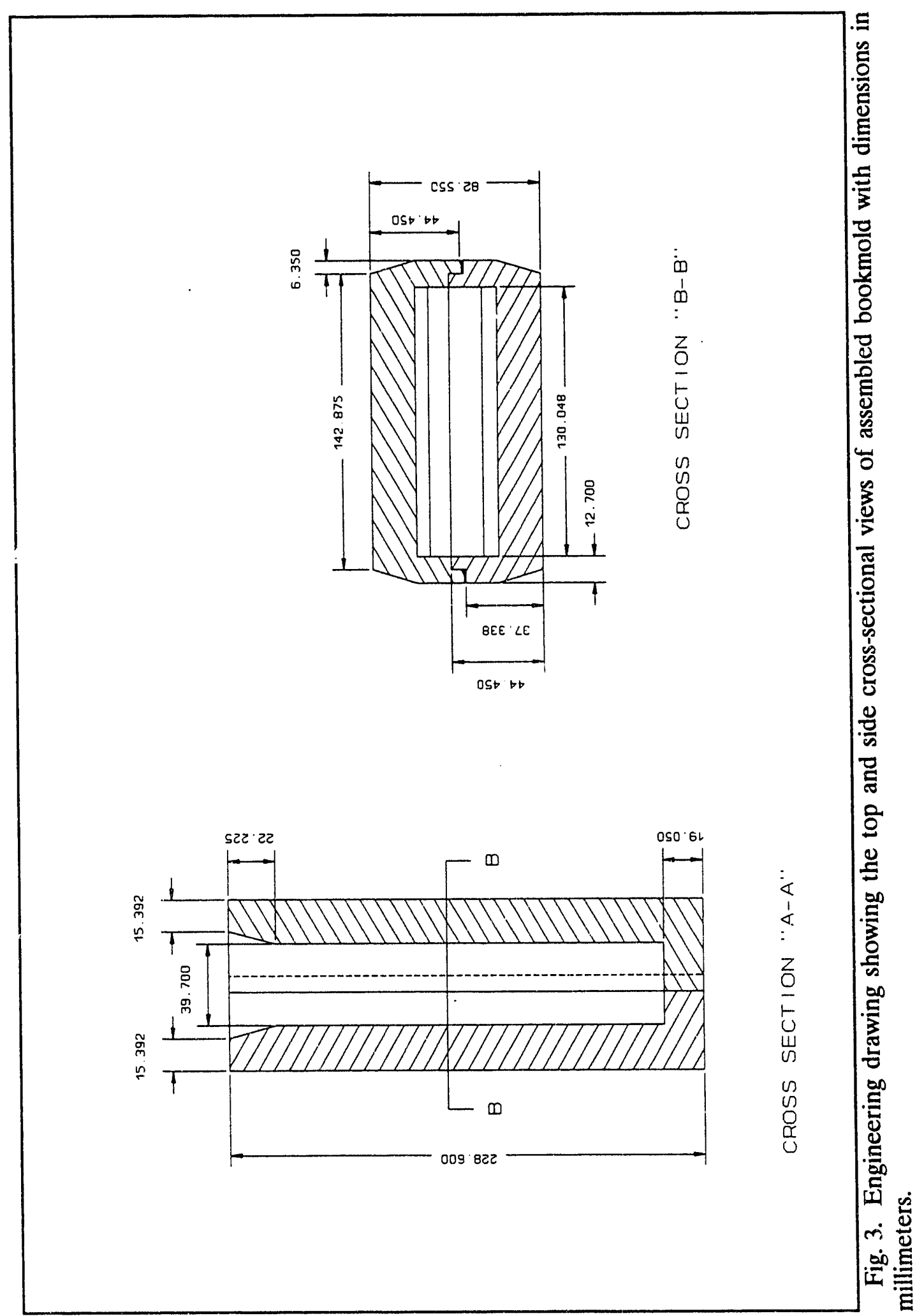



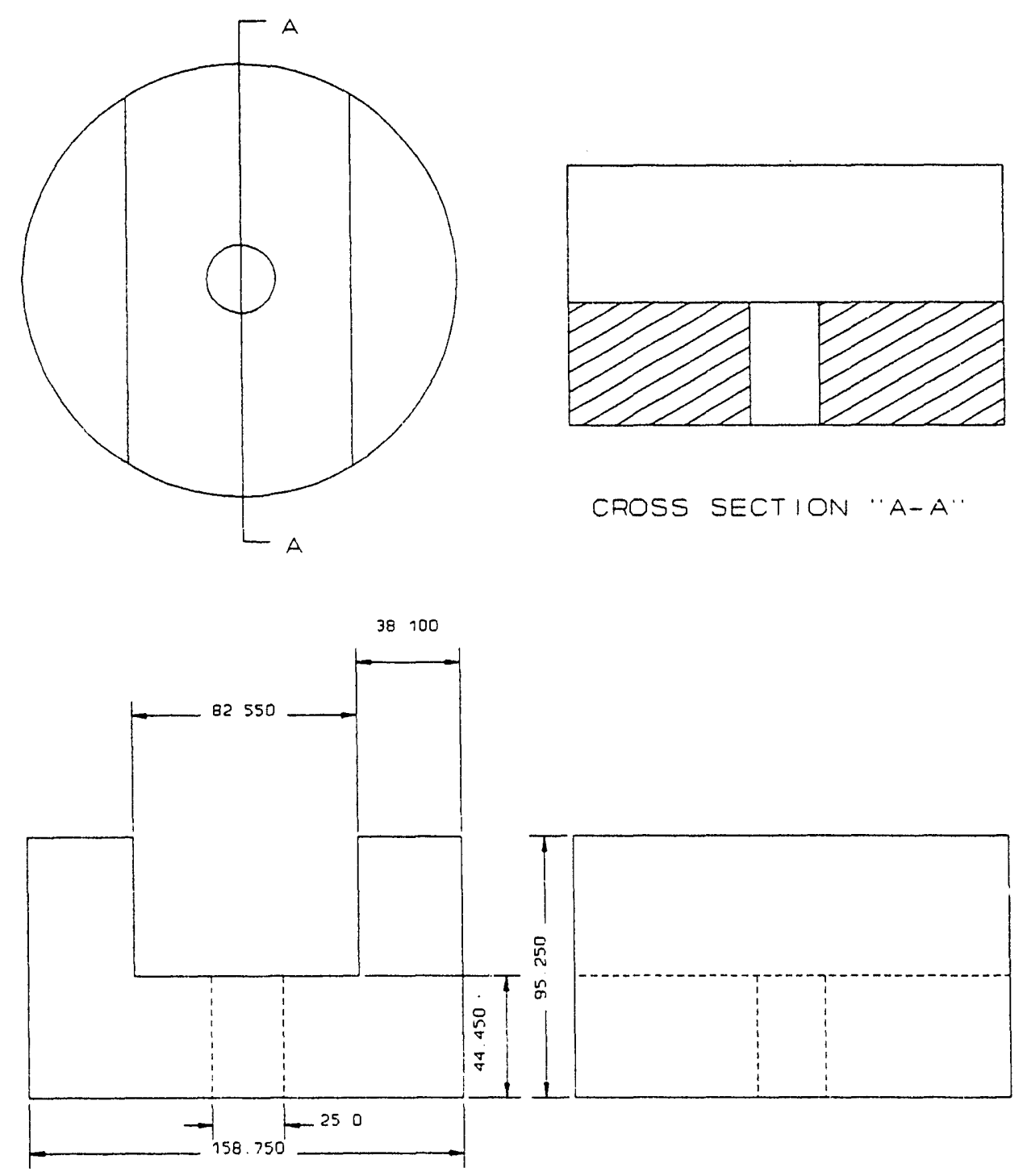

Fig. 4. Engineering drawing showing the top, front, side and cross-sectional views of typical end cap with dimensions in millimeters. 


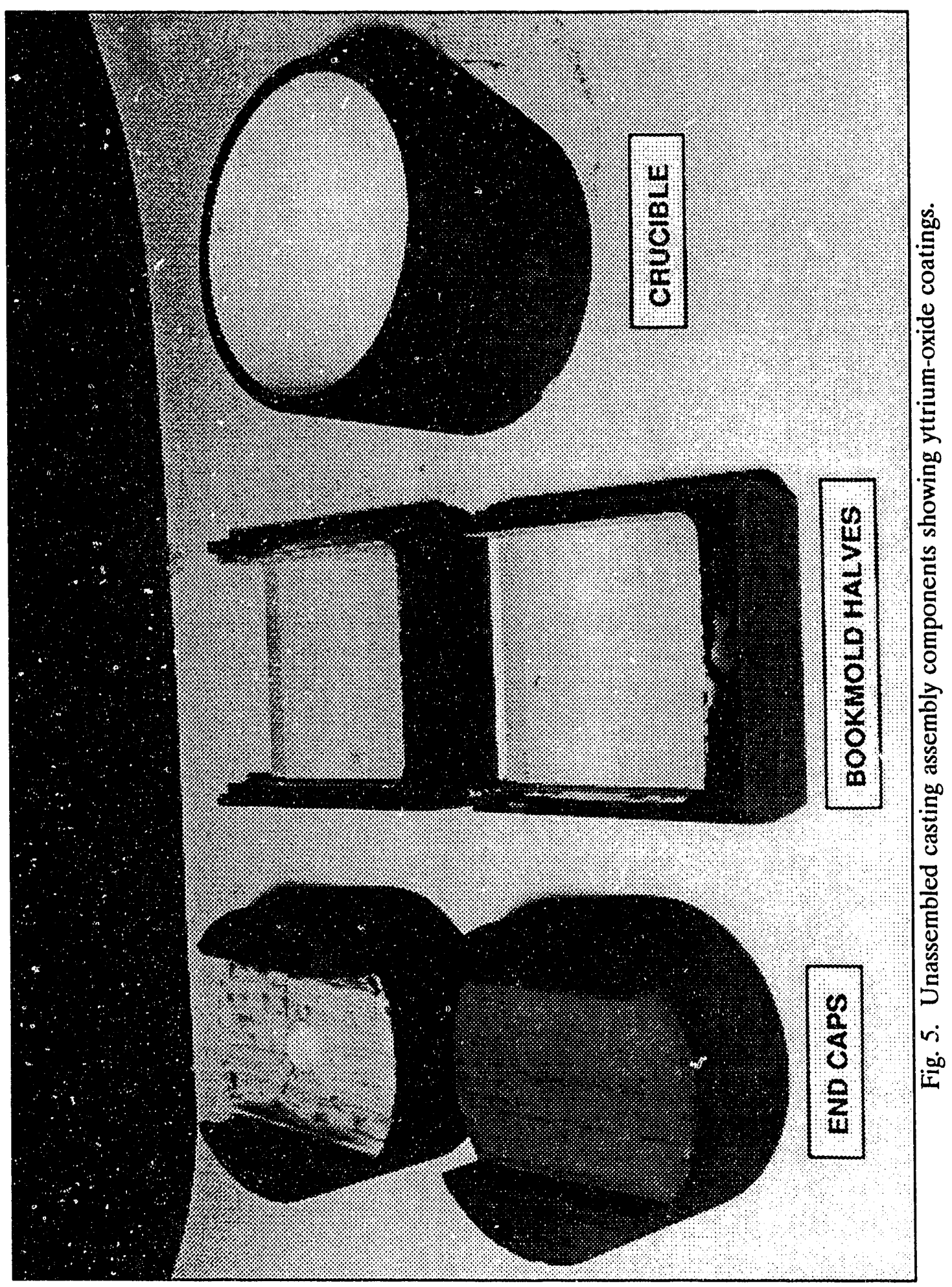




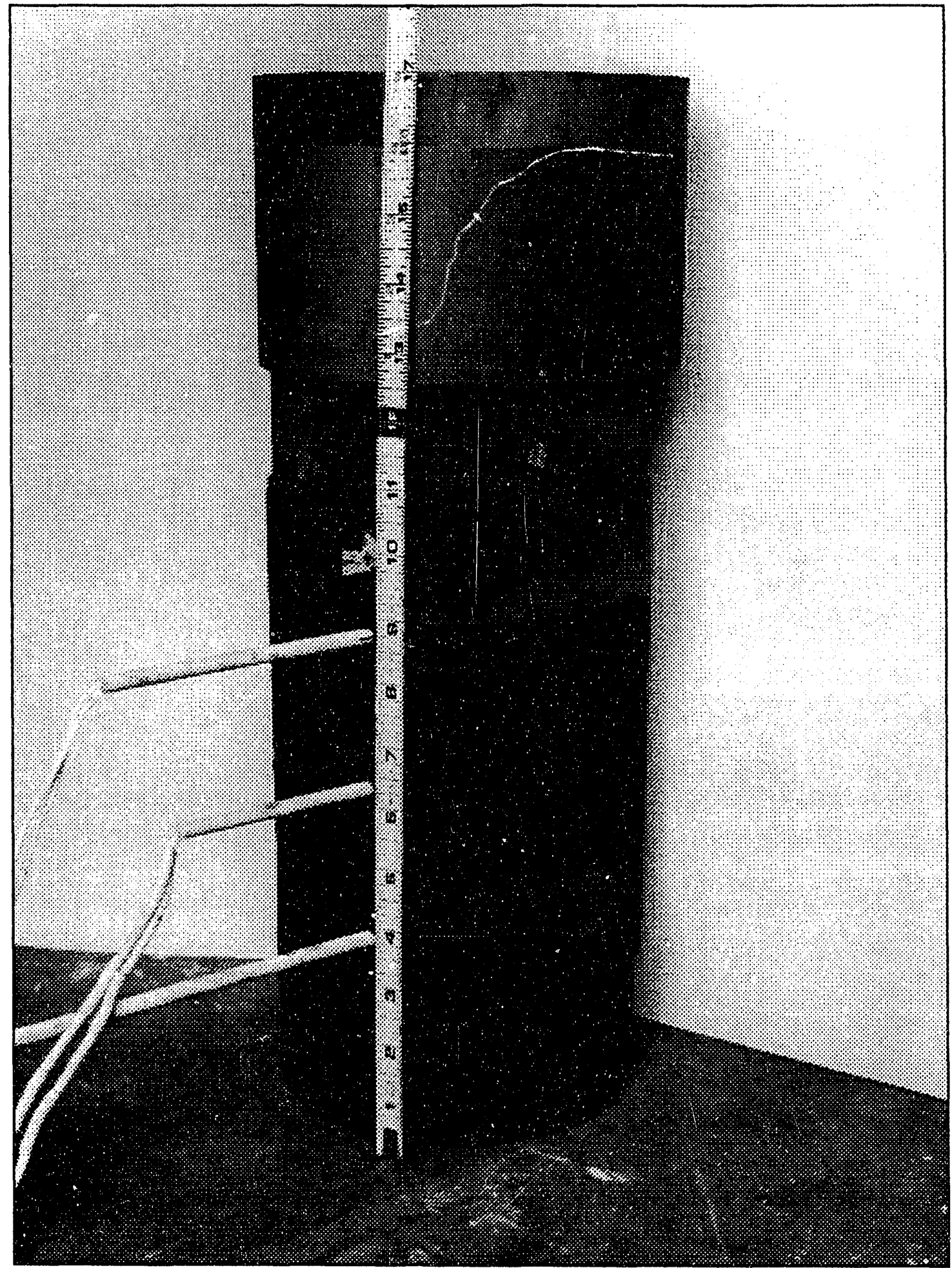

Fig. 6. Assembled casting assembly components showing thermocouple placement. 
is illustrated schematically in Fig. 7. Within the context of this problem the induction heater is divided mechanically into two sections: the heating coil primary winding located inside the vacuum-caster, and the remainder of the system located outside the caster in separate enclosures. The heating coil is formed from twelve turns of a single, small-diameter copper tube and is physically supported and electrically insulated by three nonconducting members. It has a mean radius of $10.75 \mathrm{~cm}$, is $23.5 \mathrm{~cm}$ high, and is elevated $44.5 \mathrm{~cm}$ from the bottom of the caster. Figure 8 illustrates this configuration. The copper tube is hollow to permit the flow of cooling water and has an inner diameter (ID) and wall thickness of $1.5875 \mathrm{~cm}$ and $0.1651 \mathrm{~cm}$ respectively. Cooling water from the plant process water system (i.e., cooled across a direct contact, forced draft cooling tower) enters at the bottom and exits at the top of the coil. The water is not pumped locally but rather is supplied from and returned to the ultimate heat sink via an extensive interbuilding piping network. Accordingly, the flow rate is a function of the hydraulic load on the entire network and can therefore vary between experiments, as well as during an individual run. This variability is an uncertainty that must also be addressed in the numerical studies.

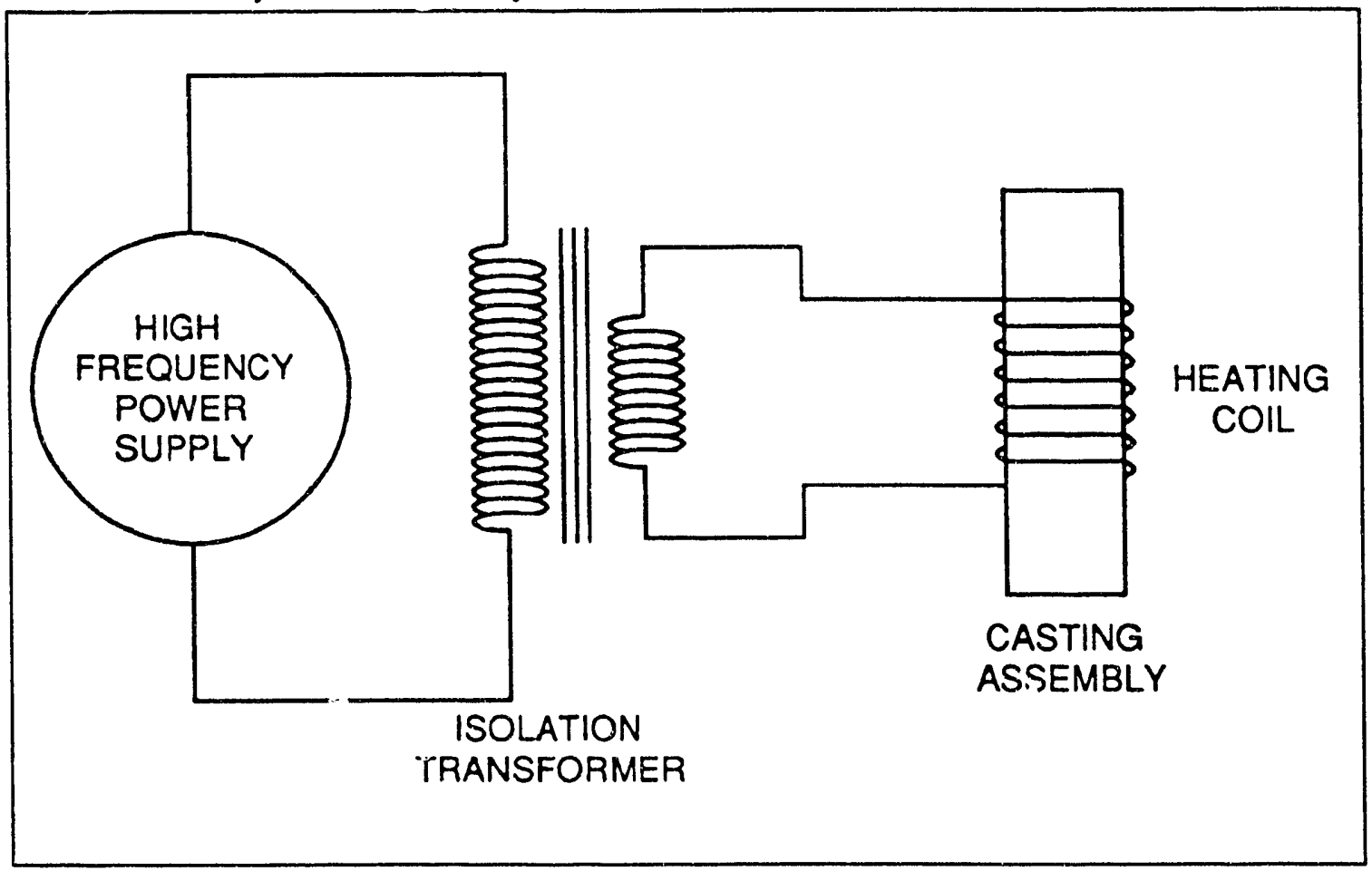

Fig. 7. Schematic illustration of induction heater design.

The vacuum-caster consists of a pressure vessel, two vacuum pumping systems, and associated piping and valves. It was originally designed, procured, and fabricated in-house. The pressure vessel is cylindrical in shape, constructed from $0.953-\mathrm{cm}$-thick carbon steel, and has an inner diameter and height of 116.0 and $106.5 \mathrm{~cm}$ respectively. It is divided into two sections: a fixed bottom half and a hinged top to facilitate loading and unloading of the casting assembly. Figure 9 shows the exterior of the vessel. The vessels's interior contains a pour rod, rod linkage, and the primary winding of the induction heater. Figure 8 also shows the rod and its linkage. Two pumping systems are required to achieve the high vacuums needed for casting of uranium alloys. The first system is a DUO-SEAL model 1398 roughing pump designed to reduce the pressure inside the vessel from atmospheric to approximately $50 \mu \mathrm{m} \mathrm{Hg}$. The second system 


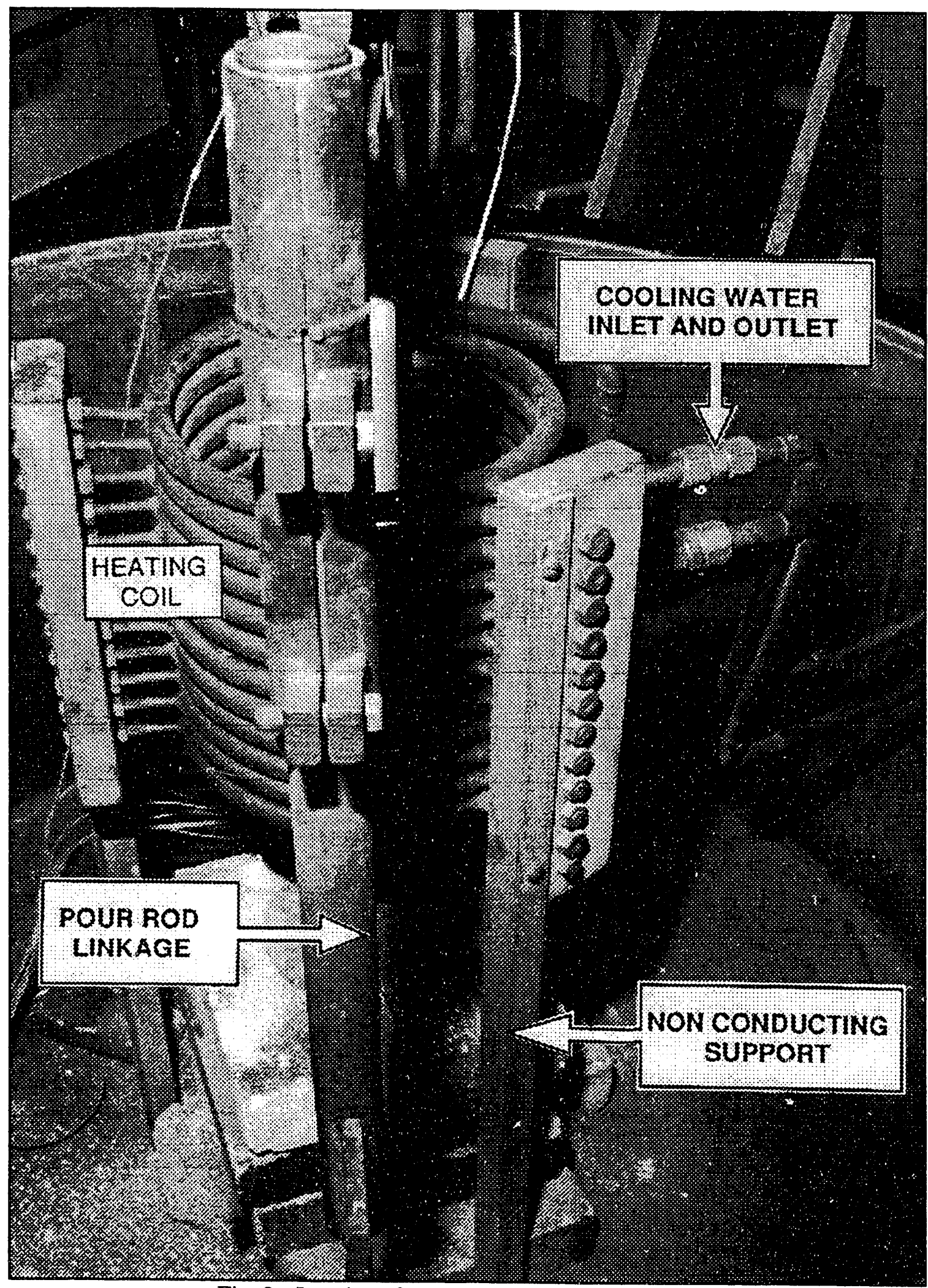

Fig. 8. Interior of vacuum-caster pressure vessel. 


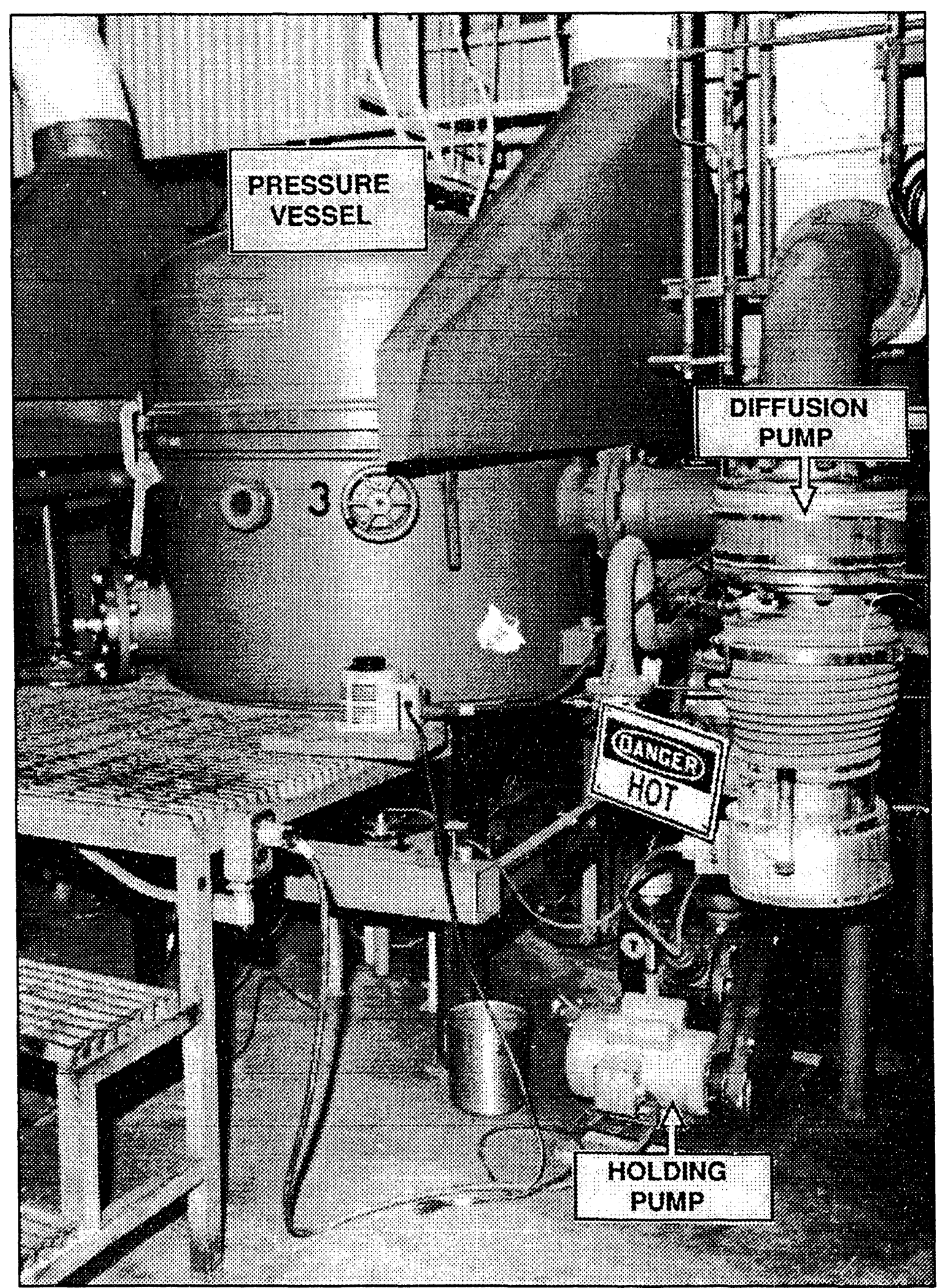

Fig. 9. Exterior of pressure vessel showing diffusion and holding pumps. 
consists of a VARIAN diffusion pump and a DUO-SEAL model 1397 holding pump connected in series. They further reduce the pressure to the desired operating level of about $5 \mu \mathrm{m} \mathrm{Hg}$. Figure 9 also shows the location of the diffusion and holding pumps.

During an experiment the casting assembly is positioned inside the heating coil, as shown in Fig. 10. Sufficient firebrick is placed under the assembly to elevate it $25.50 \mathrm{~cm}$ from the bottom of the caster. The assembly is mechanically, electrically, and thermally insulated from the heating coil by a ceramic shield constructed from $96 \%$ pure $\mathrm{Al}_{2} \mathrm{O}_{3}$. It has an ID of $17.78 \mathrm{~cm}$, a wall thickness of $0.95 \mathrm{~cm}$, and is $32.5 \mathrm{~cm}$ high. As shown in Fig. 10, the shield is positioned vertically via small pieces of firebrick such that it is elevated $12.5 \mathrm{~cm}$ from the bottom of the casting assembly. The relative position of the casting assembly, the $\mathrm{Al}_{2} \mathrm{O}_{3}$ shield, and the heating coil is critical for the proper preheating of the bookmold, and for establishing and maintaining the directional solidification required for acceptable castings. The uranium melt temperature in the crucible is measured using a single platinum $-90 \%$ platinum $/ 10 \%$ rhodium thermocouple that has been inserted in an $\mathrm{Al}_{2} \mathrm{O}_{3}$ thermowell. The thermowell is secured to the side of the crucible, rests on the bottom of the crucible, is $20.32 \mathrm{~cm}$ long, and has an ID and wall thickness of 0.6350 $\mathrm{cm}$ and $0.15876 \mathrm{~cm}$ respectively.

Within the context of this problem, the casting system has two sets of instrumentation; one to control and monitor the operation of the heating coil, and one to record pertinent process temperatures and pressures. Analog displays are provided with the induction heater to show frequency and voltage across the heating coil primary winding, as well as kilowatts, voltage, and current across the primary winding of the isolation transformer. Uranium melt and bookmold temperatures are recorded using a multichannel TOKOGAWA strip chart recorder. Pressure inside the caster is measured using a TELEDYNE-type DV6M vacuum gage tube pressure transmitter and is displayed on a HASTINGS analog vacuum gage calibrated in $\mu \mathrm{m} \mathrm{Hg}$. During the time period covered by this report there were no provisions for measuring heating-coil current, cooling-water flow rates, cooling-water inlet and outlet temperatures, or pressure-vessel wall temperatures.

A typical casting experiment has two phases: a heat-up phase in which the recycled uranium and hafnium are melted together in the crucible and a solidification phase where the alloy is poured into the bookmold and allowed to freeze. A nominal experiment proceeds as follows.

1. The casting assembly, $\mathrm{Al}_{2} \mathrm{O}_{3}$ shield, and firebrick are positioned in the caster, as shown in Fig. 10. Approximately $18 \mathrm{~kg}$ of recycled uranium containing 200 to $225 \mathrm{ppm}$ carbon is placed in the crucible along with some number of pre-alloyed uranium-ha nium buttons. The thermowell with its thermocouple are secured to the crucible wall, the pour rod is seated in the crucible, and an $\mathrm{Al}_{2} \mathrm{O}_{3}$ cover is placed on top of the crucible.

2. The caster is secured and the roughing pump started. When the pressure has dropped to approximately $50 \mu \mathrm{m} \mathrm{Hg}$, the roughing pump is valved out and the diffusion and holding pumps started and continue to run for the remainder of the experiment. When the pressure reaches $5 \mu \mathrm{m} \mathrm{Hg}$, the cooling water and power to the heating coil are turned on.

3. Coil power is manually increased at a rate to minimize the caster's instantaneous pressure rise due to assembly outgasing. Once the uranium has reached the target melt temperature, coil power is gradually reduced until the system has reached steady-state. These conditions are held for approximately $30 \mathrm{~min}$, at which time the pour rod is removed and the uranium alloy is drained into the bookmold and allowed to freeze. The induction heater continues to run for some few seconds after the pour and is then turned 


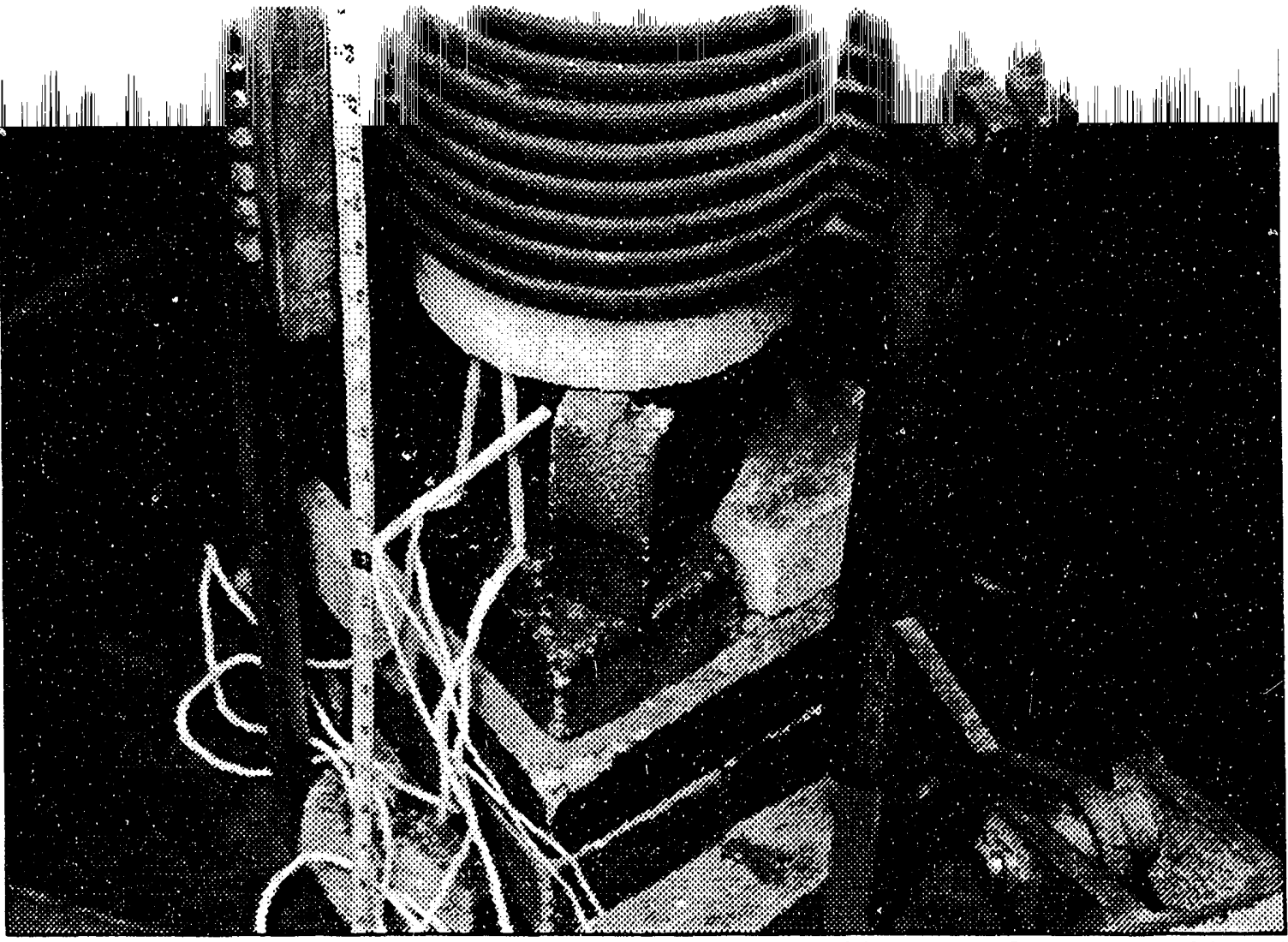

Fig. 10. Interior of pressure vessel showing casting assembly and $\mathrm{Al}_{2} \mathrm{O}_{3}$ shield positioned inside heating coil. 
off. The cooling water continues to run for the remainder of the experiment. During the melting phase the operators record time, melt temperature, isolation transformer primary coil power, and caster pressure. Beginning at the pour and continuing for several hours, the TOKOGAWA recorder prints out the three bookmold temperatures.

4. After the casting has completely solidified, the caster is backfilled with argon to a pressure of approximately $10 \mathrm{in.} \mathrm{Hg}$ vacuum and allowed to cool for an extended time period. The caster is then filled with argon to atmospheric pressure, opened up, and the casting removed for metallurgical examination.

5. The casting assembly is completely disassembled; any remaining yttrium-oxide is gritblasted off, fresh oxide is applied, and the components are stored until the next run.

A typical set of experimental temperature data are shown in Fig. 11. These data represent the transient response of the casting assembly during the solidification phase and were taken with the three thermocouples located in the bookmold vertical wall. The experiment utilized the casting assembly and vacuum-caster described above, was designated as Run No. 892, had a uranium target melt temperature of $1375^{\circ} \mathrm{C}$, a caster internal press are of $6 \mu \mathrm{m} \mathrm{Hg}$, and a total charge weight of $18,019.9 \mathrm{~g}$.

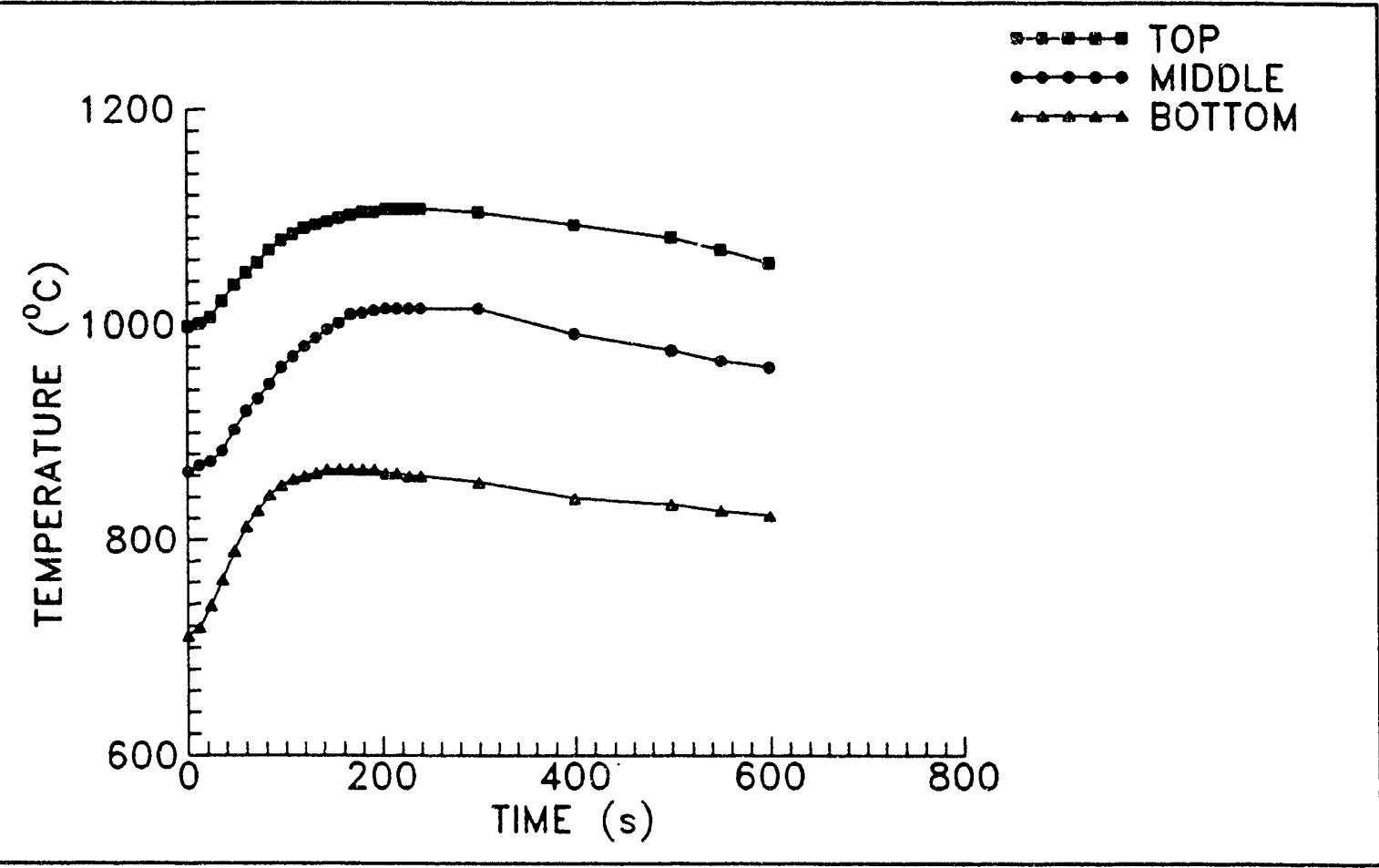

Fig. 11. Typical experimental temperature data showing transient response of cásting assembly during solidification.

\section{DETAULD PROBLEM STATEMENT}

As explained, predicting carbide transport will ultimately require a coupled fluid dynamics, heat transfer, and solution thermodynamics calculation. Formulating a tractable solution procedure requires consideration of several technical and programmatic issues, primarily the scope of the 
problem and the relative immaturity of the numerical studies. The scope of the problem is extensive. No fewer than 14 thermal-hydraulic mechanisms must be considered to some degree:

1. Three-dimensional transient heat conduction with temperature-dependent material properties.

2. Nonuniform internal heat generation in portions of the casting assembly resulting from operation of the induction heater. Because the current penetration depth into liquid uranium at $10,000 \mathrm{~Hz}$ is very small and the material properties of $\mathrm{Al}_{2} \mathrm{O}_{3}$ do not support significant eddy currents, only the carbon components are heated internally.

3. In-vacuo contact resistances between bare and coated assembly components, as well as between the assembly and $\mathrm{Al}_{2} \mathrm{O}_{3}$ shield, the $\mathrm{Al}_{2} \mathrm{O}_{3}$ shield and copper coils, and the assembly and the firebrick.

4. Radiation heat transfer between individual assembly components, from some components to the $\mathrm{Al}_{2} \mathrm{O}_{3}$ shield and pressure-vessel wall, from the liquid uranium to the crucible and bookmold walls, from the $\mathrm{Al}_{2} \mathrm{O}_{3}$ shield to the copper coils and pressure-vessel wall, and from the exterior of the copper coils to the pressure-vessel wall.

5. Enclosure natural convection heat transfer between the liquid uranium and the crucible and bookmold walls.

6. Enclosure buoyancy-driven fluid flow and carbide transport within the liquid uranium during melting and solidification.

7. Interfacial heat transfer between solidified uranium and the bookmold.

8. Free surface, momentum-driven fluid flow during the pour.

9. Multiphase, nonequilibrium, solution thermodynamics in the uranium during melting and solidification.

10. Solid-liquid, liquid-solid, and solid-solid phase-change heat transfer in the uranium alloy.

11. Forced convection heat transfer from the interior of the heater coils to the cooling water.

12. A hydraulic manifold controlling the heating coil's cooling-water instantaneous flow rate.

13. Low-pressure, enclosure natural convection heat transfer from casting assembly components during the extended cooling period.

14. Natural convection heat transfer from the exterior of the pressure vessel.

As is generally the case during the initial phases of an R\&D effort that seeks to define cause and effect, the problem contains a large number of uncertainties. These include but are not limited to the following examples:

1. Is carbide formation complete prior to the pour or does it continue during solidification? If so, is it affected by the uranium solid-liquid interface?

2. Are buoyancy forces resulting from U/HFC density differences the same magnitude as those resulting from fluid-mold temperature differences, or is one so dominant as to permit the other to be neglected?

3. Does the complete casting assembly have to be modeled to ensure the proper thermal mass and inertia, or can some components be simplified and/or eliminated?

4. Which of the 14 individual mechanisms has a prominent effect on carbide transport and must therefore be accurately modeled? Furthermore, what level of accuracy is required for these critical mechanisms?

5. Is a computational fluid dynamics (CFD) computer program needed to quantify the thermal aspects of pouring and solidification, or would a strictly heat-conduction solidliquid approximation be adequate? 
A programmatic consideration is that the systematic reduction of technical uncertainties and the evolution of numerical tools must complement each other. In the beginning when uncertainties are great, tools should be correspondingly simple. As technical uncertainties are reduced, tools must be improved to take advantage of the more accurate information. This balance is required because it is computationally and economically inefficient to construct a mathematical model with capabilities that cannot be utilized because inputs and/or system behavior are so uncertain as to preclude any meaningful results. As it concerns this problem, the uncertainty reduction/tool evolution process is extremely unbalanced. No numerical tools are available, yet there are considerable experimental data that define bookmold thermal response and macroscopic HfC behavior. Thus, any model constructed for this problem, even if it is the initial effort, must be of sufficient rigor to accommodate the existing data. An additional facet of numerical model construction is that it can be nonuniform and iterative. Nonuniform because each problem element can have uncertainties that vary in number and complexity and, therefore, require different amounts of modeling effort to reach the same level of sophistication. For this problem the distribution of uncertainties is extremely skewed: the heat transfer facet has the greatest number. Also, because of the design of the casting system, the uncertainties must be defined before meaningful solidification results can be obtained. The reduction/evolution process can become iterative when large numbers of nontrivial uncertainties exist. Under these conditions it is often necessary to make simplifying assumptions to begin the analysis. If these are shown to be incorrect, the calculations must often be repeated. These circumstances put a burden on the investigator to coordinate model construction iterations to ensure that study goals are obtained with a minimum number of iterations. As it concerns this problem, the complete lack of numerical models, the large number of thermal uncertainties, and the need to construct a model capable of accommodating existing experimental data mean that more than one iteration will be required for the thermal facet.

No single computer program is available to solve the coupled thermal-hydraulic-thermodynamic problem. Separate heat conduction and CFD codes are available, but (from the perspective of this problem) each has serious limitations. Existing conduction programs can only model the liquid-solid uranium as a conducting region with temperature-dependent material properties. Including the effects of momentum-dominated pouring or buoyancy-driven flow is beyond the capabilities of even the most sophisticated conduction program. Similarly, commercially available CFD codes have limited conjugate heat transfer capabilities. They can calculate conduction heat transfer within a containment vessel, but generally cannot accommodate complicated vessel geometries nor multiple, nonlinear heat transfer paths. An additional consideration is that even though there are at least two heat conduction programs readily available within Energy Systems, there are no CFD codes with sufficient capabilities to model the pouring operation. With respect to $\mathrm{U} / \mathrm{Hf}$ and $\mathrm{U} / \mathrm{Hf} / \mathrm{C}$ solution thermodynamics within a carbon containment vessel at the temperatures and species concentrations applicable to this problem, no computer programs are available at all.

Ultimately, the large number of uncertainties and the need to systematically quantify them completely dorninate the problem definition effort. Accordingly, the individual problem elements will initially be studied separately, and the heat transfer facet will be defined first because of its central importance to the overall solution and the availability of numerical tools. Furthermore, the study will be divided into two phases - each focused on the current laboratory-scale casting system. The first uses an existing stand-alone conduction program, contains idealized uranium regions, and casting assembly geometry considerations are minimized to permit maximum effort toward defining cause and effect. The second-phase will also use a stand-alone conduction model, accurately model the previously defined mechanisms, and iterate with a stand-alone CFD code 
to further quantify the prominent mechanisms, examine the effect of casting assembly design on carbide transport, and begin the study of the fluid dynamics problem. The macroscopic objective of the first-phase study then is to generate the anilytical experience and technical data required to construct and efficiently execute the second-phase thermal model. This goal will be achieved by completing three subtasks:

1. construction of a base-case thermal model of the current laboratory-siale casting assembly;

2. Sensitivity studies to identify those thermal mechanisms that have a prominent effect on the simulation of the bookmold thermal response; and

3. abbreviated studies to define a physical model that is as simple as possible, yet not so emaciated as to introduce unacceptable, errors into the analysis.

The remainder of this report documents the conduct and results of the first-phase study. 


\section{DEVELOPMENT OF THE BASE-CASE MODEL}

The HEATING 7.1 (ref. 2) heat conduction program was selected to conduct the firstphase studies because of its availability and low operating cost. The following macroscopic design criteria were established.

1. Because HEATING cannot accommodate mixed geometries within a single problem and since the focus of the study is the rectangular uranium region within the bookmold, a cartesian coordinate system will be used. Although the crucible, end caps, shield, and coils are cylindrical, this approximation is considered acceptable for the first-phase effort.

2. The physical model will include all major casting system components, including the insulated thermocouple junctions. The pressure vessel will not be explicitly modeled, its influence will be included using radiation heat transfer to and from a black body.

3. The thermal model will include all apparent mechanisms: conduction, temperaturedependent material properties, internal heat generation, forced and natural convection heat transfer, radiation heat transfer, thermal contact resistances, and interfacial gap conductance between the solidified uranium and bookmold. In keeping with the scope of the first-phase study, carbide formation, buoyancy-induced transport, and CFD considerations will not be included.

4. Each transient solidification analysis will require a steady-state calculation to define initial conditions (i.e. the temperature distribution in the system just prior to the pour).

5. Uranium regions will be approximated as simply conducting phase change materials with temperature dependent properties. In all cases properties of unalloyed uranium will be used.

6. The solidification analysis will begin with a uniform temperature within the solidifying uranium and the undisturbed steady-state temperature distribution within the casting assembly. That is, the effects of the pour will not be considered.

7. The only direct indication of model accuracy is a comparison between calculated and measured bookmold temperatures. This comparison then will determine the prominence of individual mechanisms.

As explained, the large number of uncertainties dictated an iterative numerical study. An initial model was conducted to qualitatively identify prominent thermal mechanisms, and a second effort actually constructed and executed the base-case rnodel. The first iteration considered only a portion of the casting assembly and used measured temperatures as boundary conditions to produce a numerical testbed with fewer uncertainties than a complete model would have had. This method allowed maximum effort toward defining thermal-hydraulic cause and effect. The second iteration used this information and a complete geometry to identify the prominent mechanisms.

\section{FIRST ITERATION}

The initial modeling effort consisted of two separate tasks, each designed to bound the thermal problem. 3 The first was a scoping study to qualitatively define the prominent heat conduction paths. It was executed using a simplified 1-D geometry and it quickly showed that a more detailed model was required to generate meaningful results. The goal of the second task then was to define, construct, and execute the more rigorous model. It consisted of a 3-D, 
quarter-symmetric, cartesian coordinate approximation of the bookmold, upper and lower end caps, firebrick base, and that portion of the $\mathrm{Al}_{2} \mathrm{O}_{3}$ shield below the top of the upper end cap Also, gaps were included to simulate contact resistances between the bookmold and lower end cap, as well as melt shrinkage between the uranium melt and bookmold. Figure 12 shows a scale drawing of the discretized casting assembly geometry; the material regions have been shaded for clarity. Figure 13 is a schematic illustration of the bookmold/end-cap portion of the discretized geometry with some nominal dimensions in millimeters. For simplicity, the firebrick base is not shown in either figure. This geometry was input to HEATING, with the following initial and boundary conditions:

1. one-dimensional radiation heat transfer from assembly exterior surfaces to the pressurevessel wall,

2. temperature-dependent material properties for solid uranium and carbon,

3. initial temperature conditions for the entire model extrapolated from three experimental measurements, and

4. a constant temperature boundary condition for the top of the upper end cap that had been derived from experimental data.

A series of sensitivity studies were conducted whose purpose, like the earlier 1-D examinations, was to qualitatively identify prominent thermal mechanisms. Ranges of likely values were specified for the above conditions and their effect on model accuracy (i.e., agreement with experimental temperature data) noted. The analyses established that the primary heat conduction path out of the uranium is in the radial direction and that model accuracy is quite sensitive to initial temperature conditions, boundary temperatures, temperature-dependent physical properties, and radiation heat transfer as applied to boundary conditions, contact resistances, and melt shrinkage. Figure 14 illustrates the best agreement obtained during the studies. It shows experimental and calculated temperatures at the three thermocouple locations in the bookmold vertical wall as a function of time. The primary observation is that model agreement is quite good at the uppermost location but steadily worsens toward the bottom location. This behavior is consistent with the structure of the model. The upper portion has a specified temperature boundary condition defined from experimental data. The boundary conditions for the middle and lower portions of the model are calculated using assumptions about initial temperatures and the magnitude of the radiation heat transfer coefficient. It is quite reasonable then to expect greater uncertainties, and therefore poorer agreement, in the middle and lower portions of the model.

\section{SECOND ITERATION}

The second iteration consisted of two parts: developing a complete physical model and defining those first-order accurate analytical relationships required to simulate the mechanisms identified in the initial effort. The resulting physical model contains a 3-D, quarter-symmetric, cartesian approximation of the firebrick base, lower and upper end caps, bookmold, crucible and its top, $\mathrm{Al}_{2} \mathrm{O}_{3}$ shield, induction heater coils, and the three insulated thermocouple junctions. The approximated assembly components are shown in Figs. 15-20. They show scale drawings (dimensions in millimeters) of, respectively, the upper and lower end caps, the bookmold, the crucible, the pair of flat plates used to represent the $\mathrm{Al}_{2} \mathrm{O}_{3}$ shield, and one pair of the plates used to represent the heater coils. The cornplete physical model is shown in Fig. 21, and the individual material regions have been shaded for clarity. There are three noteworthy features of the model: gaps between components, flat plates representing the heating coils, and dual uranium regions. 

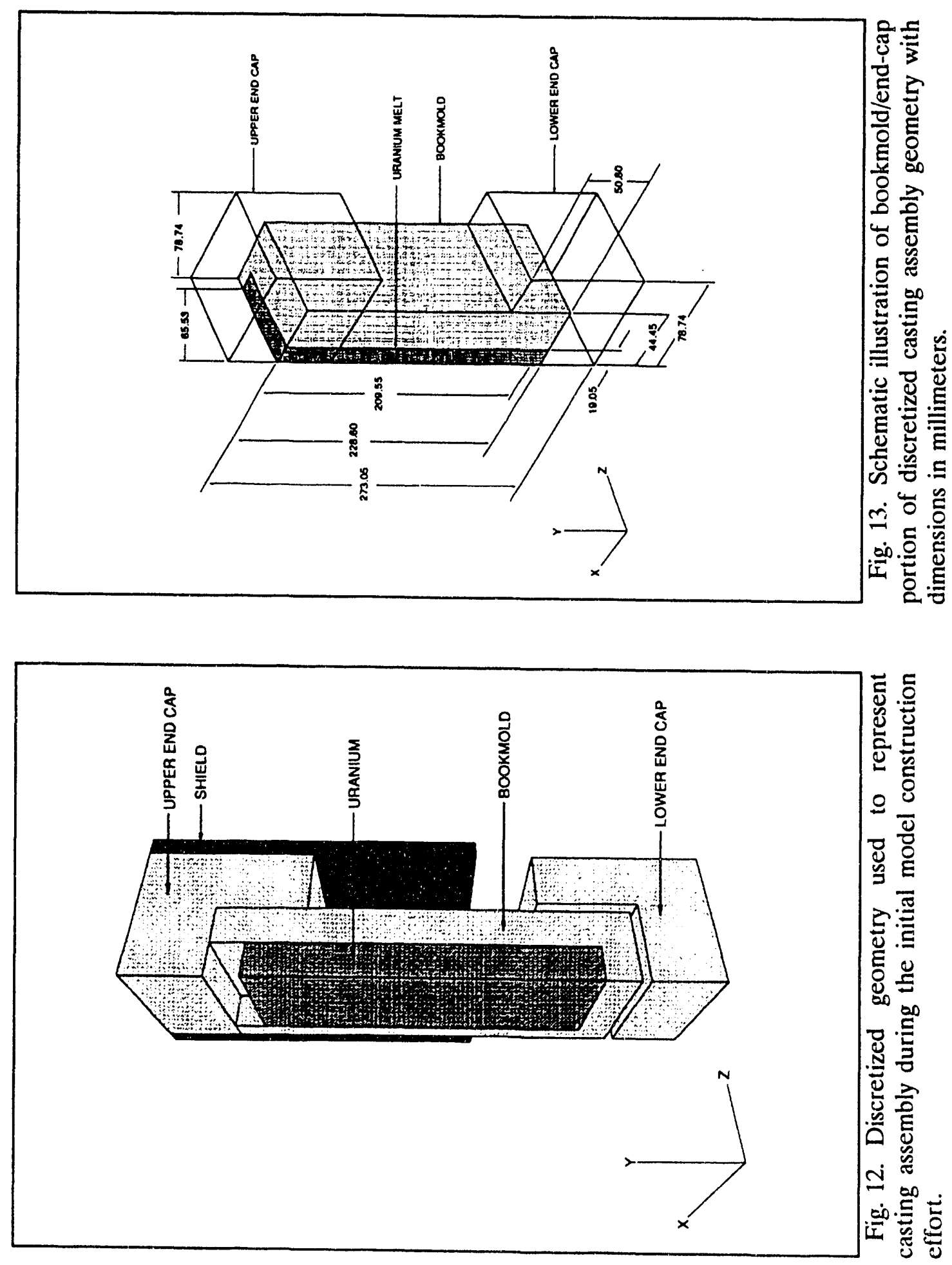

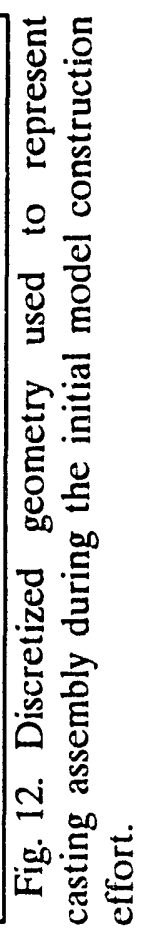




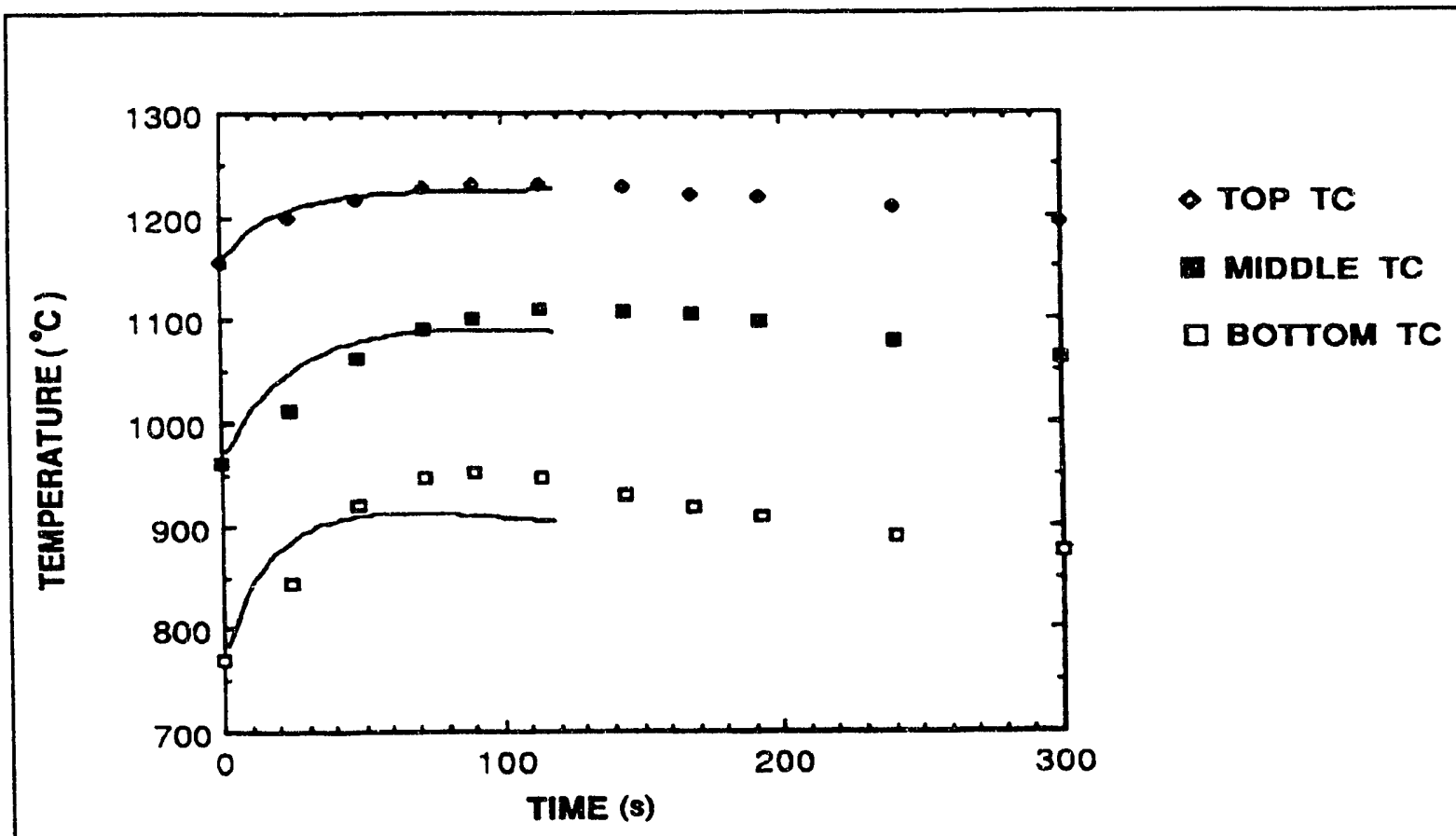

Fig. 14. Comparison of calculated and experimental bookmold temperatures for the first iteration. 


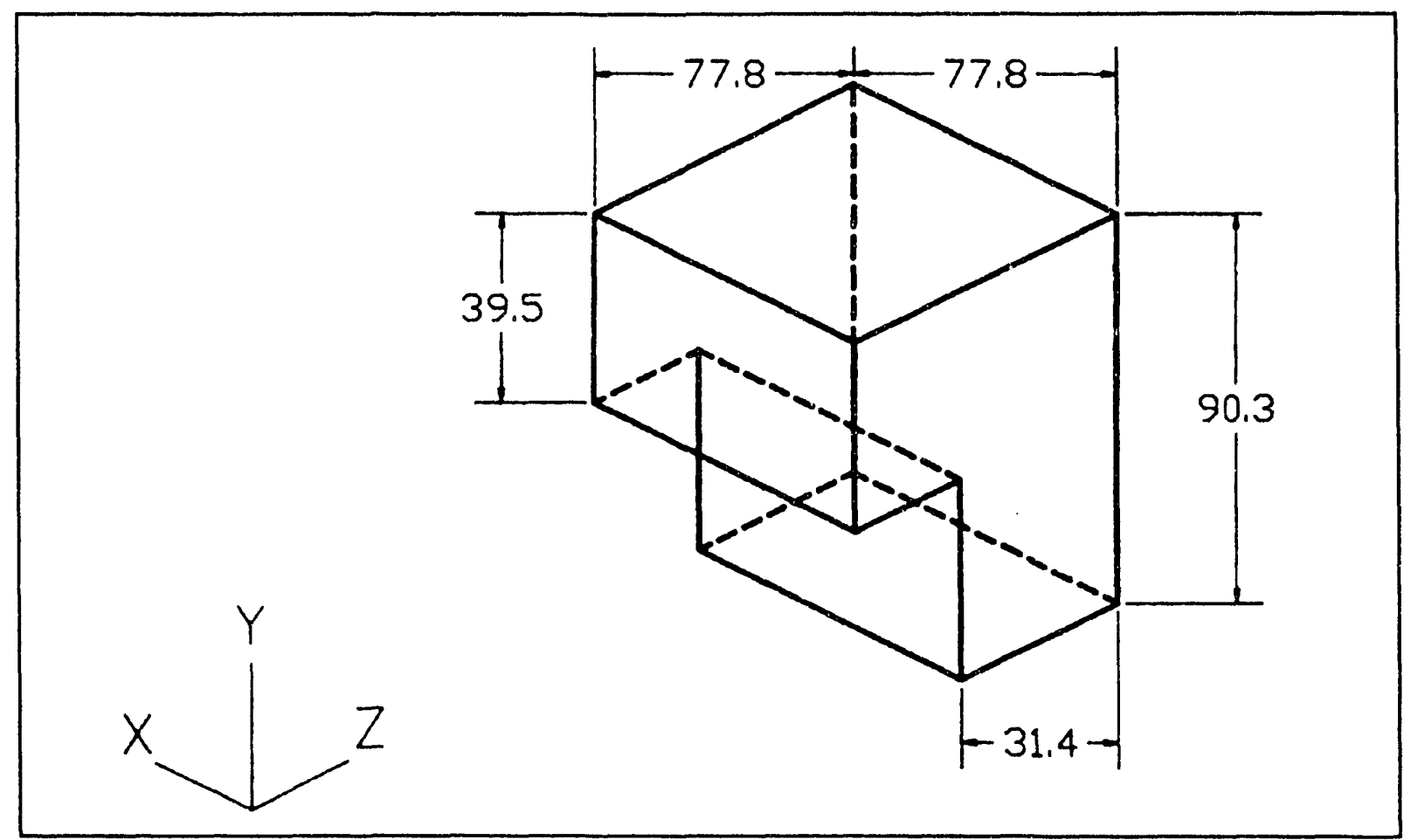

Fig. 15. Engineering drawing of the approximated upper end cap with dimensions in millimeters.

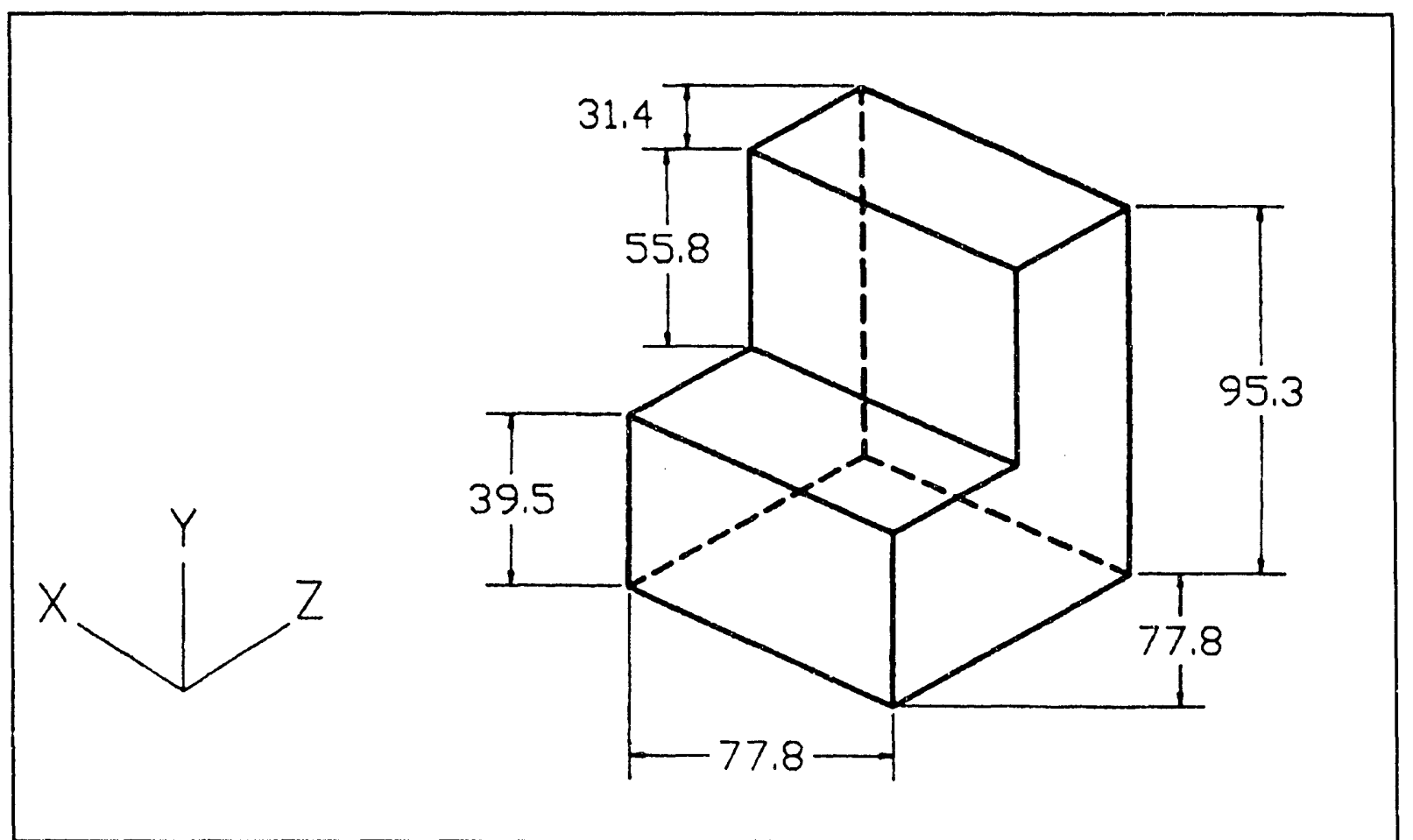

Fig. 16. Engineering drawing of the approximated lower end cap with dimensions in millimeters. 

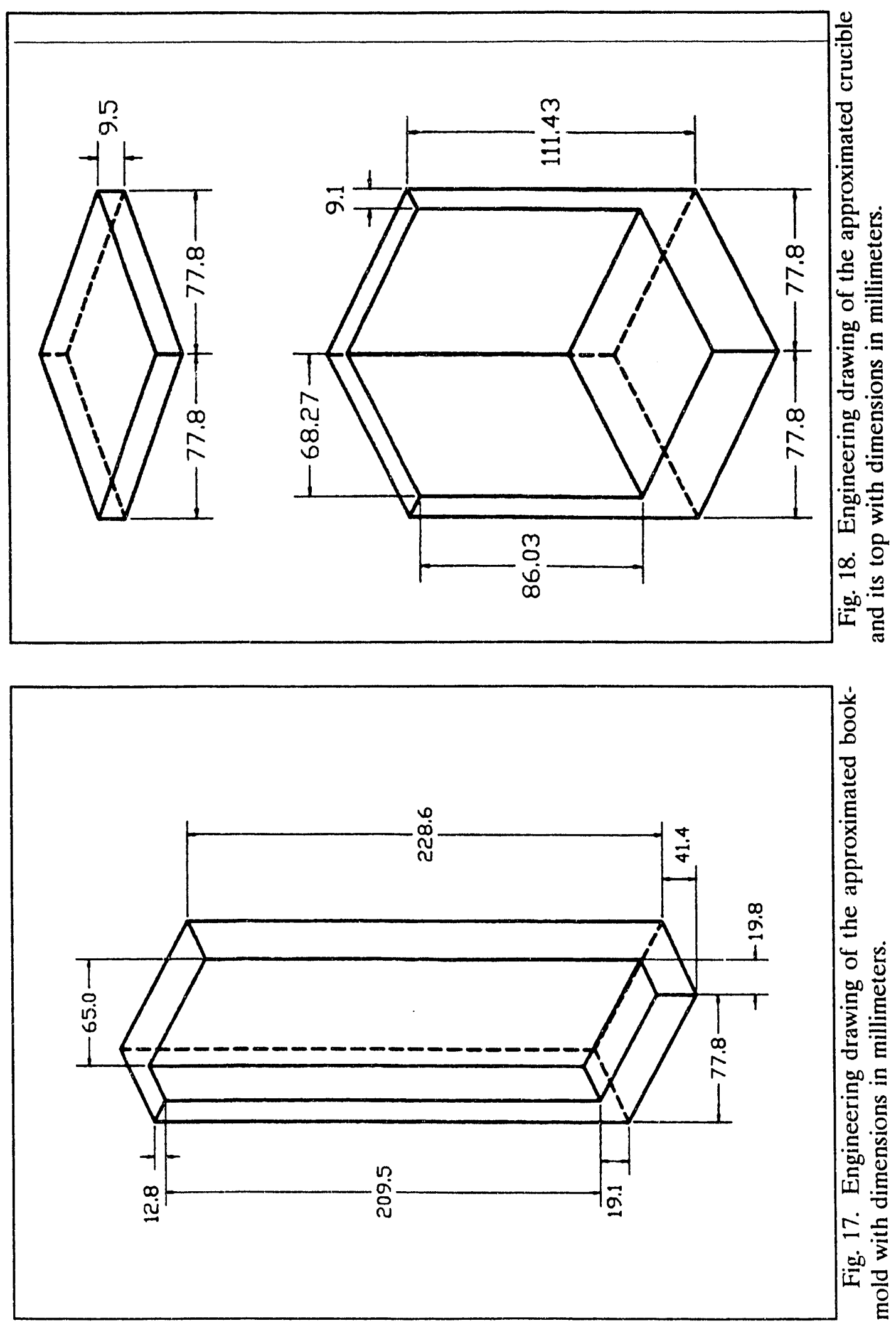

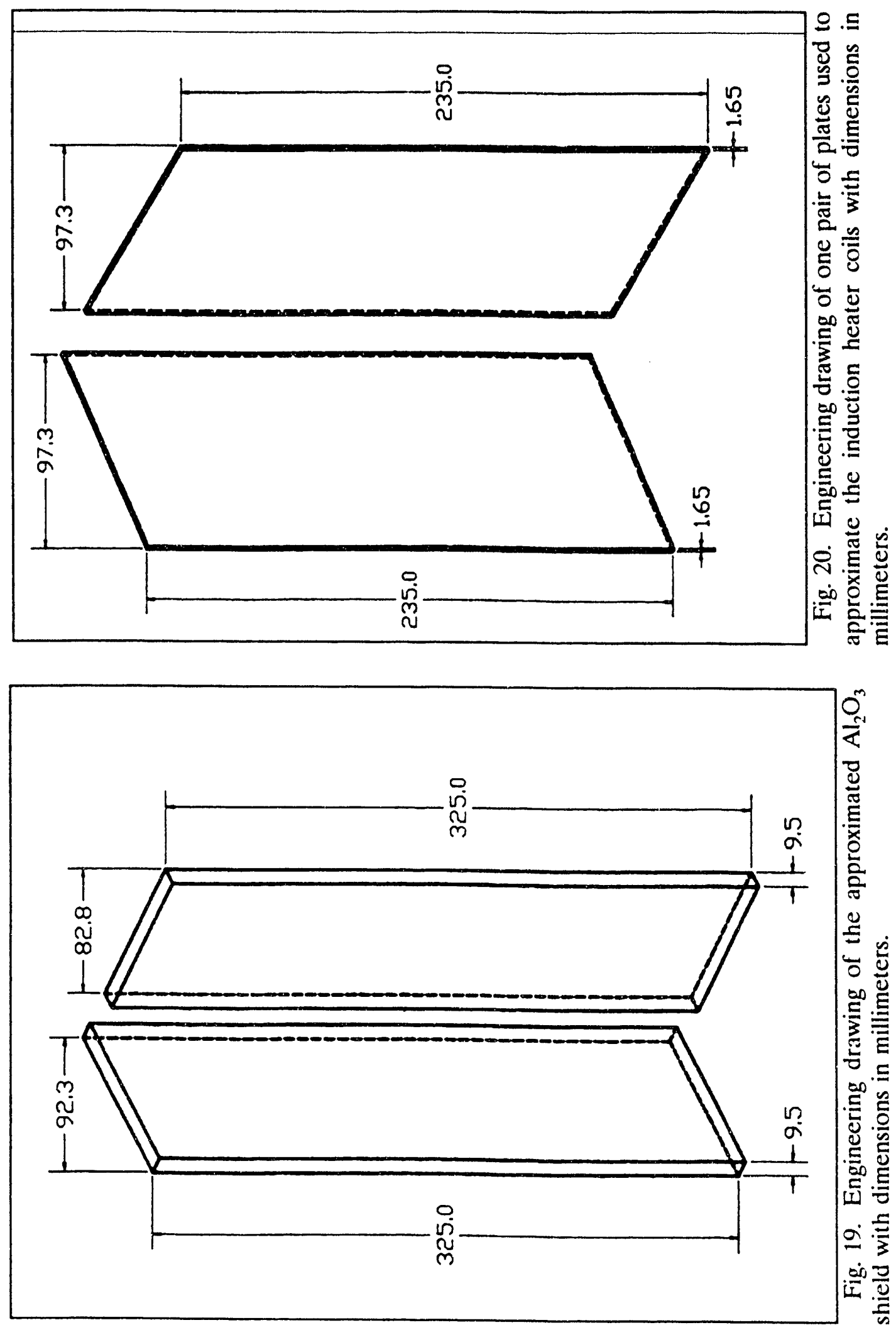

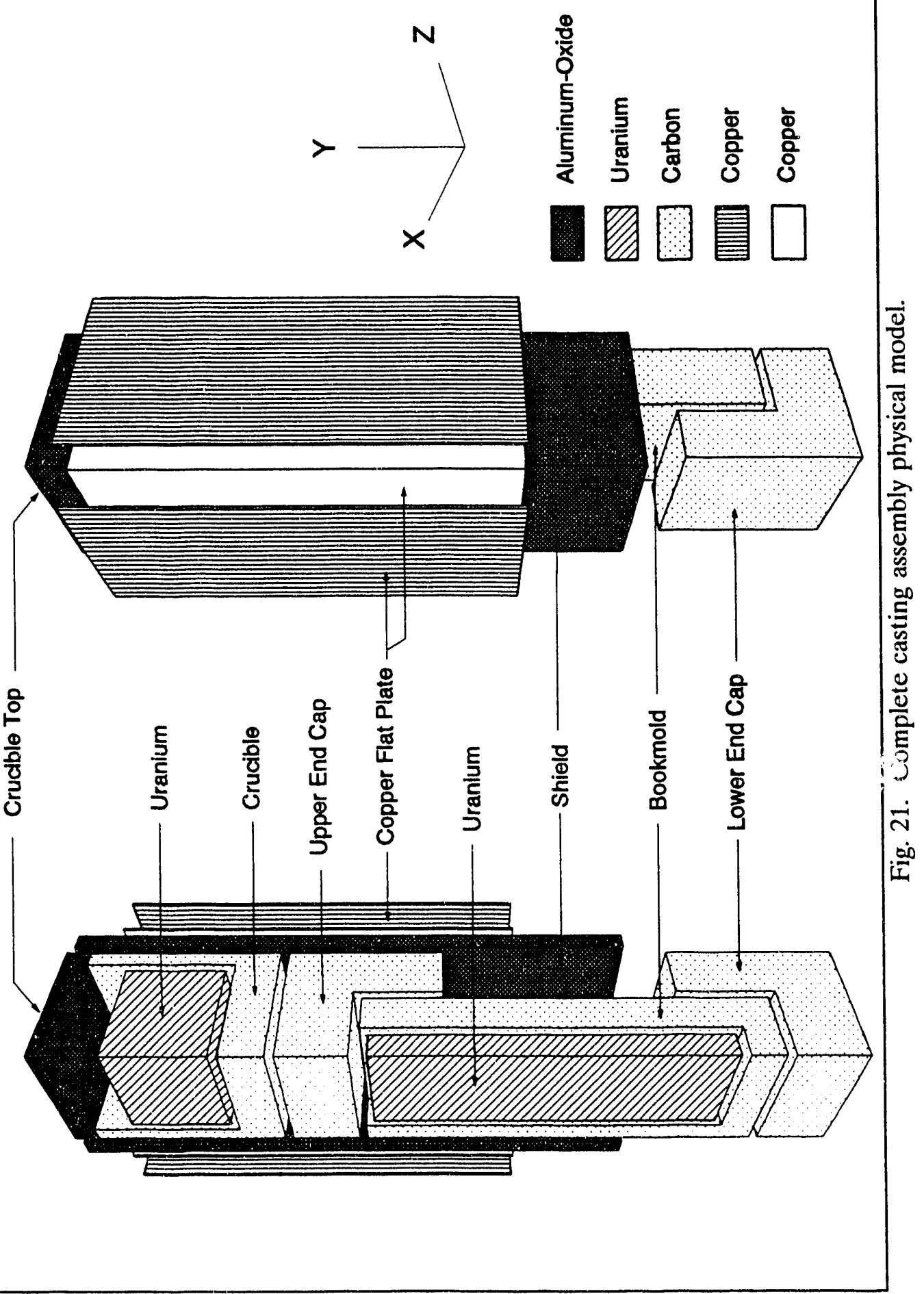
1. An exact representation of the heating coils was not possible, and to have approximated them as lengths of square tubes would have been cumbersome. A simplified 2-D (R\& $\Theta)$ transient study showed that temperatures and heat fluxes were uniformly distributed around the coil's inner surface. Because the coils are also closely spaced, it seemed reasonable to represent them as a flat plate with a thickness equal to that of an actual coil. Because the height of a single plate was limited to the actual height of the coils, two thermally connected plates were required to give the correct heat transfer surface area.

2. To transfer steady-state temperatures to the transient input file, both input files must have the same number of phase-change regions. Accordingly, dual uranium regions were incorporated. The bookmold region is thermally isolated during the steady-state analysis, and the crucible region is similarly isolated during the transient calculation.

3. A system of uniform size gaps were placed between casting assembly components to include the effects of contact resistances, sliding fits, melt shrinkage, and fluid thermal boundary layers. These were placed between the bookmold and lower and upper end caps, the lower end cap and the firebrick, the upper end cap and crucible, the crucible walls and top, the end caps and the $\mathrm{Al}_{2} \mathrm{O}_{3}$ shield, the shield and the copper flat plate, and the uranium regions and the crucible and bookmold walls. Gap regions are a capability within HEATING that permit one to specify a heat transfer rate independent of the gap's thickness. Thus, the same size gap can be made to represent a radiation heat transfer mechanism as well as a much larger forced convection coefficient. This system is also illustrated in Fig. 21. Each narrow space between components represents a gap.

With the physical model specified, the required material properties, first-order accurate analytical relationships, and boundary conditions needed to simulate the thermal mechanisms were defined.

To solve the transient heat conduction equation, HEATING requires values for the density $(\rho)$, specific heat $\left(C_{p}\right)$, and thermal conductivity $\left(k_{m}\right)$ of each material comprising the casting assembly. In addition, the latent heats of transformation and fusion are required for uranium. Although some of these data had been defined during the first iteration, they were all redefined $d^{5,6,7,8,9,10,11,12,13}$ for consistency and are summarized below.

1. The densities of each material are constant or vary only a few percent over the temperature range of interest. For this reason and because HEATING does not conserve mass, constant values were specified for each material. These were 1730, 240, 2000, 8954, 18400,17050 , and $21791 \mathrm{~kg} / \mathrm{m}^{3}$ for carbon, $\mathrm{Al}_{2} \mathrm{O}_{3}$, firebrick, copper, solid and liquid uranium, and platinum respectively.

2. The thermal conductivities of all materials except firebrick are temperature dependent. A value of $1.04 \mathrm{~W} / \mathrm{m}-{ }^{\circ} \mathrm{C}$ was specified for firebrick, and the values defined for the other materials are summarized in Fig. 22.

3. The specific heats of firebrick and liquid uranium are essentially constant and values of 960 and $198.4 \mathrm{~J} / \mathrm{kg}-{ }^{\circ} \mathrm{C}$ were specified respectively. The remaining materials are temperature dependent, and these data are summarized in Fig. 23.

4. The latent heats of transformation and their corresponding temperatures for unalloyed uranium are $-20.1 \mathrm{~kJ} / \mathrm{kg}$ at $661^{\circ} \mathrm{C}$ and $-12.3 \mathrm{~kJ} / \mathrm{kg}$ at $769^{\circ} \mathrm{C}$. The latent heat of fusion is $38.72 \mathrm{~kJ} / \mathrm{kg}$ at $1133^{\circ} \mathrm{C}$. 


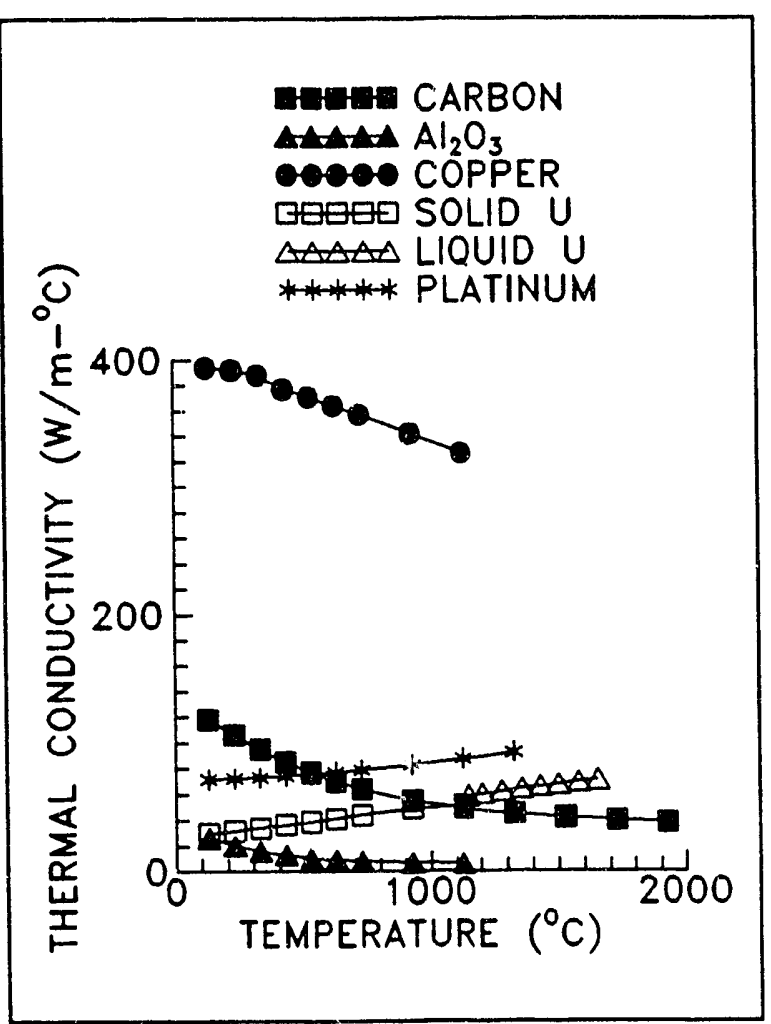

Fig. 22. Thermal conductivity data for carbon, $\mathrm{Al}_{2} \mathrm{O}_{3}$, copper, solid and liquid uranium, and platinum.

Two additional liquid uranium properties are required to calculate natural convection heat transfer coefficients: viscosity $(\mu)$, and the volume coefficient of expansion $(\beta)$. In addition, the dimensionless modulus Prandtl number $\mathrm{Pr}$, is also required. A literature survey produced several sets of experimental data for uranium viscosity and these were evaluated to define a consistent set of values. Eventually, the results of Ofte ${ }^{14,15}$ were adopted, and these data are summarized in Fig. 24.

The Prandtl number of a fluid is defined as

$$
\operatorname{Pr}=\frac{\mu C_{p}}{k_{f}} .
$$

The viscosity data shown in Fig. 24 and the previously defined specific heat and thermal

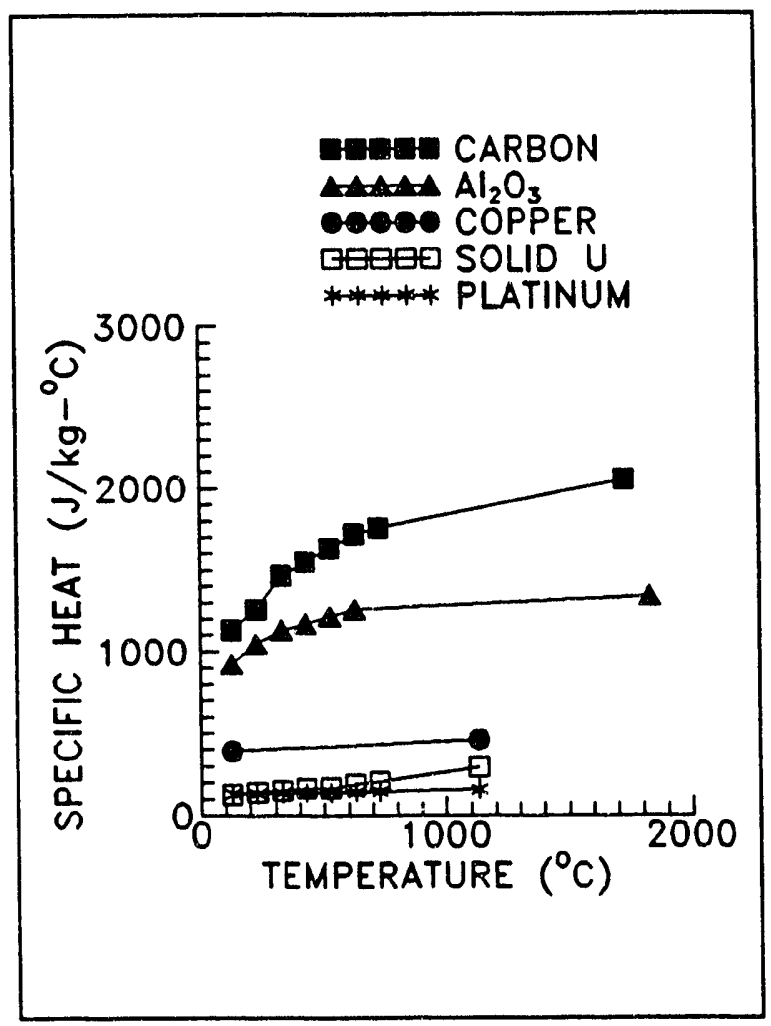

Fig. 23. Specific heat data for carbon, $\mathrm{Al}_{2} \mathrm{O}_{3}$, copper, solid uranium, and platinum.

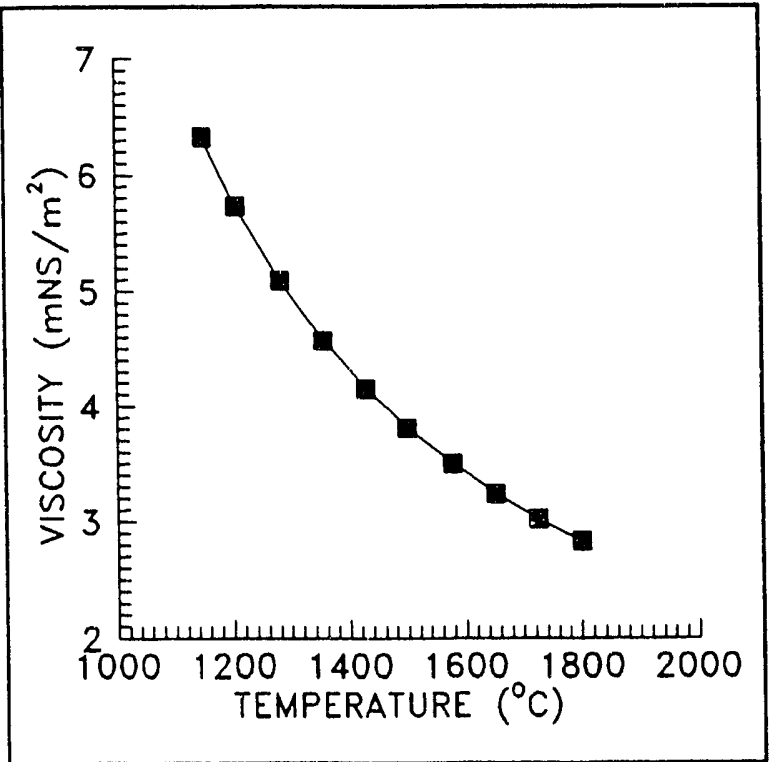

Fig. 24. Viscosity data for liquid uranium. 
conductivity were used to calculate the liquid uranium Prandtl number. These data are summarized in Fig. 25.

The volume coefficient of expansion is defined as

$$
\beta=\left(\frac{1}{\rho}\right)\left(\frac{\partial \rho}{\partial T}\right)_{p} .
$$

Liquid density data from Mulford ${ }^{12}$ were used to evaluate Eq. (2), and the resulting values are summarized in Fig. 26. Because the coefficient does not vary much over the temperature range of interest, a constant value of $1.0 \times 10^{-4}$ is used for all natural convection calculations.

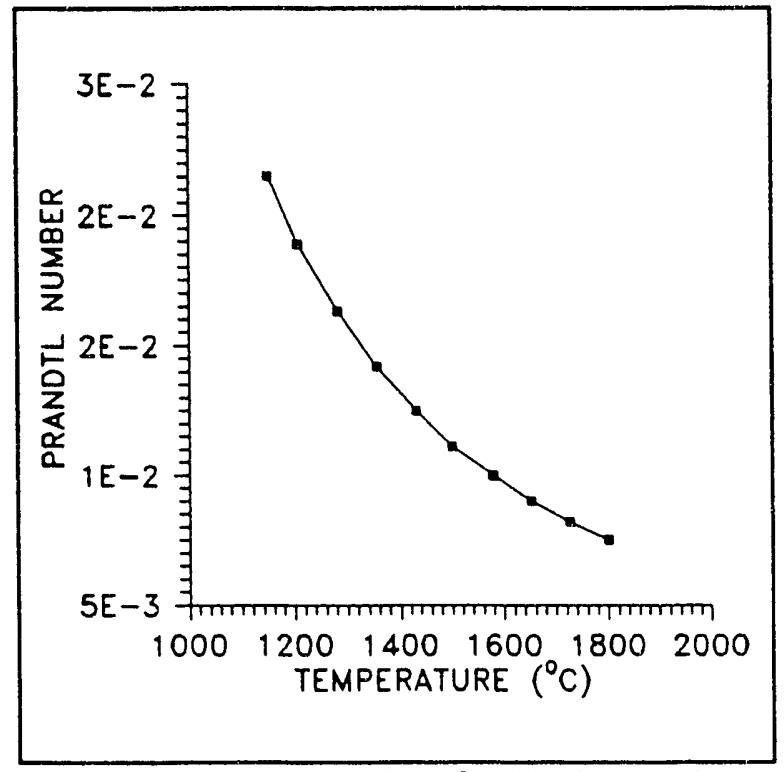

Fig. 25. Prandtl number for liquid uranium.

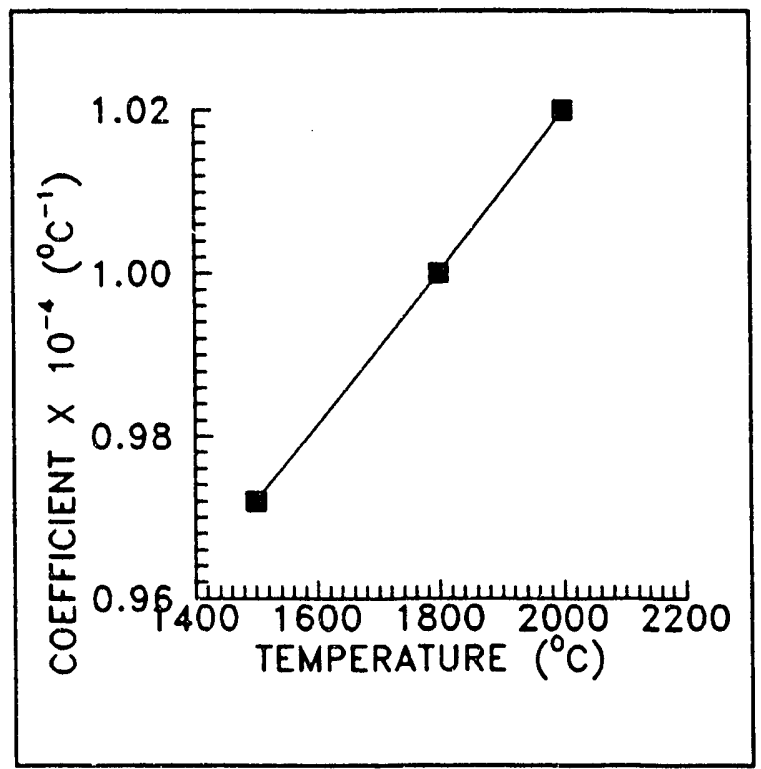

Fig. 26. Volume coefficient of expansion for liquid uranium.

Surface emissivities for each material were also defined. Constant values of 0.80 (ref. 16) 0.75 (ref. 10) and 0.37 (ref. 17) were specified for carbon, firebrick, and liquid uranium respectively. The emissivities of $\mathrm{Al}_{2} \mathrm{O}_{3}$ and copper are temperature dependent, and the available data are summarized in Figs. 27 and 28. These show the range of values given in the literature. ${ }^{18,19}$ Average values were interpolated and/or extrapolated for use in the calculations. All the $\mathrm{Al}_{2} \mathrm{O}_{3}$ data, but only the $S T A B L Y$ OXIDIZED $A T 1033 \mathrm{~K}$ copper data are used.

Radiation heat transfer occurs from exterior assembly surfaces to the pressure-vessel wall, between closely spaced components and the $\mathrm{Al}_{2} \mathrm{O}_{3}$ shield, as well as within the enclosures defined by the crucible interior and its top, the interior of the bookmold and the upper end cap, and the exterior of the bookmold, the upper and lower end caps, and the $\mathrm{Al}_{2} \mathrm{O}_{3}$ shield. With the exception of the enclosures, each of these mechanisms can be simulated to an acceptable degree of accuracy using a simple 1-D heat transfer coefficient. To accurately model enclosure radiation heat transfer, however, requires the use of exchange factors. These terms are a function of geometry and material surface emissivities and to calculate them for a discretized geometry with temperature dependent emissivities and two planes of symmetry is an extremely labor intensive and computationally demanding task. For these reasons and because 


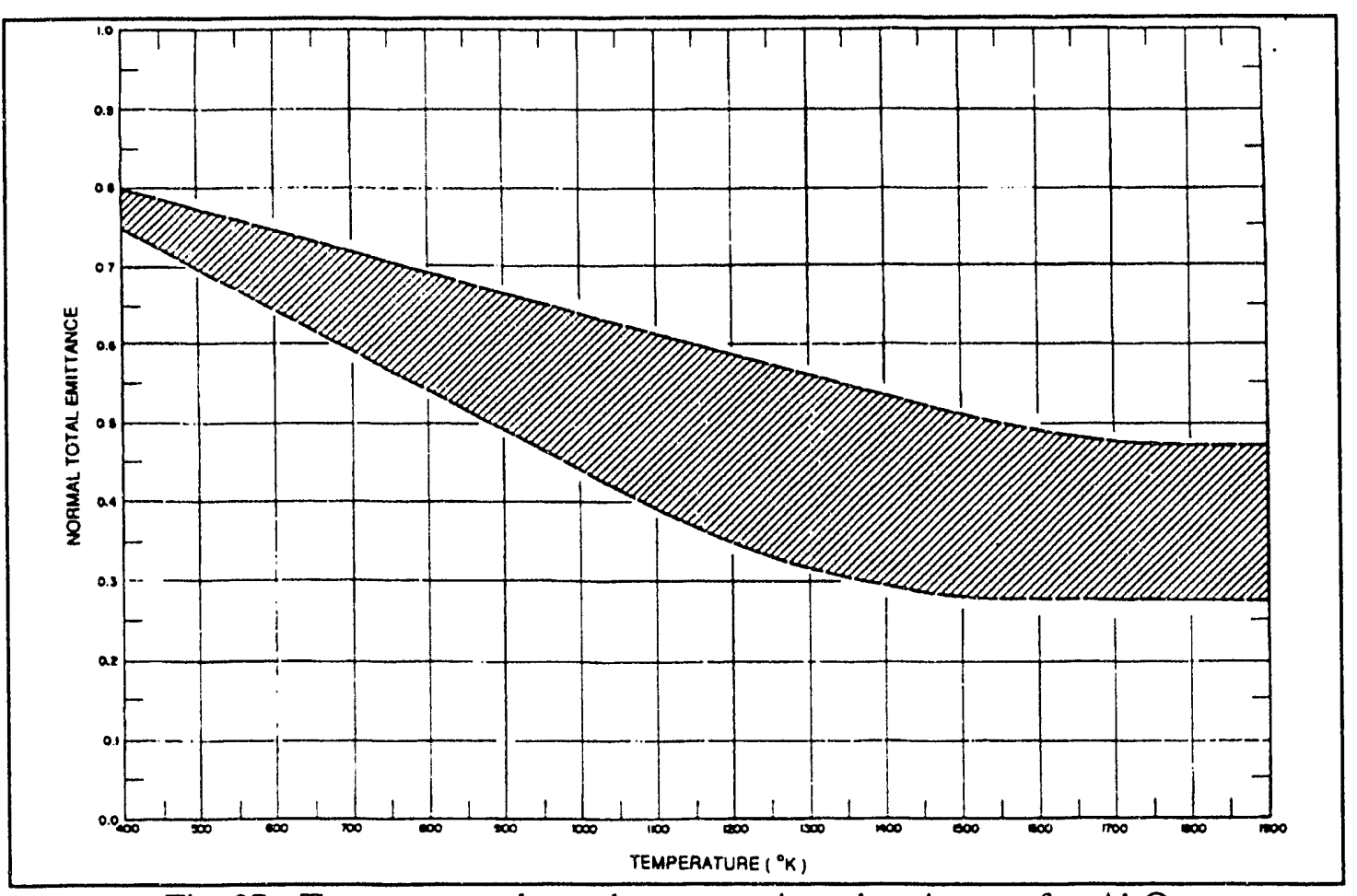

Fig. 27. Temperature-dependent normal total emittance for $\mathrm{Al}_{2} \mathrm{O}_{3}$.

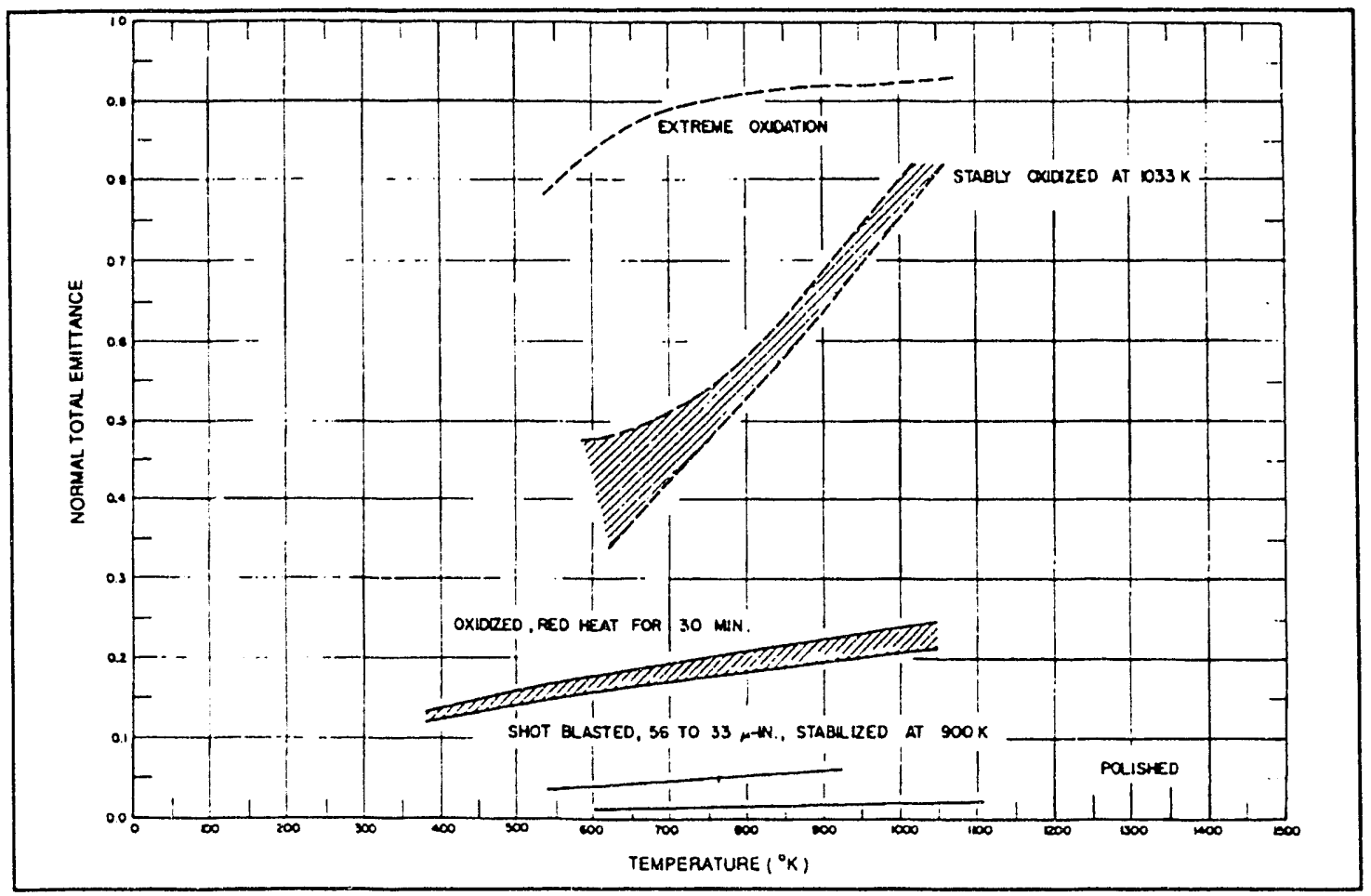

Fig. 28. Temperature-dependent normal total emittance for copper. 
1. the goal of the first-phase studies is to identify prominent mechanisms, and it is already known ${ }^{20}$ that an accurate representation of radiation heat transfer effects is important in correctly modeling uranium solidification;

2. exchange factors are geometry dependent, and it was felt the cartesian approximation would introduce considerable error; and

3. necessary software was not currently available for the IBM RS/6000 computer, it was decided that a rigorous treatment of enclosure radiation would be left for the second-phase effort. For the current studies the following relationship ${ }^{10}$ is used to calculate 1-D radiant energy exchange between any two directly opposing, gray, diffuse surfaces:

$$
h_{r}=\frac{\sigma}{\left(\frac{1}{\epsilon_{1}}\right)+\left(\frac{A_{1}}{A_{2}}\right)\left(\frac{1}{\epsilon_{2}}-1\right)},
$$

where the subscripts 1 and 2 refer to the surfaces with the smaller and larger surface areas respectively. For radiation to a black body, Eq. (3) reduces to the product of the emissivity and the Stefan-Boltzmann constant:

$$
h_{r}=\epsilon \sigma \text {. }
$$

Thermal boundary layers resulting from buoyancy-induced fluid motion occur at all uranium-carbon boundaries, and accurately calculating the associated heat transfer coefficients is nontrivial. In external free convection, the ambient fluid is considered to be infinite, isothermal, and unaffected by the resulting buoyancy-driven flow. This assumption considerably simplifies any analysis because it permits one to independently specify conditions outside the boundary layer. In the crucible and bookmold enclosures, however, the flows between adjacent surfaces (i.e., the horizontal bottom and vertical walls) are coupled to each other and to the thermally stratified core region formed by the individual boundary layers. Furthermore, these interacting boundary layers cause regions of stagnant flow at those locations where surface orientations change. Consequently, pressure and buoyancy force terms must be retained in the governing equations. As previously explained, it is not possible to include these effects within the HEATING program. Also, there are no analytical relationships directly applicable to the crucible and bookmold configurations, and defining such relationships via a separate numerical study is beyond the scope of the first-phase studies. It was decided reasonable results could be obtained by applying heat transfer coefficients to each surface in the enclosure, where the value of the coefficient had been calculated using empirical correlations appropriate for external natural convection from that surface's orientation. These are an upward-facing horizontal flat plate for the bottoms of the enclosures and a vertical flat plate for the vertical walls. For external, steadystate, laminar flow over an isothermal, upward-facing flat plate in an infinite region of quiescent fluid, the average heat transfer coefficient is calculated ${ }^{10}$ using

$$
h_{n c, h}=(0.54)\left(\frac{k_{f}}{L_{h}}\right)\left(\frac{g \beta \Delta T L_{h}^{3} \rho^{2} C_{p}}{\mu k_{r n}}\right)^{0.25} .
$$

For these same conditions the average heat transfer coefficient for a vertical flat plate is calculated $^{10}$ using 


$$
h_{n c, v}=\frac{(0.67)\left(\frac{k_{f}}{L_{v}}\right)\left(\frac{g \beta \Delta T L_{v}^{3} \rho^{2} C_{p}}{\mu k_{m}}\right)^{0.35}}{\left(1+\left(\frac{0.492}{P r}\right)^{0.562}\right)^{0.444}}
$$

The induction heater induces a current in the crucible, upper end cap, and parts of the bookmold. The shield material is essentially transparent to the magnetic field, and field penetration (and therefore induced current) into the uranium at the coil frequency of $10^{4} \mathrm{~Hz}$ is extremely small, on the order of $0.25 \mathrm{~cm}^{21}$ There are three basic options for calculating induced energy: an algebraic relationship for average (i.e., integrated over volume) power induced in a complete workpiece of extremely simple geometry, an algebraic relationship for energy induced at a particular $\mathrm{X}, \mathrm{Y}$, and $\mathrm{Z}$ location in an extremely simple geometry, and a numerical solution of the governing differential equations for an arbitrary geometry. A numerical solution was beyond the scope of the first-phase studies, and it was not possible to define a consistent set of relationships for energy induced at a point within the time allowed for model coustruntion. Accordingly, a total average power approach was adopted with some slight modifications. An average power is calculated for a cylindrical workpiece, multiplied by the volume of interest (i.e., the volume of a particular assembly component) to get total power $i$ duced in the piece, and then $86 \%$ of this amount is uniformly applied acioss one skin depth. The average power induced in a cylindrical workpiece contained within a multiturn induction coil is caliulated ${ }^{2}$ using

$$
P_{\text {avg }}=\mu \omega H_{o}^{2} W(\xi) \Gamma^{2} \zeta,
$$

where $\mathrm{H}_{\mathrm{o}}$ is the strength of the magnetic field at the surface of a coil and at its axial centerline, and is defined as

$$
H_{0}=\frac{N I}{2 L}
$$

$\mathrm{W}(\xi)$ is the classical ${ }^{23}$ power dissipation function and is defined as

$$
W(\xi)=\frac{2}{\xi} \frac{M_{1}(\xi)}{M_{0}(\xi)} \cos \left(\theta_{1}-\theta_{2}-0.5 \pi\right),
$$

and $\xi$ is an evaluation parameter defined as

$$
\xi=\frac{2 r}{\delta}
$$

where $\mathrm{r}$ is the workpiece outer radius, and $\delta$ is that distance where the induced power has droppec to $14 \%$ of its surface value (i.e., 1 skin depth). For the S. I. system of units, $\delta$ is defined as 


$$
\delta=5.03 \sqrt{\frac{\rho}{\mu f}} .
$$

The $\Gamma$ and $\zeta$ terms in Eq. (7) represent magnetic field radial and axial attenuation respectively. The relationship used by Lavers and Biringer ${ }^{22}$ to define axial attenuation was incompatible with the need to approximate induced energy at a point. Consequently $\Gamma$ and $\zeta$ were dropped, and the generic field attenuation data ${ }^{24}$ shown in Fig. 29 were used instead. This figure shows the ratio of field strength at a coil's surface and axial centerline to field strength at the surface of an arbitrary workpiece with a radius and length not equal to that of the coil. Although none of the data shown in Fig. 29 exactly matches the casting assembly geometry, Curve 6 is close and is used in the calculations.

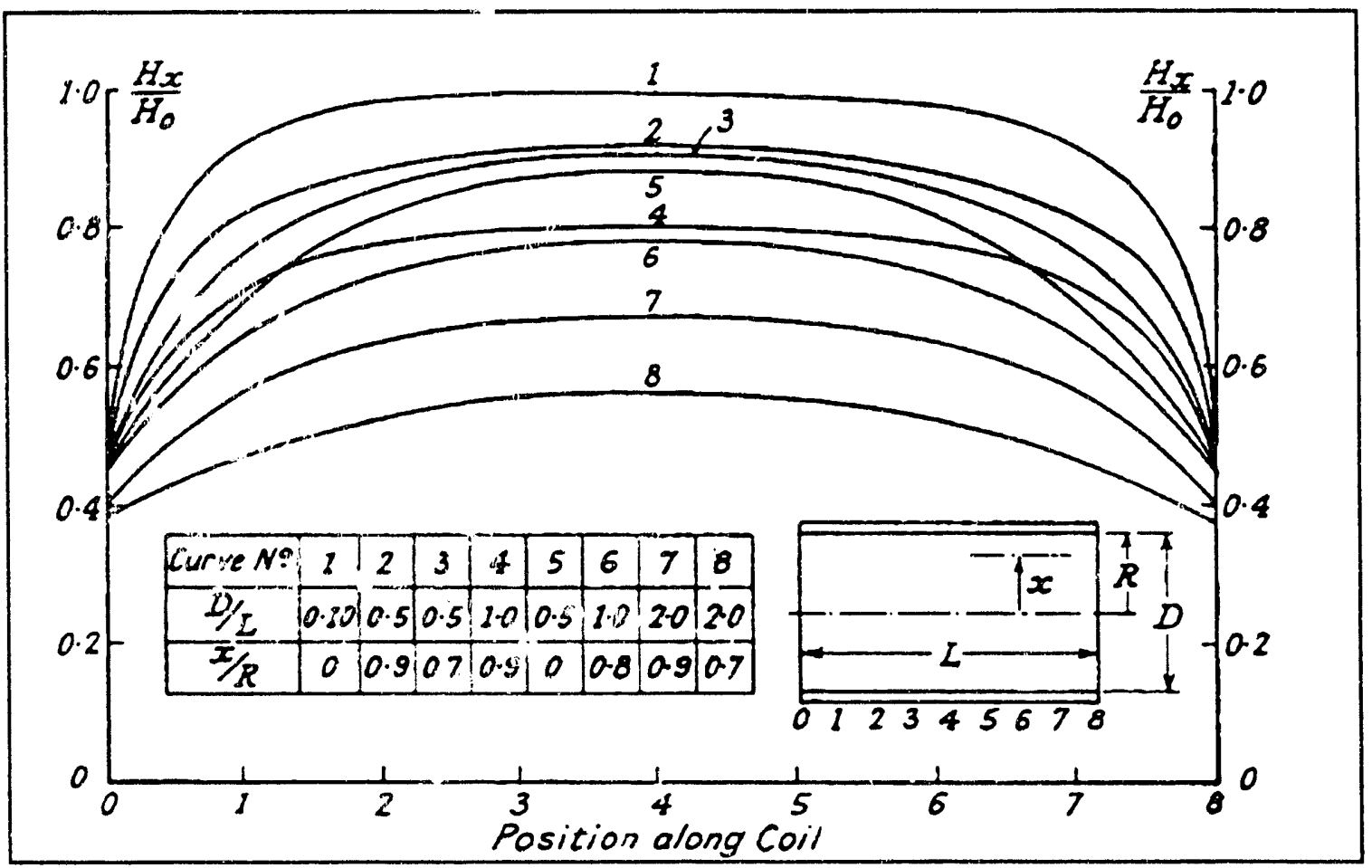

Fig. 29. Generic magnetic field radial and axial attenuation for short coils.

Forced convective heat transfer occurs from the interior of the coil to the cooling water. For turbulent flow in a constant cross-section circular tube with constant fluid properties and neglecting strong temperature gradients across the boundary layer, the heat transfer coefficient is calculated ${ }^{10}$ using

$$
h_{\text {conv }}=0.023\left(\frac{k_{f}}{D_{i}}\right) R e^{0.8} \operatorname{Pr}^{0.40}
$$

where $\operatorname{Re}$ is the fluid Reynolds number and is defined as 


$$
R e=\frac{G D_{i}}{\mu} \text { and } G=\frac{\dot{m}}{A_{c s}} \text {. }
$$

Thermal contact resistances occur at those locations where components touch and result from less-than-perfect mechanical contact. One-dimensional analytical relationships abound to calculate these terms, but selecting a particular equation requires a great deal of information about the material properties and surface characteristics of the individual components. Since most of this information was not available at the beginning of the numerical studies and could not be defined within the time allowed for model construction, it was decided initially to use a constant resistance appropriate for metal-to-metal contact in a vacuum and then define model agreement sensitivity to changes in the value. In this way a range of appropriate values (i.e., values that improved thermocouple agreement) would be available for use in selecting the most suitable analytical relationship for the second-phase study. Accordingly, a constant value of 2000 $\mathrm{W} / \mathrm{m}^{2}-{ }^{\circ} \mathrm{C}$ is utilized ${ }^{25}$ for the base-case model.

An additional thermal resistance required is for the interfacial conductance between solidified uranium and the bookmold. Such terms are extremely system dependent, and no experimental data were available to make the required definition. It was decided to use the value from Rollett and Lewis, ${ }^{20}$ which gave good model agreement for that particular uranium solidification analysis. Accordingly, a value of $0.5 \mathrm{~W} / \mathrm{m}^{2}-{ }^{\circ} \mathrm{C}$ is utilized for the base-case model.

The final relationship defined for the base-case model was included to mitigate some of the negative effects of the cartesian approximation. When a cartesian approximation of cylindrical geometries is used, it is often necessary to adjust the total heat capacities and surface conductances of the individual material regions. The total heat capacity is defined as the product of the density and specific heat: the goal is to make this product for a particular model volume equal to the product for the actual volume, that is

$$
\left(\rho C_{p}\right)_{\text {model }}(\text { Volume })_{\text {model }}=\left(\rho C_{p}\right)_{\text {acrual }}(\text { Volume })_{\text {acrual }} \text {. }
$$

If one chooses to adjust the heat capacity by modifying only the density (i.e., $C \mathrm{p}_{\text {actual }}=C \mathrm{p}_{\text {model }}$ ) then Eq. (14) can be rearranged to give

$$
\rho_{\text {madel }}=\rho_{\text {actual }}\left(\frac{\text { Volume }_{\text {actual }}}{\text { Volume }_{\text {madel }}}\right) .
$$

The material densities of all approximated cylindrical regions are adjusted using Eq. (15). The total conductance associated with a material's surface is defined as the product of the heat transfer coefficient and heat transfer surface area. As before, the goal is to equate the actual and modeled products. The modeled heat transfer coefficients are, therefore, defined as the product of the actual coefficient and the ratio of actual-to-modeled surface areas, that is, 


$$
h_{\text {model }}=h_{\text {actual }}\left(\frac{\text { Surface } \text { Area }}{\text { actual }}\right) .
$$

At this point all the information needed to specify the base-case thermal model was available, and two HEATTNG input files were constructed: one to calculate the steady-state temperature distributions in the casting assembly prior to pour, and one that would use these distributions as initial conditions for the transient solidification analysis. A strictly numerical consideration that had to be addressed at this point was the choice of solution procedures. For the steady-state solution there are three options within the HEATING program: direct solve, successive overrelaxation, and conjugate gradient. The direct solution is not implemented for 3-D problems and there was concern that the conjugate gradient would be slow to converge given the problem's size, complexity, and highly nonlinear nature. Thus, the successive overrelaxation procedure was used. Choices for the transient solution procedure are more limited. For problems involving phase-change materials, HEATING must use an explicit time-integration procedure that is stable only so long as the time step meets certain criteria that are functions of discretized geometry and material properties. For a 3-D geometry the maximum time step for an interior node is defined as

$$
\Delta t \leq\left[\frac{\sum_{i=1}^{8} C p_{i} \rho_{i} V_{i}}{\sum_{m=1}^{6} \sum_{n=1}^{4} \frac{1}{L_{m}} k_{m, n} A_{m, n}}\right],
$$

where the numerator represents the sum of the heat capacities for the eight material volumes surrounding a particular node and the denominator represents the sum of the conductances between a particular node and its six neighbor nodes. A time step is calculated for each node in the problem using Eq. (17), and the minimum value in the set is used for the calculations. The time step limitation defined in Eq. (17) can, for some geometries and material properties, result in execution times (and therefore costs) becoming so great that the explicit procedure becomes impracticable. For these circumstances HEATING has the option of the Levy modification to the explicit procedure. The modification results in a stable solution procedure for any size time step so long as the discretized heat conduction equation for temperature at the $n+1$ time step is defined as

$$
T^{n+1}=T^{n}+\frac{1}{1+Z}\left\{\frac{\Delta t}{C}\left[P^{n}+\mathrm{K}_{l, m}\left(T_{l, m}^{n}-T^{n}\right)\right]+Z\left[T^{n}-T^{n-1}\right]\right\},
$$

where

$$
Z=\left\{\begin{array}{cc}
0 & \frac{\Delta t}{\left(\Delta t_{\max }\right)} \leq 1 \\
0.5\left[\frac{\Delta t}{\left(\Delta t_{\max }\right)}-1\right], \frac{\Delta t}{\left(\Delta t_{\max }\right)}>1
\end{array},\right.
$$


and $\Delta \mathrm{t}$ is the maximum step size defined in Eq. (17). Because it was felt that the geometry discretization used in the problem would result in very small time steps, the Levy modified explicit solution procedure was used for all transient calculations.

To summarize, the base-case steady-state and transient HEATING models have the following structure:

1. A 3-D, quarter-symmetric cartesian approximation of the complete experimental system; the heater coils, firebrick base, and three $\mathrm{Al}_{2} \mathrm{O}_{3}$ insulated platinum thermocouple junctions. In addition two uranium regions are also included: one inside the crucible and one inside the bookmold. Their dimensions were defined using the data from Run No. 892.

2. A successive overrelaxation solution procedure for the steady-state calculation and an explicit solution procedure with Levy's modification for the transient calculations.

3. S.I. units; watts (W), joules (J), meters (m), kilograms (kg), seconds (s), and temperature $\left({ }^{\circ} \mathrm{C}\right)$. Specific properties were thermal conductivity in $\mathrm{W} / \mathrm{m}-{ }^{\circ} \mathrm{C}$, specific heat in $\mathrm{J} / \mathrm{kg}-{ }^{\circ} \mathrm{C}$, density in $\mathrm{kg} / \mathrm{m}^{3}$, heats of transformation and fusion in $\mathrm{J} / \mathrm{kg}-{ }^{\circ} \mathrm{C}$, internal heat generation in $\mathrm{W} / \mathrm{m}^{3}$, fluid viscosity in $\mathrm{mN}-\mathrm{s} / \mathrm{m}^{2}$, Stefan-Boltzmann as $5.67 \times 10^{-8} \mathrm{~W} / \mathrm{m}^{2}-\mathrm{K}^{4}$, and heat transfer coefficients in $\mathrm{W} / \mathrm{m}^{2}-{ }^{\circ} \mathrm{C}$.

4. Temperature-dependent material properties, except for density where constant (with respect to (wrt) temperature) average values are used. In addition, two solid-solid and one solid-liquid phase changes are included for uranium. During steady-state analyses the uranium in the crucible is treated as a simply conducting phase-change region with liquid properties. During the transient calculation the uranium in the bookmold is treated as a simply conducting phase-change region with temperature dependent properties; i.e., liquid for those portions above melting temperature and solid for those below the melting temperature.

5. Adjusted heat capacities for those assembly components approximated with the cartesian geometry. The actual densities were adjusted using Eq. (15), and the specific heats were not modified. Components, actual densities, volume ratios, and adjusted densities are the following:
a. $\quad$ carbon end caps: $1730 \mathrm{~kg} / \mathrm{m}^{3}, 1.11$, and $1920.3 \mathrm{~kg} / \mathrm{m}^{3}$;
b. $\quad$ copper plates: $8954 \mathrm{~kg} / \mathrm{m}^{3}, 2.12$, and $18990 \mathrm{~kg} / \mathrm{m}^{3}$;
c. $\quad \mathrm{Al}_{2} \mathrm{O}_{3}$ shield: $240 \mathrm{~kg} / \mathrm{m}^{3}, 3.38$, and $811.2 \mathrm{~kg} / \mathrm{m}^{3}$;
d. $\quad \mathrm{Al}_{2} \mathrm{O}_{3}$ thermocouple insulation: $240 \mathrm{~kg} / \mathrm{m}^{3}, 1.57,376.8 \mathrm{~kg} / \mathrm{m}^{3}$; and
e. platinum thermocouple junctions: $21791 \mathrm{~kg} / \mathrm{m}^{3}, 1.57,34212 \mathrm{~kg} / \mathrm{m}^{3}$.

6. Induction heater modeled with a modified total average power scheme.

a. $\quad 0.86 \%$ of the total average induced power for a cylindrical workpiece is calculated and uniformly applied across one current penetration depth to the crucible, upper end cap, and upper part of the bookmold. The actual value is calculated at run time within a user-supplied subroutine that reads the coil current from the HEATING input file, determines the axial location of the current node of

- User-supplied subroutines are a HEATING option that allow the user to override default procedures for calculating such terms as boundary temperatures, heat transfer coefficients, and/or internal heat generation. 
interest, calculates a corresponding ${ }^{\dagger}$ value for the magnetic field intensity using a coil power frequency of $10,000 \mathrm{~Hz}$ and the information in Fig. 29, and then calculates a value for the heat generation rate using Eq. (7). In addition, the rate for the upper end cap is adjusted by the ratio of actual region volume to modeled volume: 1.11 .

b. No internal heat generation in the $\mathrm{Al}_{2} \mathrm{O}_{3}$ shield, firebrick base, uranium, lower part of the bookmold, or lower end cap.

c. Coil cooling-water flow rate constant wrt time and equal to $7 \mathrm{gpm}^{26}$

d. Steady-state cooling-water temperature rise constant wrt time and equal to $6^{\circ} \mathrm{C}^{26}$

e. Transient cooling-water temperature rise constant wrt time and equal to $1^{\circ} \mathrm{C}^{26}$

f. Cooling-water inlet temperature constant wrt time and equal to $24^{\circ} \mathrm{C}{ }^{26}$

g. Pressure-vessel wall temperature constant wrt time and equal to $43^{\circ} \mathrm{C}^{26}$

h. Internal heat generation for the copper plates calculated using a simple $I^{2} R$ relationship and actual value equal to $4.938 \times 10^{1} \mathrm{w} / \mathrm{m}^{3} \times I$, where $\mathrm{I}$ is coil current. A user-supplied subroutine reads the HEATING input file for the coil current and then calculates a value for heat generation.

i. Internal heat generation at the base-case values for the first $15 \mathrm{~s}$ of the solidification transient.

7. Contact resistances using a constant (wrt temperature) coefficient of $2000 \mathrm{~W} / \mathrm{m}^{2}-{ }^{\circ} \mathrm{C}$ and are applied between the crucible and crucible top, upper end cap and crucible, upper end cap and bookmold in both the vertical and horizontal orientations, lower end cap and bookmold in both the vertical and horizontal orientations, and lower end cap and firebrick.

8. External natural convection heat transfer from the following surfaces.

a. Crucible bottom and walls to liquid uranium during a steady state. Horizontal and vertical values calculated using Eqs. (5) and (6) and actual values are vertical $h$ $=4.258 \times 10^{3} \mathrm{~W} / \mathrm{m}^{2}-{ }^{\circ} \mathrm{C}$ and horizontal $\mathrm{h}=1.415 \times 10^{4} \mathrm{~W} / \mathrm{m}^{2}-{ }^{\circ} \mathrm{C}$.

b. Bookmold bottom and walls to liquid uranium during transient so long as the fluid temperature at a node is above the melting point. Horizontal and vertical values calculated using Eqs. (5) and (6) and actual values are vertical $h=1.5778 \times 10^{4}$ $\mathrm{W} / \mathrm{m}^{2}-{ }^{\circ} \mathrm{C}$ and horizontal $\mathrm{h}=1.595 \times 10^{4} \mathrm{~W} / \mathrm{m}^{2}-{ }^{\circ} \mathrm{C}$.

9. Constant wrt temperature heat transfer coefficient applied across the gap separating the solidified uranium and bookmold vertical and horizontal walls when the fluid temperature drops below the melting point. Actual value used is $0.5 \times 10^{3} \mathrm{~W} / \mathrm{m}^{2}-{ }^{\circ} \mathrm{C}$. A user-supplied subroutine stores all the node pairs at the three uranium-carbon interfaces, determines the pair of nodes containing the current node of interest, and then assigns a value for the gap conductance based on the temperature of the node on the uranium side of the gap. For a node temperature above the melting point, a natural convection coefficient is used; below the melt temperature, the constant coefficient is used.

10. Forced convection heat transfer between interior surfaces of the copper flat plates and cooling water using Eq. (12) and actual value is $\mathrm{h}=1.2931 \times 10^{4} \mathrm{~W} / \mathrm{m}^{2}-{ }^{\circ} \mathrm{C}$.

11. One-dimensional radiation heat transfer using Eqs. (3) and (4) applied at the following locations.

+ Field attenuation was calculated using a single radial spacing, when in fact, there are three. 
a. Between the top of the crucible uranium region and the bottom of the crucible top during steady state; nominal $\mathrm{h}=1.889 \times 10^{-8} \mathrm{~W} / \mathrm{m}^{2}-{ }^{\circ} \mathrm{C}$ and is a function of $\mathrm{Al}_{2} \mathrm{O}_{3}$ temperature. A user-supplied subroutine identifies a typical temperature in the crucible top, calculates a value for $\mathrm{Al}_{2} \mathrm{O}_{3}$ emissivity, and then calculates the coefficient.

b. Between the top of the bookmold uranium region and the bottom of the upper end cap during the transien $t$ analysis; nominal $\mathrm{h}=1.920 \times 10^{-8} \mathrm{~W} / \mathrm{m}^{2}-{ }^{\circ} \mathrm{C}$ and is constant wrt temperature.

c. From the upper surface of the crucible top to the pressure vessel wall; nominal $\mathrm{h}=4.366 \times 10^{-8} \mathrm{~W} / \mathrm{m}^{2}-{ }^{\circ} \mathrm{C}$ and is a function of $\mathrm{Al}_{2} \mathrm{O}_{3}$ temperature.

d. Between the crucible exterior walls and the $\mathrm{Al}_{2} \mathrm{O}_{3}$ shield; nominal $\mathrm{h}=3.661 \times$ $10^{-8} \mathrm{~W} / \mathrm{m}^{2}-{ }^{\circ} \mathrm{C}$ and is a function of $\mathrm{Al}_{2} \mathrm{O}_{3}$ temperature. The same user-supplied subroutine described above in $(a)$ is used to determine shield temperature and calculate a value for the coefficient.

e. Between the $\mathrm{Al}_{2} \mathrm{O}_{3}$ shield and the first copper plate; nominal $\mathrm{h}=1.797 \times 10^{-8}$ $\mathrm{W} / \mathrm{m}^{2}-{ }^{\circ} \mathrm{C}$ and is a function of both $\mathrm{Al}_{2} \mathrm{O}_{3}$ and copper temperatures. A usersupplied subroutine determines the temperatures of the current copper and $\mathrm{Al}_{2} \mathrm{O}_{3}$ nodes of interest, calculates values for their emissivities, and then calculates the coefficient.

f. From the nonobstructed (i.e., above and below heater coils) portion of the $\mathrm{Al}_{2} \mathrm{O}_{3}$ shield to the pressure vessel wall; nominal $\mathrm{h}=4.366 \times 10^{-8} \mathrm{~W} / \mathrm{m}^{2}-{ }^{\circ} \mathrm{C}$ and is a function of $\mathrm{Al}_{2} \mathrm{O}_{3}$ temperature.

g. With respect to the $\mathrm{Y} / \mathrm{Z}$ plane of the model shown in Fig. 21, a nominal, constant coefficient of $4.536 \times 10^{-8} \mathrm{~W} / \mathrm{m}^{2}-{ }^{\circ} \mathrm{C}$ is applied to the following surfaces using a boundary temperature that is the average of the $\mathrm{Al}_{2} \mathrm{O}_{3}$ and pressure vessel wall temperatures:

- lower Y surface of that portion of the upper end cap directly facing the lower end cap,

- upper Y surface of that portion of the lower end cap directly facing the upper end cap,

- upper $\mathrm{Z}$ surface of the bookmold wall in the elevation between the top of the lower end cap and the lower edge of the $\mathrm{Al}_{2} \mathrm{O}_{3}$ shield, and

- upper $\mathrm{Z}$ surface of that portion of the lower end cap facing the pressure vessel wall.

A user-supplied subroutine receives the pressure-vessel wall temperature, calculates the average temperature of a subset of shield nodes, and then defines the average of the two values as the boundary temperature.

h. With respect to the $\mathrm{Y} / \mathrm{X}$ plane of the model shown in Fig. 21, the same constant coefficient is applied to that portion of the bookmold wall below the $\mathrm{Al}_{2} \mathrm{O}_{3}$ shield, as well as the upper face of the lower end cap. The boundary temperature for these two locations is a weighted percentage of pressure vessel wall and $\mathrm{Al}_{2} \mathrm{O}_{3}$ temperatures: specifically, $75 \%$ of the pressure-vessel wall and $25 \%$ of the $\mathrm{Al}_{2} \mathrm{O}_{3}$. The same user-supplied subroutine described above determines the average temperature of a collection of $\mathrm{Al}_{2} \mathrm{O}_{3}$ nodes and then calculates the boundary temperature. 
i. From the bottom of the crucible to a boundary temperature defined from a nominal node in the bottom of the crucible top during the solidification analysis, from the lower surface of the crucible top to a boundary temperature defined from a nominal node in the bottom of the crucible during the solidification analysis, from the bottom of the bookmold to a boundary temperature defined from a nominal node in the lower surface of the upper end cap during the steadystate analysis, and from the lower surface of the upper end cap to a boundary temperature defined using a nominal node in the bottom of the bookmold during the steady-state analysis. These circuitous boundary conditions are required because the dual uranium regions preclude the use of straightforward surface to surface boundary conditions. A user-supplied subroutine defines the temperatures at the nominal nodes and then calculates the heat transfer coefficient.

j. $\quad$ From the outer surface of the second copper plate to the pressure-vessel wall; nominal $\mathrm{h}=1.985 \times 10^{-8} \mathrm{~W} / \mathrm{m}^{2}-{ }^{\circ} \mathrm{C}$ and is a function of copper temperature. Also, from the firebrick base to the pressure-vessel wall; actual $h=4.252 \times 10^{-8}$ $\mathrm{W} / \mathrm{m}^{2}-{ }^{\circ} \mathrm{C}$ and is constant wrt temperature.

12. Adjusted surface conductances; the actual heat transfer coefficients were modified using Eq. (16). The locations, actual values, area surface ratios, and adjusted values are
a. vertical crucible walls facing the uranium: $4.258 \times 10^{3} \mathrm{~W} / \mathrm{m}^{2}-{ }^{\circ} \mathrm{C}, 0.99,4.215 \times 10^{3}$ $\mathrm{W} / \mathrm{m}^{2}-{ }^{\circ} \mathrm{C}$;
b. horizontal crucible walls facing the uranium: $1.415 \times 10^{4} \mathrm{~W} / \mathrm{m}^{2}-{ }^{\circ} \mathrm{C}, 1.01,1.557$ $\times 10^{4} \mathrm{~W} / \mathrm{m}^{2}-{ }^{\circ} \mathrm{C}$;
c. vertical crucible walls facing the $\mathrm{Al}_{2} \mathrm{O}_{3}$ shield: $3.661 \times 10^{-8} \mathrm{~W} / \mathrm{m}^{2}-{ }^{\circ} \mathrm{C}, 1.01,3.698$ $\times 10^{-8} \mathrm{~W} / \mathrm{m}^{2}-{ }^{\circ} \mathrm{C}$;
d. uranium surface facing the $\mathrm{Al}_{2} \mathrm{O}_{3}$ cover: $1.889 \times 10^{-8} \mathrm{~W} / \mathrm{m}^{2}-{ }^{\circ} \mathrm{C}, 1.011 .908 \times 10^{-8}$ $\mathrm{W} / \mathrm{m}^{2}-{ }^{\circ} \mathrm{C}$;
e. upper end cap facing the $\mathrm{Al}_{2} \mathrm{O}_{3}$ shield: $3.661 \times 10^{-8} \mathrm{~W} / \mathrm{m}^{2}-{ }^{\circ} \mathrm{C}, 0.807,2.95 \times 10^{-8}$ $\mathrm{W} / \mathrm{m}^{2}-{ }^{\circ} \mathrm{C}$;
f. lower end cap facing the pressure-vessel wall: $4.536 \times 10^{-8} \mathrm{~W} / \mathrm{m}^{2}-{ }^{\circ} \mathrm{C}, 0.807,3.66$ $\times 10^{-8} \mathrm{~W} / \mathrm{m}^{2}-{ }^{\circ} \mathrm{C}$;
g. $\quad \mathrm{Al}_{2} \mathrm{O}_{3}$ shield facing the copper plates: $1.797 \times 10^{-8} \mathrm{~W} / \mathrm{m}^{2}-{ }^{\circ} \mathrm{C}, 1.78,3.2 \times 10^{-8}$ $\mathrm{W} / \mathrm{m}^{2}-{ }^{\circ} \mathrm{C}$; and
h. $\quad \mathrm{Al}_{2} \mathrm{O}_{3}$ shield facing the pressure-vessel wall: $4.366 \times 10^{-8} \mathrm{~W} / \mathrm{m}^{2}-{ }^{\circ} \mathrm{C}, 1.78,7.78 \times$ $10^{-8} \mathrm{~W} / \mathrm{m}^{2}-{ }^{\circ} \mathrm{C}$.

The steady-state and transient models were then run to define a base-case transient response. The steady-state model was executed with a series of values for the coil current until the target uranium melt temperature of $1375^{\circ} \mathrm{C}$ had been calculated in the crucible. The resulting casting assembly 3-D temperature distribution was then used as initial conditions for the solidification transient. The transient analysis was limited to approximately $100 \mathrm{~s}$ of problem time to conserve computing resources. The size and complexity of the models, combined with the explicit solution procedure constraint, resulted in $40 \mathrm{~h}$ of RS/6000-320 machine time being needed to simulate $100 \mathrm{~s}$ of problem time. The results are shown in Fig. 30, and listings of the input files and user-supplied subroutines are included in Appendix A. As Fig. 30 indicates, the base-case model predicts the actual bookmold thermal response to within $\pm 10 \%$. Considering the relatively crude relationships used to model the thermal mechanisms, the many assumptions that had to be made concerning induction heater operation, and the detrimental influence of the cartesian 
approximation on internal heat generation, region volumes and surface areas, this level of agreement is quite satisfactory. 


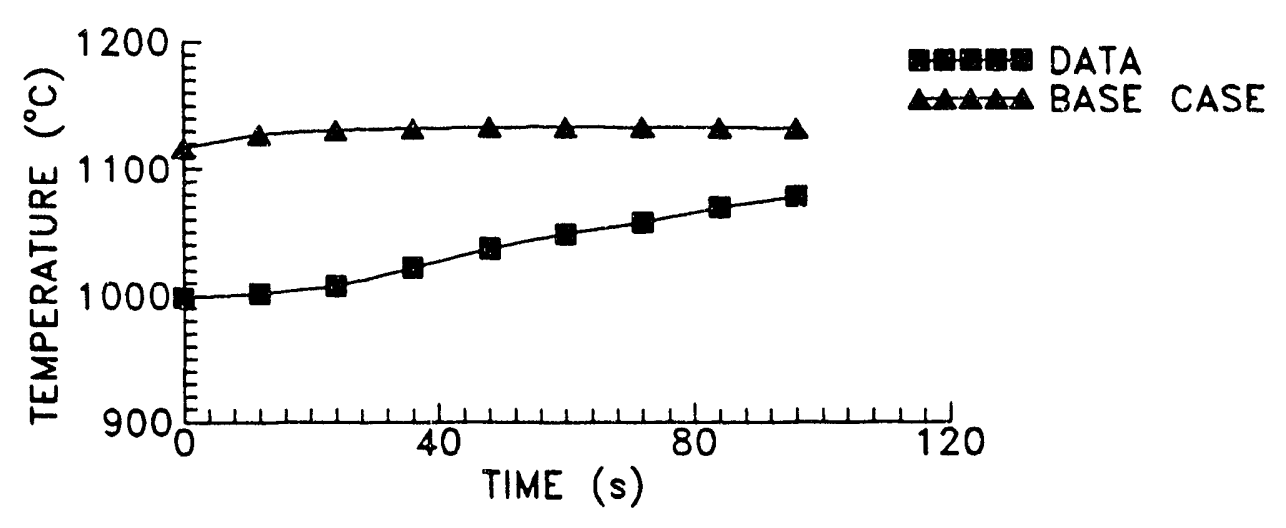

(a) top thermocouple

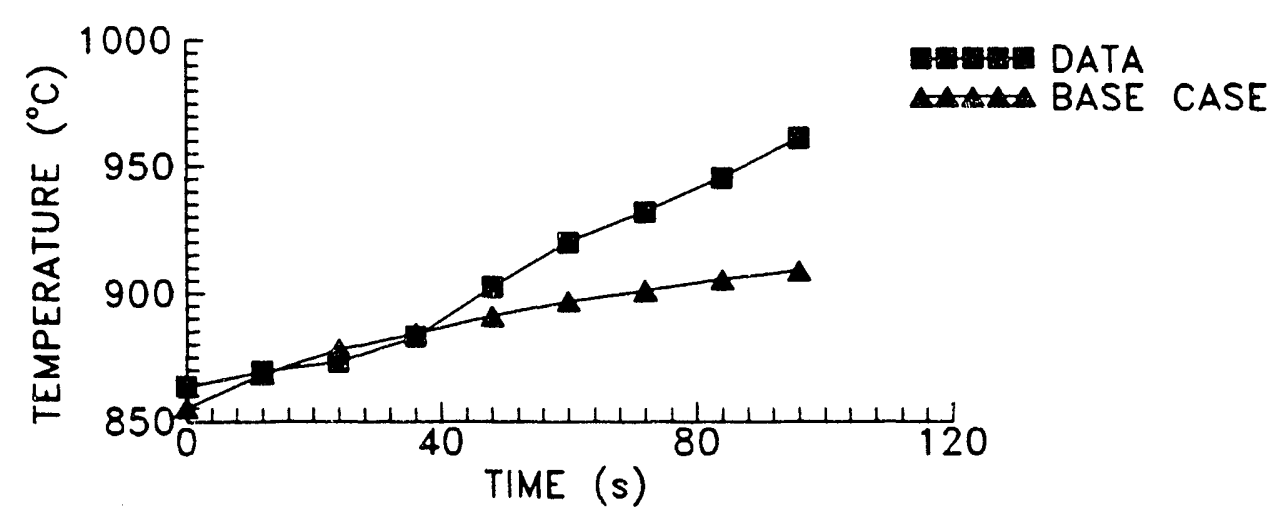

(b) middle thermocouple

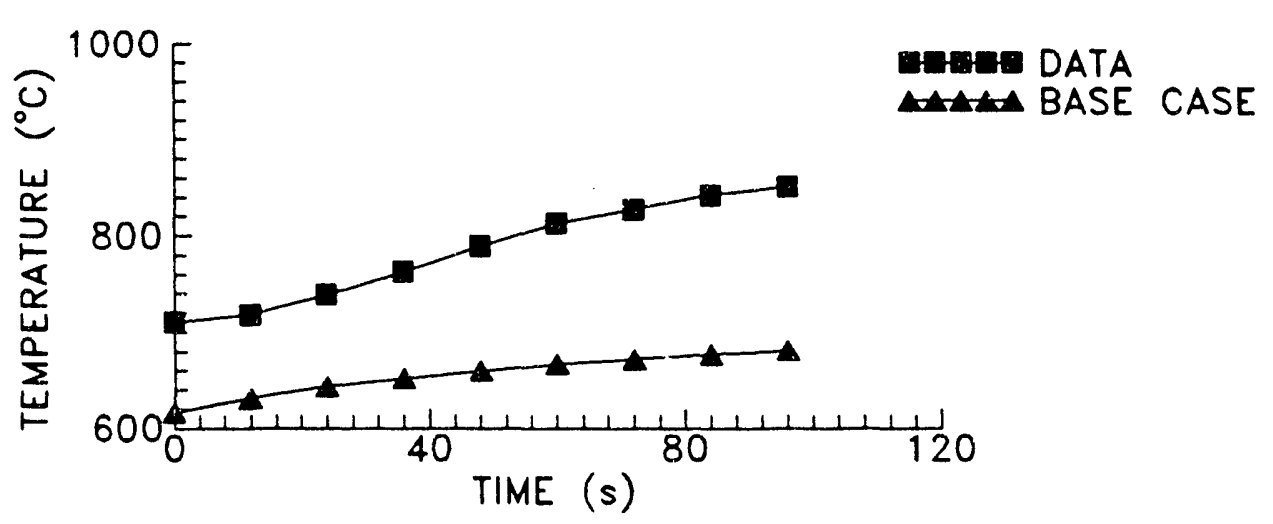

(c) bottom thermocouple

Fig. 30. Base-case HEATING model thermocouple agreement. 


\section{SENSITTVITY STUDIES}

Twenty-one scenarios were examined to characterize the sensitivity of base-case thermocouple agreement. Even though the focus of the studies is the solidifying uranium region, the only direct measure of model performance is a comparison with experimental bookmold temperatures. For each scenario the variable of interest was changed from its base-case value, and a series of steady-state runs were made to determine the coil current that gave a uranium melt temperature of $1375^{\circ} \mathrm{C}$ in the crucible. The resulting casting assembly temperature distribution was then used as initia -onditions for a 100 -s transient solidification analysis. Each case is described in Table 1, and the results are summarized graphically in Figs. 31-41. Each figure shows typical experimental data (Run No. 892), base-case response, and study results at the three thermocouple locations. Also, the fraction of base-case current required to obtain the desired melt temperature is summarized in Table 1.

The most significant macroscopic observation is that the slopes of the transient responses closely match the experimental data. This match represents a considerable improvement from an earlier second-iteration study ${ }^{27}$ that utilized a simplified thermal model. Typical (i.e., all thermocouple locations and variable values examined) results from the earlier study are shown in Fig. 42. This figure summarizes model agreement for the middle thermocouple for various values of pressure-vessel wall temperature, cooling-water temperature, cooling-water flow rate, and thermal contact resistance. As these data show, agreement is uniformly poor in both the absolute value of temperatures at a point and the slopes of the temperature transients. Therefore, all the thermal mechanisms must be included in the numerical model to some degree to obtain meaningful thermocouple agreement. This result was expected, but prudence dictated the effort to ensure that the more rigorous (and expensive) model was necessary.

As it concerns the prominence of individual mechanisms, these most current results indicate that model agreement is unaffected or only slightly sensitive to nominal changes in vertical thermal contact resistances between casting assembly components, heating coil coolingwater flow rates, pressure-vessel interior wall temperatures, enclosure radiation heat transfer, interfacial gap conductances between solidified uranium and the bookmold, magnetic field axial direction attenuation, and induced power distribution. With the exception of enclosure radiation, gap conductance, and power induced distribution, these results appear reasonable. Specific results and their implication on the structure of the second-phase thermal model are discussed below.

1. Pressure-vessel wall temperatures and cooling-water outlet temperatures resulting from changes in cooling-water flow rate represent sink temperatures for the solidifying uranium. Given that the uranium temperatures are quite large in comparison to all the sink temperatures examined in this study, one would not expect the overall temperature difference, and therefore model response, to change significantly. Accordingly, pressurevessel wall and cooling-water temperatures should be included in the second-phase model, but only macroscopically. Each should be implemented as a constant (wrt time) value boundary temperature. 
Table 1. Summary of variable values used in the sensitivity studies

\begin{tabular}{|c|c|c|}
\hline Case & Description & Coil Current \\
\hline 1 & Thermal contact resistance for all gaps decreased by 5 . & 1.29 \\
\hline 2 & Thermal contact resistance for all gaps increased by 5 . & 1.43 \\
\hline 3 & $\begin{array}{l}\text { Thermal contact resistance for those gaps with a vertical } \\
\text { orientation increased by } 5.0 \text {. }\end{array}$ & 1.41 \\
\hline 4 & $\begin{array}{l}\text { Thermal contact resistance for those gaps with a vertical } \\
\text { orientation increased by } 10.0 \text {. }\end{array}$ & 1.41 \\
\hline 5 & Heating coil cooling-water flow rate decreased by $30 \%$. & 1.41 \\
\hline 6 & Heating coil cooling-water flow rate increased by $30 \%$. & 1.41 \\
\hline 7 & Pressure vessel interior wall temperature decreased by $50 \%$. & 1.41 \\
\hline 8 & Pressure vessel interior wall temperature increased by $50 \%$. & 1.41 \\
\hline 9 & $\begin{array}{l}\text { Natural convection heat transfer coefficients decreased by } \\
50 \% \text {. }\end{array}$ & 1.41 \\
\hline 10 & Natural convection heat transfer coefficients increased by $50 \%$. & 1.41 \\
\hline 11 & Enclosure radiation approximation removed. & 1.36 \\
\hline 12 & $\begin{array}{l}\text { Interfacial gap conductance made equal to base-case natural } \\
\text { convection coefficient. }\end{array}$ & 1.41 \\
\hline 13 & $\begin{array}{l}\text { Interfacial gap conductance made equal to base-case contact } \\
\text { resistance. }\end{array}$ & 1.36 \\
\hline 14 & Magnetic field axial direction attenuation decreased by $10 \%$. & 1.48 \\
\hline 15 & Magnetic field axial direction attenuation increased by $10 \%$. & 1.33 \\
\hline 16 & No internal heat generation during solidification transient. & 1.41 \\
\hline 17 & $\begin{array}{l}\text { Radiation heat transfer coefficient between crucible walls and } \\
\mathrm{Al}_{2} \mathrm{O}_{3} \text { insulating shield increased by } 100 \text {. }\end{array}$ & 1.58 \\
\hline 18 & $\begin{array}{l}\text { Radiation heat transfer coefficient between crucible walls and } \\
\mathrm{Al}_{2} \mathrm{O}_{3} \text { insulating shield increased by } 1000 \text {. }\end{array}$ & 1.56 \\
\hline 19 & Heating coil estimated current decreased by $10 \%$. & 1.55 \\
\hline 20 & Heating coil estimated current increased by $10 \%$ & 1.27 \\
\hline 21 & $\begin{array}{l}\text { Distribution of induced power changed to an exponentially } \\
\text { decaying rate applied across one current penetration depth. }\end{array}$ & 1.18 \\
\hline
\end{tabular}




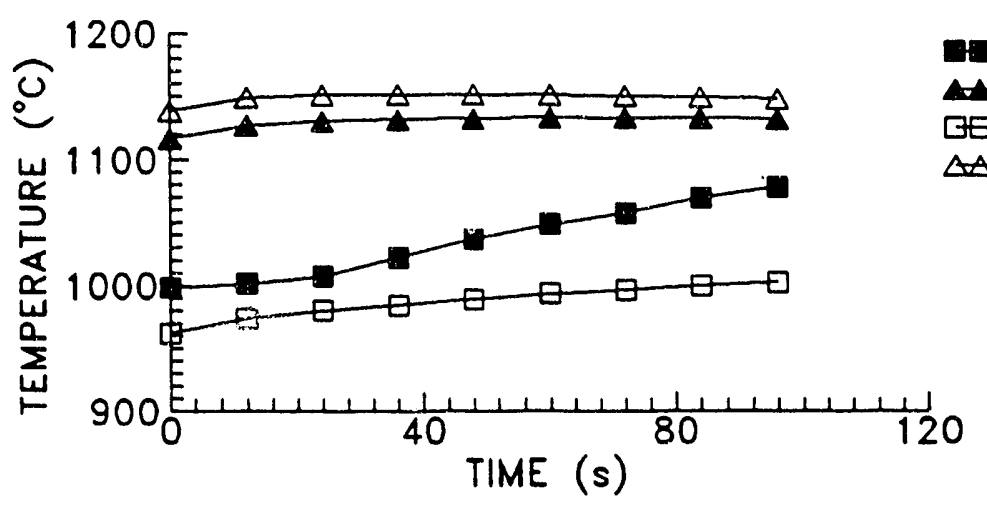

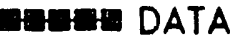

AaA BASE CASE

Re日 $R_{\text {th }}=200$

$\triangle \triangle \triangle R_{\mathrm{lh}}=10,000$.

(a) top thermocouple location

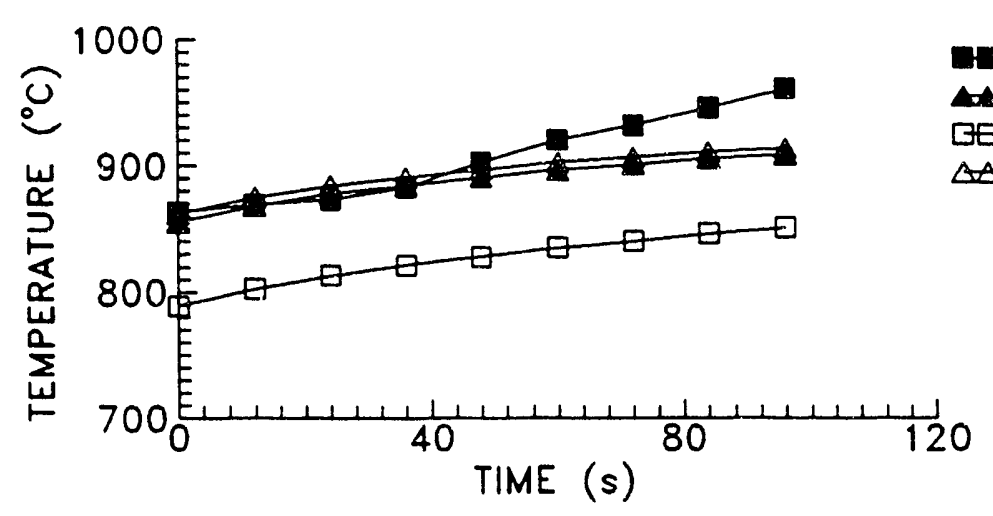

19ere DATA

maAa BASE CASE

Defth $R_{\text {th }}=200$.

$\triangle \triangle R_{\mathrm{th}}=10,000$.

(b) middle thermocouple location

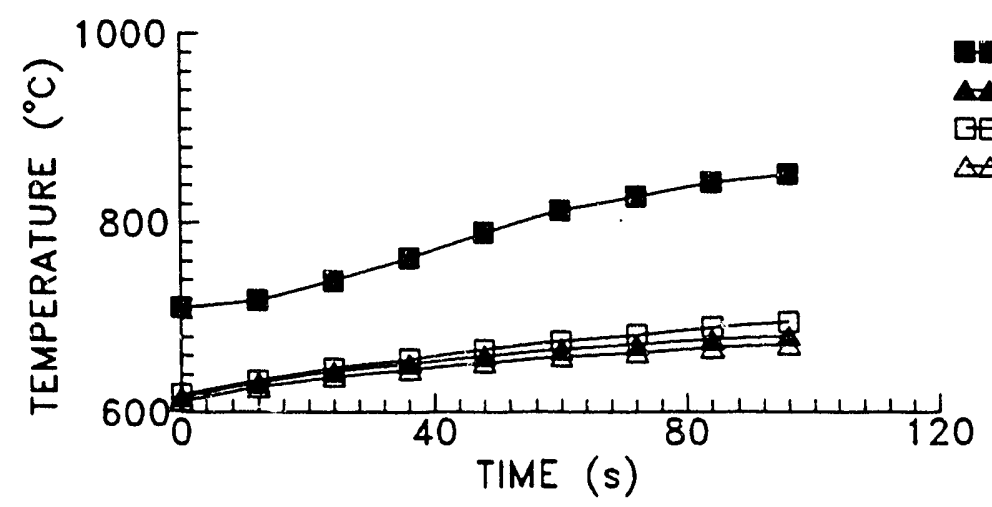

두를 DATA

aAA BASE CASE

GeEee $R_{\text {th }}=200$.

$\triangle \triangle R_{\mathrm{lh}}=10,000$.

(c) bottom thermocouple location

Fig. 31. Model agreement for the cases where the vertical and horizontal thermal contact resistances (Rth) were increased and decreased by a factor of 5 . 


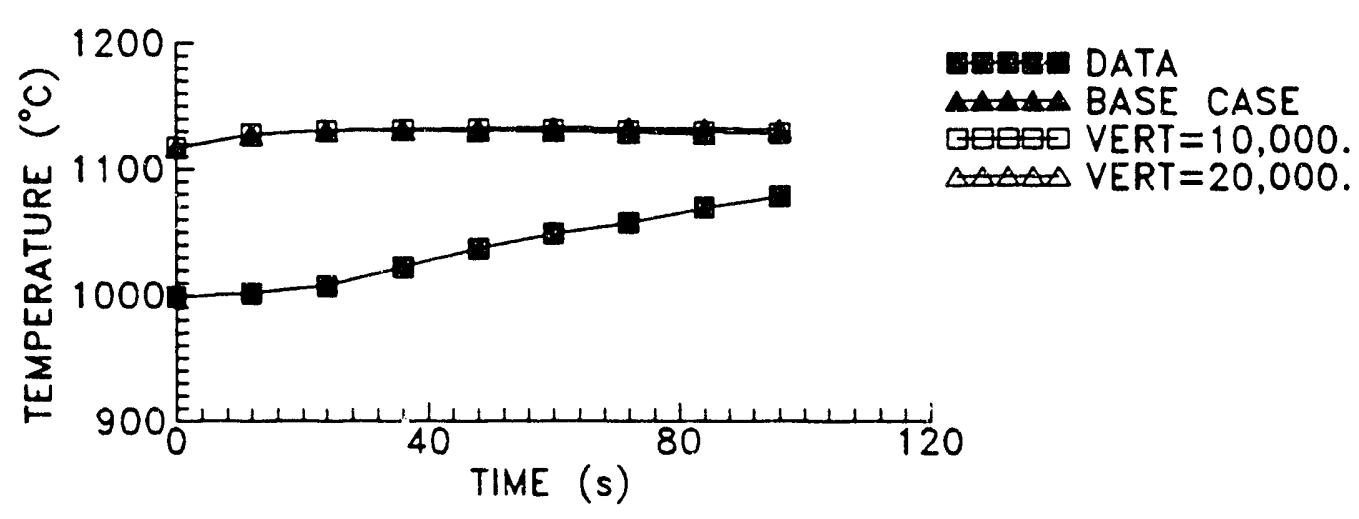

(a) top thermocouple location

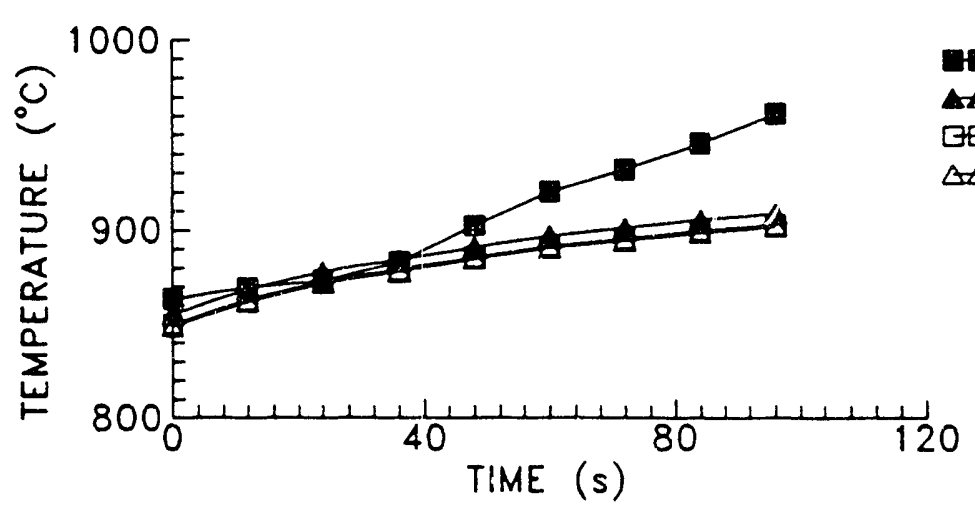

(b) middle thermocouple location

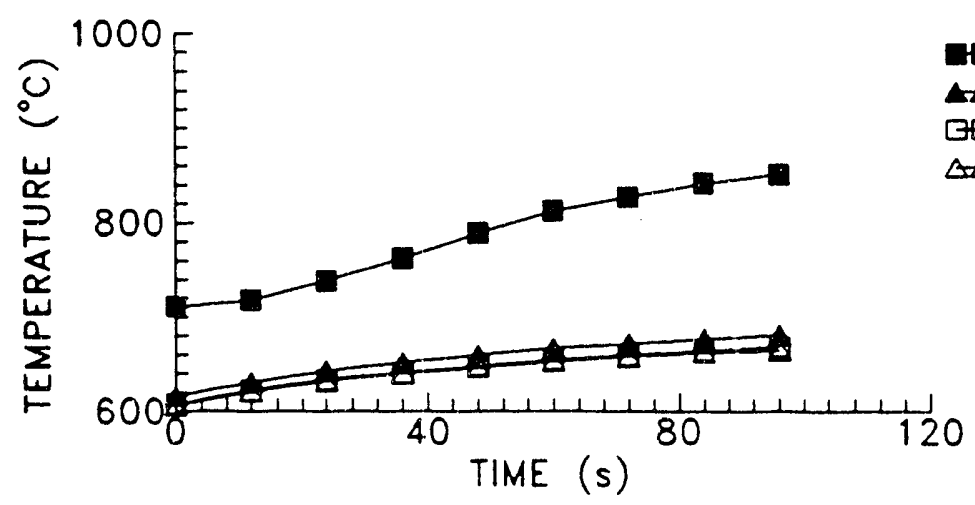

aㅡ를 DATA

ataAa BASE CASE VERT $=10,000$ $\triangle \triangle$ VERT $=20,000$

(c) bottom thermocouple location

Fig. 32. Model agreement for the cases where the vertical thermal contact resistances were increased by factors of 5 and 10 . 


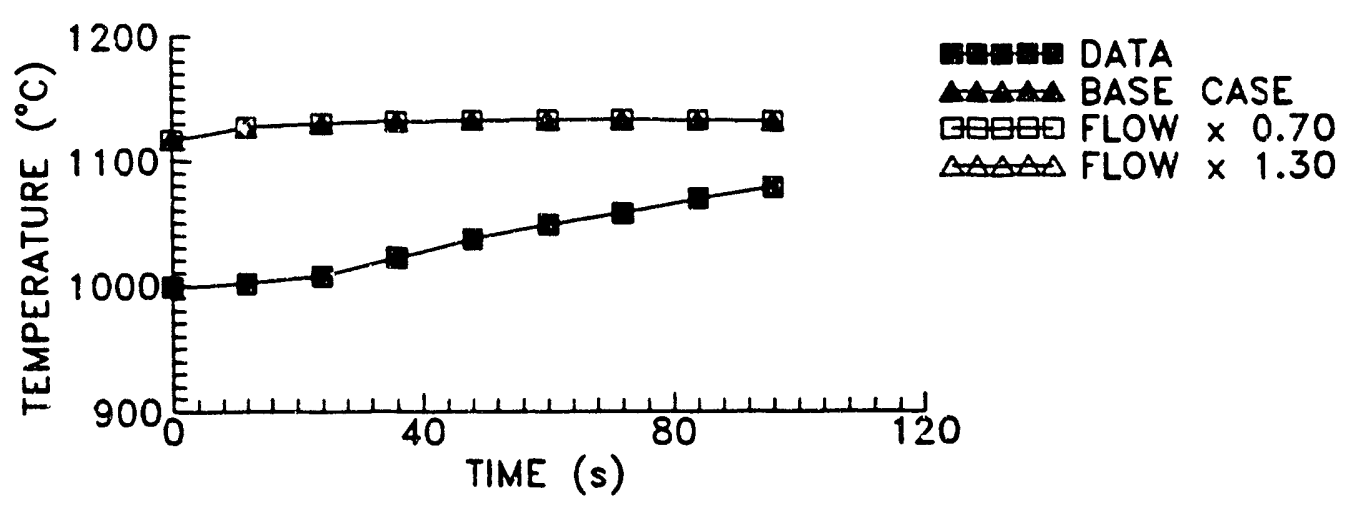

(a) top thermocouple location

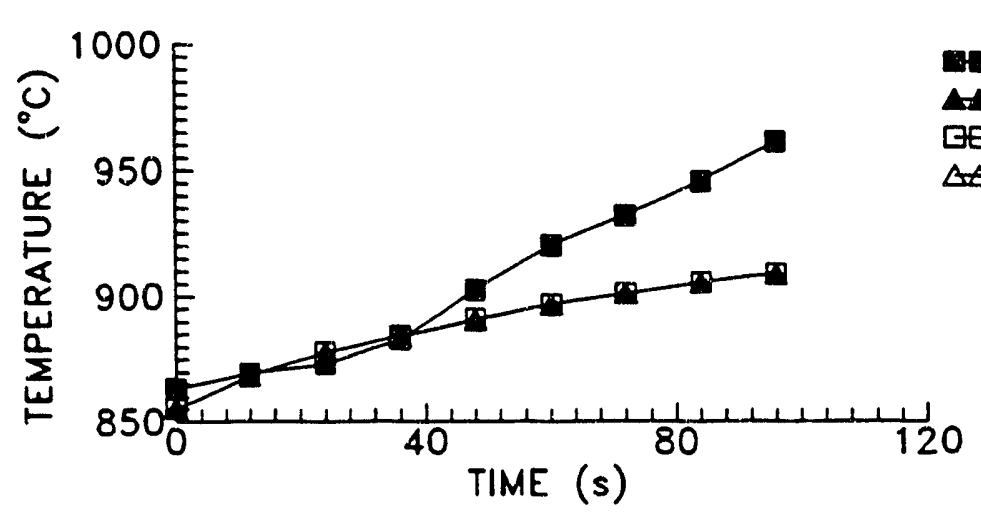

(b) middle thermocouple location

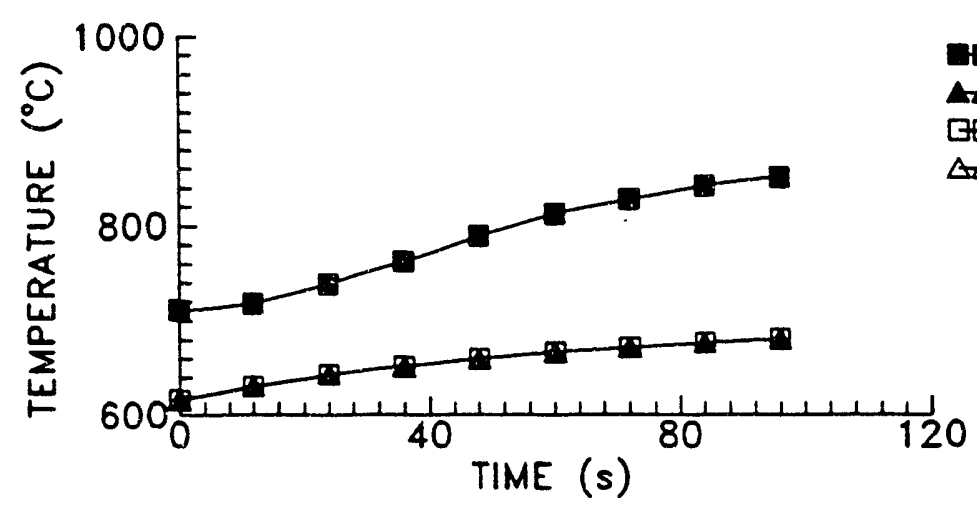

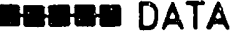

$\triangle A \rightarrow A$ BASE CASE

FLOW $\times 0.70$

$\triangle$ FLOW $\times 1.30$

(c) bottom thermocouple location

Fig. 33. Model agreement for the cases where the heating coil cooling-water flow rate was varied by $\pm 30 \%$. 


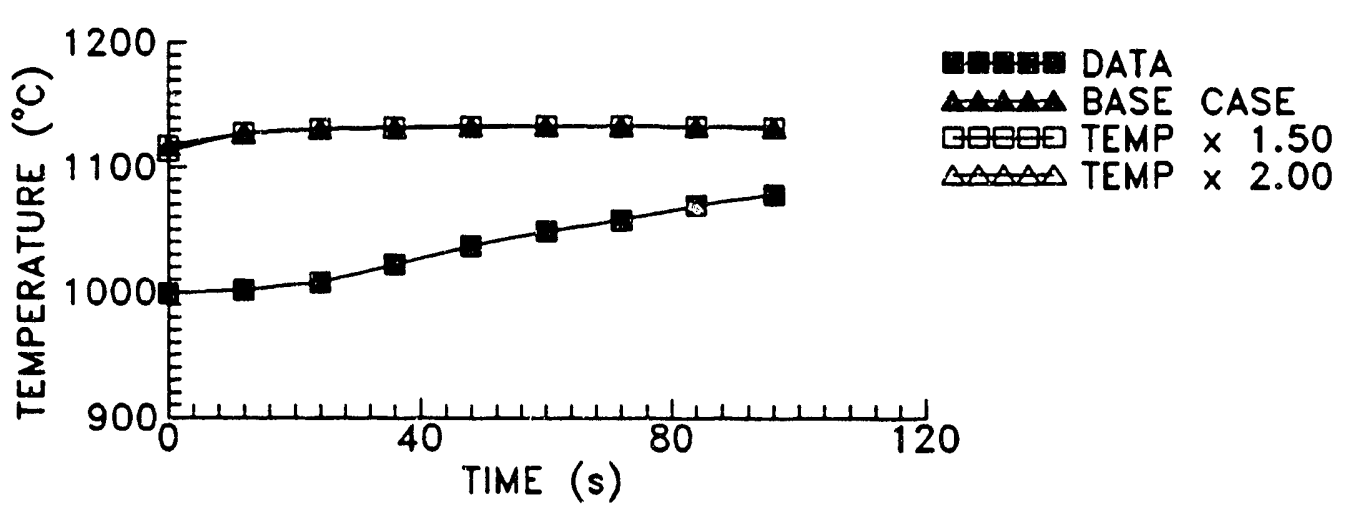

(a) top thermocouple location

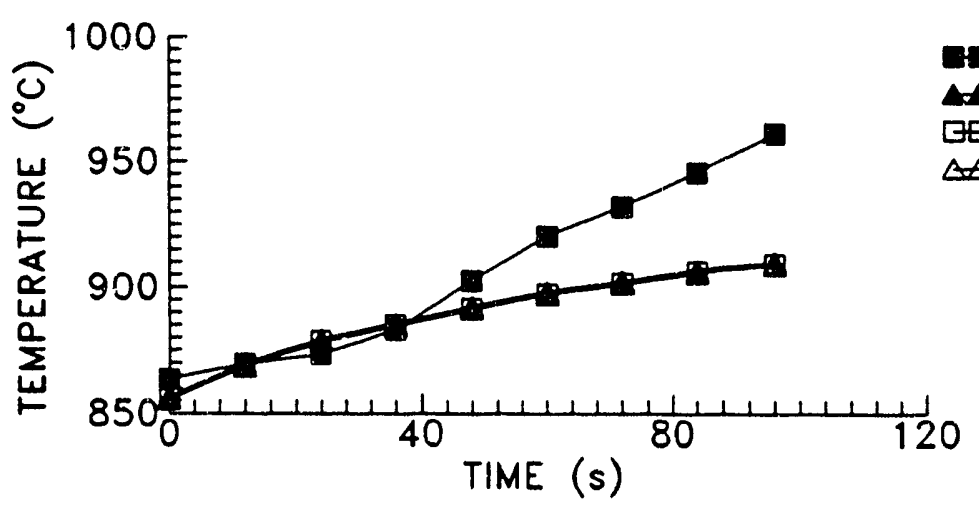

ATIFI DATA

AAAAA BASE CASE

TEMP $\times 1.50$

$\triangle \triangle$ TEMP $\times 2.00$

(b) middle thermocouple location

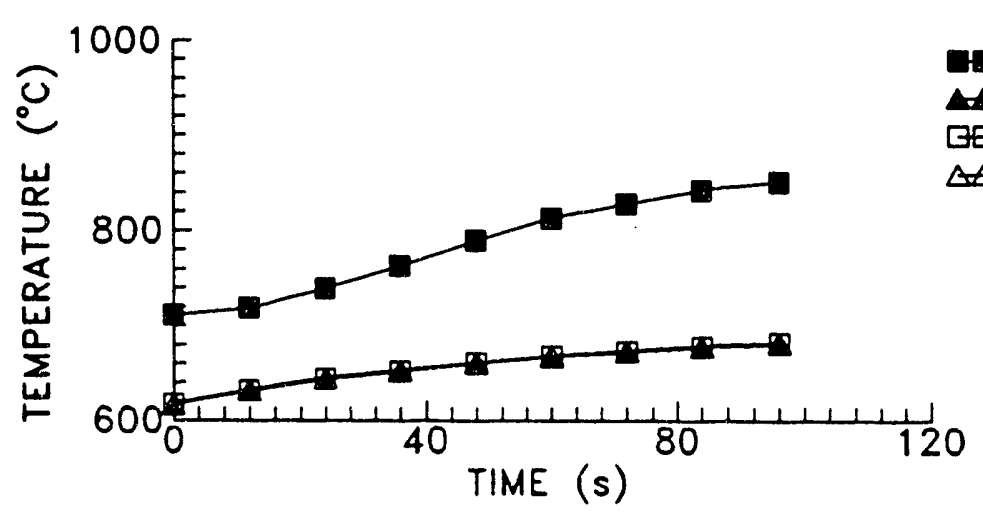

(c) bottom thermocouple location

Fig. 34. Model agreement for the cases where the pressure-vessel wall temperature was varied by $\pm 50 \%$. 


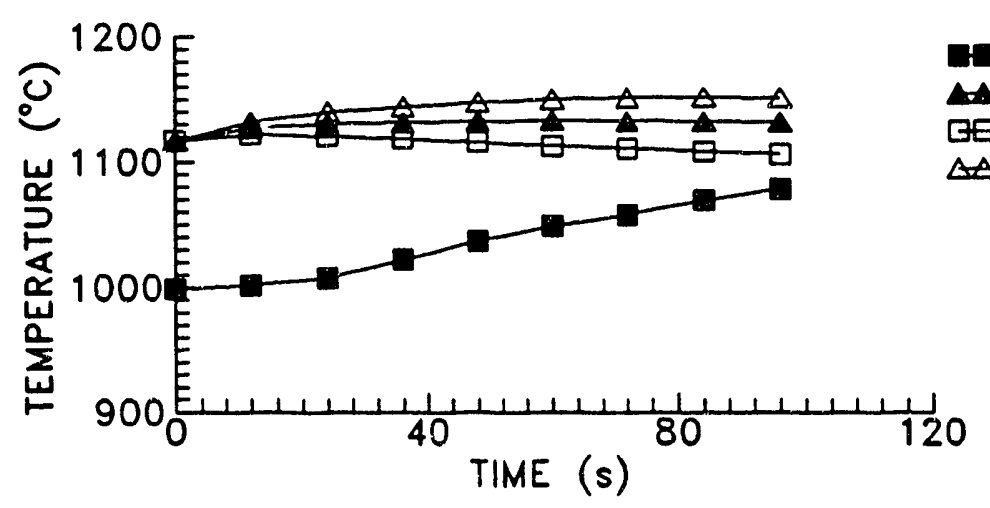

DEm DATA

BASE CASE

GEOEE COEF $\times 0.50$

$\triangle$ COEF $\times 1.50$

(a) top thermocouple location

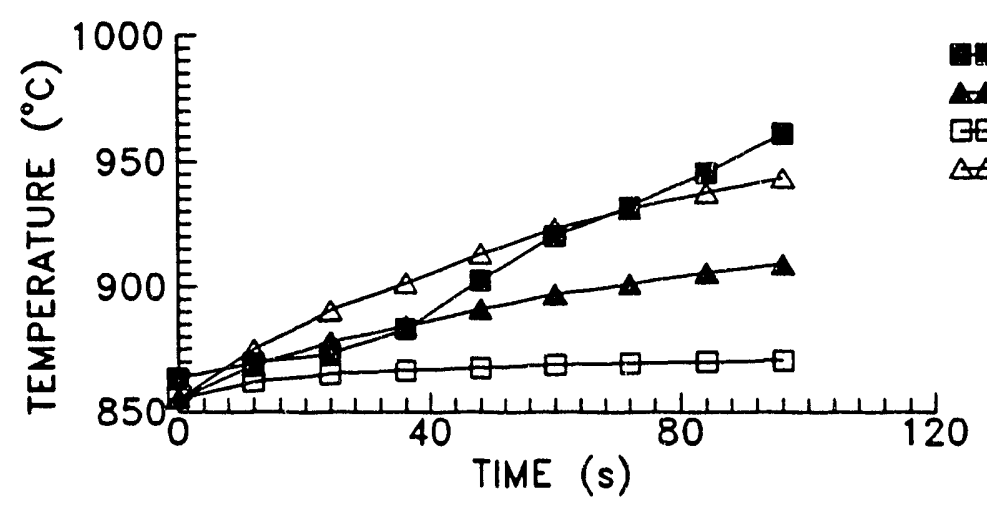

aren DATA

A BASE CASE

[GEAE COEF $\times 0.50$

$\triangle \triangle \triangle$ COEF $\times 1.50$

(b) middle thermocouple location

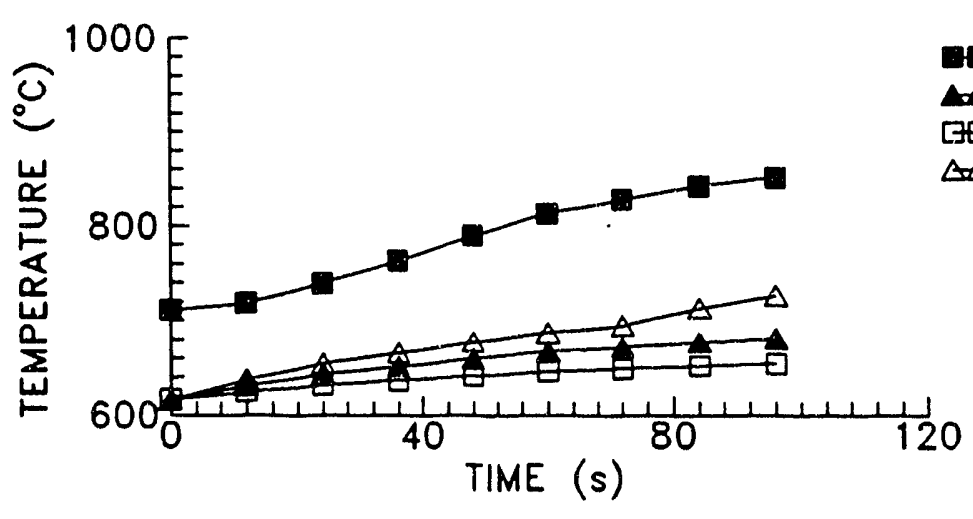

Darian DATA

AASE CASE

COEF $\times 0.50$

$\triangle$ COEF $\times 1.50$

(c) bottom thermocouple location

Fig. 35. Model agreement for the cases where the liquid uranium natural convection heat transfer coefficients were varied by $\pm 50 \%$. 


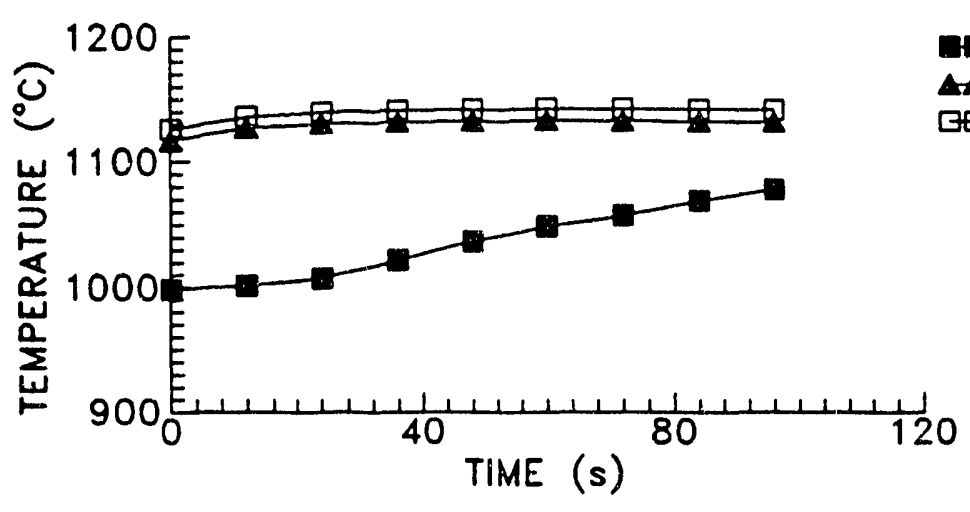

Dares DATA

$\triangle A$ BASE CASE

NO ENCLOSURE

(a) top thermocouple location

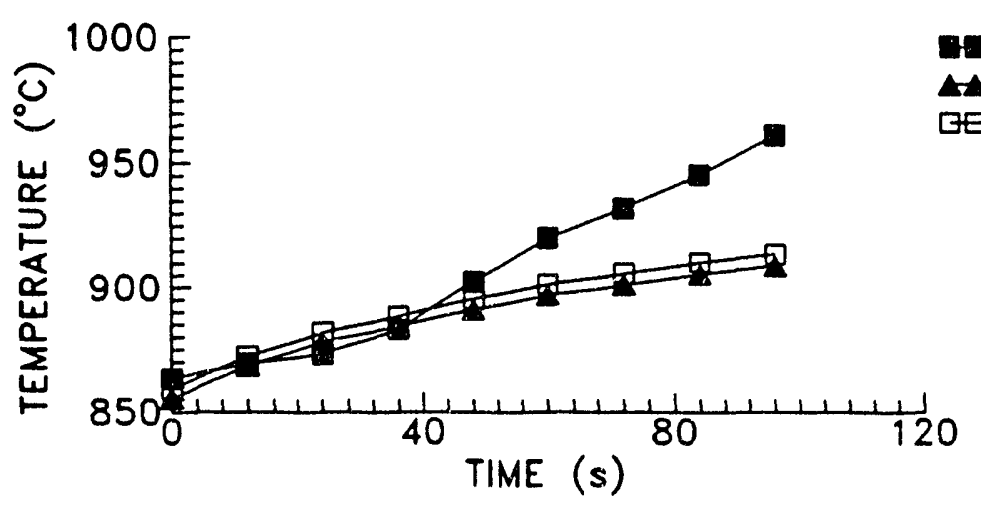

DERE DATA

$\triangle A$ BASE CASE

NO ENCLOSURE

(b) middle thermocouple location

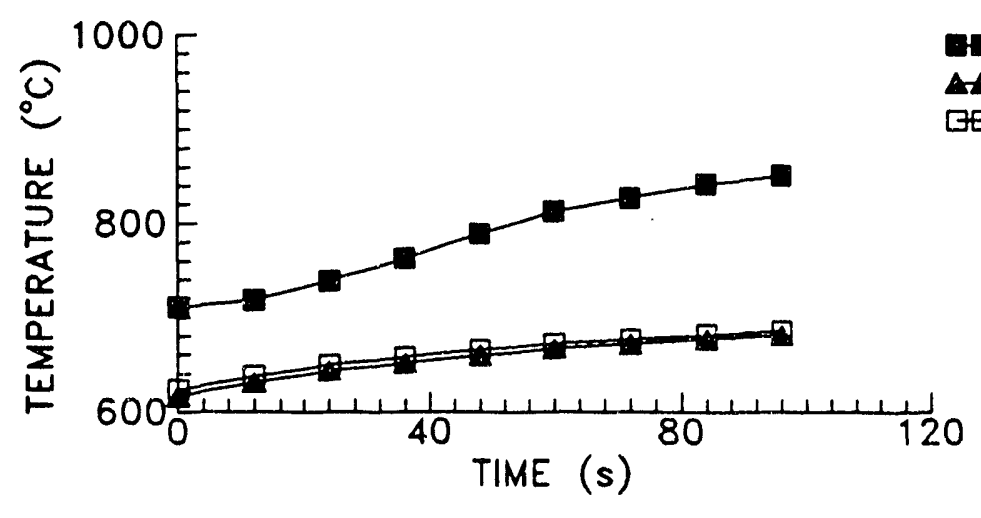

무를 DATA

$\triangle A$ AAA BASE CASE

GEE NO ENCLOSURE

(c) bottom thermocouple location

Fig. 36. Model agreement for the case where enclosure radiation approximation was removed. 


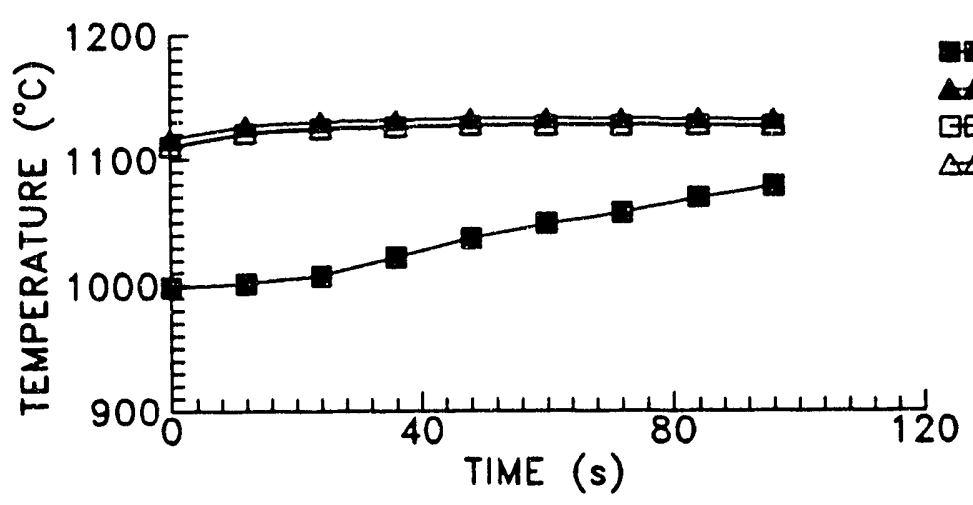

Date- DATA

ata BASE CASE $k=N A T$ CONV $\triangle \mathrm{k}=\mathrm{CONTACT} \mathrm{R}_{\mathrm{th}}$

(a) top thermocouple location

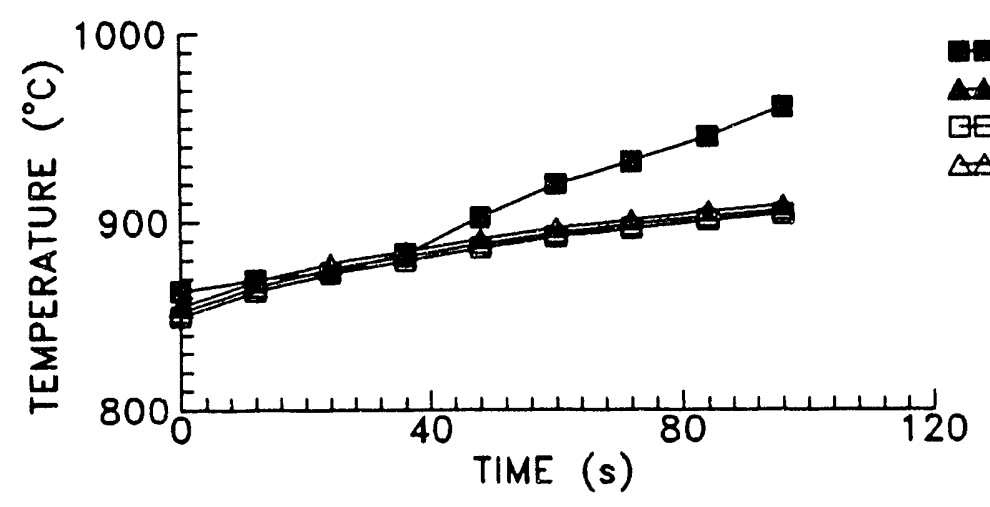

arean DATA

AAAA BASE CASE DANAT CONV $\triangle \triangle \mathrm{k}=\mathrm{CONTACT} \mathrm{R}_{\text {th }}$

(b) middle thermocouple location

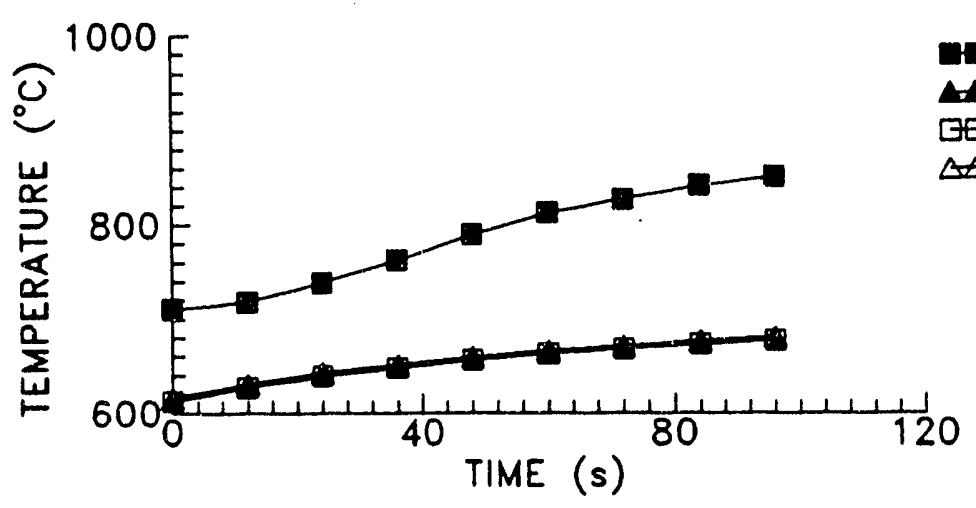

MTan DATA

AAAA BASE CASE

W $k=N A T$ CONV

$\triangle k=C O N T A C T R_{\text {th }}$

(c) bottom thermocouple location

Fig. 37. Model agreement for the cases where the solidified uranium-bookmold interfacial gap conductance was equal to the base-case liquid uranium natural convection heat transfer coefficient and thermal contact resistance. 


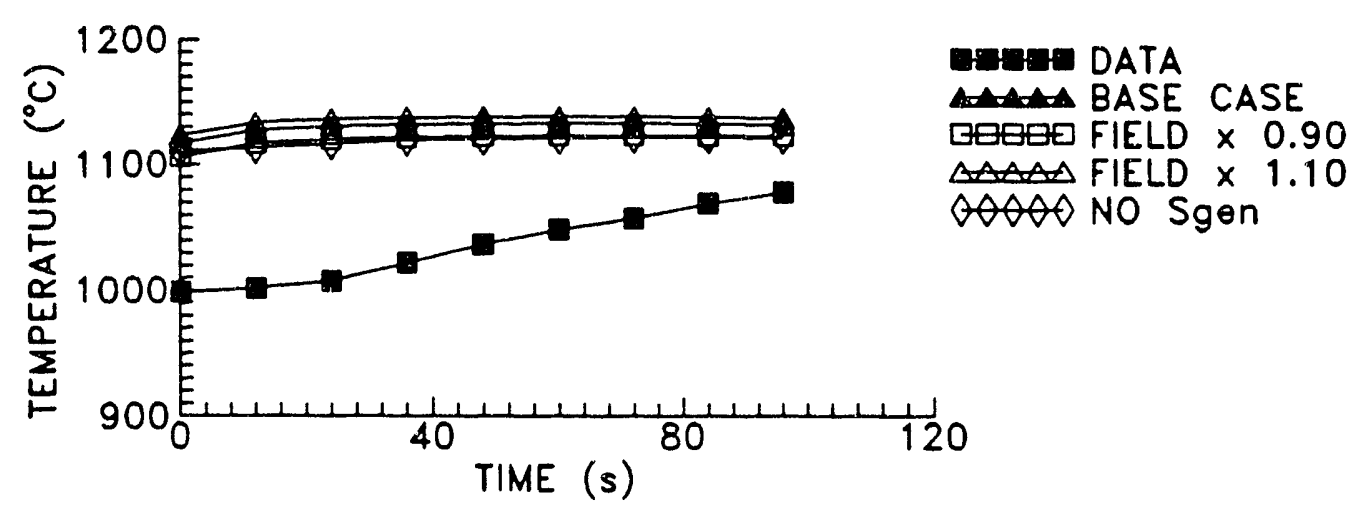

(a) top thermocouple location

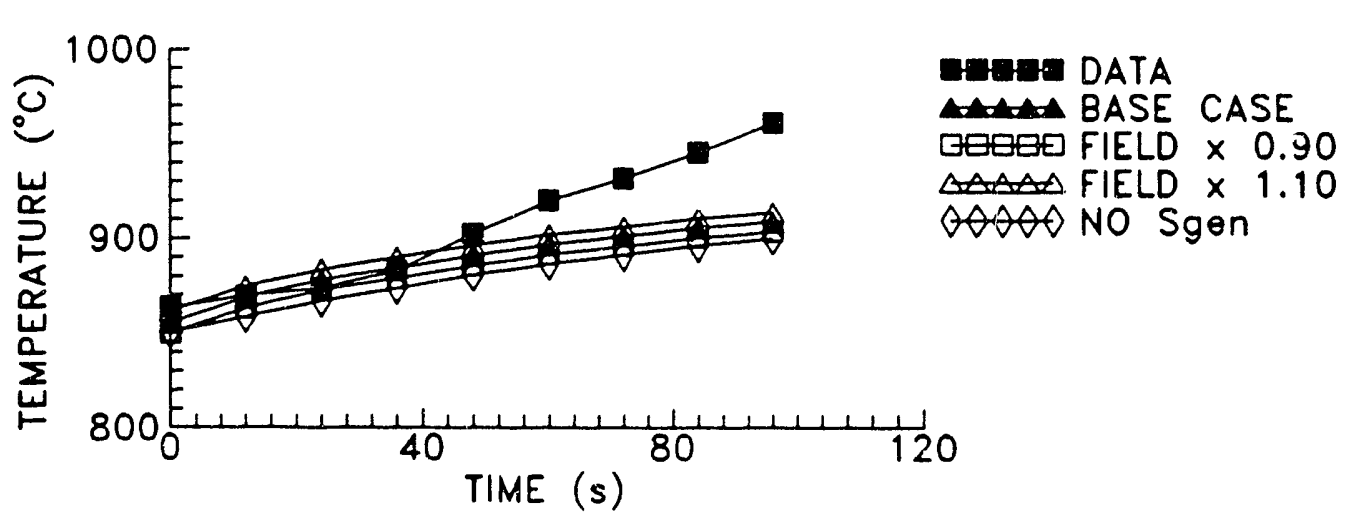

(b) middle thermocouple location

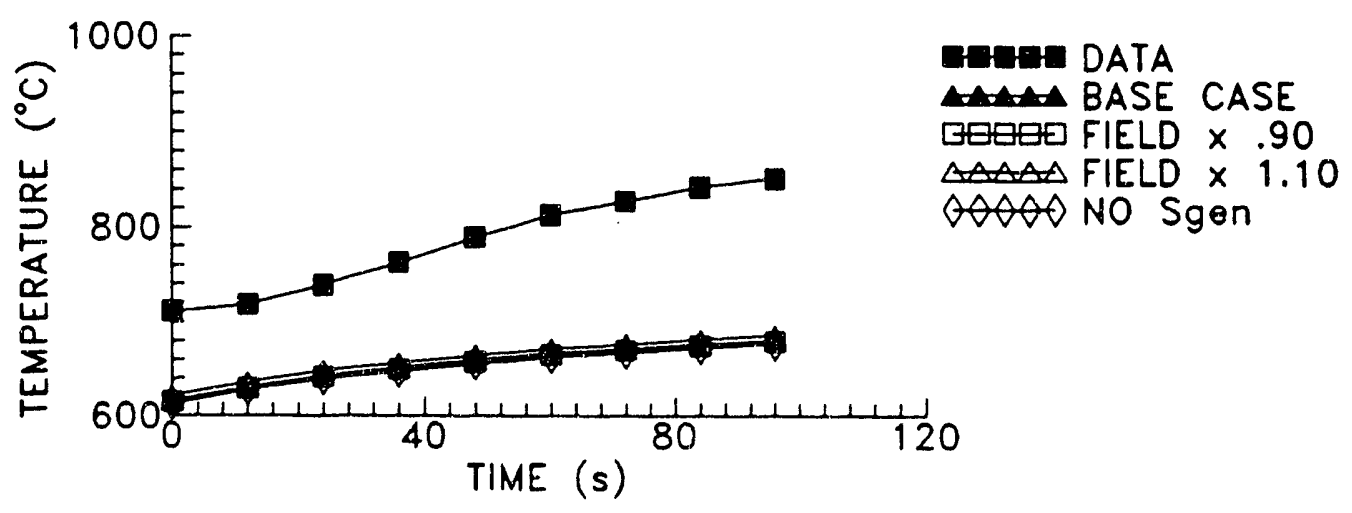

(c) bottom thermocouple location

Fig. 38. Model agreement for the cases where the magnetic field axial direction attenuation was varied by $\pm 10 \%$ and where there was no internal heat generation during the solidification transient. 


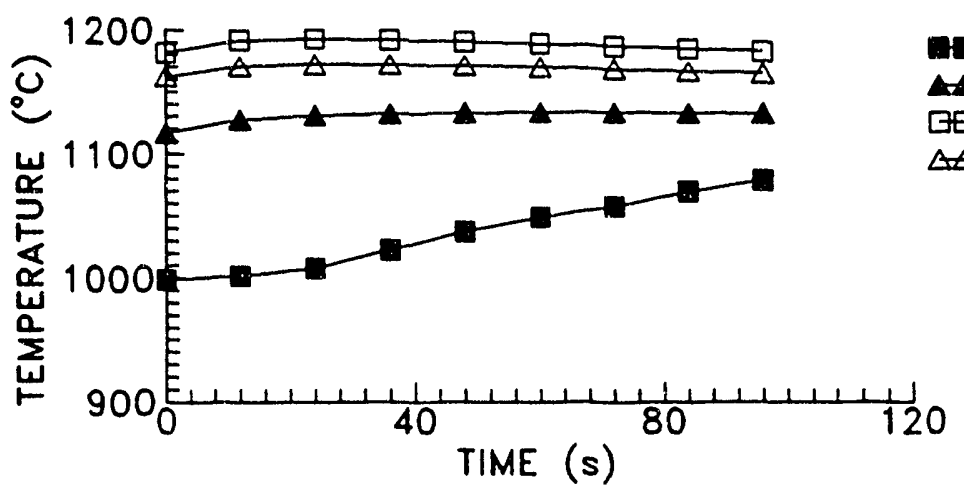

Hen DATA

arata BASE CASE

RAD HTX $\times 100$

$\triangle \triangle \triangle$ RAD HTX $\times 1000$.

(a) top thermocouple location

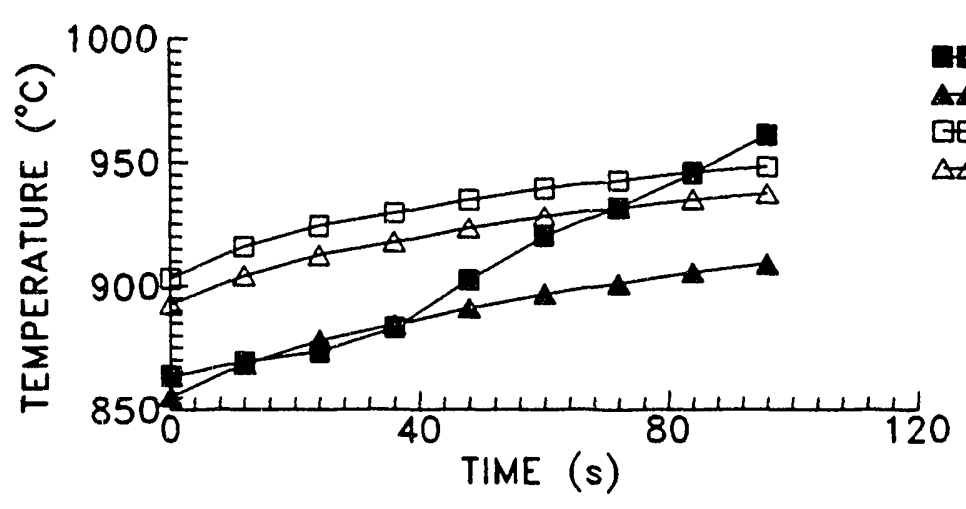

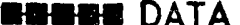
AaAAA BASE CASE IOEE RAD HTX $\times 100$ $\triangle$ RAD HTC $\times 1000$

(b) middle thermocouple location

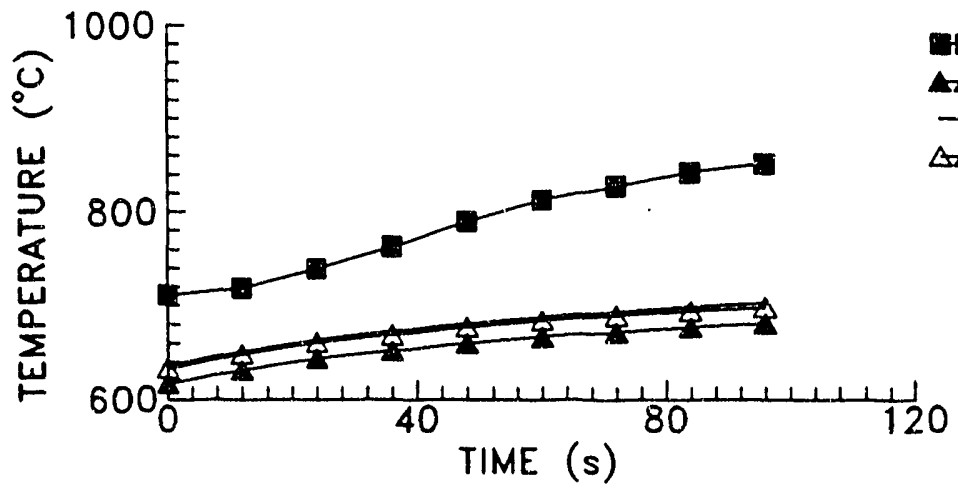

Dines DATA

AASE CASE

RAD HTX $\times 100$

$\triangle$ RAD HTX $\times 1000$.

(c) bottom thermocouple location

Fig. 39. Model agreement for the cases where the radiation heat transfer coefficient between the vertical crucible walls and the $\mathrm{Al}_{2} \mathrm{O}_{3}$ shield was increased by factors of 100 and 1000 . 


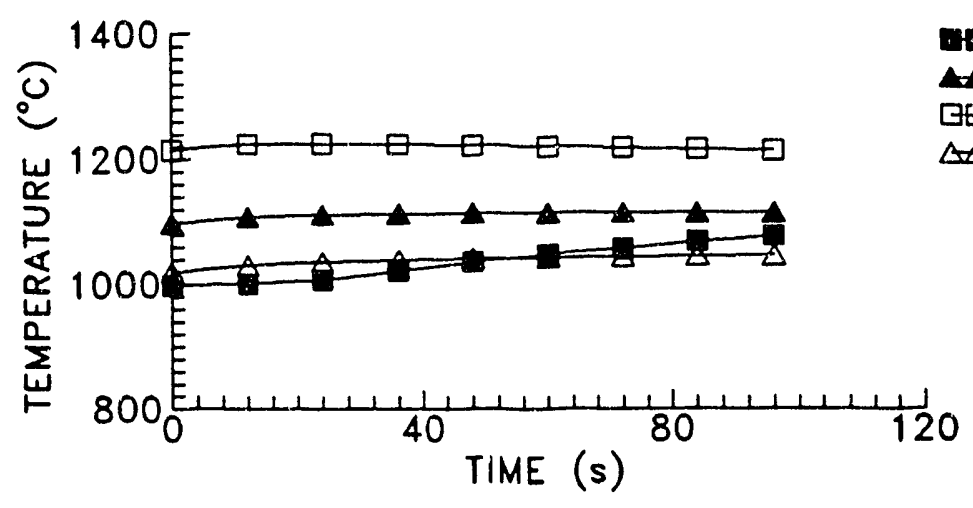

vares DATA

BASE CASE

CURRENT $X 1.1$

$\triangle \triangle$ CURRENT $\times 0.9$

(a) top thermocouple location

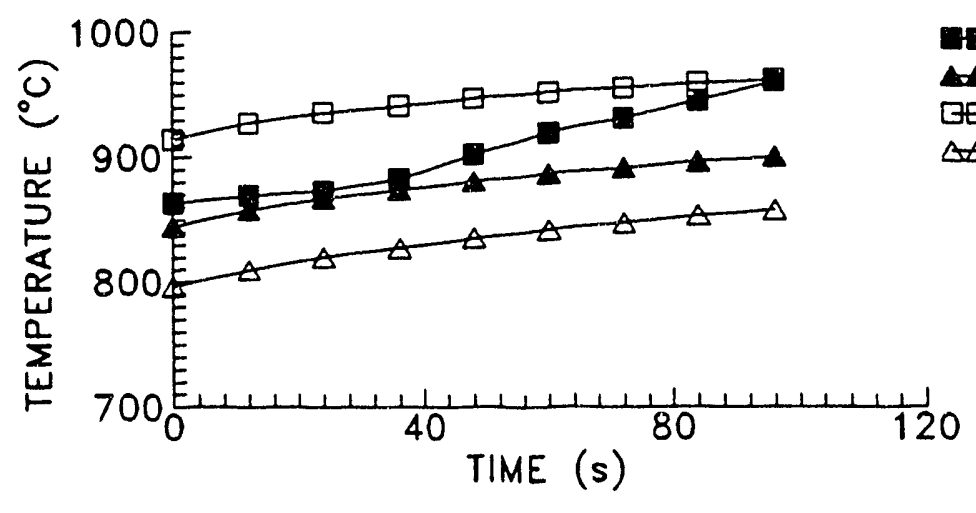

(b) middle thermocouple location

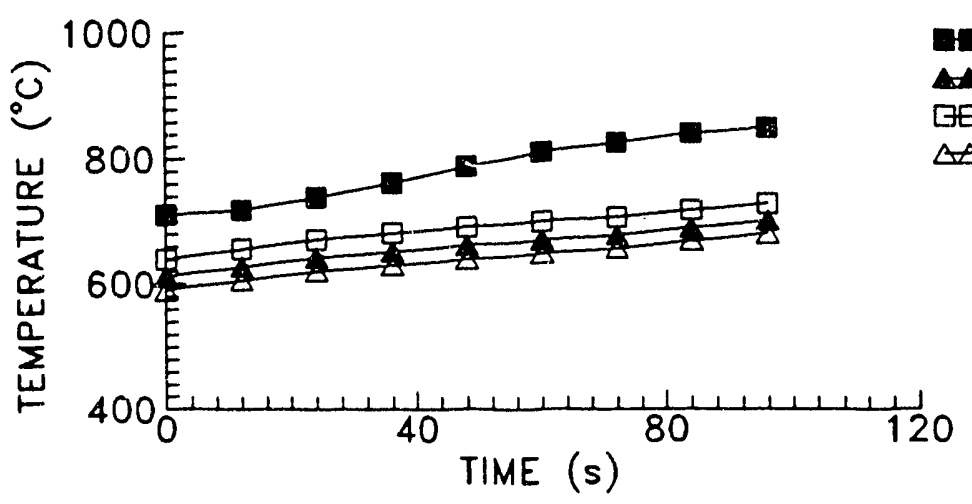

aromera DATA

aAA BASE CASE

CURRENT $\times 1.1$

$\triangle \triangle$ CURRENT $\times 0.9$

(c) bottom thermocouple location

Fig. 40. Model agreement for the cases where the heating coil current was varied by $\pm 10 \%$. 


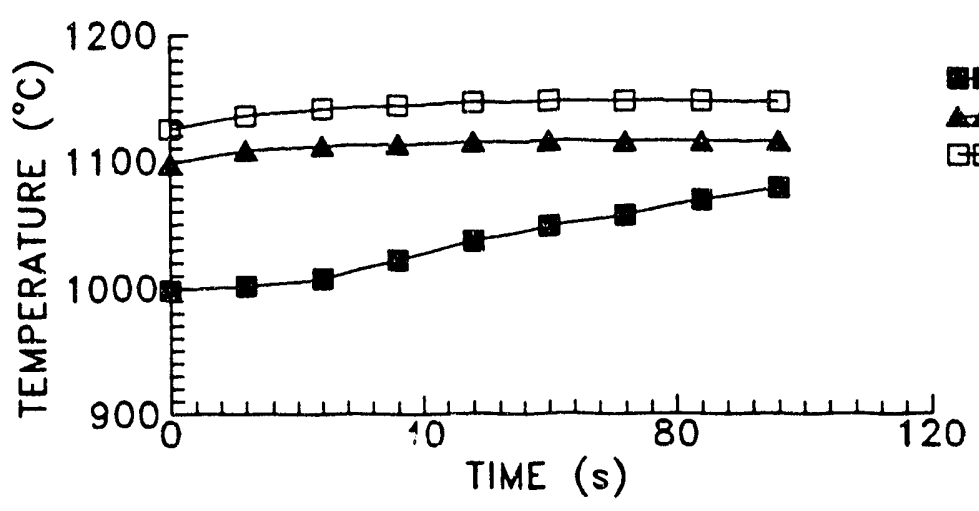

- Deren DATA

BASE CASE

DEEE EXP DECAY

(a) top thermocouple location

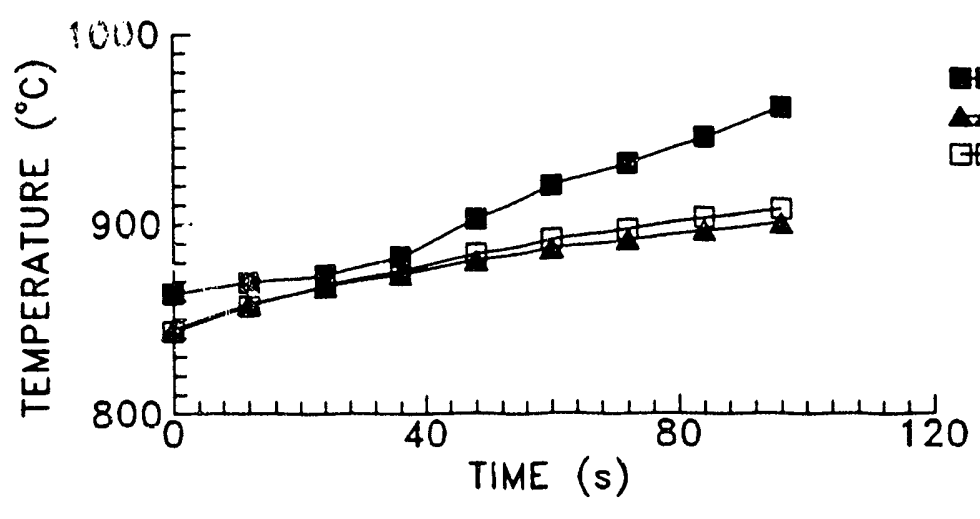

(b) middle thermocouple location

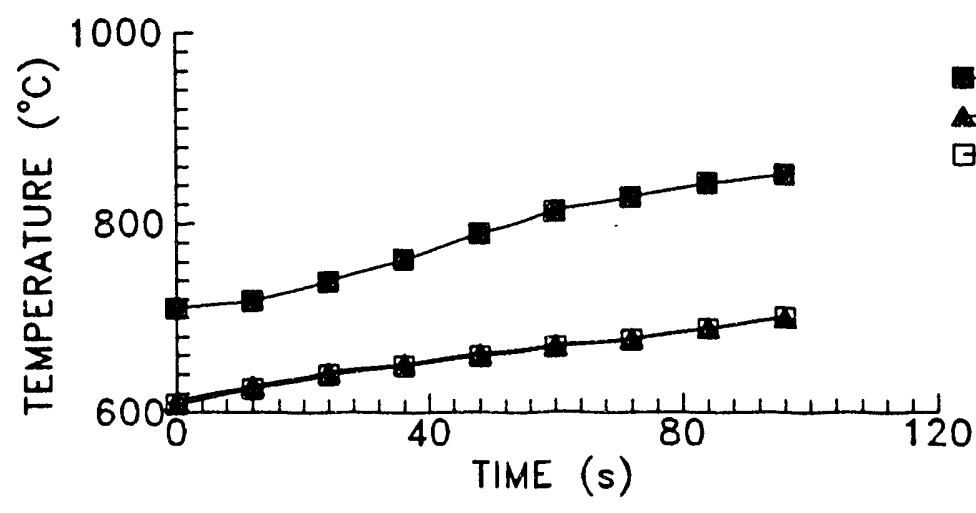

Man DATA

BASE CASE

EXP DECAY

(c) bottom thermocouple location

Fig. 41. Model agreement for the cases where the induced power distribution had an exponential decay. 


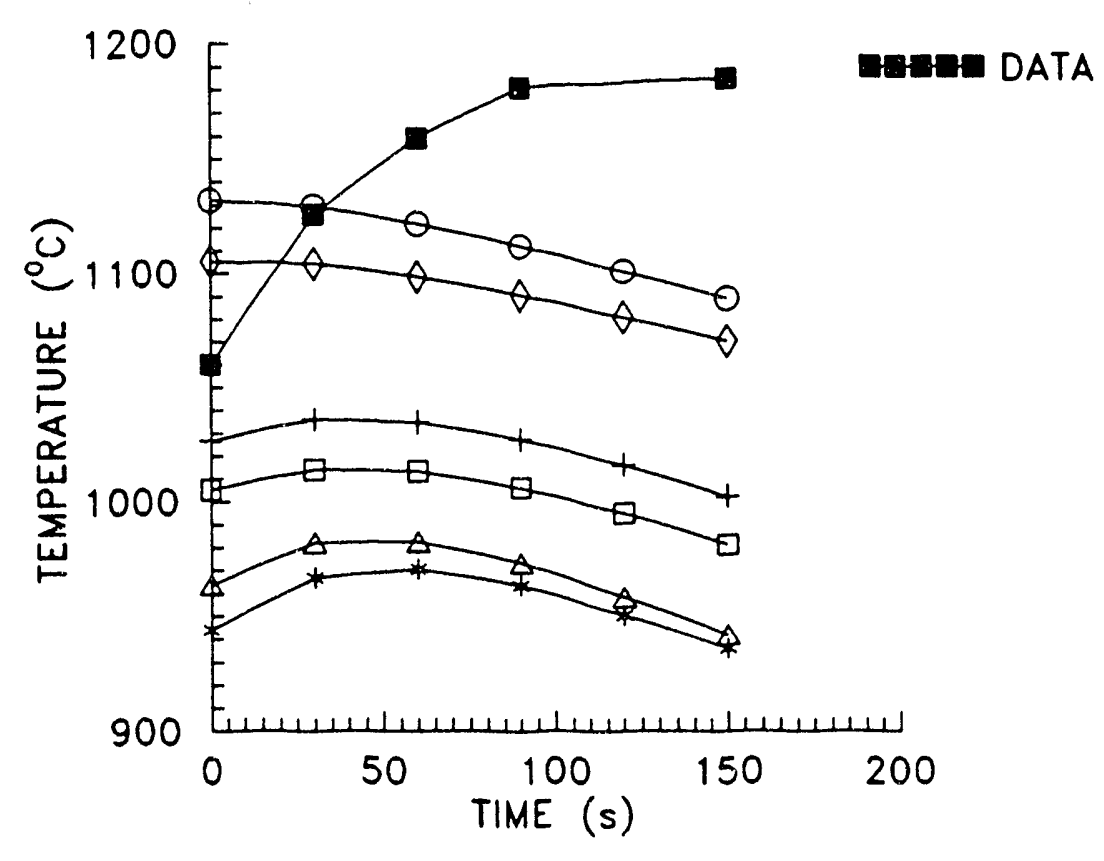

Fig. 42. Typical model agreement from the earlier sensitivity study for the middle thermocouple location for several combinations of pressure vessel wall temperature, contact resistance, water flow rate, and water inlet temperature.

2. The insensitivity to vertical contact resistances and the resistances due to cooling-water convective heat transfer coefficients is attributed to their relative magnitude compared with all the thermal resistances between the solidifying uranium and the temperature sinks, that is, liquid uranium convective heat transfer coefficient, material conduction, radiation heat transfer and/or thermal contact resistance between the casting assembly and the insulating shield, as well as between the shield and coils. Vertical contact resistances should be included in the second-phase model but only as accurately as the other contact resistances, and the forced convective heat transfer coefficient should be calculated with the same simple relationship used in this analysis and applied as a constant (wrt coil length) value boundary condition.

3. Removing induction heating during the early transient had a negligible effect on model agreement, and the result is believed to be real. It is conceivable, however, that some amount of prolonged induction heating or direct current (DC) magnetic field could be required to achieve the desired carbide transport. Thus, it would be prudent to include the mechanism in the second-phase model.

4. The observed insensitivity to gap conductance between solidified uranium and the bookmold is attributed to the fact that over the relatively short transient (approximately $100 \mathrm{~s}$ ), only a fraction of the melt has solidified. Thus, only a small portion of the uranium's total surface area sees the interfacial conductance, too small an amount to influence the overall response. Because interfacial gap conductance has been identified as a prominent mechanism in the literature ${ }^{20}$ it should also be included in the secondphase model. 
5. The negligible effect of removing the enclosure radiation heat transfer approximation is attributed to its relative crudeness. It did not include surface emissivities nor significant percentages of enclosure surface area. Again, because of its prominence in the literature, it should also be included in the second-phase model.

6. Changing the distribution of the induced power to an exponentially decaying function only slightly affected agreement at the top thermocouple location. It is noteworthy, however, that the fraction of heating coil current required to obtain the target melt temperature in the crucible dropped considerably. Whereas for most cases $40 \%$ more current was required than was estimated, changing the distribution to the more correct exponential decay resulted in only $18 \%$ excess current being required. From the perspective then of constructing an accurate stand-alone predictive second-phase model, the exponential distribution should be included.

Those mechanisms that had a prominent effect on thermocouple agreement and must therefore be accurately represented in the second-phase model were contact resistances, natural convection heat transfer coefficients, the value of the heat transfer coefficient between the vertical crucible wall and the insulating shield, and heating coil current. These results are believed to be real because specific effects resulting from changes in these variables are consistent with the physics of the problem.

1. Decreasing the thermal contact resistance between assembly components decreases the resistance to heat flow. Since steady-state thermal energy is internally generated, this reduction means the energy is more able to distribute itself among components. This manifests itself in smaller currents being required to give the same steady-state melt temperature in the crucible and lower steady-state and transient temperatures in the casting assembly. Similarly, increasing the contact resistance requires greater coil currents to achieve the same temperature in the crucible and gives larger overall temperatures.

2. Varying the liquid uranium natural convection heat transfer coefficient does not significantly affect steady-state temperatures but does influence the transient response. Within the context of this model, the convection coefficient represents a thermal resistance between the uranium and the local thermal sink. Decreasing the resistance by increasing the coefficient allows greater energy flows and higher overall temperatures. Increasing the resistance would, of course, have the opposite effect. The magnitude of the temperature change for a given variation is a function of the local thermal environment and will be discussed below.

3. Increasing the heat transfer coefficient between the crucible and insulating shield results in increased overall temperatures for both values examined. Increasing the rate of heat transfer from the crucible walls initially results in lower wall temperatures, and higher coil currents are required to compensate and maintain the desired uranium melt temperature. These increased currents cause the higher temperatures. The fact that the required current remains essentially the same (1.56 vs 1.58$)$ for a large increase in heat transfer rate $(1000$ vs 100$)$ is attributed to the relative size of the heat transfer coefficient/temperature difference product; increased heat transfer gives larger shield temperatures and smaller crucible/shield temperature differences, resulting in essentially the same total heat flow out of the crucible.

4. The effect of varying coil current is quite straightforward; increased amounts give higher rates of internal heat generation and correspondingly higher steady-state temperatures. 
Note that the top and middle thermocouple locations experienced approximately the same change in temperature for a given change in current.

An additional observation is that for each of the prominent mechanisms the level of agreement varies between thermocouple locations and the transient response for exin variation parallels the base-case response. This behavior is attributed to the location of the thermocouples relative to the casting assembly geometry and the heating coil magnetic field. These positions are illustrated in Fig. 43 and show that the thermal resistances surrounding each thermocouple vary with axial position.

1. The top location is bounded on the left by convection from the uranium and conduction through the bookmold; on the right by conduction through the bookmold, radiation heat transfer to the shield, and conduction through contact resistances to the upper end cap; on the top by conduction through the bookmold and conduction across contact resistances to the upper end cap and crucible; and on the bottom by conduction through the bookmold.

2. The middle location is bounded on the left by convection from the uranium and conduction through the bookmold; on the right by conduction through the bookmold and radiation heat transfer to the shield; on the top by conduction through the bookmold; and on the bottom by conduction through the bookmold.

3. The bottom location is bounded on the left by convection from the uranium and conduction through the base of the bookmold; on the right by conduction through the bookmold, conduction through contact resistances to the lower end cap, and radiation heat transfer to the pressure-vessel wall; on the top by conduction through the bookmold; and on the bottom by conduction through the bookmold and conduction through contact resistances to the lower end cap.

4. The lower boundary of the heating coil magnetic field is approximately located at the lower edge of the insulating shield. Thus, the bookmold region containing the bottom thermocouple is not internally heated.

5. Within the context of uranium regions being thermal sources, note that the position of the problem's source changes relative to the thermocouple locations between the steadystate and transient analyses. During steady state it is in the crucible, while during the transient analysis it is further down in the bookmold.

Because these localized thermal environments extend for several wall thicknesses into the width of the bookmold wall, it is believed they are responsible for the varying thermocouple agreement.

1. When coil current is varied the resulting temperature changes at the top and middle locations are about equal, but the change at the bottom is much smaller. Because the bottom thermocouple is outside the magnetic field, it is only heated by conduction from the internally heated regions. Thus, it is reasonable to expect smaller temperature changes at the bottom as thermal energy is diffused away from the hotter regions.

2. For the cases where contact resistances are varied, the magnitude of the steady-state temperature change from base-case values decreases from top to bottom with essentially no change at the bottom location; smaller currents are required for the lower resistance case and higher currents for the higher resistance case; middle temperatures for the lower resistance case are warmer than would be expected if only the coil current had been 
changed; and middle temperatures for the higher resistance cases are cooler than would be expected if only the coil current had been changed. The varying temperatures at the middle location results from the value of the contact resistance; less gives more heat flow from the hot crucible region and warmer than expected temperatures in the cooler bookmold, whereas more resistance restricts heat flow from the hot crucible region, thus allowing localized energy within the bookmold wall to diffuse more and give lower than expected temperatures. The much lower temperature changes at the bottom location is again attributed to conduction effects from warmer regions.

3. When the liquid uranium natural convection heat transfer coefficient is varied, the steadystate temperatures are not affected, but the transient responses are and the magnitude of the change varies between thermocouple locations. During

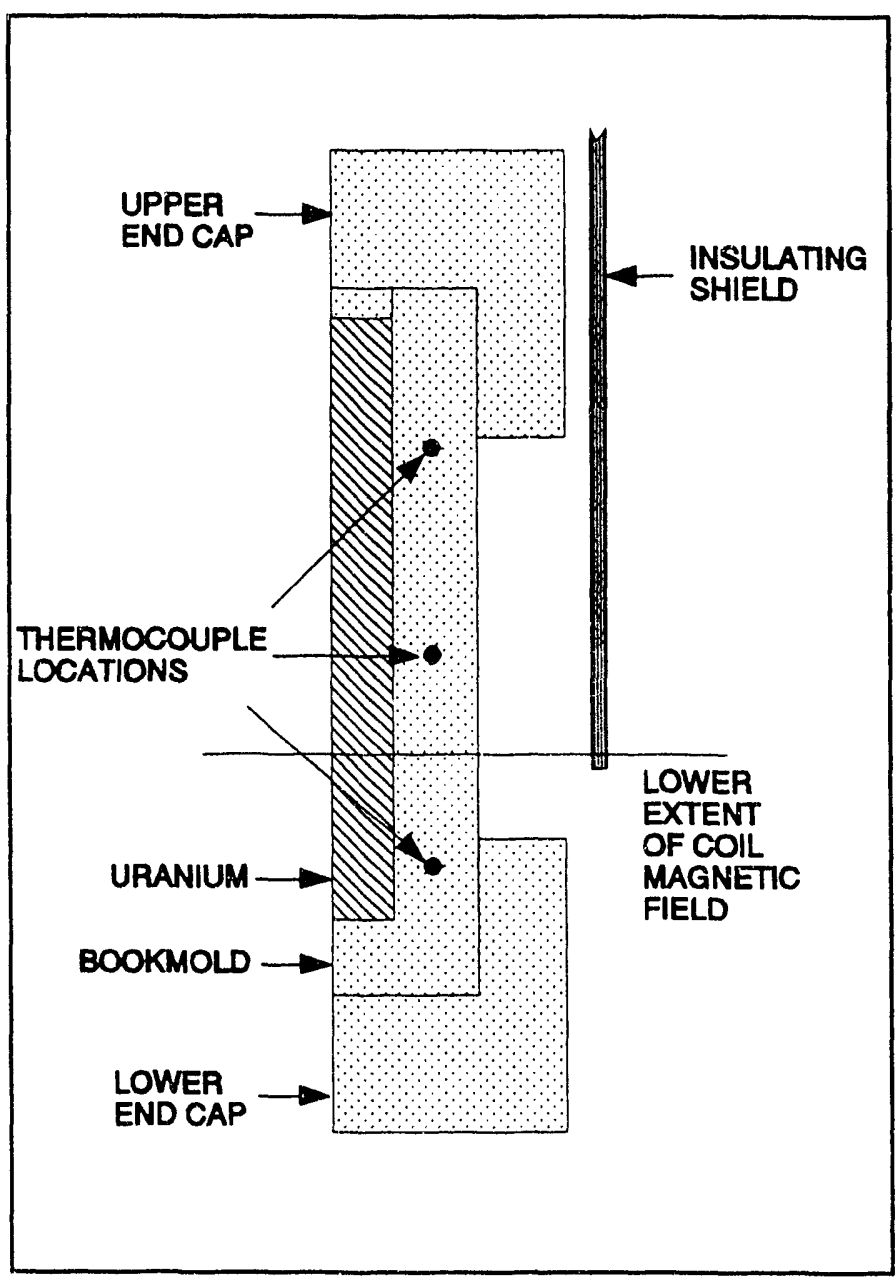

Fig. 43. Thermocouple locations relative to the casting assembly geometry.

steady-state the liquid uranium is located in the crucible, and heat transfer to the thermocouples is a function of all the intervening thermal resistances. The insensitivity of the steady-state temperatures is attributed to the relative size of the natural convection coefficient. The size did not represent a significant fraction of all the resistances. During the transient analysis the uranium is located in the bookmold, and the relative size of the coefficient when compared with local conduction and radiation heat transfer at the exterior wall is such that it is a significant fraction of the total resistances. As the data in Fig. 35 show, the middle thermocouple's response is greater than either the top or bottom locations. The bookmold exterior wall in the vicinity of the middle thermocouple has a radiation heat transfer boundary condition, but the top and bottom locations have mixed radiation and conduction influences. When compared with these two classes of boundary conditions, the relative size of the convection coefficient (which is modeled as a constant along the interior bookmold surface) is such that it influences middle location response to a greater degree than either the top and bottom locations.

4. When the heat transfer rate between the crucible walls and insulating shield is varied, the resulting temperature change from base-case values increases for both heat transfer rates; the amount of the change for the top and middle locations is essentially equal; and the 
temperature change for the bottom location is negligible. The equal temperature changes for the top and middle locations are attributed to the increased coil current. As we have seen, varying only the coil current gives equal iemperature cha'sges at these locations. The small change at the bottom location is again attributed to its location relative to the coil magnetic field and the diffusion of thermal energy away from the warmer regions.

This behavior indicates that an accurate representation of localized thermal systems is essential for improved thermocouple agreement. Macroscopically this means the second-phase model must contain an exact casting assembly geometry, as well as accurate mathematical models for natural convection heat transfer from the uranium, radiation heat transfer from exterior surfaces, and contact resistances between assembly components.

The second macroscopic trend observed for the four prominent thermal mechanisms is that the slope of their transient responses essentially parallels the base-case response, even when initial temperatures are different from base-case values. Because this trend is consiste $e_{\text {il }}$ for small and large initial temperature differences and because localized thermal environments strongly influence agreement, the behavior is attributed to the time-varying thermal resistances between the uranium and the two thermal sinks (i.e., the pressure-vessel wall and coil-cooling water). This result is interpreted as additional justification for requiring the second-phase model to have an exact physical representation and rigorous mathematical descriptions of the prominent mechanisms. 


\section{THERMAL MODEL MACROSCOPIC PERFORMANCE}

Further insight into ine physics of the problem was gained by examining base-case thermocouple agreement, uranium melt behavior, and casting assembly temperature distributions for the complete time period covered by the Run No. 892 experimental data. An additional reason for defining these data at this time is that they will serve as a benchmark for future model improvements. It is conceivable (and even likely) that past a point, continued model refinements will only affect thermocouple agreement and not the simulation of carbide transport. In the final analysis carbide transport and not thermocouple agreement is the subject of interest.

Base-case thermocouple agreement at the three thermocouple locations for the complete experimental transient is shown in Fig. 44. Melt behavior at 0,60, 120, 180, 240, 300, 360, and $420 \mathrm{~s}$ into the transient is shown in Figs. 45-52 respectively. Each figure shows the bookmold uranium region from two perspectives. The left-hand side is from the plane of symmetry viewpoint; that is the same perspective as the left hand side of Fig. 21 . The right $n$ land side shows the melt rotated approximately $180^{\circ}$; that is viewed from the bookmold surfaces immediately adjacent to the uranium. The color represents liquid and solid regions; red for those locations with temperatures above the melting point of $1133^{\circ} \mathrm{C}$ and blue for those below $1133^{\circ} \mathrm{C}$. Temperature distributions for portions of the casting assembly at the same eight elapsed times are shown in Figs. 53-60. Each figure shows the uranium, bookmold, and end caps from the plane of symmetry viewpoint. The following observations are made.

1. Model agreement at each location during the extended period (i.e., past $100 \mathrm{~s}$ ) basically parallels the experimental data but consistently has lower absolute temperatures. Again this is attributed to the incorrect modeling of time-dependent thermal mechanisms.

2. The uranium region completely solidifies between 6 and $7 \mathrm{~min}$ after pour and exhibits the overall directional solidification required for acceptable castings. However, there appears to be a slight meniscus at the solid-liquid boundary and it is not known at this point if it is real. It results from strictly thermal considerations: those portions of the uranium in contact with the bookmold experience higher rates of heat transfer due to its cooler temperature. It is conceivable that once CFD considerations are included the meniscus could disappear.

3. As it concerns temperature distributions in the casting assembly during a solidification transient, the largest gradient is in the $Y$ direction, there are relatively small gradients in the $\mathrm{X}$ and $\mathrm{Z}$ directions, the upper portion of the assembly cools down during the transient while the lower portion heats up, and there is a significant temperature gradient along the height of the bookmold wall. The macroscopic energy flows are consistent with the physics of the problem and the structure of the base-case model. At steady-state the upper portion of the assembly is inside the heating coil and also contains the liquid uranium. The lower portion is outside the coil and can conduct to the firebrick. Thus, a strong axial direction gradient is to be expected. The macroscopic cooling trends in the assembly during the transient result from draining the uranium into the bookmold. This draining allows the crucible and upper-end cap to cool but causes the bookmold, lowerend cap, and firebrick to heat up. The most noteworthy results are the distributions in the bookmold. Specifically, the small $\mathrm{X}$ and $\mathrm{Z}$ direction gradients and the large $\mathrm{Y}$ direction gradient. The small $\mathrm{X}$ and $\mathrm{Z}$ gradients are attributed to the essentially uniform boundary conditions in those directions. These boundary conditions also influence the magnitude of the $\mathrm{Y}$ direction gradient. This particular gradient must be accurately 
modeled for two reasons: it influences melt-behavior including carbide transport, and the value at the bottom of the bookmold influences the quality of the casting. ${ }^{20}$ It is conceivable that once enclosure radiation and accurate contact resistances are included, the uniformity will be lost. The problem will become more two-dimensional, and the $\mathrm{Y}$ direction gradient will be severely affected.

Again, these results reinforce the need to model problem physics as accurately as possible. 


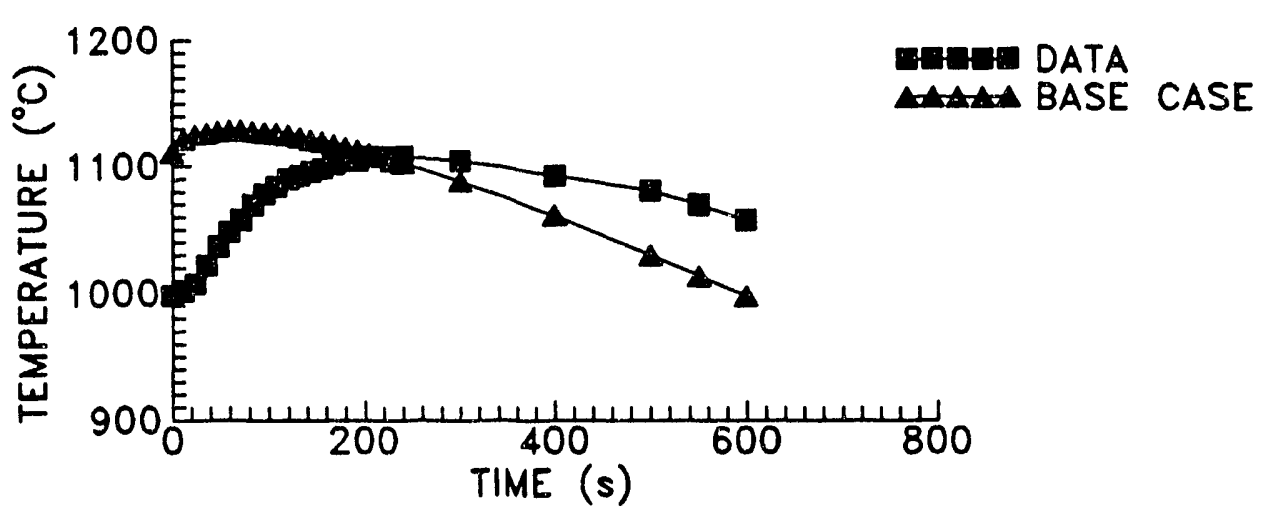

(a) top thermocouple location

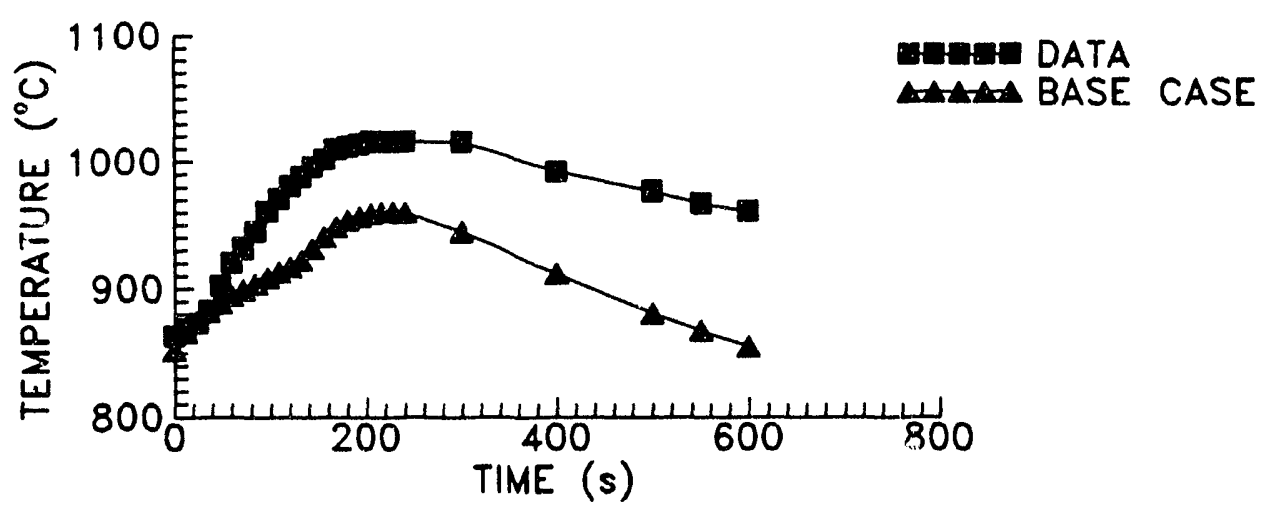

(b) middle thermocouple location

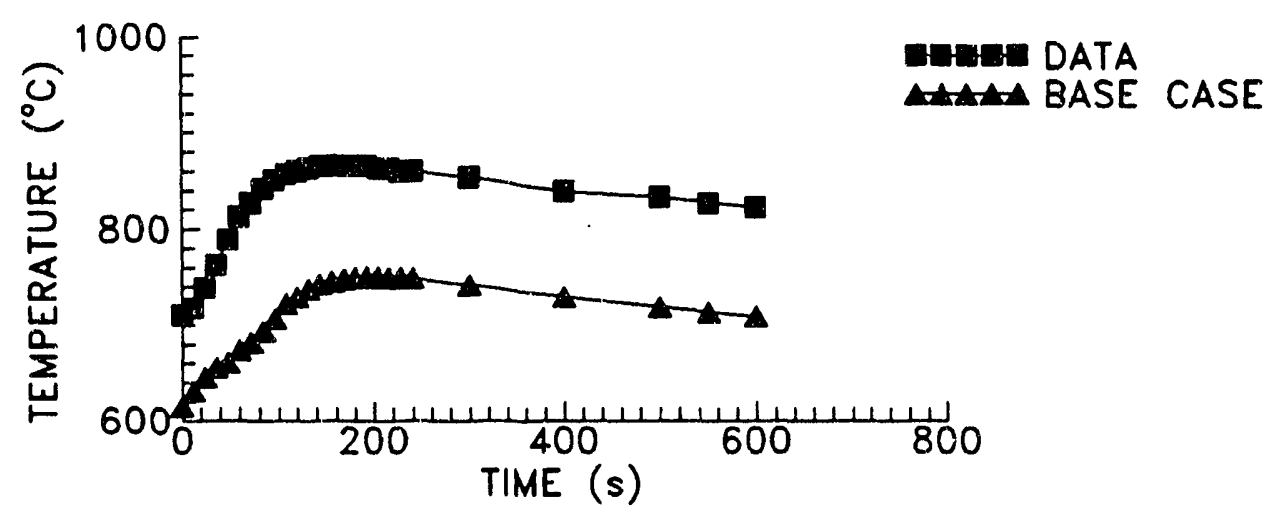

(c) bottom thermocouple location

Fig. 44. Base-case model agreement for the complete time period covered by experimental run 892. 


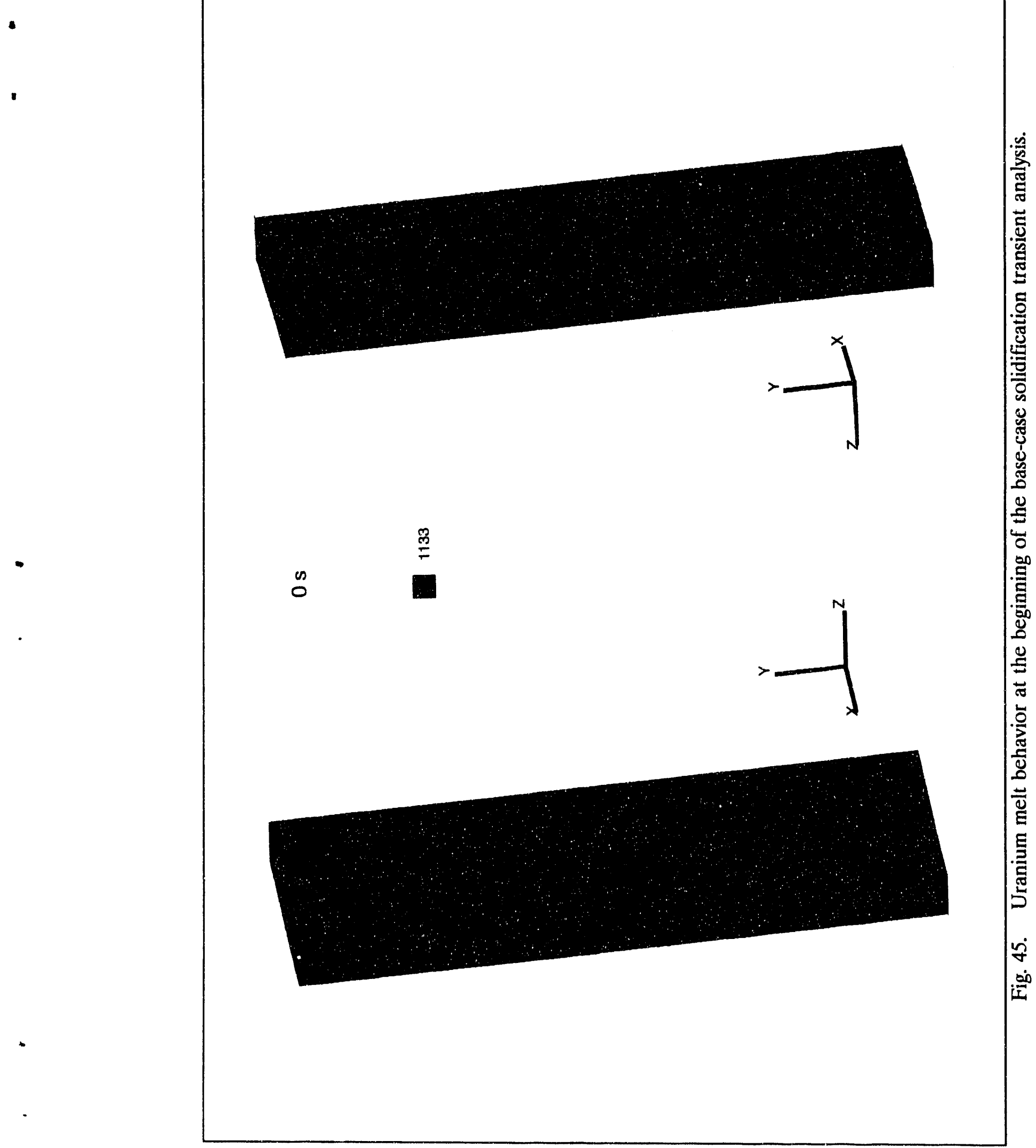




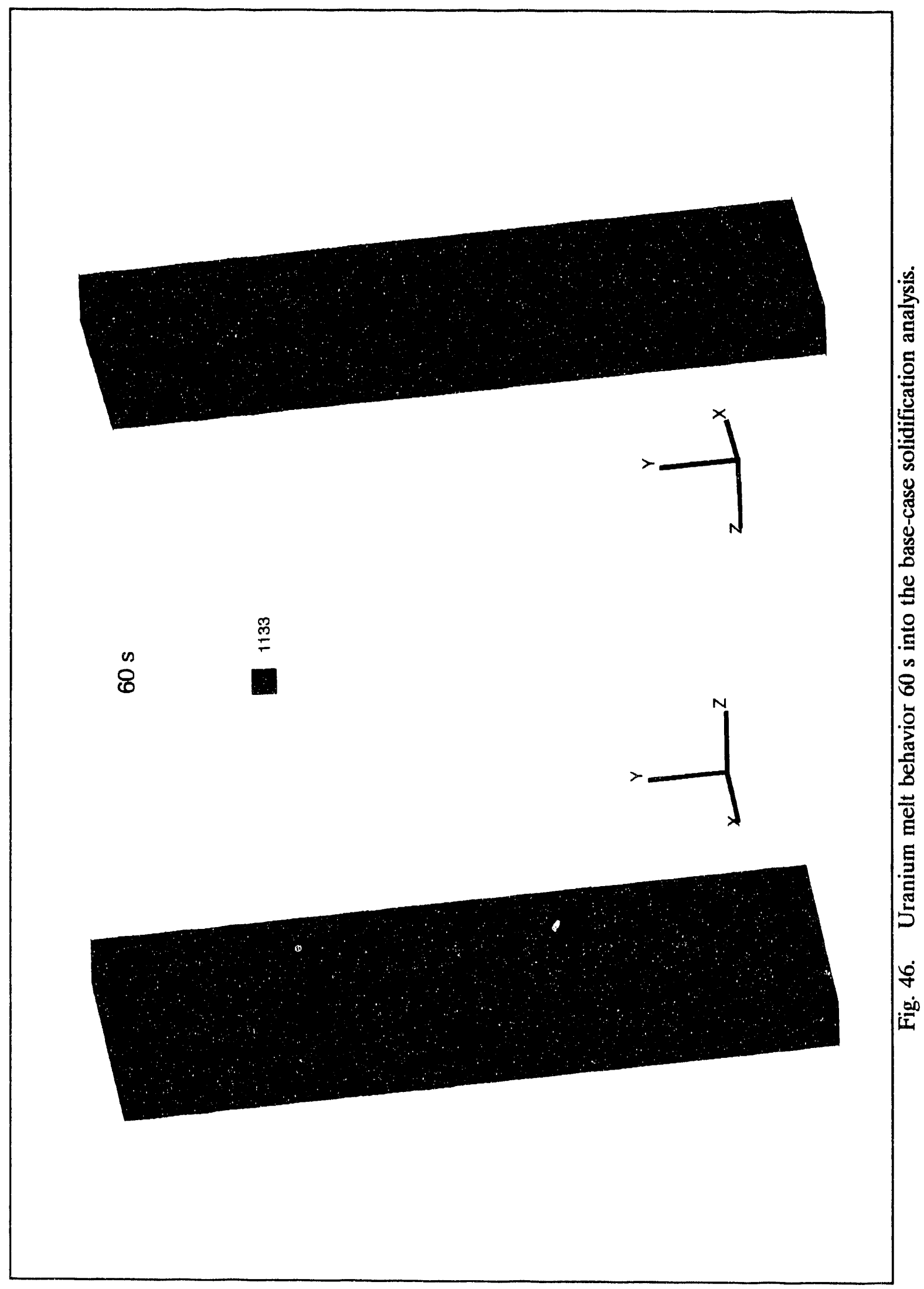




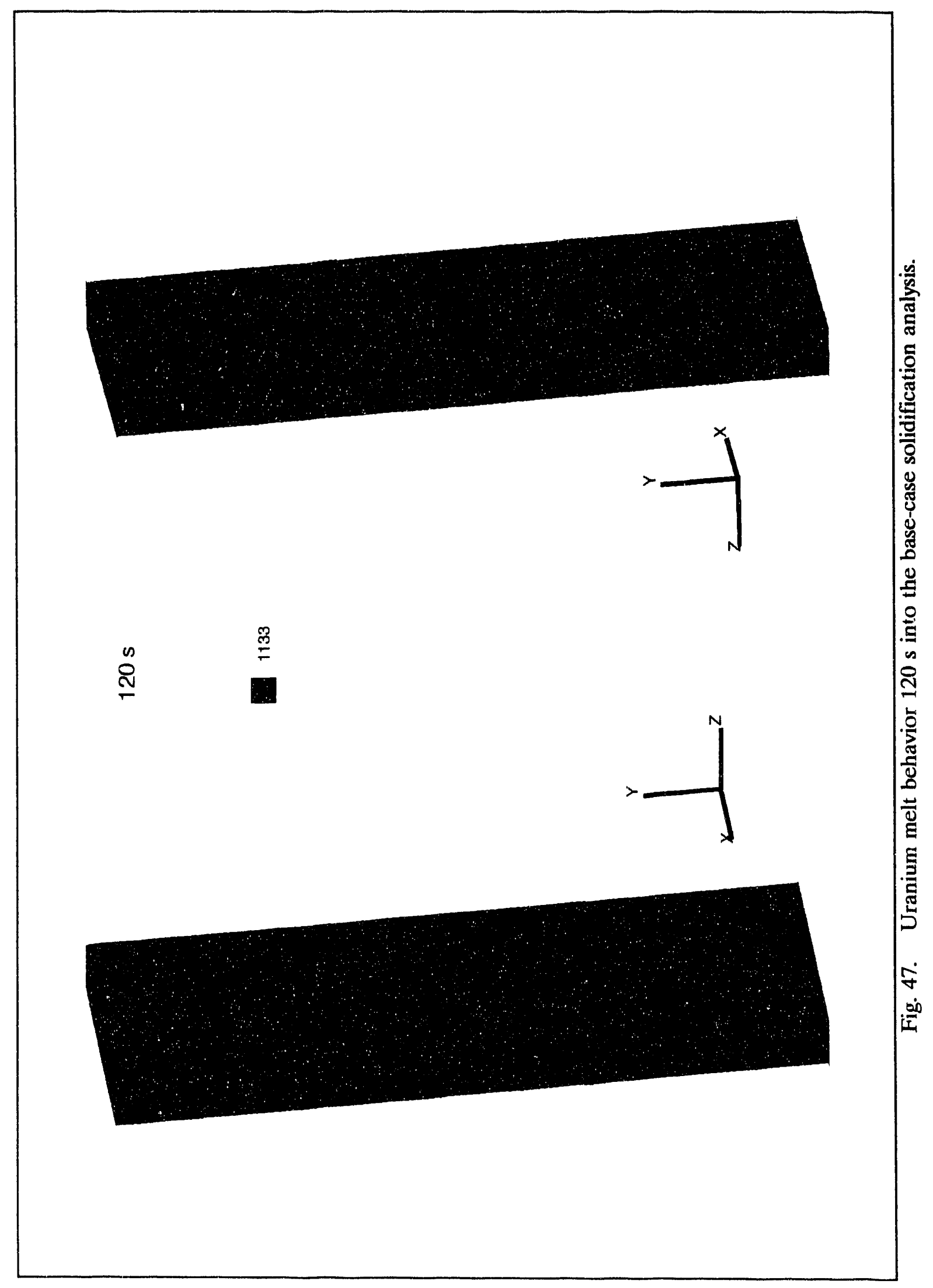




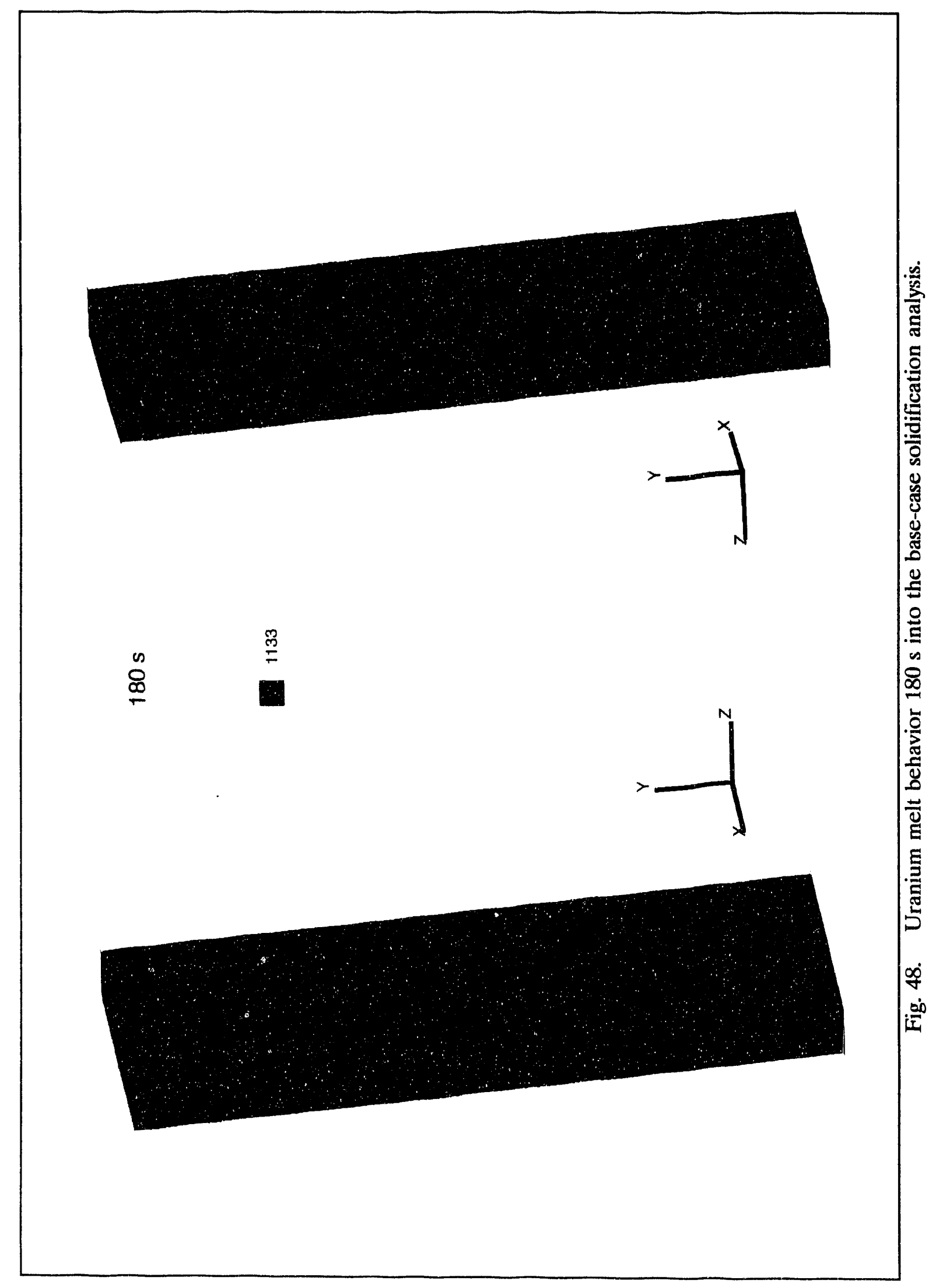




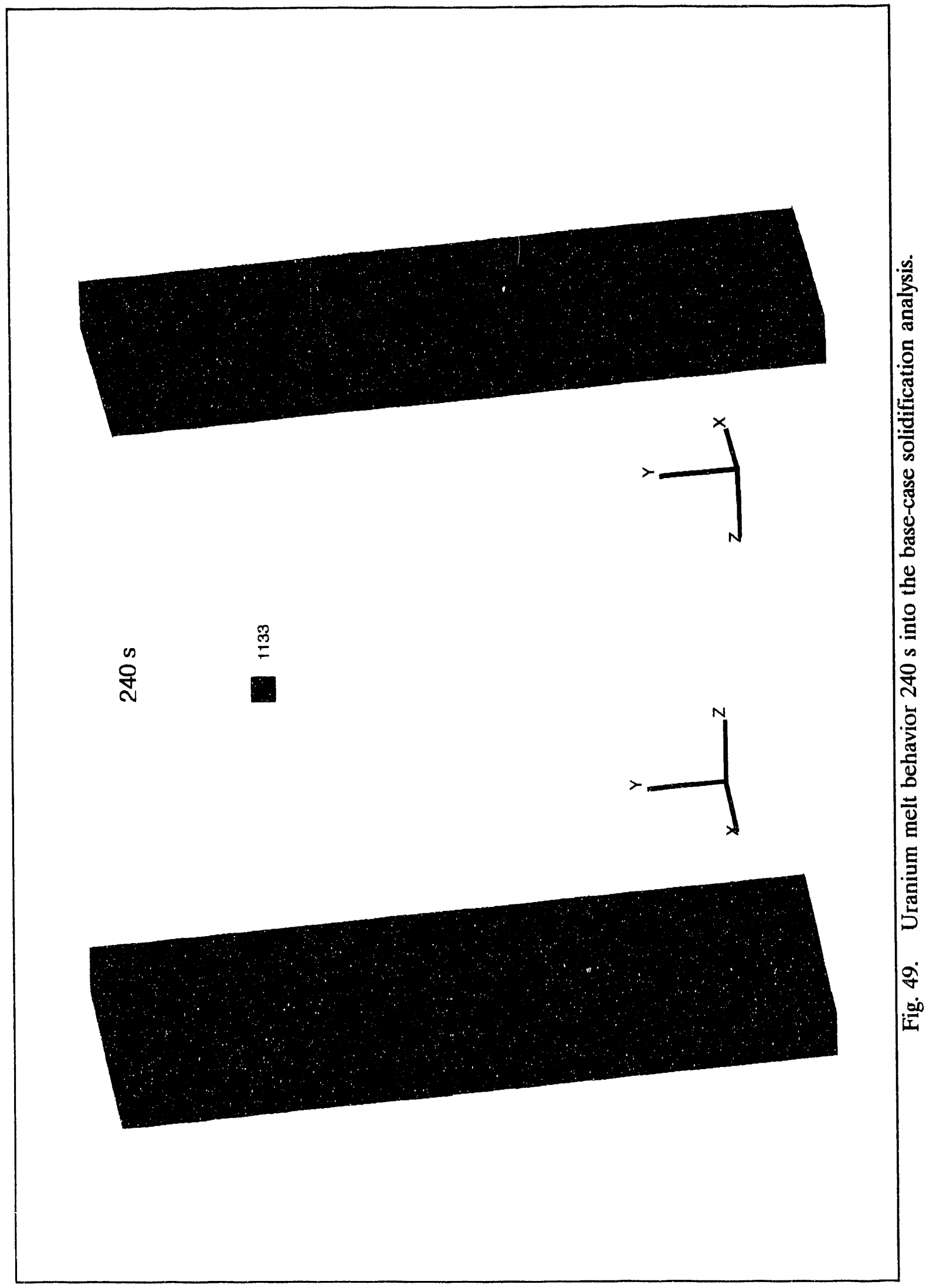




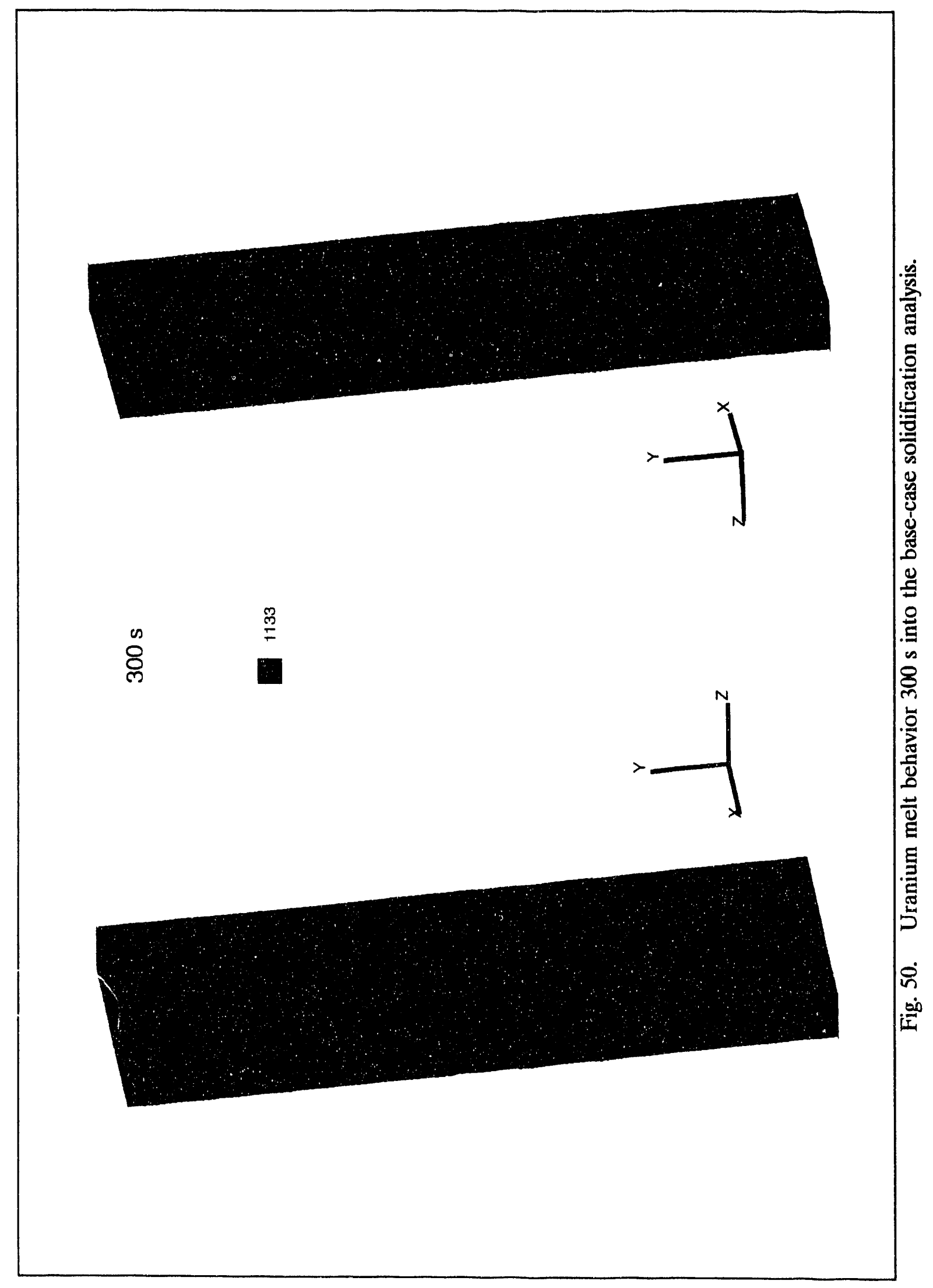




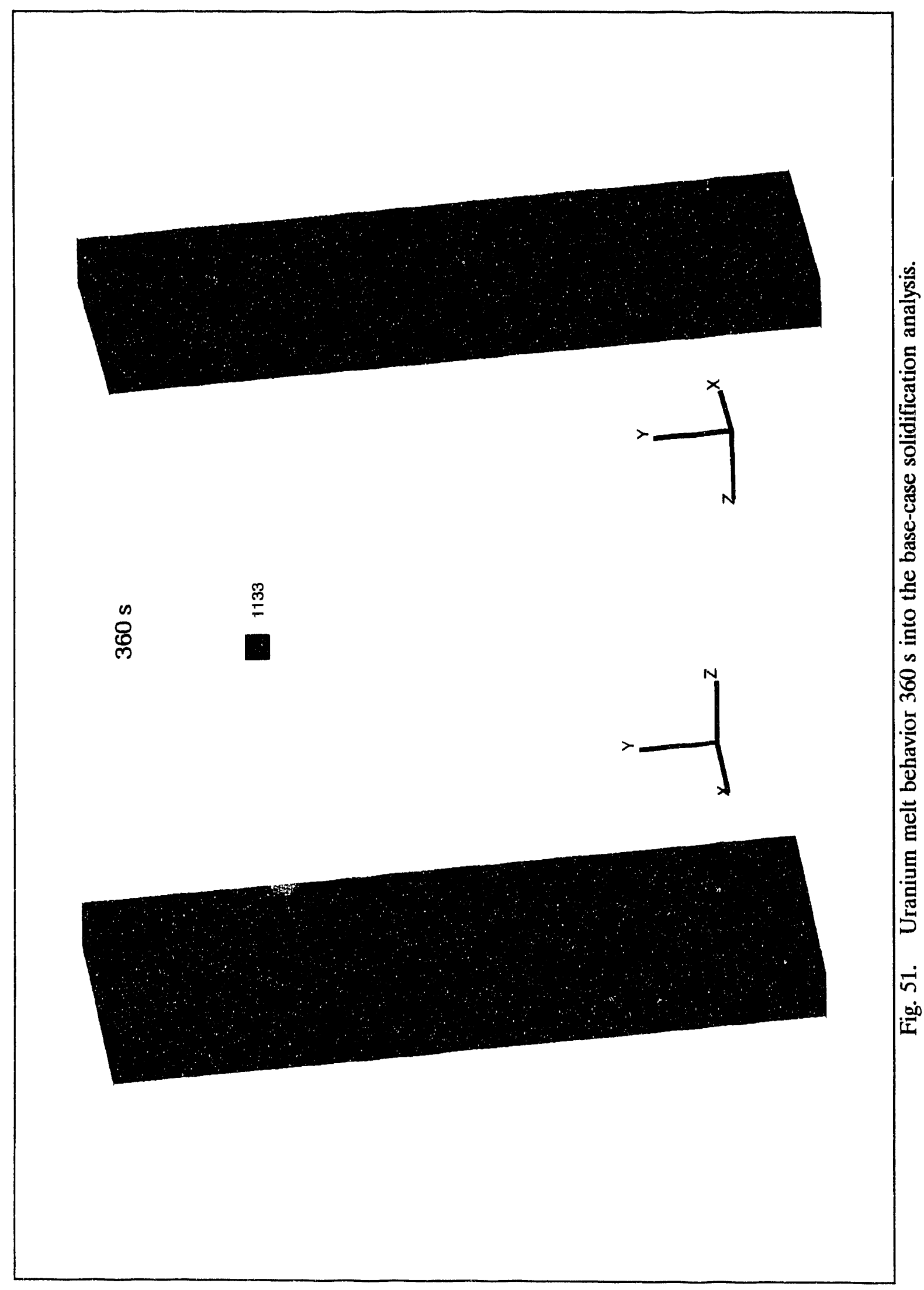




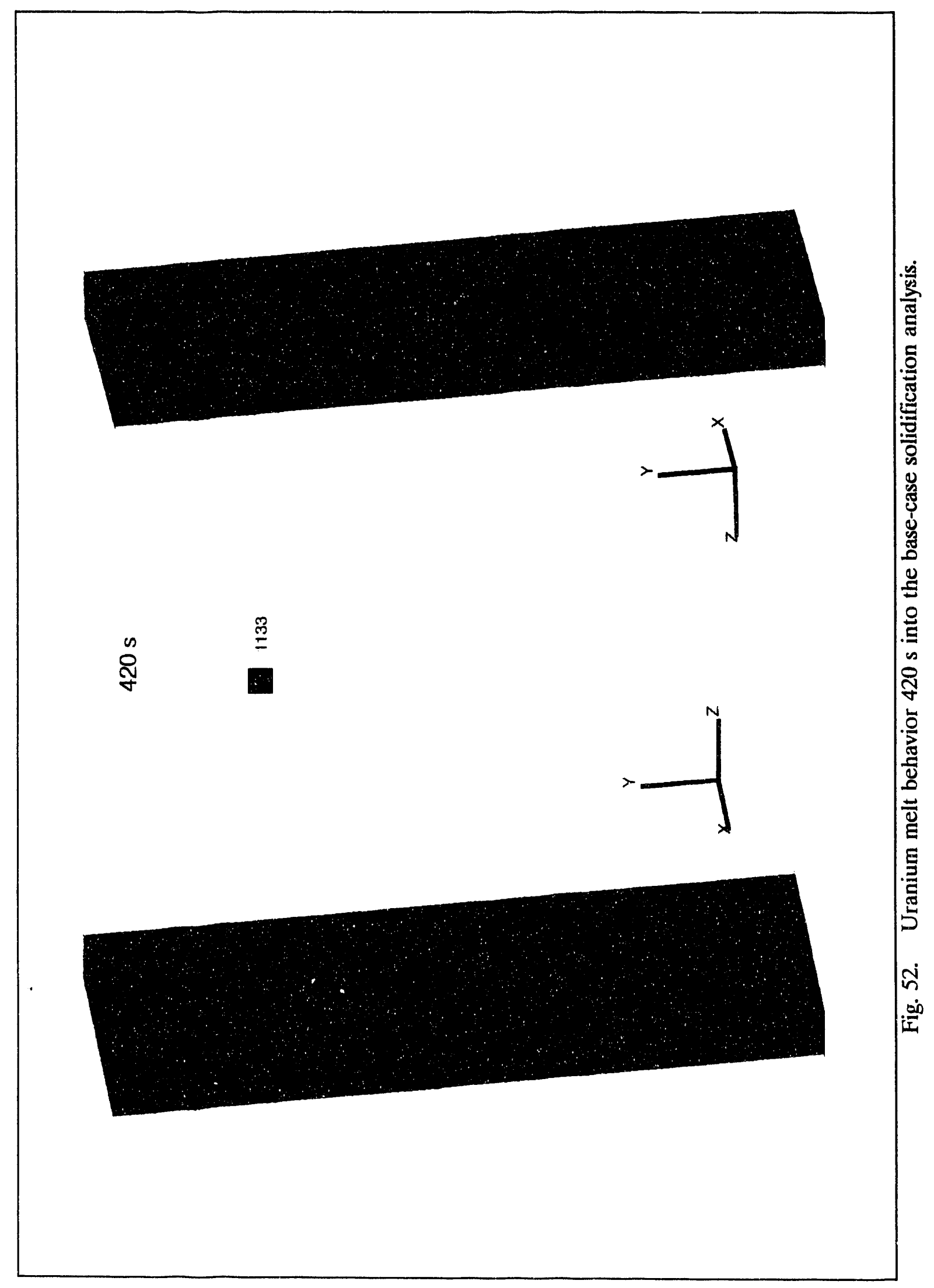




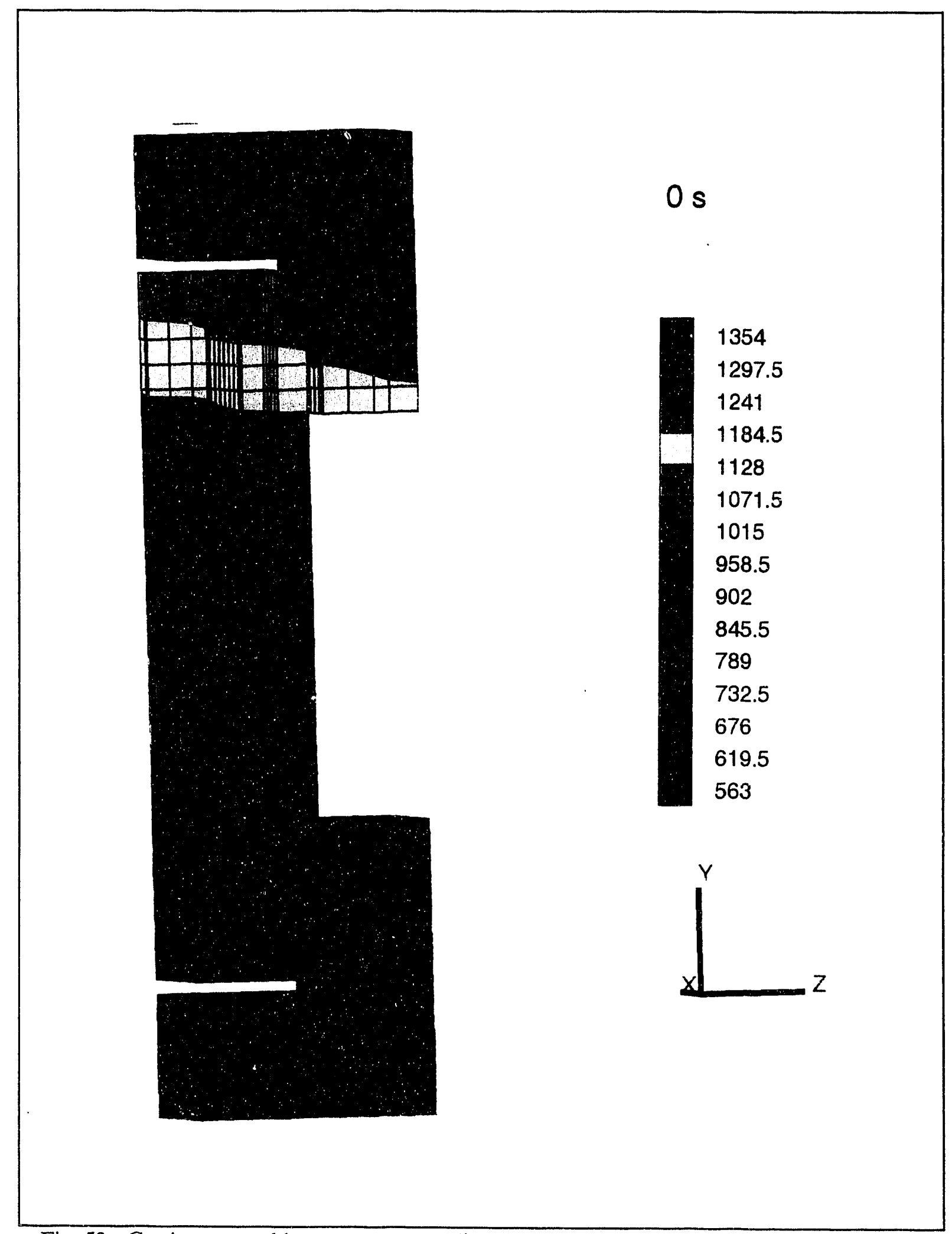

Fig. 53. Casting assembly temperature distribution at the beginning of the base-case solidification analysis. 


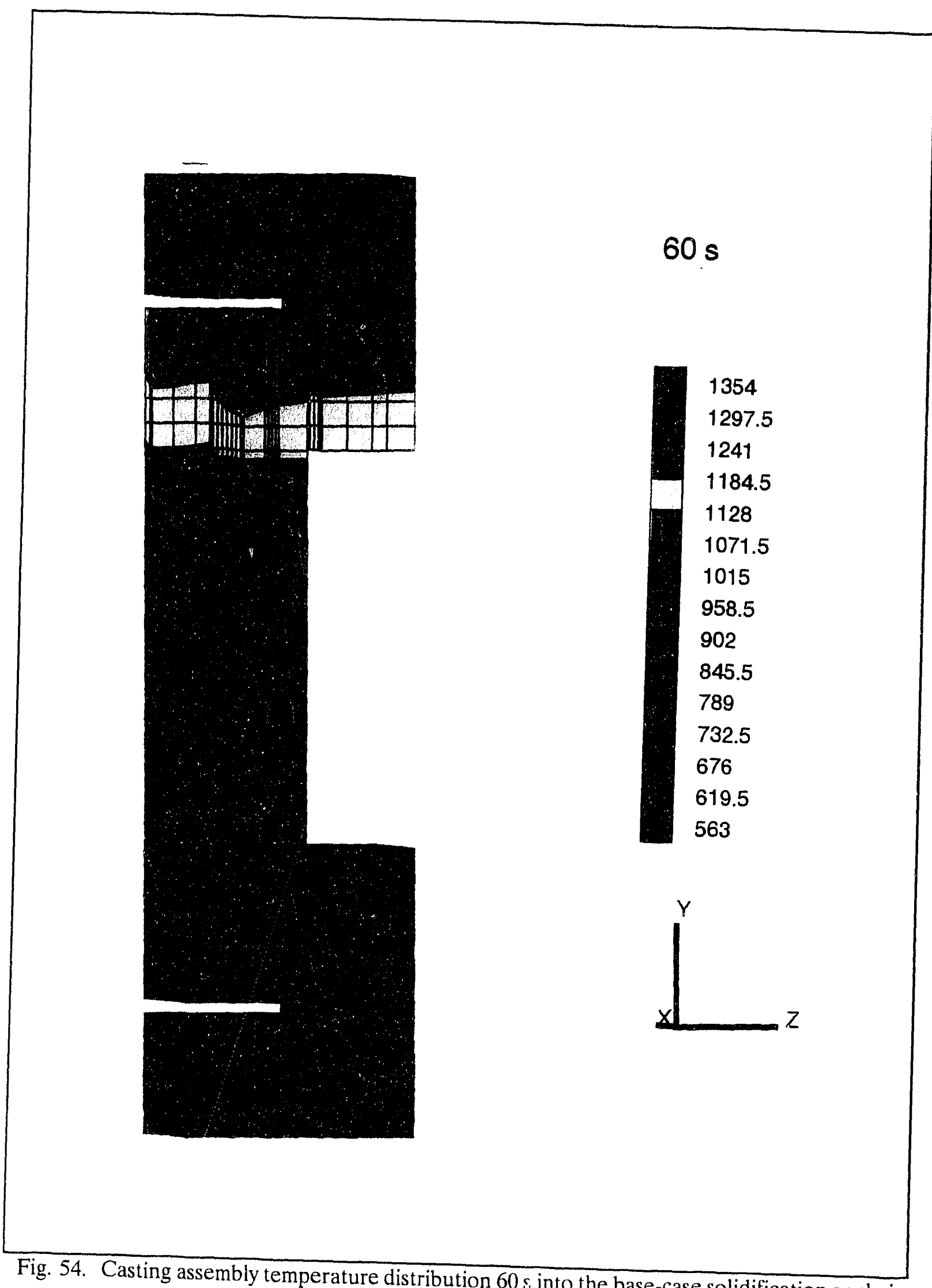

Fig. 54. Casting assembly temperature distribution $60 s$ into the base-case solidification analysis. 


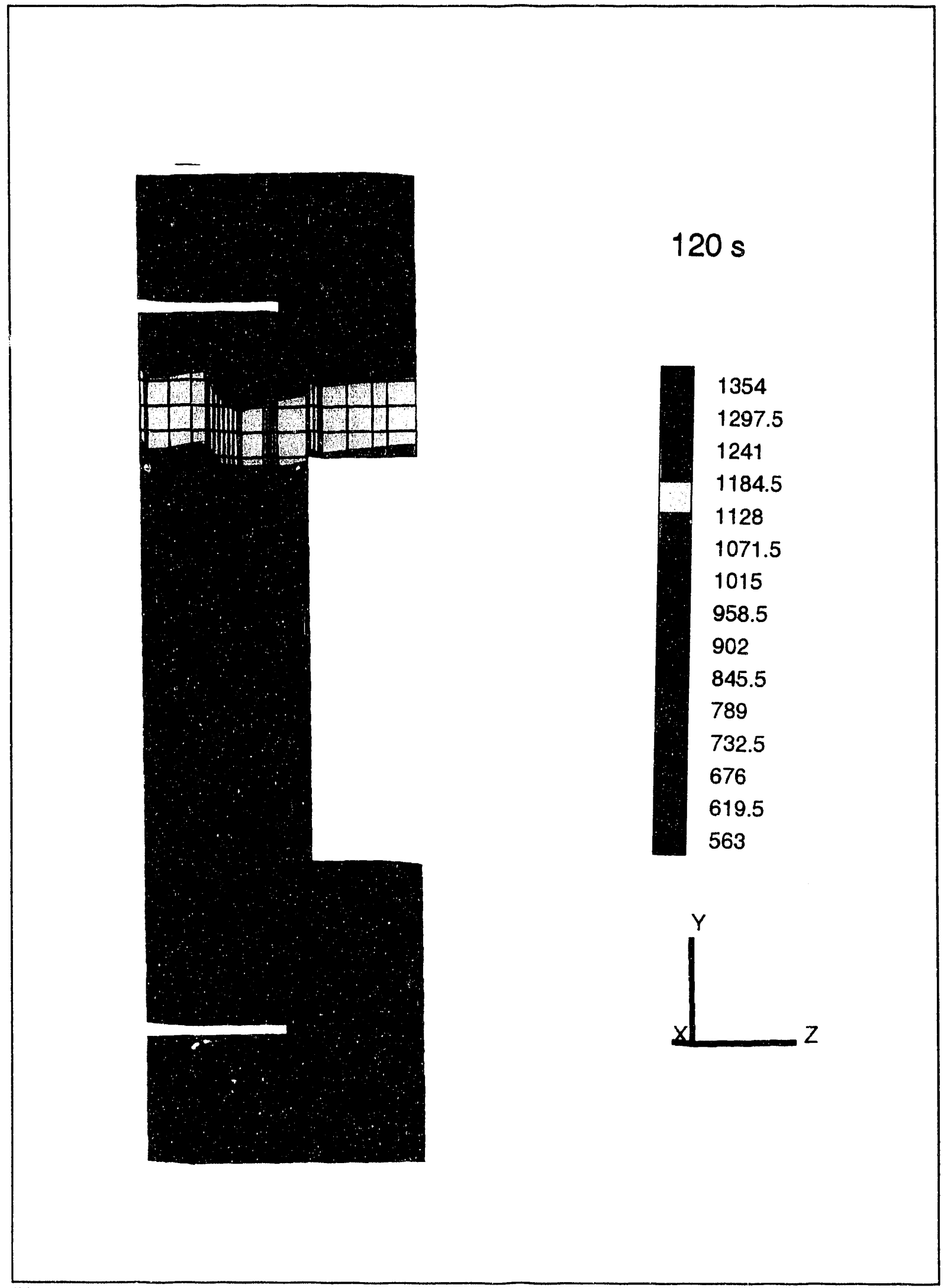

Fig. 55. Casting assembly temperature distribution $120 \mathrm{~s}$ into the base-case solidification analysis. 


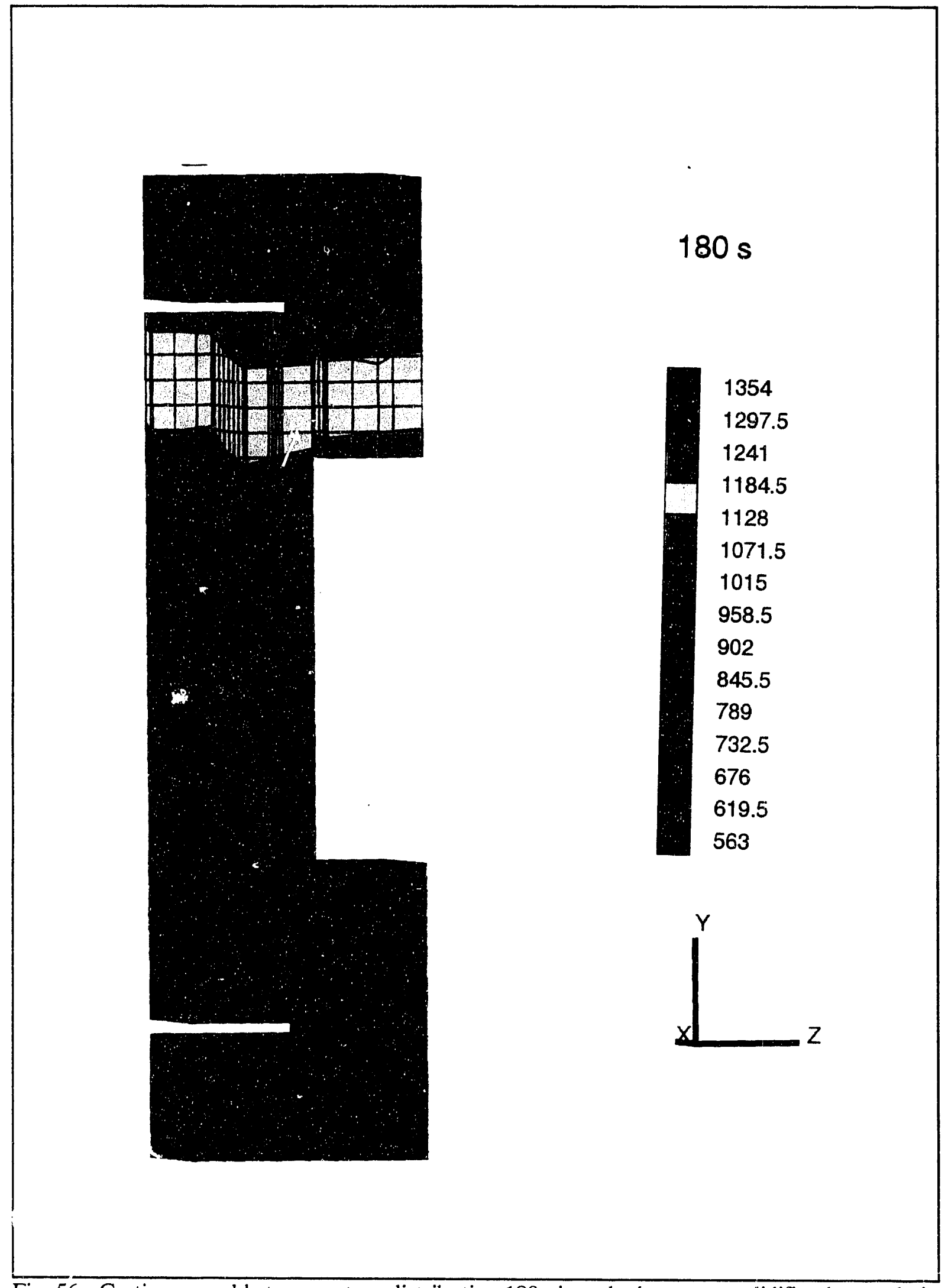

Fig. 56. Casting assembly temperature distribution $180 \mathrm{~s}$ into the base-case solidification analysis. 


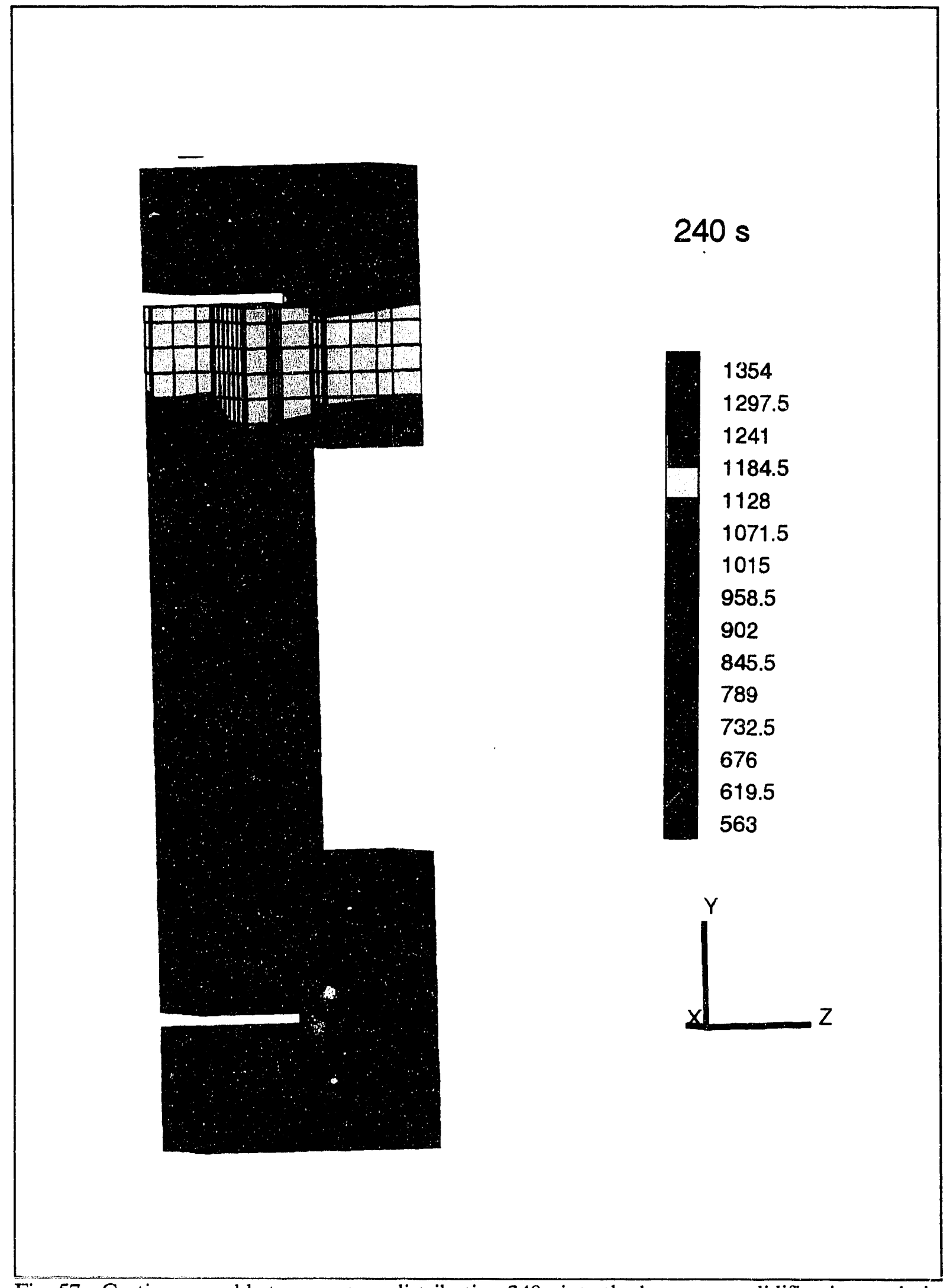

Fig. 57. Casting assembly temperature distribution $240 \mathrm{~s}$ into the base-case solidification analysis. 


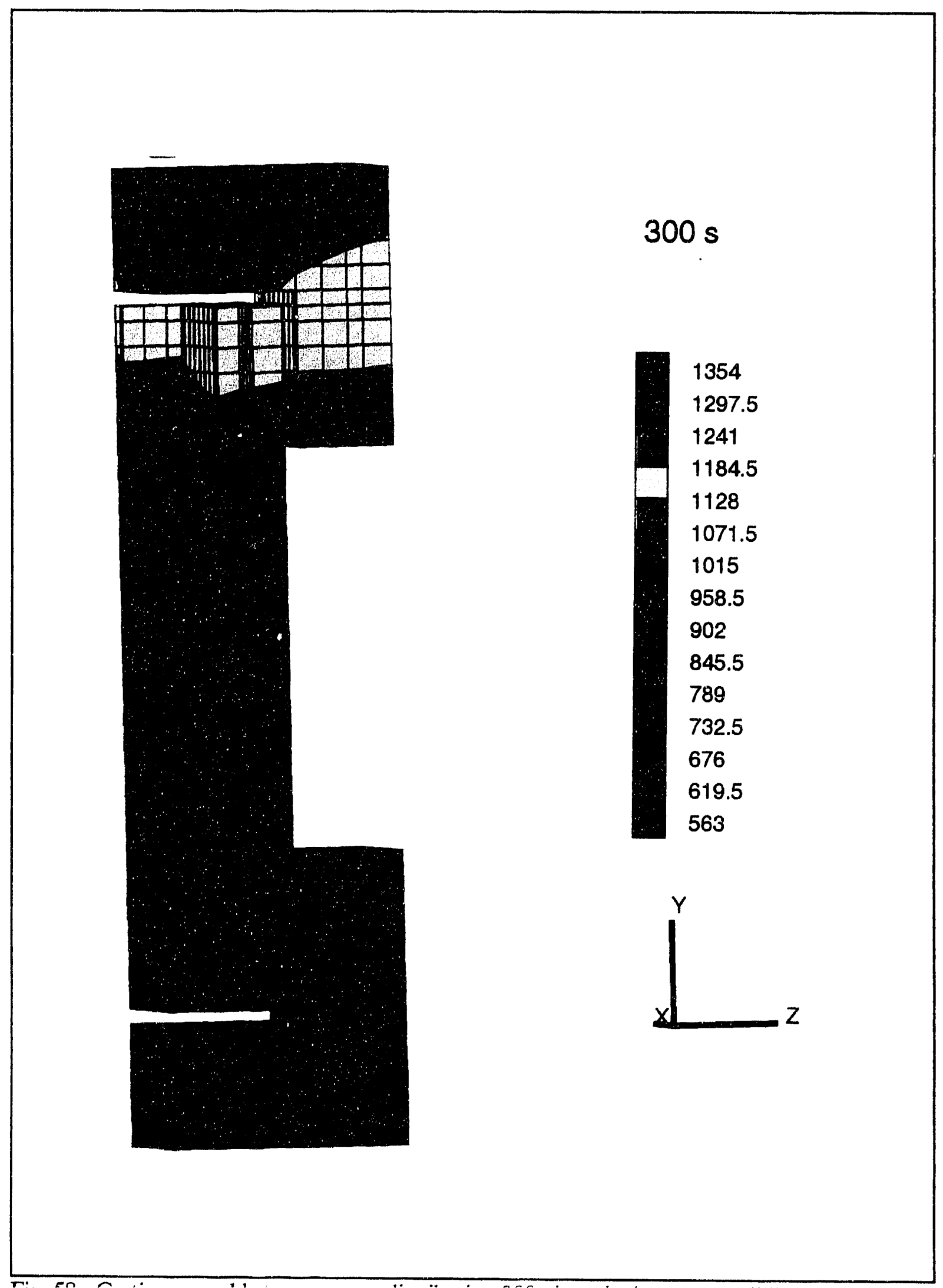

Fig. 58. Casting assembiy temperature distribution $300 \mathrm{~s}$ into the base-case soliditication analysis. 


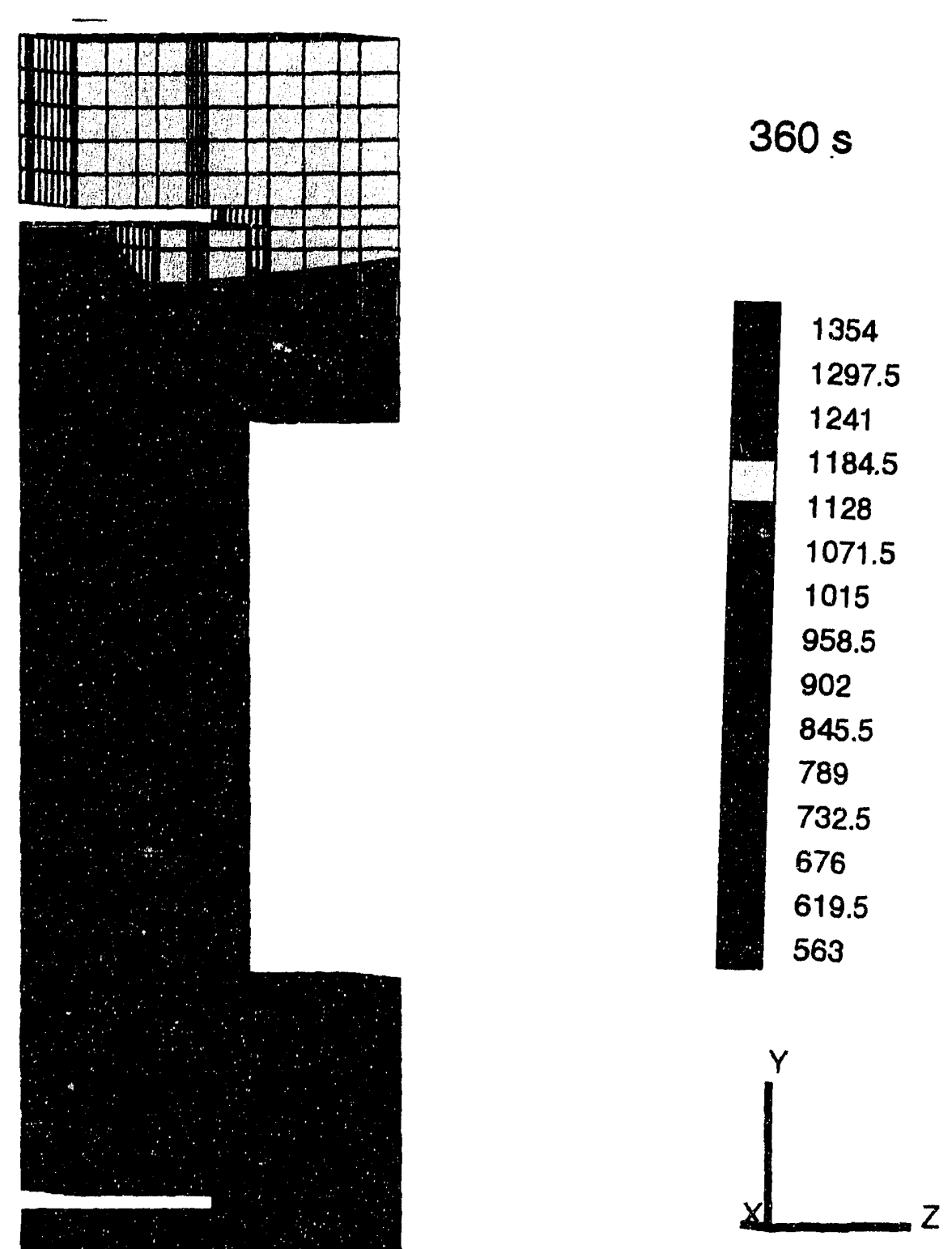

Fig. 59. Casting assembly tempcraturc distribution $360 \mathrm{~s}$ into the base-case solidification analysis. 

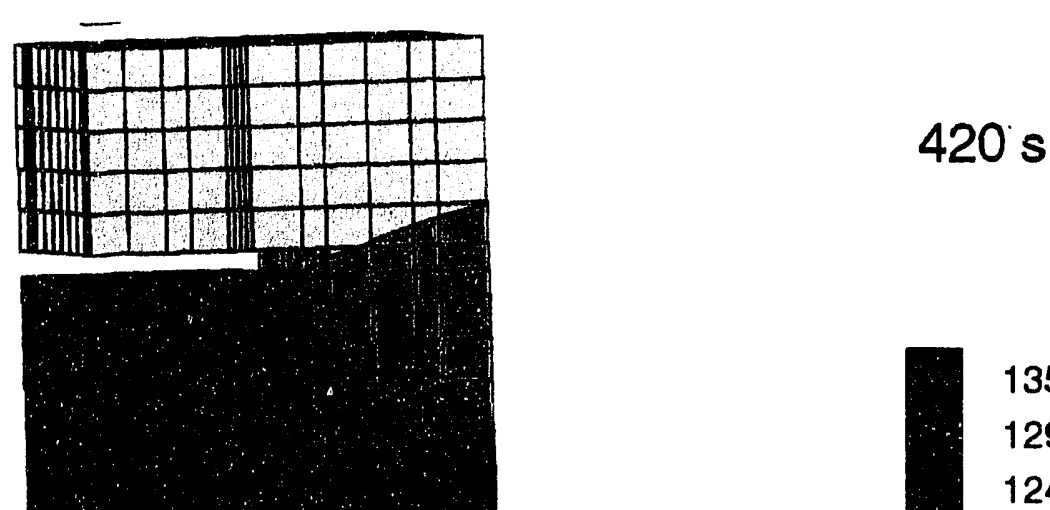

$420 \mathrm{~s}$
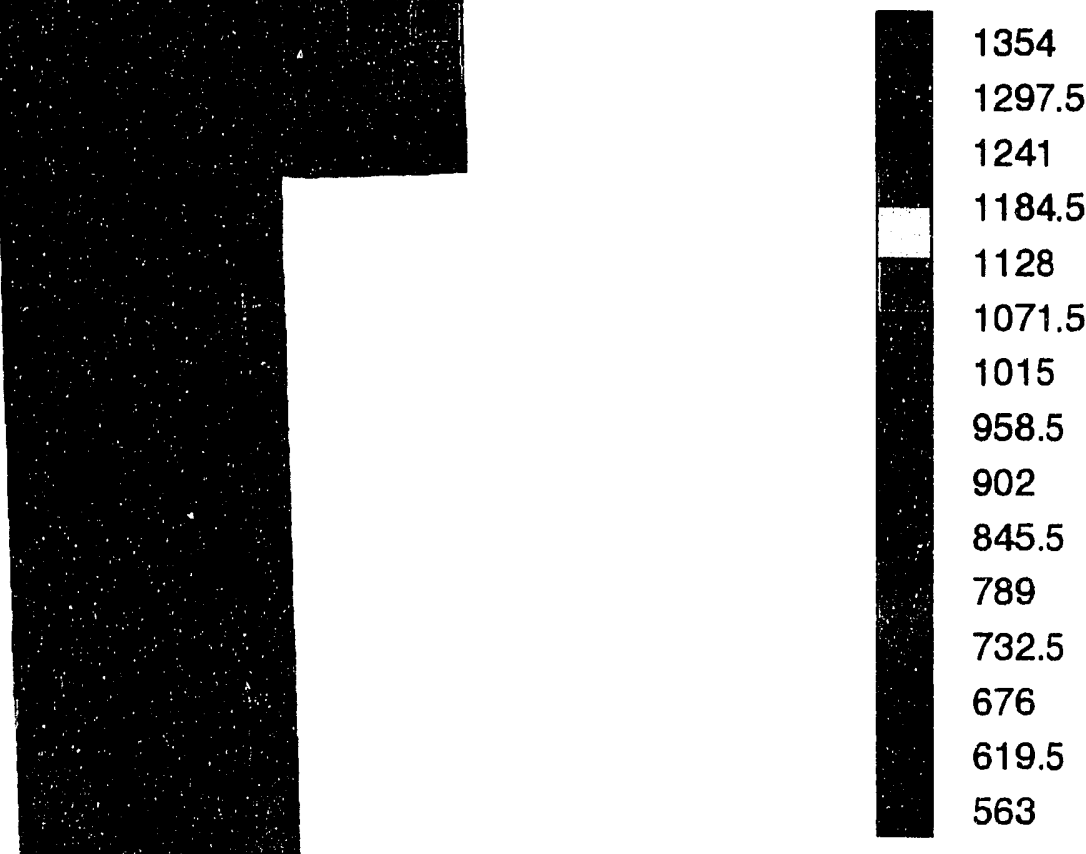

1128

1071.5

1015

958.5

902

845.5

789

732.5

676

619.5

563
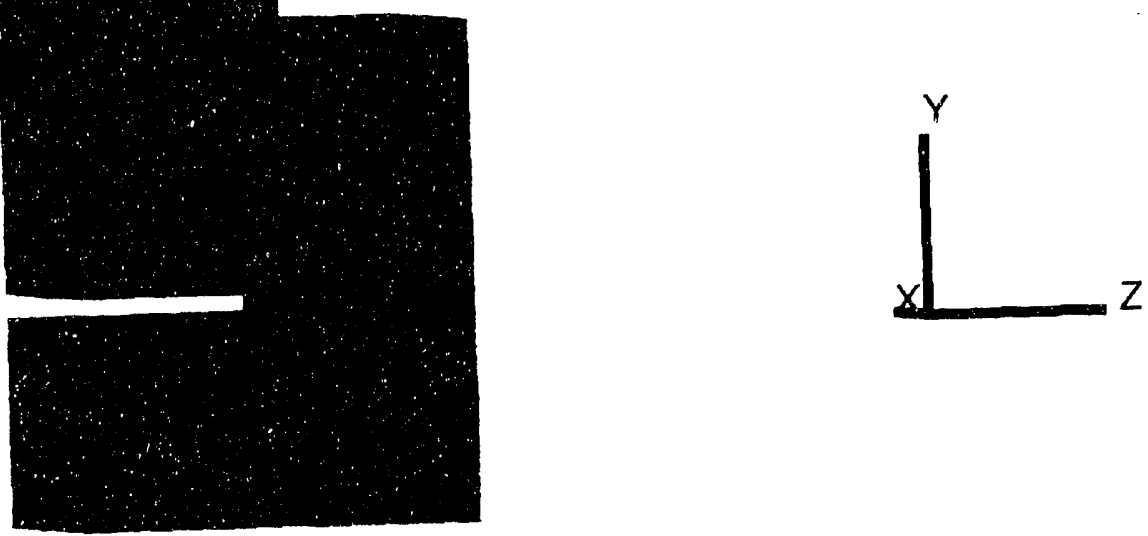

Fig. 60. Casting assembly temperature distrihutinn $420 \mathrm{~s}$ into the base-case solidification analysis. 


\section{PHYSICAL MODEL SIMPLIFICATION}

It was known that the second-generation studies would require a large number of computer runs to characterize carbide transport and examine the effect of casting assembly design changes. Economic considerations dictated the use of a physical model that was as simple as possible yet still gave meaningful agreement with experimental data. Accordingly, three simplifications to the base-case model were examined: removing the platinum thermocouple junctions and/or their insulating sheaths; eliminating portions of the firebrick base; and replacing the heater coil representation (i.e., the flat plates) with a boundary condition representative of the thermal resistances between the shield and cooling water.

To determine how much of the firebrick base could be removed, base-case transient temperatures at four locations in the $\mathrm{X} / \mathrm{Z}$ plane were plotted for several different $\mathrm{Y}$ elevations. The goal was to find that elevation where temperatures were constant for the duration of the transient, preferably at ambient. All material below this point could then be eliminated and replaced with a constant temperature boundary condition. The four locations correspond to the corners of the base of the lower end cap and are illustrated in Fig. 61. The four Y elevations were the base of the lower end cap and $5.5,15.5$, and $25.5 \mathrm{~cm}$ into the firebrick. These temperature data are summarized in Figs. $62-65$ and show that:

1. Temperatures do not become constant wrt time until $5.5 \mathrm{~cm}$ into the firebrick.

2. At each elevation there is a temperature difference between the set of nodes on the inside (i.e., $\mathrm{Z}=0$.) of the end cap and the outside set. This is attributed to the design of the casting assembly: the inside surfaces contact the bookmold containing the hot uranium, but the back side is separated from the bookmold by the thickness of the end cap. Thus, it is reasonable to expect cooler temperatures at the insulated locations on the back side of the end cap.

3. The absolute values of temperatures, as well as temperature

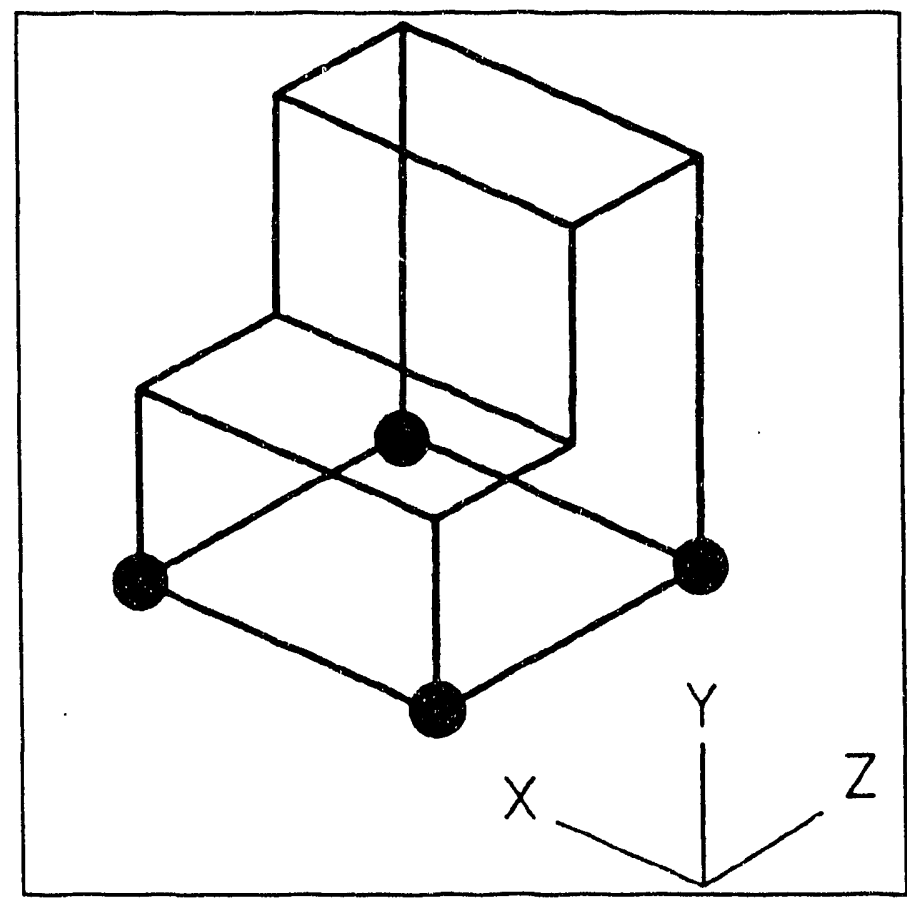

Fig. 61. The set of $\mathrm{X}-\mathrm{Z}$ plane monitored locations. differences between the inside and outside locations, decrease with increasing distance into the firebrick, but at no elevation are they equal to ambient.

Note that all temperatures are greater than ambient. Experimental data had indicated constant temperatures approximately equal to ambient $15.24 \mathrm{~cm}$ into the firebrick. The higher calculated temperatures are attributed to the fact that the base was modeled as a single solid 


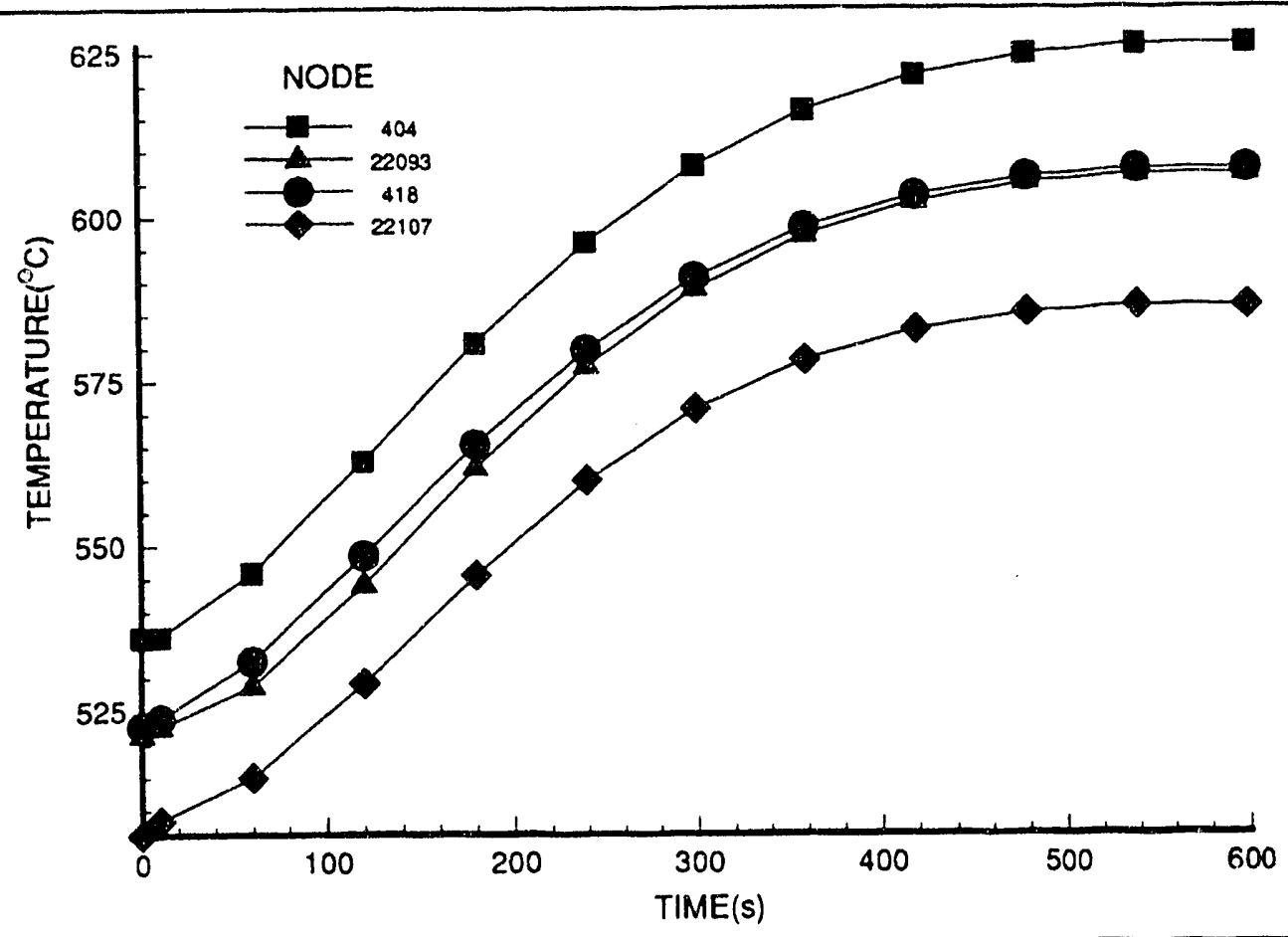

Fig. 62. Temperature history of selected nodes at the base of the lower end cap.

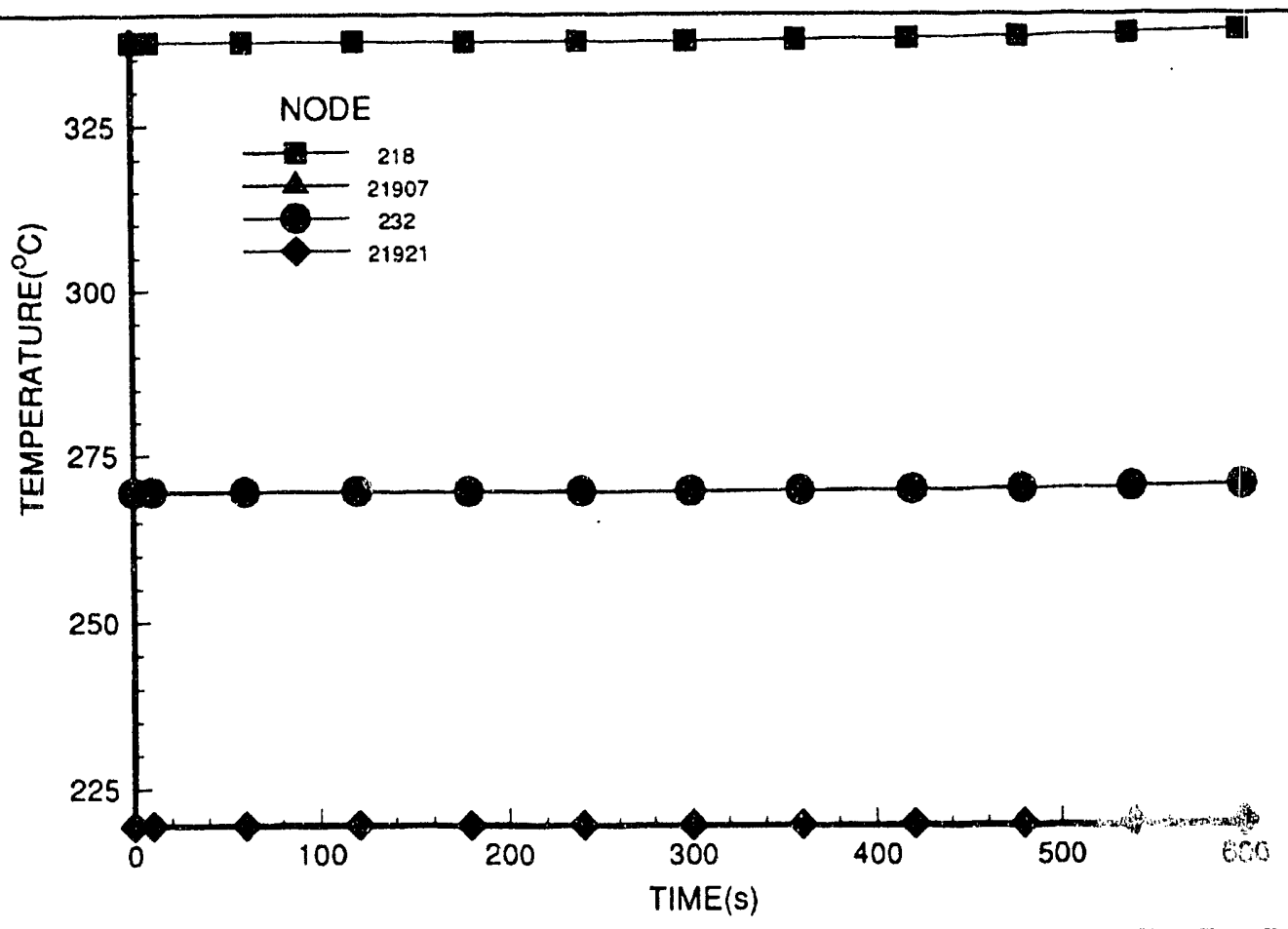

Fig. 63. Temperature history of selected nodes at $5.5 \mathrm{~cm}$ into the firebrick base. 


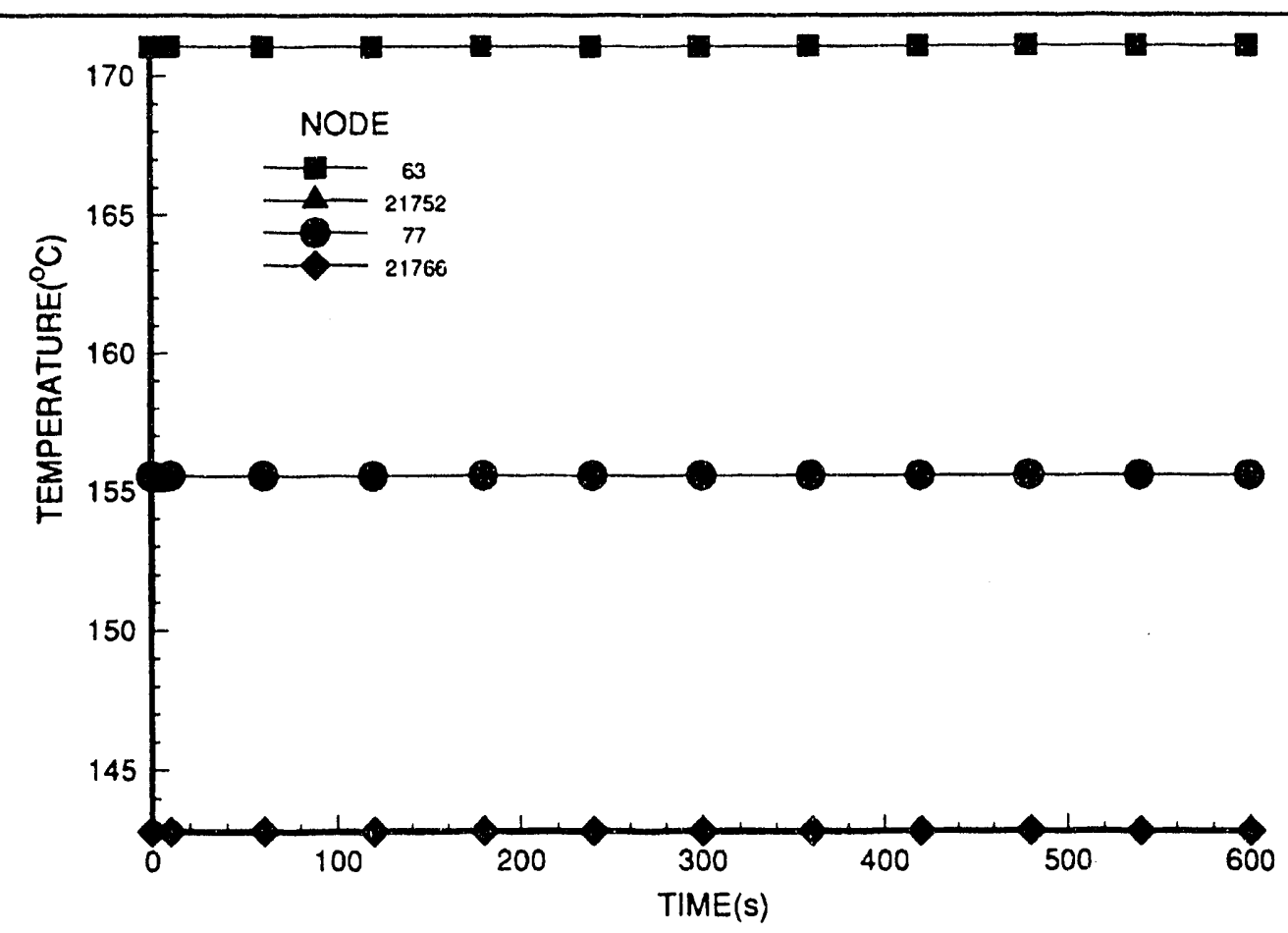

Fig. 64. Temperature history of selected nodes at $15.5 \mathrm{~cm}$ into the firebrick base.

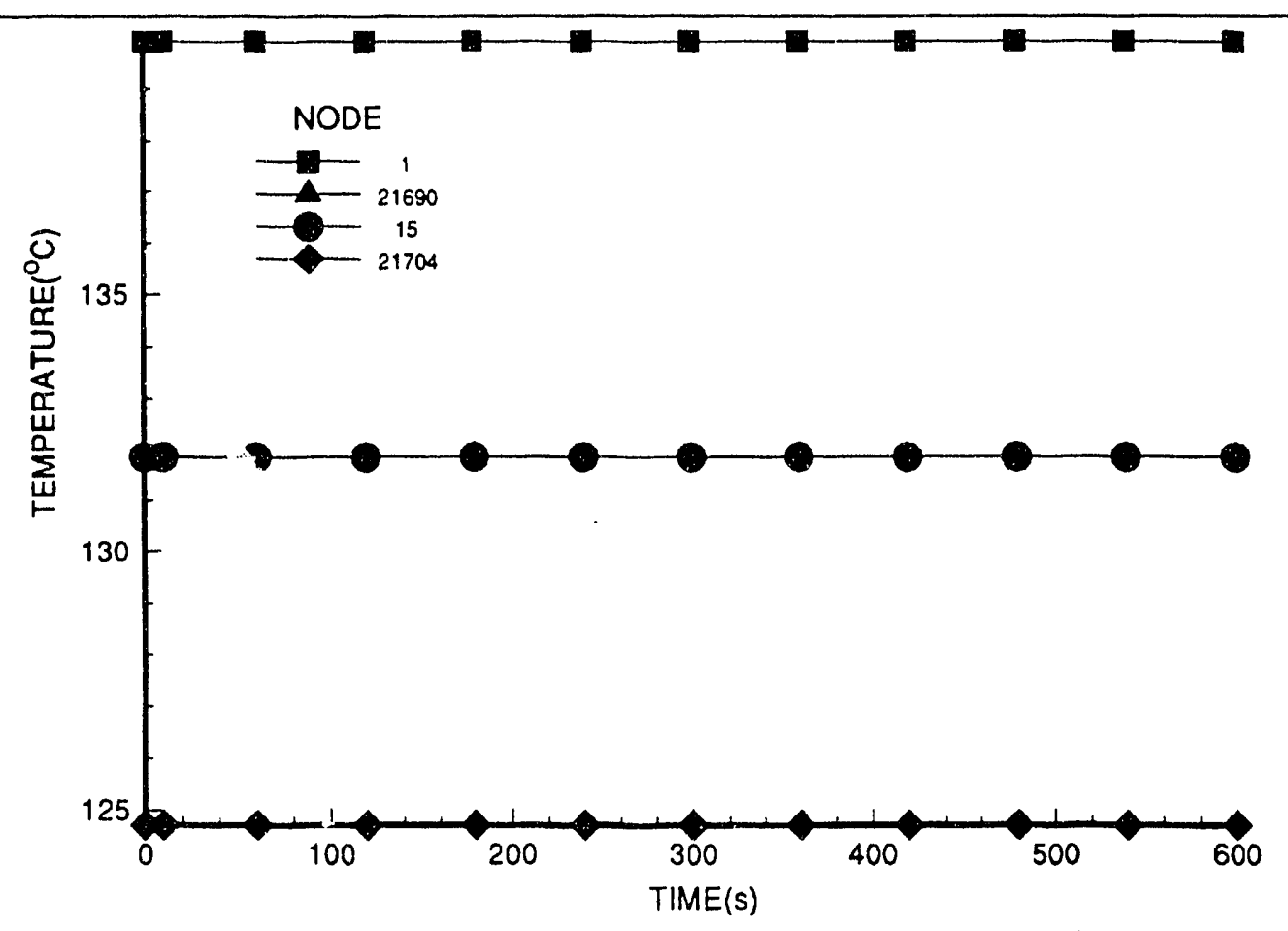

Fig. 65. Temperature history of selected nodes at $25.5 \mathrm{~cm}$ into the firebrick base. 
region when it is actually a loose stacking of several bricks. Thus, there were no void regions to impede conduction away from the casting assembly. It is also believed this is one of the reasons for the consistently low temperatures calculated for the bottom thermocouple location during the sensitivity studies. Based on these data and the belief that future melt temperatures are likely to be the same magnitude as Run No. 892, a case could be made for placing a constanttemperature boundary condition of approximately $275^{\circ} \mathrm{C}$ at $5.5 \mathrm{~cm}$ into the firebrick and then removing all material below that point. However, given the macroscopic result that all thermal mechanisms need to be included to some degree to obtain meaningful agreement, the most prudent action would be to model $15.24 \mathrm{~cm}$ of the actual stacking with its void spaces and place a constant temperature boundary condition of $25^{\circ} \mathrm{C}$ at the bottom of the stack.

To determine if the thermocouples and/or their insulating sheaths could be removed without adversely affecting model agreement, two configurations were examined: one where only the sheath was removed, and a second where the junction was removed as well. Model agreement for these two cases is summarized in Fig. 66 and shows that neither had a significant impact. The last potential simplification examined was to replace the flat plates with a radiation heat transfer coefficient applied to that portion of the insulating shield covered by the plates. Temperature data monitored during the sensitivity studies had indicated that the coils had an essentially constant temperature approximately equal to the cooling-water temperature. Accordingly, the boundary temperature for the new coefficient was made equal to the cooiingwater temperature. Model agreement for this case is also summarized in Fig. 66 and shows that the simplification did not significantly effect agreement. It appears that both the thermocouple system and the heating coil approximation could be removed from the second-phase model without adversely effecting its accuracy. Removing the coil approximation, however, is conditional upon not altering the cooling- water flow rate during the solidification transient. The primary reason the plates could be replaced was that the plate temperature was essentially constant during the transient. If the water flow rate were to be significantly decreased or stopped, the coil temperature would vary with time, and this response would then have to be modeled to correctly calculate the energy leaving the casting assembly. 


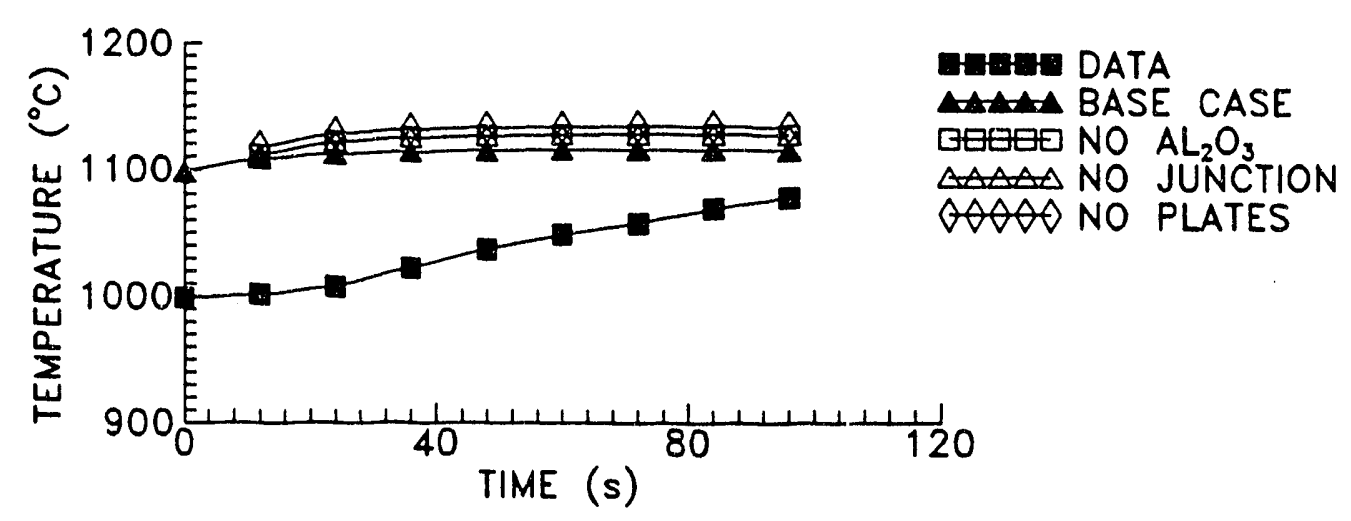

(a) top thermocouple location

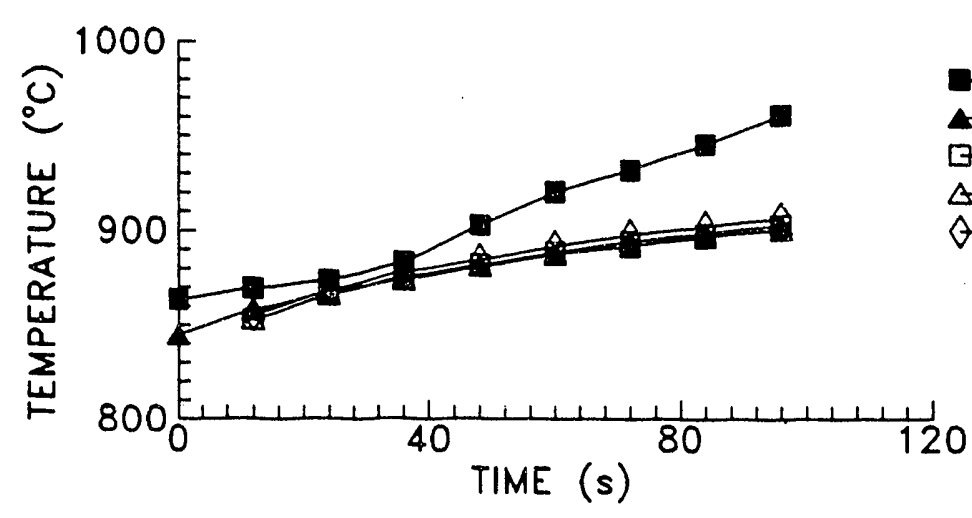

물 DATA

ana BASE CASE

$\mathrm{NO} \quad \mathrm{AL}_{2} \mathrm{O}_{3}$

$\triangle \triangle N O$ JUNCTION

$\triangle$ NO PLATES

(b) middle thermocouple location

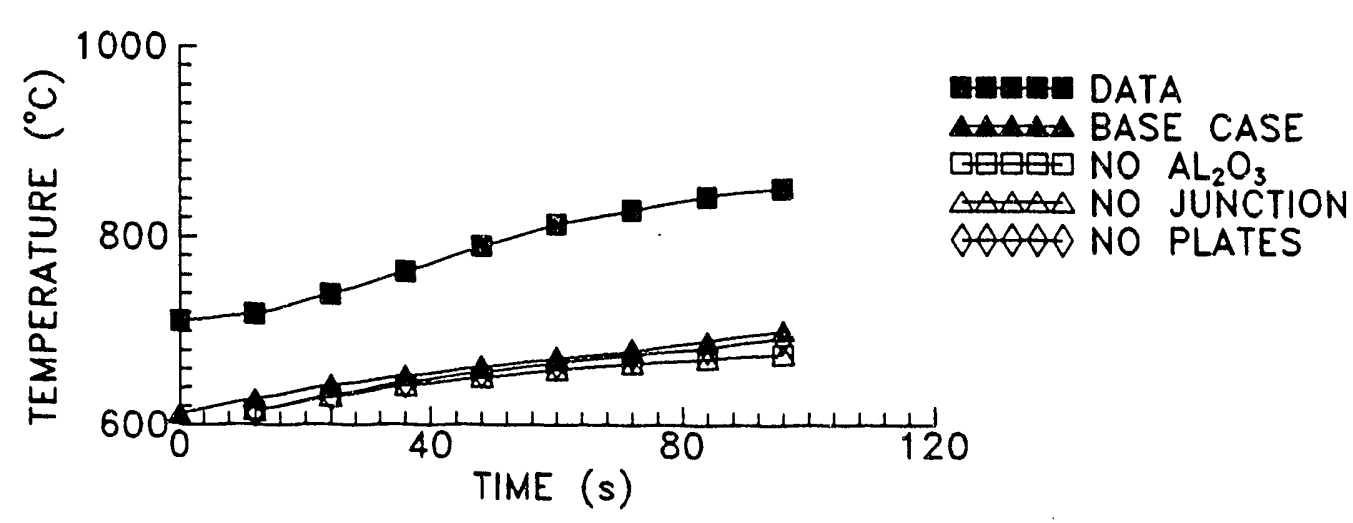

(c) bottom thermocouple location

Fig. 66. Model agreement for the thermocouple and flat plate simplification scenarios. 


\section{CONCLUSIONS AND RECOMMENDATIONS}

Two macroscopic conclusions can be drawn from the results of the first-phase study concerning modeling heat transfer in the current laboratory scale casting assembly:

1. those convection/conduction/radiation heat transfer mechanisms that locally influence net heat flow through casting assembly components have a greater impact on model accuracy than the absolute values of sink temperatures and coil cooling water flow rates; and

2. although this subset of prominent mechanisms exists; all major assembly components, heat transfer mechanisms, and boundary conditions must be included to some degree to obtain meaningful agreement with experimental data.

Accordingly, the following recommendations are made to facilitate the planning and execution of the second-phase thermal studies.

1. The design of the vacuum-caster system should be modified to permit routine measurements of pressure vessel interior wall temperature, cooling-water flow rate, water inlet and outlet temperatures, and heating coil current.

2. The experimental casting procedure should be slightly modified to ensure that thernally: consistent data are collected.

3. The second-phase thermal model should have the following macroscopic design features:

a. a precise physical model exclusive of the heater coils;

b. first-order accurate mathematical definitions for radiation heat transfer to the pressure vessel wall and between closely spaced components; and

c. second-order accurate definitions for thermal contact resistances (including that between the crucible wall and insulating shield), liquid uranium natural convection heat transfer, interfacial gap conductance between the solidified uranium and bookmold, internal heat generation, and radiation enclosure heat transfer.

The following briefly discusses some of the details associated with implementing these recommendations.

The only measure of computational accuracy is a comparison between measured and calculated bookmold temperatures. Thus, accurate measurements are required for bookmold temperatures as well as for those data used to define initial and/or boundary conditions for the analyses. Within this context there are two areas of concern with the current experimental casting procedure: the execution of the procedure itself and the placement of the bookmold thermocouples. The current procedure should be modified as per the following guidelines to ensure that consistent thermal data are taken.

1. The single most important consideration is to establish a thermal steady state prior to pour. Currently the only criteria is a non-changing melt temperature for $30 \mathrm{~min}$, and the coil current is continually reduced during this time period to achieve this condition. Steady state must be redefined to be that condition where coil current, melt temperature, and bookmold temperatures have all remained unchanged for $30 \mathrm{~min}$.

2. It is also very important to coordinate the operation of the data recorder with the pour that is, define a time 0 for the solidification analysis. To achieve this the data recorder 
should be turned on very early in the melting phase and left on for the duration of the experiment, at least to the point where the caster is first.backfilled with argon. Once the operators are satisfied that steady-state conditions exist (i.e., non-changing coil current and temperatures), the pour rod should be removed. The exact time the rod is removed should be recorded on the data sheet and a notation made on the strip shart.

3. In addition to the data currently taken by the operators, heating coil current, coil frequency, cooling water flow rate, and water inlet and outlet temperatures should also be recorded at steady-state conditions (i.e., just prior to the pour) as well as during the solidification portion of the experiment. These data should be recorded at the same time and with the same frequency as the bookmold temperatures. Also, it is especially important to continue to record coil current and frequency during and just after the pour, as well as the exact amount of time the power remains on after the pour rod has been removed.

4. When the caster is first backfilled with argon, the exact time the procedure was begun should be recorded on the data sheet and a notation made on the strip chart. In addition, the final pressure in the caster should also be noted on the data sheet.

There are two aspects of bookmold thermocouple placement that are of concern: location and installation. It is extremely important that the location of the three bookmold thermocouple junctions be well defined. Otherwise a comparison of measured and calculated temperatures cannot be made and it will not be possible to estimate the accuracy of the carbide transport calculations. The recommended locations have been previously documented, ${ }^{28}$ but are summarized here as well for completeness. The locations were actually defined to achieve two goals: obtaining temperature data within the bookmold wall to help in establishing the accuracy of the solidification analyses, and obtaining temperature differences across assembly components to help in defining the magnitude of thermal contact resistances. Six locations are recommended: one each in the crucible and end caps, and three in a particular bookmold half-section. Figures 67-69 illustrate these locations in the upper end cap, lower end cap, and bookmold half-section respectively. When studying these figures, please note the following.

1. Each drawing shows a TOP, FRONT, and SIDE VIEW of a particular component with the thermocouple location(s) identified by a filled circle, letter, and complete set of dimensions.

2. Each drawing shows a REFERENCE CORNER. When the components are assembled, all of these corners must line up.

3. The bookmold drawing shows a specific half-section; the one that wraps around the other half-section.

4. The end cap drawings, and therefore the location of their REFERENCE CORNERS, are oriented as they would be in the assembled bookmold; that is, the slot in the bottom cap is visible in its TOP VIEW, but the slot in the upper end cap is not visible in its TOP VIEW.

5. Vertical, horizontal, up, and down are defined in the traditional sense; that is, with respect to the top, bottom and sides of a flat sheet of paper.

6. Height is defined as the vertical direction in the SIDE and FRONT VIEWS.

7. Width is defined as the vertical direction in the TOP VIEW and the horizontal direction in the FRONT VIEW.

8. Depth is defined as the horizontal direction in the SIDE and TOP VIEWS. 


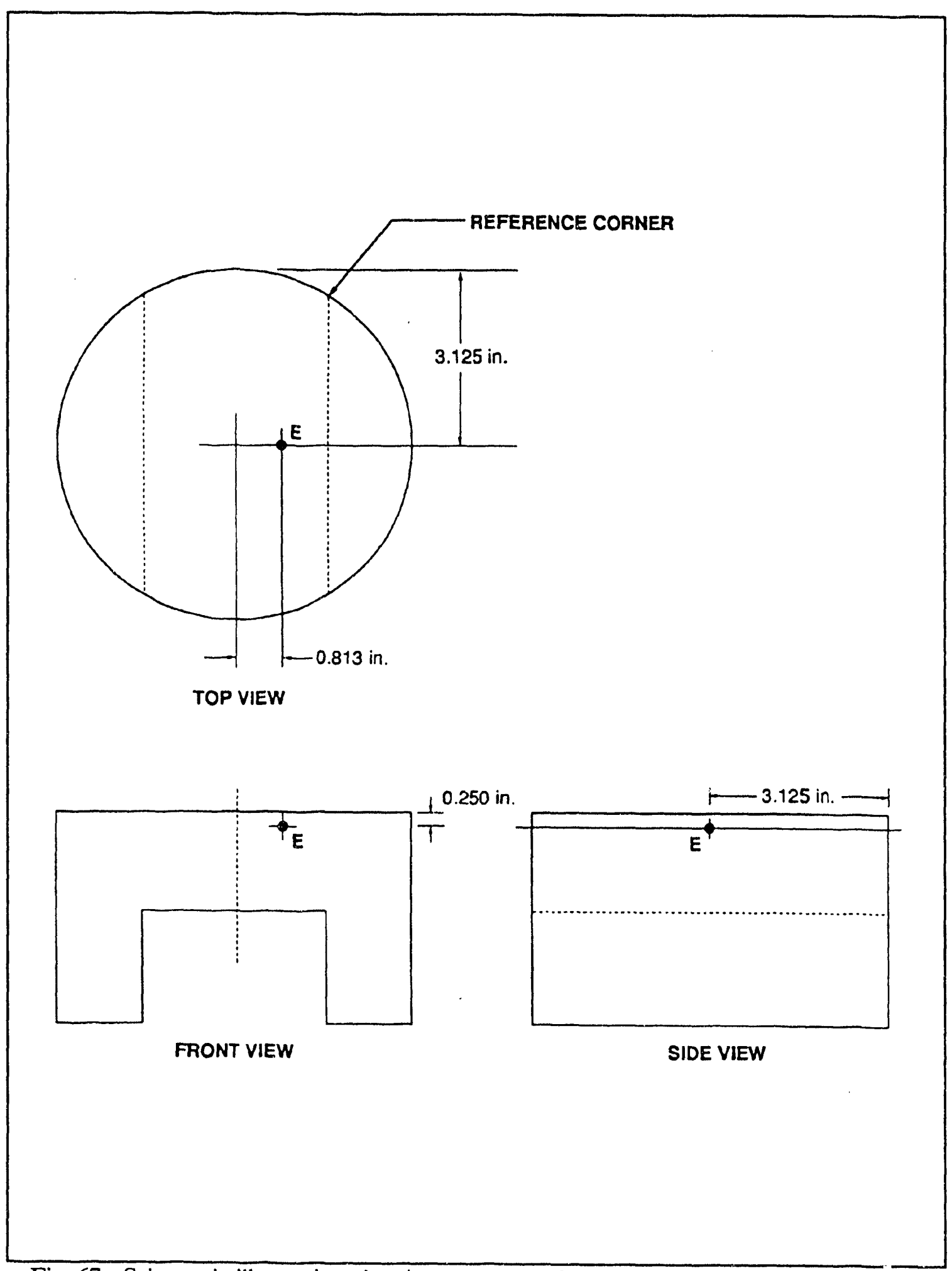

Fig. 67. Schematic illustration showing recommended thermocouple locations for upper end cap. 


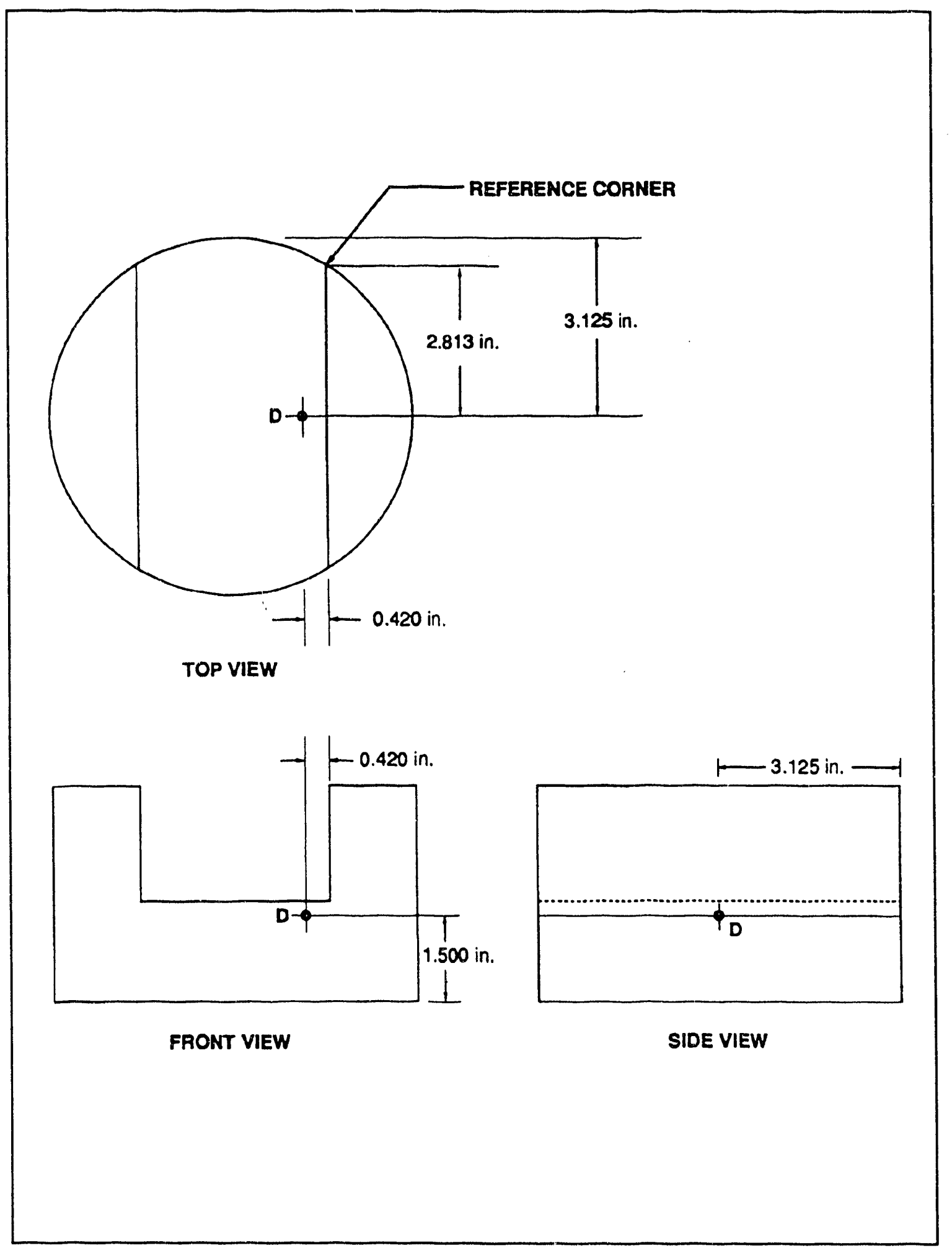

Fig. 68. Schematic illustration showing recommended thermocouple locations for the lower-end cap. 


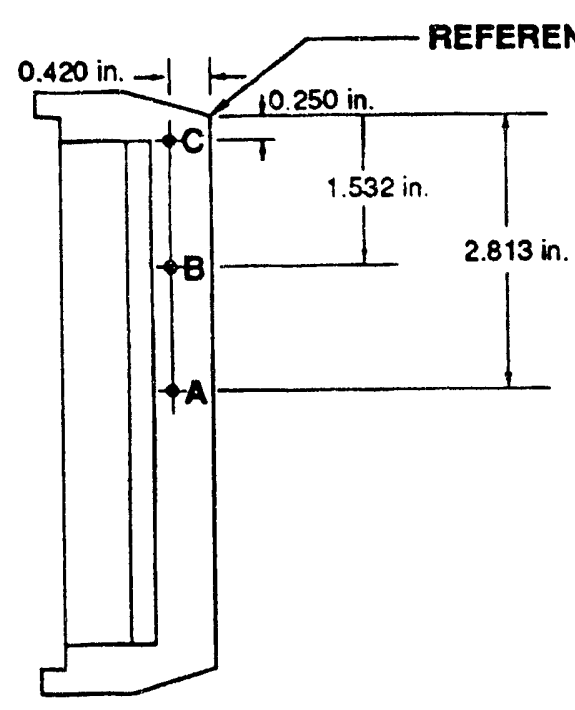

TOP VIEW

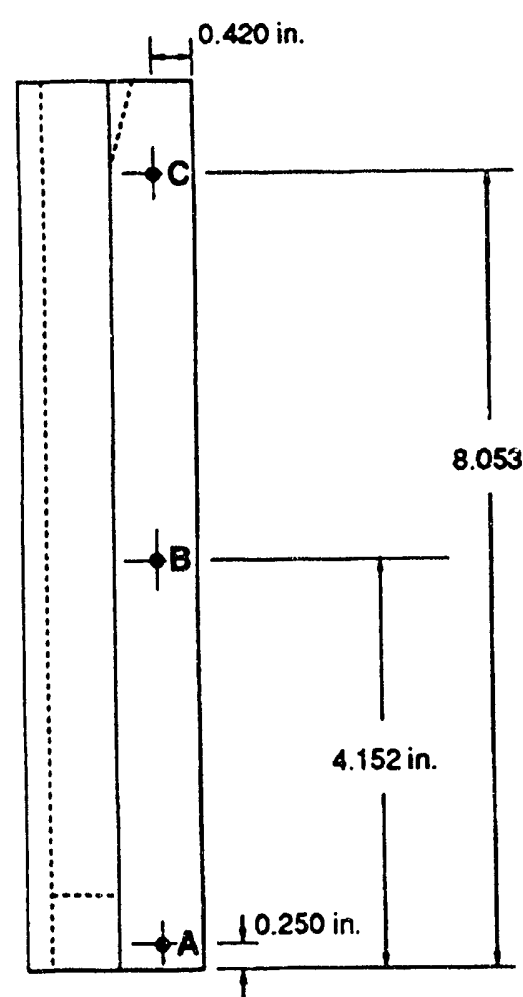

SIDE VIEW

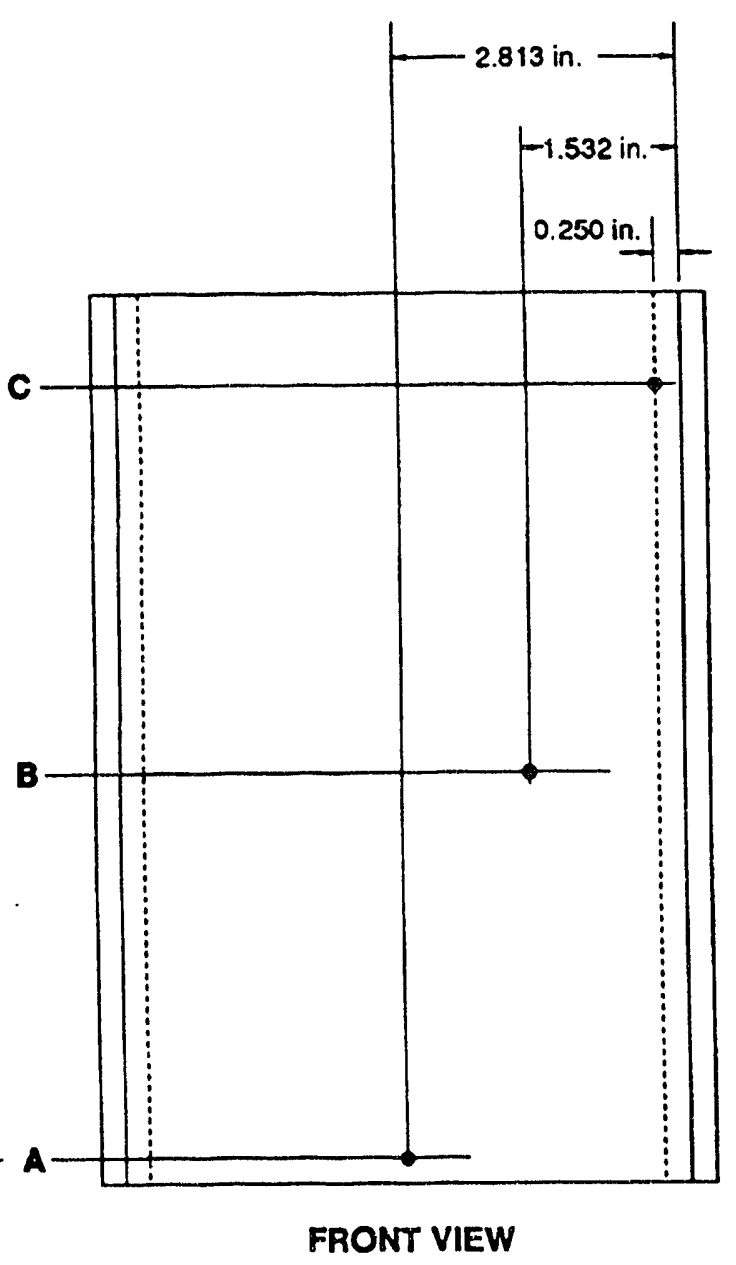

Fig. 69. Schematic illustration showing recommended thermocouple locations for the bookmold half-section. 
The following verbal descriptions compliment and reinforce the illustrations. Thermocouples A, B, and C should all be placed in the center of the indicated wall; that is, at a distance equal to half the depth of the indicated wall. Thermocouple A should be placed at a point half way across the width of the section and 0.25 in. up from the bottom of the section. Thermocouple $C$ should be placed 0.25 in. into the width of the section measured from the REFERENCE CORNER, and 7.303 in. from the bottom of the mold cavity. Since the bottom of the cavity is 0.75 in. from the bottom of the section, thermocouple $\mathrm{C}$ should be placed 8.053 in. up from the bottom of the section. Thermocouple B should be placed midway between thermocouples $A$ and $C$ in both the width and height of the section. Thermocouples $A$ in the bookmold half-section and $\mathrm{D}$ in the lower end cap will be used to characterize the contact resistance between uncoated components. Thermocouple $\mathrm{D}$ must align with thermocouple $\mathrm{A}$ and be separated by a distance of $0.5 \mathrm{in}$. Its location, therefore, should be halfway into the width of the end cap, 0.42 in. to the right of the slot wall, and 1.5 in. up from the bottom of the cap. Thermocouple $\mathrm{E}$ in the upper end cap and the crucible thermocouple will be used to define contact resistances between coated carbon components and they should also be aligned, one over the other. The only placement criterion for Thermocouple $E$ is that it should be separated from the thermocouple in the crucible by a distance of $0.5 \mathrm{in}$. Accordingly, its position should be half way into the width of the cap, midway between the centerline of the cap and the right hand wall of the slot, and 0.25 in. down from the top surface of the cap. The crucible thermocouple (not shown) should be positioned anywhere on a 0.813 in. radius measured from the center of the crucible and 0.25 in. into the bottom wall thickness. The 0.25 in. should be measured from the bottom of the crucible; that is, from the surface that contacts the upper end cap. Because of the crucible's uniform cylindrical geometry, it is not possible to define a REFERENCE CORNER. Accordingly, care should be taken during the assembly process to ensure these two thermocouples are properly aligned.

An additional concern is the actual installation of the thermocouples: specifically, the diameter of the holes that are drilled in the assembly components to accommodate the thermocouples. I have noticed that the diameter of the holes in the existing bookmold section is very much larger than the diameter of the thermocouple junction. Unless the leads are somehow mechanically secured (brazing or cementing is not recommended for this application), the junction will almost certainly move away from the end of the hole during a casting experiment. This, in turn, will introduce considerable uncertainty in the temperature measurements. The hole diameter should be approximately equal to the diameter of the insulating sheath on the thermocouple leads. This should permit friction to hold the junction in place.

A precise physical model will be required for the second-phase model as well as very accurate calculations for enclosure radiation heat transfer, liquid uranium natural convection heat transfer, thermal contact resistances, internal heat generation, and interfacial gap conductance. Considerable effort will be required to develop and execute these numerical capabilities.

The PATRAN family of integrated software will be the primary numerical tool used to construct and execute the second-phase physical model and calculate radiation heat transfer configuration factors. The PATRAN Plus module will be used to construct a 3-D, quarter symmetric finite-element mesh of the casting assembly. The P/VIEWFACTOR module will be used to calculate configuration factors for the crucible/crucible top, bookmold/upper end cap, and bookmold $/ \mathrm{Al}_{2} \mathrm{O}_{3}$ shield radiation heat transfer enclosures. The P/THERMAL module will utilize the mesh and configuration factors to conduct the thermal analysis. These codes are currently available within Energy Systems and are among the most sophisticated commercially available programs for mesh generation and thermal analysis. 
The effects of natural convection heat trinsfer within the crucible and bookmold buoyancy induced flow enclosures will be included via the technique used to iterate between the PATRAN and FLOW-3D codes. The FLOW-3D code will be used to study fluid motion and carbide transport, and inherent limitations in both PATRAN and FLOW-3D make it necessary to iterate between them to define a complete thermalhydraulic solution. The iteration sequence that will be used is based on having each code supply boundary and initial conditions for its counterpart. To fix ideas consider the simplified steady-state buoyancy-driven flow system shown in Fig. 70. It consists of a vertical flat plate in an infinite, quiescent fluid at a constant temperature $T_{\infty}$. The plate is heated from the exterior surface and is assumed to have a constant temperature. Velocity and thermal boundary layers develop along the height of the plate. Fluid velocities and temperature within the boundary layer, as well as the thickness of the layers, are a function of $\mathrm{X}$ and $\mathrm{Y}$. At the edge of the boundary layer the fluid has a zero velocity and a temperature equal to ambient. Furthermore, the temperature of the interior wall (i.e., facing the uranium) is controlled by this flow system. However, the comparable system for an enclosure is considerably more complicated. The wall has a varying temperature along its height and the fluid outside the

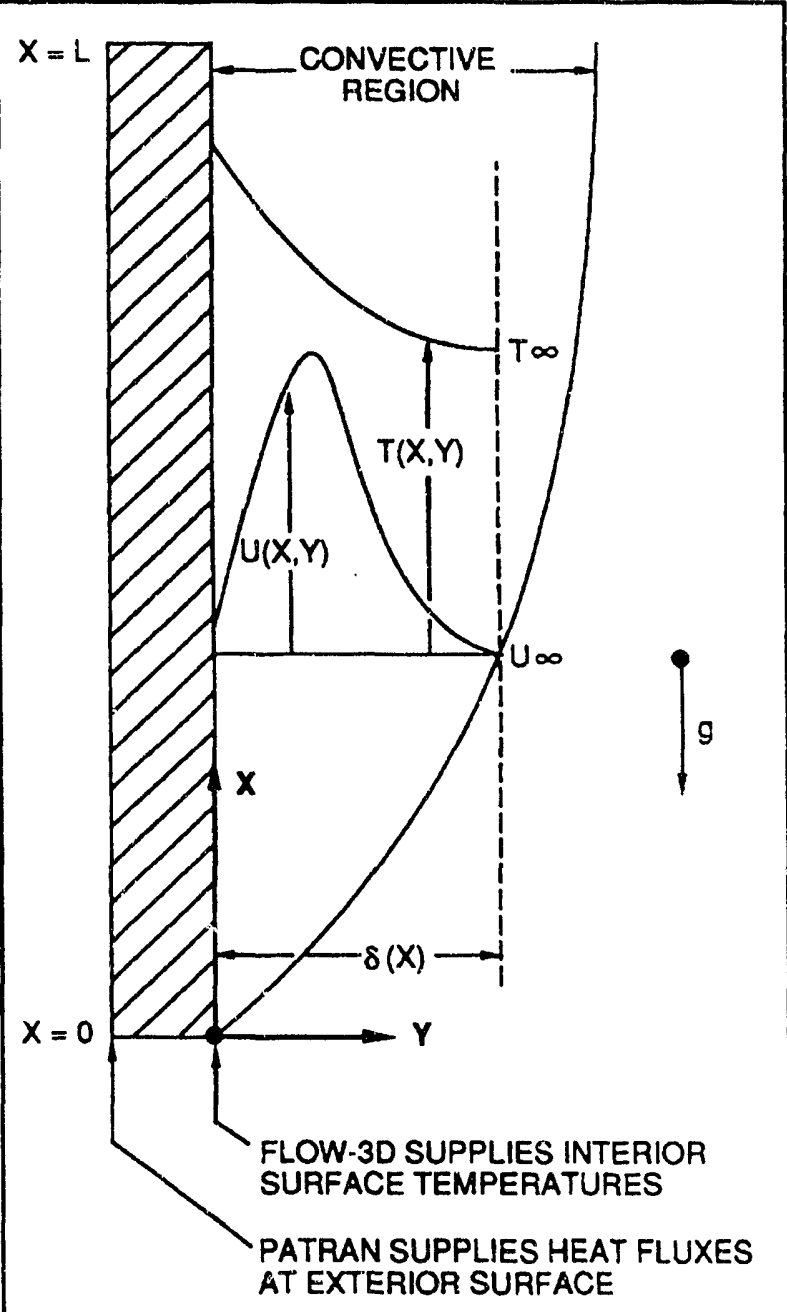

Fig. 70. Simplified buoyancy-driven flow system showing velocity and thermal boundary layers. boundary layer is stratified; it has temperatures greater than ambient and non-zero velocities. Also, as previously explained, each wall comprising the enclosure has similar systems and they all interfere with each other. Now, FLOW3D can calculate the stratified conditions at all locations within the enclosure but cannot calculate the complicated heat fluxes at the exterior surface of the enclosure. PATRAN can easily calculate conditions at the exterior wall given temperatures at the interior wall but cannot model the stratified conditions within the liquid uranium. Accordingly, the iteration sequence is conceptualized as follows.

1. The PATRAN physical model will initially include a simple phase-change uranium region within the bookmold and Eqs. (5) and (6) will be used to calculate a value for the heat transfer coefficient at the interior wall. A solidification analysis will then be run that will produce transient temperatures at a mid-plane in each of the bookmold walls. 
2. FLOW-3D will use this information as boundary conditions for a fluids analysis that will calculate temperatures at the bcokmold interior surfaces as a function of the buoyancyinduced flow system described above.

3. The phase-change region will be removed from the PATRAN model and replaced with a specified temperature boundary condition defined from the FLOW-3D results. The solidification analysis will then be repeated and the resulting mid-plane wall temperatures again supplied to FLOW-3D.

4. These temperature iterations will continue until differences between successive values have become acceptably small. At this point a complete thermal-hydraulic solution will have been defined.

Thermal contact resistances between assembly components will be calculated using the following engineering correlation: $:^{29}$

$$
U=1.0+\frac{B C}{K \tan ^{-1}\left[\left(\frac{1.0}{C}\right) \sqrt{1.0-\left(\frac{1.0}{U}\right)}-1.0\right]} .
$$

The conductance number, $\mathrm{U}$, is defined as

$$
U=\frac{u \delta}{k_{f}}
$$

where

$\delta=$ effective gap thickness between surfaces and can be approximated using:

$\delta=3.56\left(\ell_{1}+\ell_{2}\right)$ for $\left(\ell_{1}+\ell_{2}\right)<7 \mu \mathrm{m}$

$\delta=0.46\left(\ell_{1}+\ell_{2}\right)$ for $\left(\ell_{1}+\ell_{2}\right)>7 \mu \mathrm{m}$

$\mathrm{k}_{\mathrm{f}}=$ effective thermal conductivity of the fluid in the void spaces of the contact joint.

The effective conductivity for a liquid is simply its thermal conductivity. When the fluid is a gas transparent to thermal radiation, $\mathrm{k}_{\mathrm{f}}$ is defined as

$$
k_{f}=\frac{k_{g, 0}}{1.0+\left[\frac{8 \gamma \eta L_{m}\left(a_{1}+a_{2}-a_{1} a_{2}\right)}{\delta P_{r} a_{1} a_{2}(\gamma+1.0)}\right]}+\frac{4 \sigma \delta \epsilon_{1} \epsilon_{2} T_{m}^{3}}{\epsilon_{1}+\epsilon_{2}-\epsilon_{1} \epsilon_{2}} .
$$

For our problem, where contact occurs in a vacuum, energy exchange across voids occurs only by radiation heat transfer. Thus, Eq. (22) reduces to

$$
k_{f}=\frac{4 \sigma \delta \epsilon_{1} \epsilon_{2} T_{m}^{3}}{\epsilon_{1}+\epsilon_{2}-\epsilon_{1} \epsilon_{2}} .
$$

The constriction number of a contact joint, $\mathrm{C}$, is defined as 


$$
C=\sqrt{\frac{P}{M}} .
$$

The conductivity number of a contact joint, $\mathrm{K}$, is the ratio of the effective fluid conductivity to the harmonic mean of the material conductivities and is defined as

$$
K=k_{f}\left(\frac{k_{1}+k_{2}}{2 k_{1} k_{2}}\right) \text {. }
$$

The gap number of a contact joint, B, is defined as the ratio of the effective void thickness to the radius of the contact element and can be approximated using

$$
B=0.335 C^{\Psi}, \text { where } \Psi=0.315\left(\frac{\sqrt{A}}{\delta}\right)^{0.137} .
$$

There are three noteworthy considerations associated with incorporating Eq. (20) into the second-phase model: a solution procedure, defining surface roughness and hardness, and estimating contact pressures within the casting assembly as well as between the crucible wall and the $\mathrm{Al}_{2} \mathrm{O}_{3}$ insulating shield.

1. Equation (20) is transcendental and, therefore, requires an iterative solution procedure. Furthermore, temperature-dependent values for hardness and thermal conductivity as well as position dependent contact pressures are required. Because it would be inefficient to perform these calculations at run-time, a stand-alone FORTRAN program will be written to solve Eq. (20) as a function of temperature for each desired location (i.e., $\mathbf{Z}$ position) in the casting assembly. The resulting discrete data will then be input to the P/THERMAL model.

2. Surface roughness and Meyer hardness measurements for each assembly component are required. To my knowledge these data are not currently available and should be defined as soon as possible for the following locations:

a. the underside of the crucible and its exterior wall;

b. those portions of the upper end cap that contact the crucible and the bookmold;

c. those portions of the bookmold that contact the upper and lower end caps;

d. the firebrick; and

e. the $\mathrm{Al}_{2} \mathrm{O}_{3}$ insulating shield.

The actual casting assembly and firebrick should be used for the measurements, and those surfaces normally coated with yttrium-oxide should have a fresh application. Also, some estimate of the change in hardness with temperature should be made, a direct measurement if possible or a generic relationship from the literature.

3. Defining contact pressures has the potential to be quite complicated. As a first approximation for joints with a horizontal orientation, the weights of the individual 
components above a joint can be used to estimate pressure. Thus, accurate weights of each component will be required. For those bookmold-end cap joints with a vertical orientation, a direct measurement of forces will be required. One possible procedure is to secure the upper end cap to a fixture, seat the bookmold, and then apply a force to the bookmold (either extra weights or a measured downward pull) until it unseats. The combined weights of the bookmold and the additional force could then be used to estimate the contact pressure. All of these values, however, could be significantly altered by thermal distortion of the casting assembly at the high temperatures encountered during a casting experiment. This effect must be defined if only qualitatively. Accordingly, the ADINA stress analysis computer program will be used to calculate the deformations. Thus, accurate dimensions for each assembly component will also be required. ADINA is currently in use within Energy Systems, can utilize a PATRAN mesh, and there are experienced personnel within the Technical Applications Engineering Department to help expedite the calculations.

The effective conductance between the crucible wall and insulating shield will also be approximated using Eq. (20). The ADINA code will be used to estimate the thermal growth (and therefore contact pressure) for the two components.

Internal heat generation will also have to be calculated independently of the second-phase model and then input as discrete data. Because of the complicated casting assembly-induction heater geometry, it will be necessary to solve the electromagnetic field governing equations (i.e., Maxwell's equations) directly. The Computing and Telecommunication Division does not have the necessary computer program to make this calculation, but the capability will soon exist within Energy Systems. Engineering Division is in the process of acquiring the EMAS code from the MacNeal-Schwendler Corporation. EMAS is a general analysis program for calculating electromagnetic fields in three dimensions using a finite-element solution procedure. This code should be more than adequate for our needs. One advantage of EMAS is that it can utilize a PATRAN mesh, thus reducing the total amount of time needed to construct and execute a case. We have spoken with the individual responsible for acquiring EMAS, and he has agreed to allow us access to the code. A great deal of properties and experimental data will be required to execute EMAS, and, except for heating coil current, the information should be readily available.

Defining a value for the interfacial conductance between the solidified uranium and bookmold could also require a considerable numerical effort. The literature ${ }^{30,31}$ indicates that the mechanisms controlling the formation, growth, and thermal conductance of a gap are quite involved.

1. A vertical ${ }^{\ddagger}$ gap will develop only after a sufficiently thick solid skin has formed around the melt permitting it to shrink away from the mold wall, which is simultaneously expanding because of its sudden exposure to the hot liquid metal.

2. The transient gap size will vary as a function of the coefficients of expansion of the metal and mold and will eventually shrink to (essentially) zero as they cool.

3. Typically the gap is too small for natural convection heat transfer and too large for contact resistance effects (i.e., those fluid-solid interactions represented by

\# It is assumed that heat transfer between the bottom of the solidified melt and the mold can be calculated using Eq. (20). 
accommodation coefficients). Thus, energy transfer across a gap will be by conduction through any gas that might be present and radiation heat transfer.

It is not clear if this entire sequence applies to our problem. Specifically, during the time it takes the uranium to completely solidify (which is our current focus), is the differential expansion such that radiation heat transfer is the only mechanism or do contact resistance effects become significant? This question can only be accurately answered experimentally and/or numerically, and it is not clear at this time if such an effort is warranted. Accordingly, vertical gap conductances will be calculated in the second-phase model assuming only radiation heat transfer. As a part of the model verification process, we will examine the model's sensitivity to changes in this value and then make a determination as how to proceed. If an extremely accurate value is required to achieve meaningful thermocouple agreement, it is likely that a series of minor solidification experiments and/or numerical studies using ADINA will be necessary. In any event, the implementation of the conductance mechanism within the model will also be modified. Recall that in the first-phase study the value was applied to individual nodes once the uranium at that location had solidified. In the second-phase model the conductance will only be applied after all of the uranium has solidified. Given the highly directional solidification in the current casting assembly, it is unlikely that a skin will form before the melt has completely solidified. Furthermore, it will be assumed that once the gap forms, its behavior for the remainder of the analysis is such that only radiation heat transfer occurs. It should be understood that if the scope of the analyses changes to include very long times, a numerical study of differential metal-mold expansion using ADINA might be required.

An additional category of information required to support the second-phase studies is experimental casting data. At least one consistent set of data, including direct measurements of heating coil current and cooling water temperature rise, will be needed during the model construction phase. As we have previously discussed, the current test procedure will have to be slightly modified to ensure that consistent thermal data are taken.

As can be seen, a great deal of data collection and preprocessing of input data will be required to conduct the second-phase thermal studies. This includes, but is not necessarily limited to,

1. modifying the vacuum-caster's instrumentation and conducting at least one casting experiment;

2. measuring surface roughness, Meyer hardness, and contact pressures of casting assembly components;

3. preparing input and executing EMAS as well as reading results into the P/THERMAL input file;

4. constructing a FORTRAN program to calculate contact resistances as a function of measured contact pressure data and temperature dependent material properties, and then reading results into the P/THERMAL input file;

5. calculating radiation heat transfer configuration factors using P/VIEWFACTOR and reading results into the P/THERMAL input file;

6. preparing input and executing ADINA as well as reading the results into the contact resistance program; and

7. constructing a FOR'TRAN program to read FLOW-3D results into the P/THERMAL input file. 
Now, completing these tasks before developing the P/THERMAL model will almost certainly cause the July target for the first P/THERMAL - FLOW-3D iteration to slip. To prevent this, I propose to combine the construction and verification phases into discrete steps which have been designed to demonstrate the feasibility of a P/THERMAL - FLOW-3D iteration by the end of July. Once this has been accomplished, the remainder of the numerical/informational infrastructure required to support routine transport studies will then be developed. These steps are summarized below.

1. The efforts to construct the P/THERMAL model, conduct a casting experiment, measure surface characteristics and contact pressures, and define weights and dimensions of assembly components will begin immediately.

2. Steady-state and transient P/THERMAL models will be constructed. The models will contain uranium regions in the crucible and bookmold and will have the following macroscopic features.

a. Natural convection heat transfer within the liquid uranium will be approximated with the same technique as was used for the first-phase study.

b. Enclosure radiation heat transfer will be accurately calculated using configuration factors from P/VIEWFACTOR.

c. Temperature-dependent contact resistances will be specified for each contact joint using predefined discrete data. Rather than run the ADINA code at this point, values will be approximated using Eq. (20), the measured surface characteristic, and contact pressure data. Specifically, the combined weights of assembly components will be used for horizontal joints and the measured forces will be used for vertical joints. As explained, a stand-alone FORTRAN program will have to be written to solve Eq. (20).

d. Constant (i.e., not a function of time) internal heat generation rates for each affected node will be approximated with the same basic technique as was utilized for the firstphase study. The EMAS code will not be run at this point.

e. Interfacial gap conductance will be accurately calculated as described above (i.e., radiation heat transfer between neighbor nodes once the entire melt has solidified).

f. The conductance between the crucible wall and the $\mathrm{Al}_{2} \mathrm{O}_{3}$ insulating shield will be approximated assuming only radiation heat transfer.

g. A specified heat flux boundary condition will be defined for that portion of the insulating shield normally covered by the heating coils. The value will be approximated assuming a $2^{\circ} \mathrm{C}$ temperature rise in the cooling water.

3. These simplified models will be verified and a nominal transient response definer. FORTRAN programs will then be written to read selected FLOW-3D output temperatures into P/THERMAL and write selected P/THERMAL temperatures to a data file for use by FLOW-3D. The uranium regions will then be removed from the P/THERMAL models and replaced with specified temperature boundary conditions and one complete P/THERMAL/FLOW-3D iteration will be completed. These tasks will be completed by the end of July 1992.

4. $T:$ EMAS code will be executed to define accurate values for internal heat generation. The data will be read into P/THERMAL, replacing the simplified values.

5. The ADINA code will be run to define the contact pressure between the crucible wall and insulating shield as well as examine the effect of thermal growth on the contact resistances between assembly components. 
6. Experimental data will be used to redefine the specified heat flux boundary condition on the insulating shield.

7. P/THERMAL - FLOW-3D will then be rerun and the results compared to experimental thermocouple data. An abbreviated sensitivity study will also be conducted to establish macroscopic accuracy limits for P/THERMAL This will be accomplished by characterizing thermocouple agreement for nominal changes in certain prominent variables. The specific variables are those used to calculate macroscopic mechanisms (e.g., radiation heat transfer) but which have a natural variability (i.e., uncertainty) associated with their typical values. These include, but are not limited to, surface emissivity, material roughness and hardness, and electrical resistivity. One last caveat: the intent of the study is to quantify accuracy and not identify a single variable that could be used to calibrate the model. However, should it become apparent that such a dominant variable exists and the value needed to force agreement is physically real, some small amount of additional analyses might be required to formalize the calibration effort.

At this point, all of the properties data and numerical tools needed to support the secondphase thermal studies will be available, and carbide transport studies will begin. It should be understood that the combined thermal, hydraulic, and metallurgical problem is extremely complex. As such, it is unrealistic at this time to attempt to define a detailed action plan. This constraint results from the nature of the problem. For any development effort that seeks to define cause and effect for an actual engineering system, it is typically not possible to predefine the exact sequence of steps that will be taken. At any point in time the focus of current activities, as well as the perception of what is a potentially productive future activity, are functions of the current level of technical understanding. As cause and effect become better defined and understanding matures, the execution sequence must change to accommodate the new knowledge. Within this environment the most efficient procedure is to have a well-defined goal and a reasonable starting point. This is the approach that will be taken. The macroscopic goal of the second-phase studies is to understand transport physics to the degree required to specify those casting assembly design and/or casting procedure changes needed to force the carbide contaminants to migrate and remain at the top of the billet. These specifications will be the major deliverable of the secondphase studies. The near-term modeling tasks have been designed to accurately quantify fundamental carbide transport mechanisms within the current casting assembly during a complete casting sequence. Specifically, they will confirm the assumption that pouring completely mixes the carbide contaminants, define the effect of pouring on initial temperature distribution within the casting assembly, and characterize carbide transport in the crucible during steady state and in the bookmold during solidification. Once these results are clearly understood, a second set of analyses will be defined and executed which will ultimately produce the design and/or process modifications.

As it concerns the combined P/THERMAL - FLOW-3D studies, there is one final category of information that will have to be defined. To accurately characterize carbide transport it will be necessary to understand solidus-liquidus effects on carbide formation and transport. The most useful tool for defining these effects appears to be a U-C-Hf phase diagram. Thus, it will also be necessary to generate this information as a part of the second-phase studies. 


\section{ACKNOWLEDGMENTS}

The authors are pleased to acknowledge the contributions of A. I. Rose for word processing, C. H. Shappert for technical editing, and R. S. Wallace for computer graphics. The efforts of W. C. Pullen and C. A. Henderson in preparing and conducting the casting experiments are also greatly appreciated. We would also like to thank J. E. Park for his participation in defining the Computational Fluid Dynamics - Heat Conduction iterative solution procedure required for future numerical studies. The peer reviewers for this report were $P$. T. Williams, $K$. W. Childs, and M. Olszewski. The authors are grateful for their constructive comments and suggestions. 


\section{REFERENCES}

1. G. Mackiewicz-Ludtka, W. C. Pullen, C. A. Henderson, W. Chu, and M. W. Wendel, Carbon Reduction in Uranium Alloys Utilizing Hafnium Additions, YDV-980, Martin Marietta Energy Systems, Inc., Oak Ridge Y-12 Plant, August 1990.

2. K. W. Childs, HEATING 7.1 Users Manual, K/CSD/TM-96, Martin Marietta Energy Systems, Inc., Oak Ridge K-25 Site, July 1991.

3. W. Chu and M. W. Wendel, Oak Ridge K-25 Site, letter to G. Mackiewicz-Ludtka, Summary of $U_{\sigma} N b$ Solidification Model Results, Oak Ridge Y-12 Plant, December 15, 1989.

4. M. W. Wendel, Oak Ridge K-25 Site, letter to G. Mackiewicz-Ludtka, Update of Uranium Alloy Solidification-in-a-book-mold Analysis, Oak Ridge Y-12 Plant, May 31, 1990.

5. Handbook of Tables for Applied Engineering Science, Table 1-113, p. 180.

6. Y. S. Touloukian, R. W. Powell, Y. C. Ho, and P. G. Klemens, Thermophysical Properties of Matter, Vol. 1, Thermal Conductivity Metallic Element and Alloys, IFI/Plenum, New York, 1970.

7. Y. S. Touloukian, R. W. Powell, Y. C. Ho, and P. G. Klemens, Thermophysical Properties of Matter, Vol. 2, Thermal Conductivity Non-Metallic Solids, IFI/Plenum, New York, 1970.

8. Y. S. Touloukian and E. H. Buyco, Thermophysical Properties of Matter, Vol. 4, Specific Heat Metallic Elements and Alloys, IFI/Plenum, New York, 1970.

9. Y. S. Touloukian and E. H. Buyco, Thermophysical Properties of Matter, Vol. 5, Specific Heat Non-Metallic Solids, IFI/Plenum, New York, 1970.

10. J. P. Holman, Heat Transfer, Fifth Edition, McGraw-Hill, New York, 1981.

11. G. H. Llewellyn, G. A. Aramayo, M. Siman-Tov, K. W. Childs, and G. M. Ludtka, Computer Simulation of Immersion Quenching of Uranium - 0.75 wt Titanium Alloy Cylinders, Y-2355, Martin Marietta Energy Systems, Inc., Oak Ridge Y-12 Plant, June 1986.

12. R. N. Mulford and R. I. Sheldon, "Density and Heat Capacity of Liquid Uranium at High Temperatures," J. Nucl. Mater., 154, 268-275 (1988).

13. C. T. Ewing, B. E. Walker, J. A. Grand, and R. R. Miller, "Thermal Conductivity of Metals," Chem. Eng. Progr. Symp. Ser., 20, (53) 19-24, (1957).

14. Metals Reference Handbook, fifth ed., Butterworths, 1976.

15. D. Ofte, "The Viscosities of Liquid Uranium, Gold, and Lead, J. Nucl. Mater. 22, 28-32 (1967). 


\section{REFERENCES (continued)}

16. A. F. Grens and A. P. Levitt, "The Spectral Emissivity and Total Normal Emissivity of Commercial Graphites at Elevated Temperatures," Proceedings of the 5th Annual Conference on Carbon, Vol. 2, pp. 639-646, 1963.

17. P. Moore, unpublished communication to P. T. Williams, Emissivity of Liquid Uranium, Oak Ridge Y-12 Plant, February 16, 1983.

18. Y. S. Touloukian and D. P. DeWitt, Thermophysical Properties of Matter, Vol. 7, Thermal Radiative Properties Metallic Elements and Alloys, IFI/Plenum, New York, 1972.

19. Y. S. Touloukian and D. P. DeWitt, Thermophysical Properties of Matter, Vol. 8, Thermal Radiative Properties Non-Metallic Solids, IFI/Plenum, New York, 1972.

20. A. D. Rollett and H. D. Lewis, "Casting Simulation in Vacuum Induction Melting," Trans. Am. Foundrymen's Society, 94, 349-372 (1986).

21. K. J. Jackson, Vacuum-Induction Melting, aning, and Casting of Uranium and itloys, RFP-4186 UC-704 MATERIALS DOE/C 51 1- 500 (Interim 3), Rockwell International, Aerospace Operations, Rocky Flats Plant, Goiden, Col., October 1989.

22. J. D. Lavers and P. P. Biringer, "An Improved Method of Calculating the Power Generated in an Inductively Heated Load," Conference Record of 1971 Tenth Biennial IEEE Conference on Electric Process Heating in Industry, pp. 44-50, April 1971.

23. N. W. McLachlan, Bessel Functions for Engineers, 2nd Edition, Clarendon Press, Oxford, 1955.

24. E. May, Industrial High Frequency Electric Power, John Wiley and Sons, New York, 1950.

25. R. P. Tye, ed. Thermal Conductivity, Volume 2, Academic Press, New York, 1969.

26. P. Hunley, Oak Ridge Y-12 Plant, personal communications to M. J. Taylor, Oak Ridge K-25 Site, 1991.

27. G. Mackiewicz-Ludtka and M. J. Taylor, Utilizing Analytic Modeling to Optimize Carbon Reduction During Casting of Uranium, Y/DV-1108, Martin Marietta Energy Systems, Inc., Oak Ridge Y-1? Plant, September 1991.

28. M. J. Taylor, Oak Ridge K-25 Site, letter to G. M. Ludtka, Proposed Thermocouple Locations for the U-Nb Bookmold Assembly, Oak Ridge Y-12 Plant, October 19, 1990.

29. T. N. Vezirogula, "Correlation of Thermal Contact Conductance Experimental Results," Prog. Astron. Aero, 20, Academic Press, New York (1967). 


\section{REFERENCES (continued)}

30. B. P. Winter et al., "Volumetric Shrinkage and Gap Formation During Solidification of Copper-Base Alloys," Trans. Am. Foundrymen's Societ 91, 81-88 (1983).

31. C. Y. Ho and R. D. Pehlke, "Transient Methods for Determiniation of Metal-Mold Interfacial Heat Transfer." Trans. Am. Foundrymen's Society, 91, 689-698 (1983). 


\section{APPENDIX A}

PROGRAM LISTINGS:

HEATING 7.1 BASE-CASE STEADY-STATE AND TRANSIENT INPUT FILES AND USER-SUPPLIED SUBROUTINES 


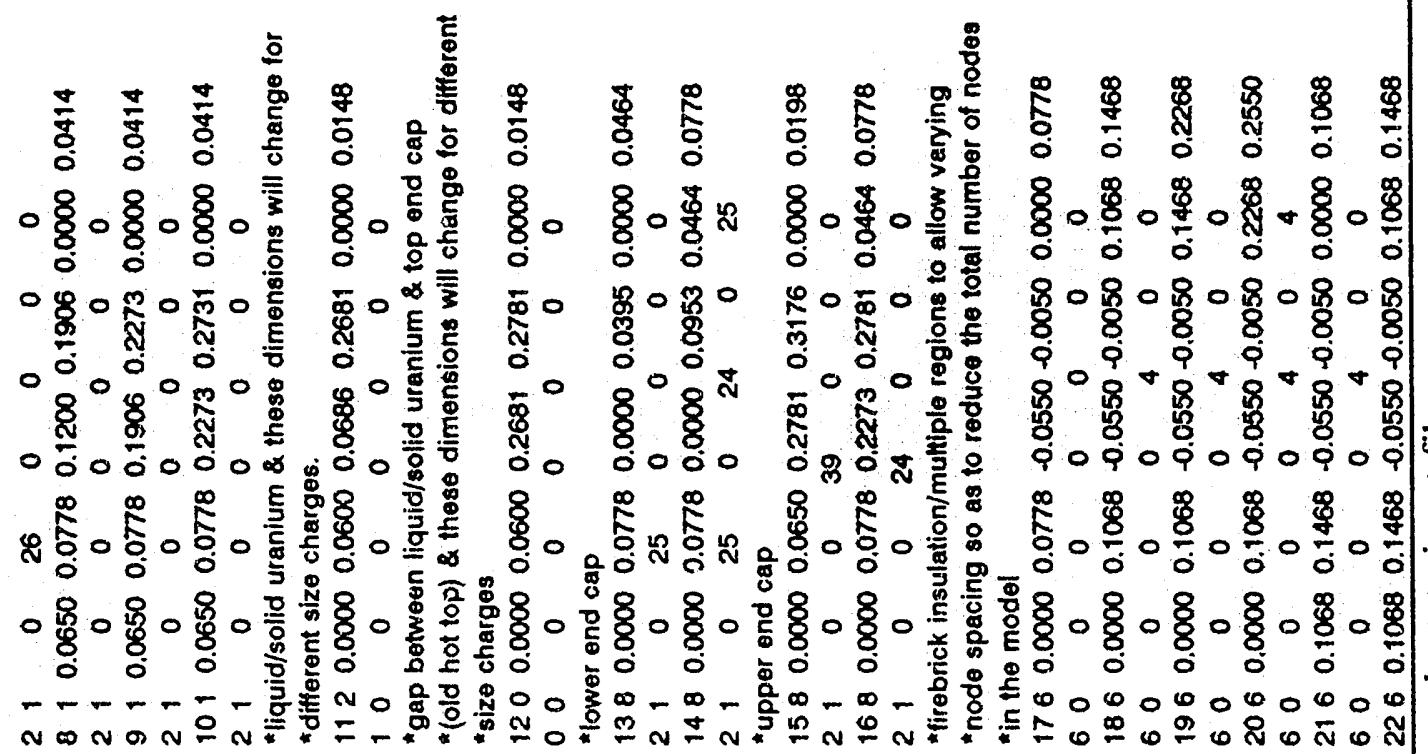
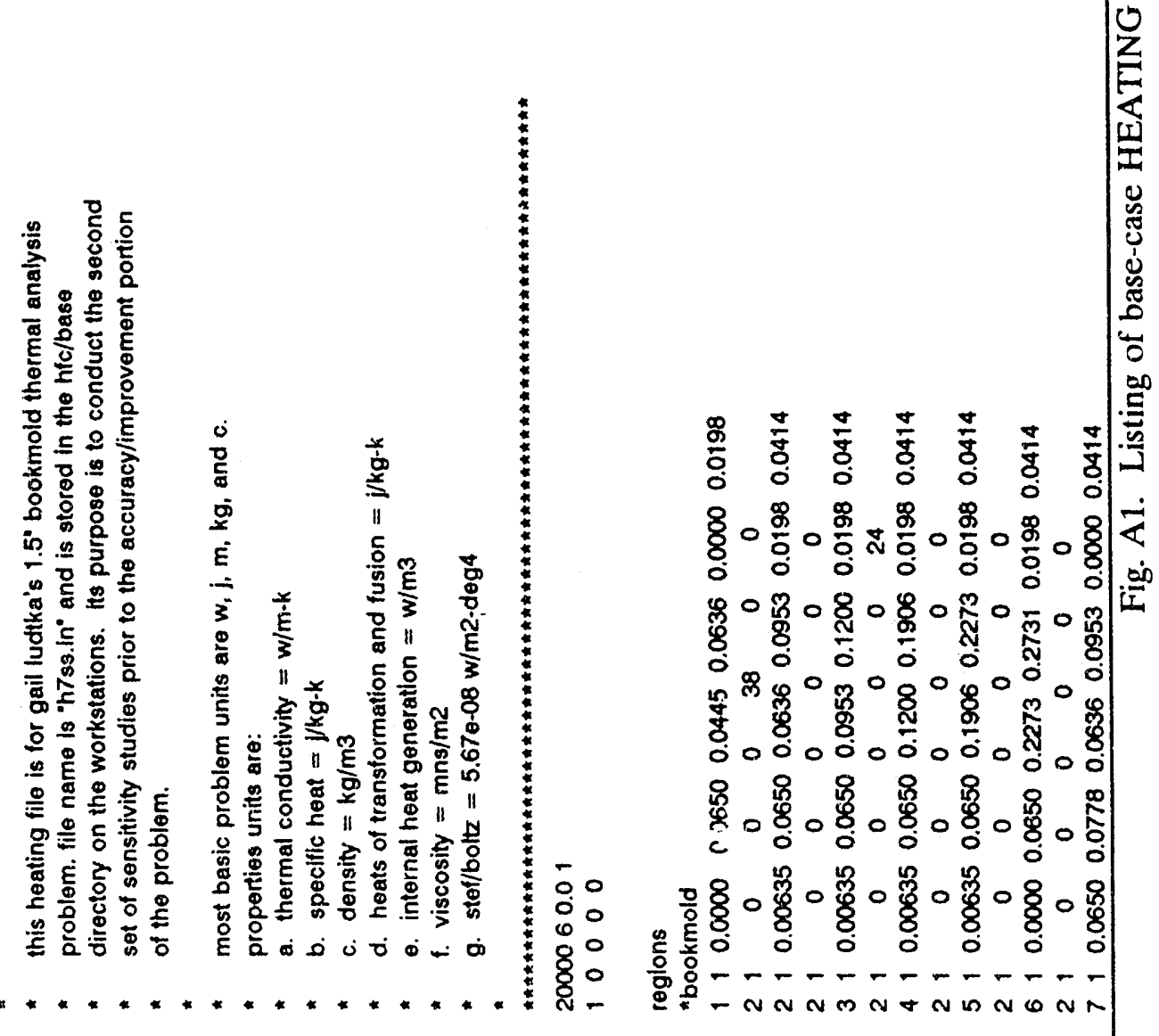


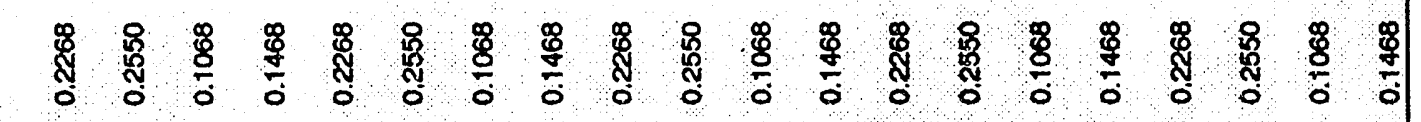

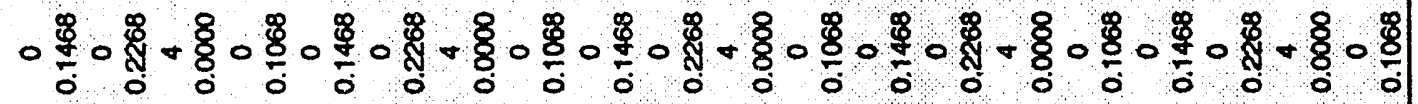

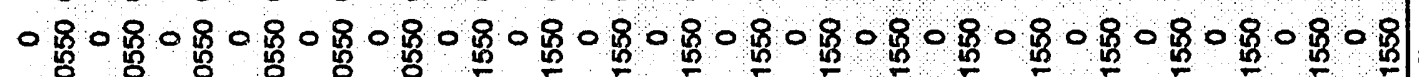

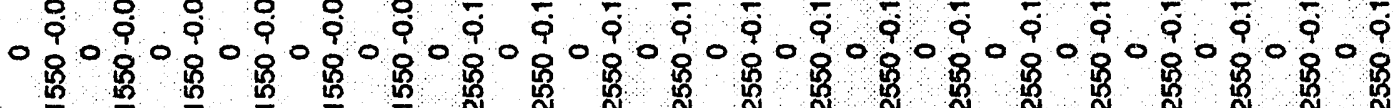
-

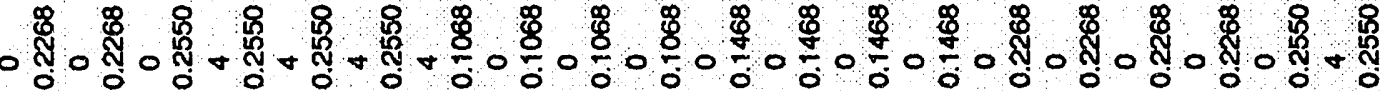
०

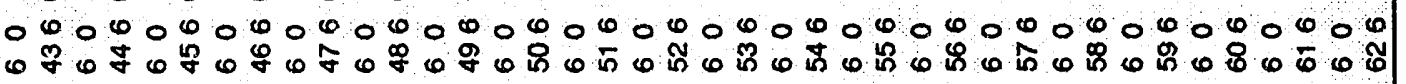

疍

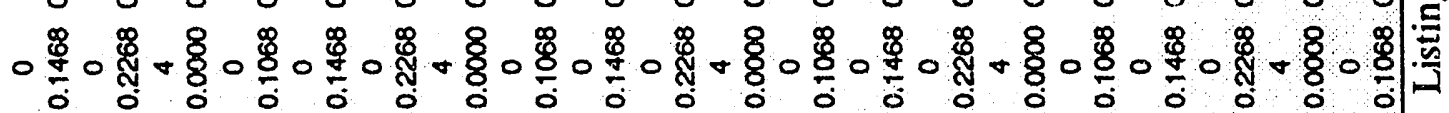

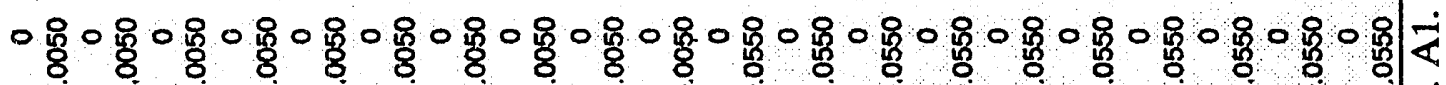

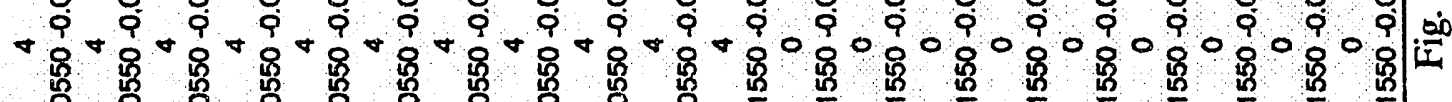

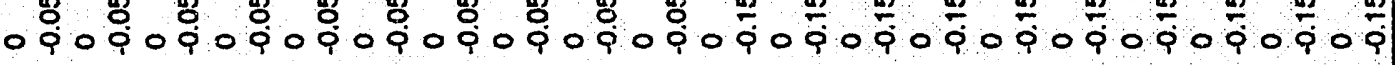

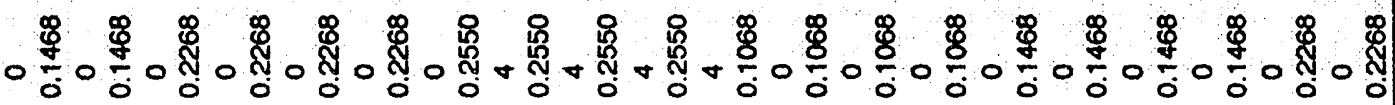

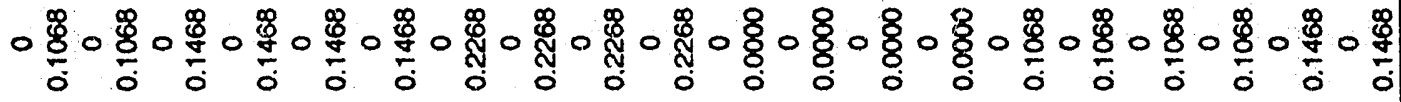
00060000000000010000000000000000000000000

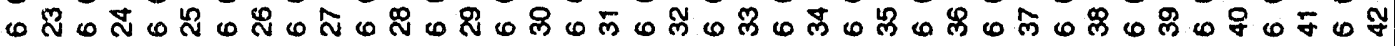




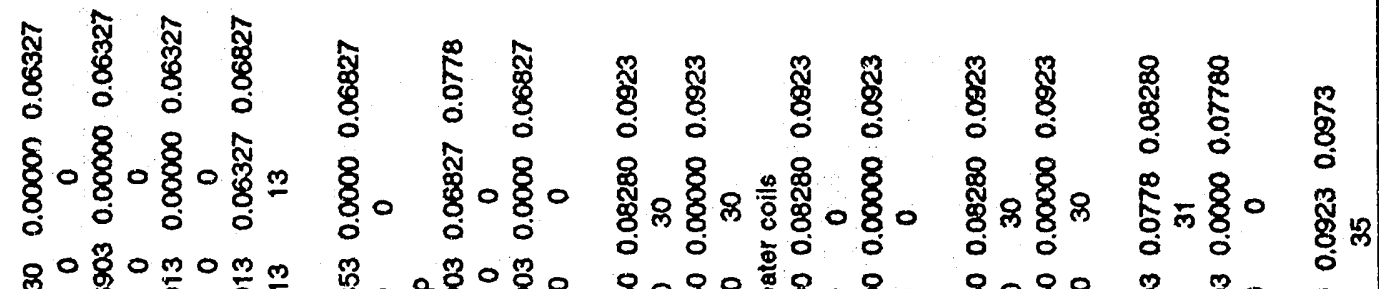

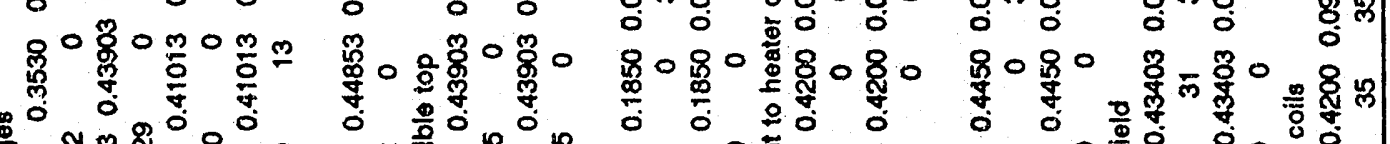

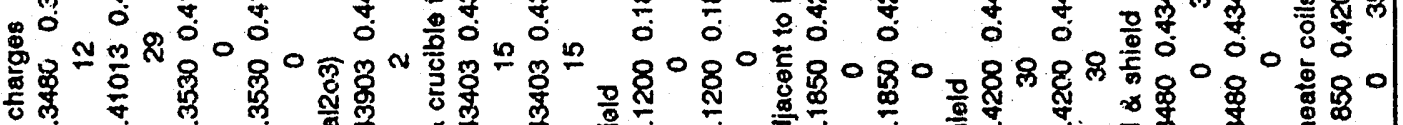

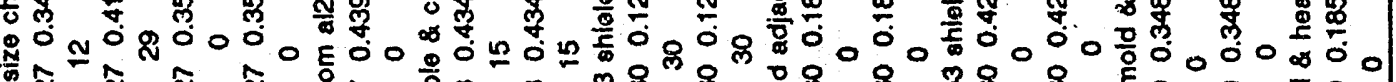

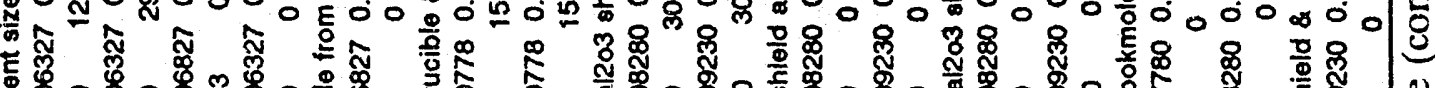

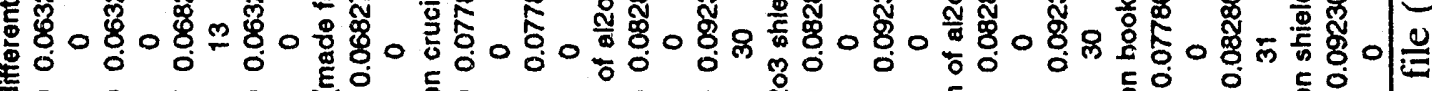
客

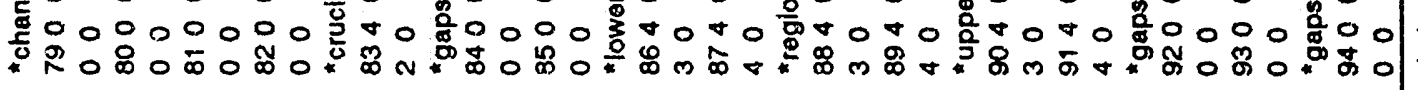

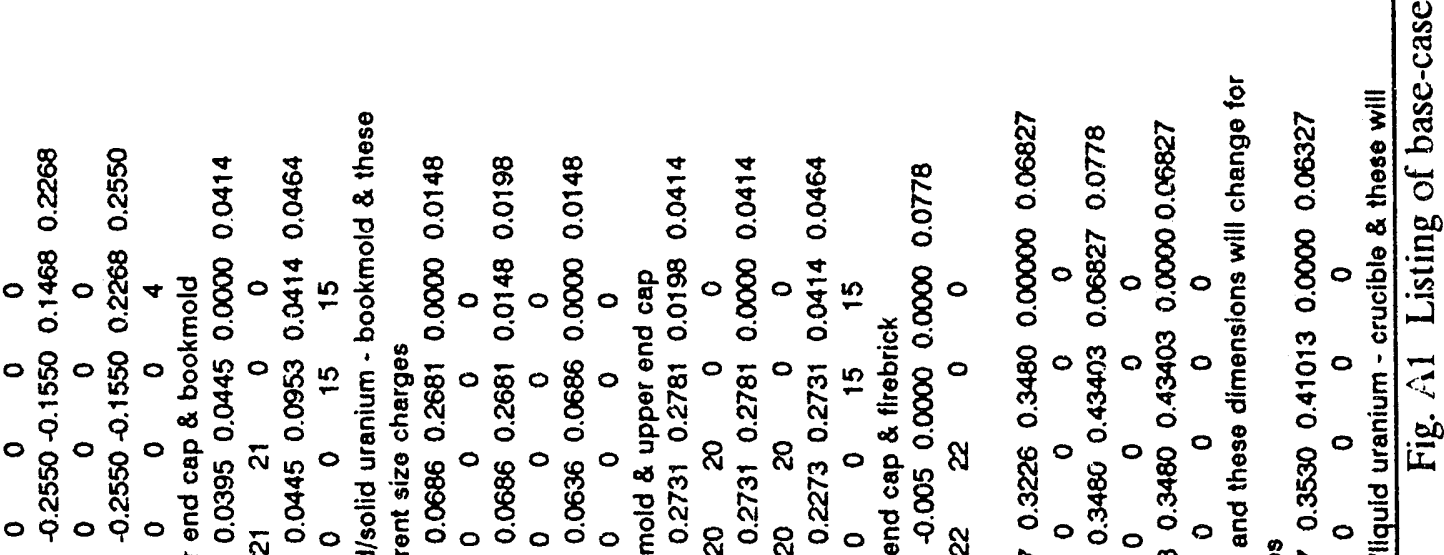

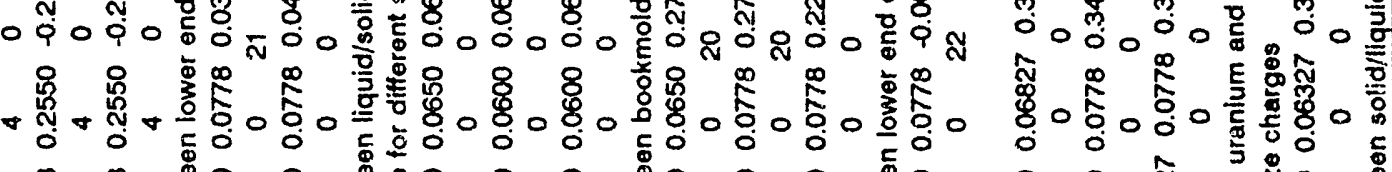

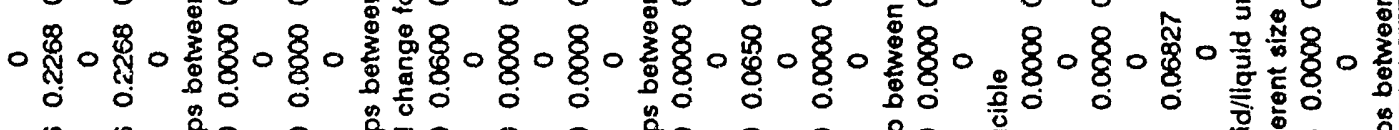

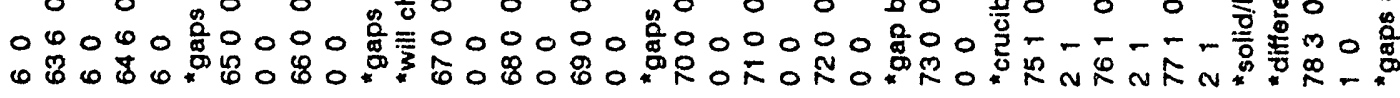




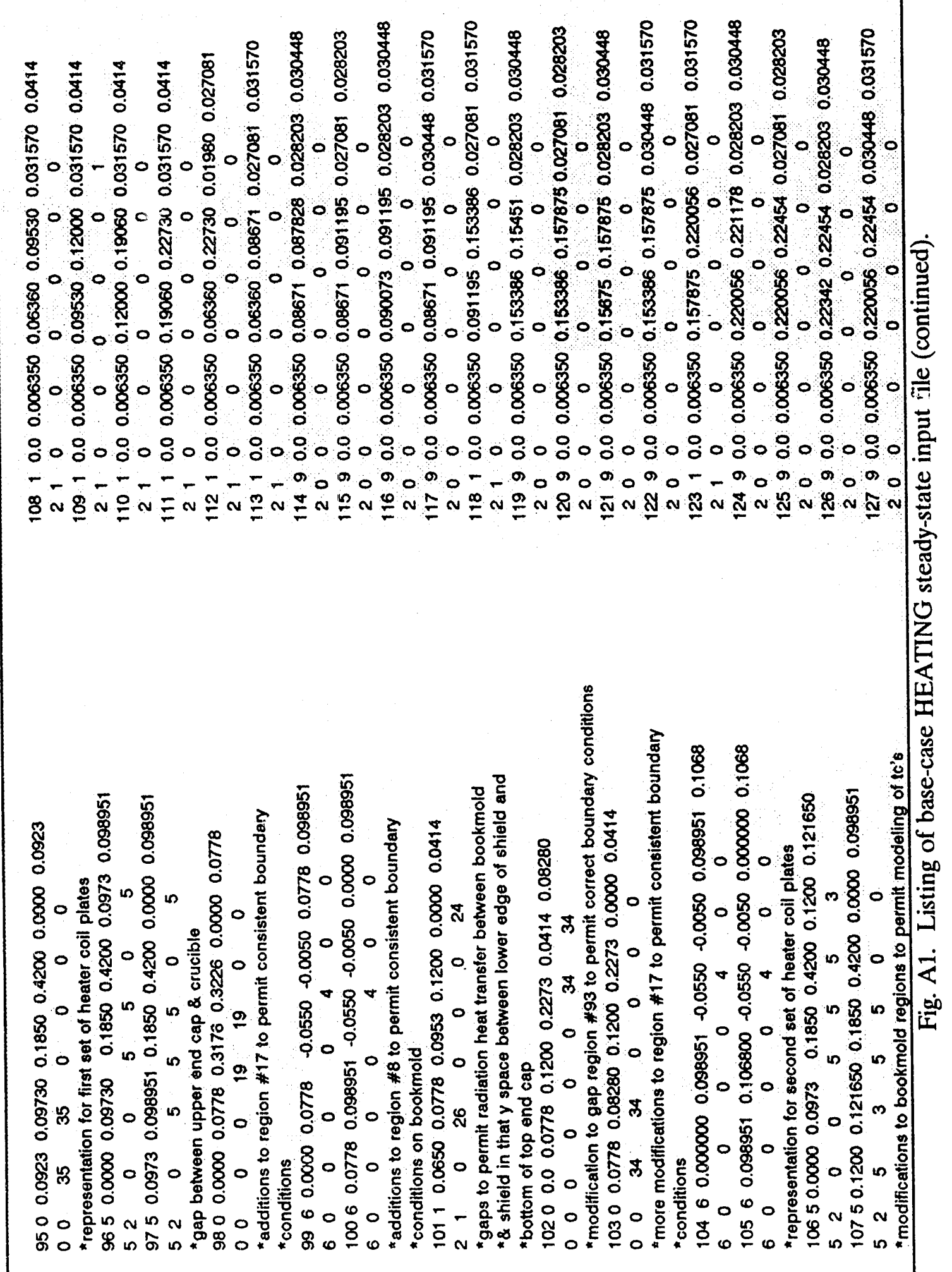




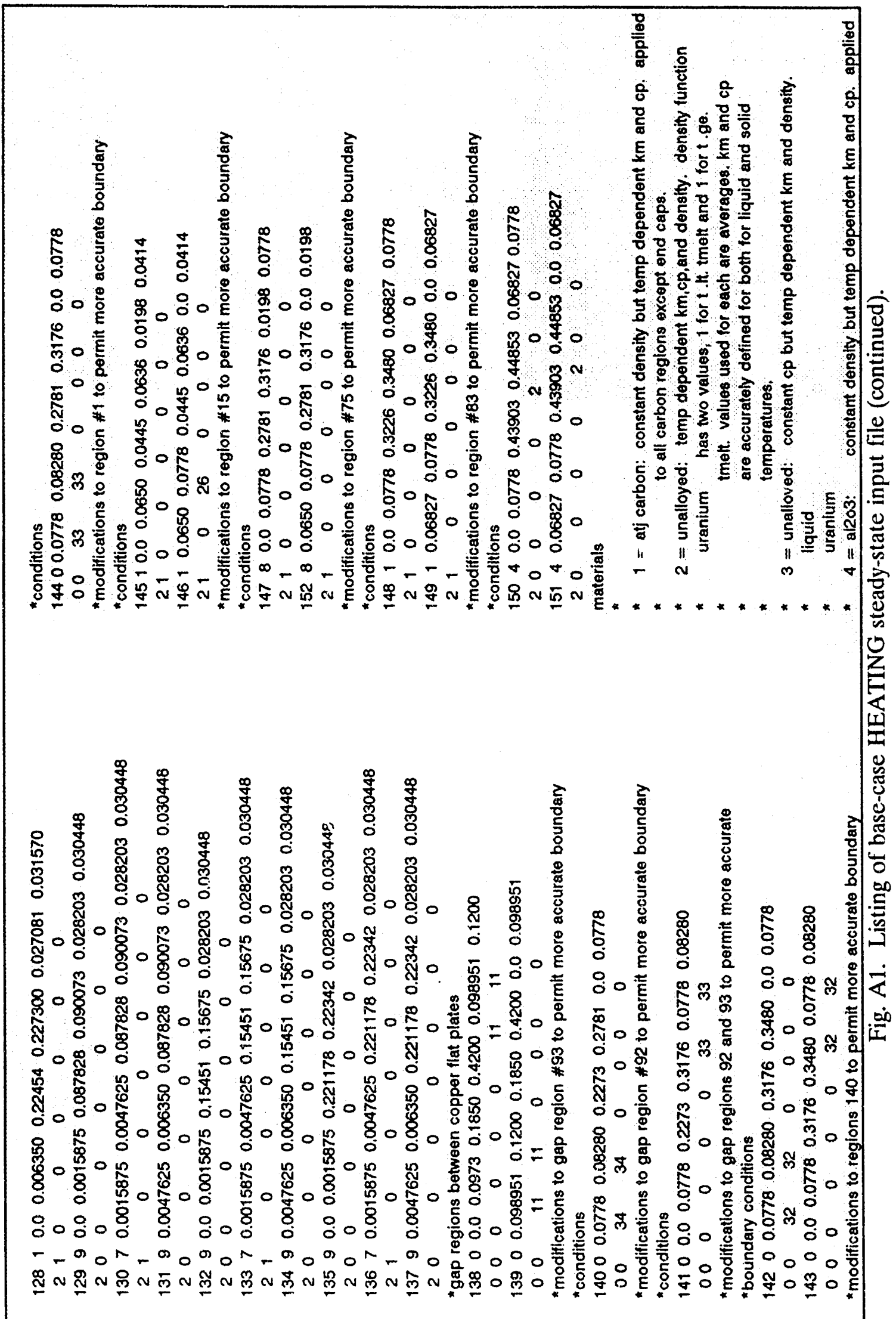




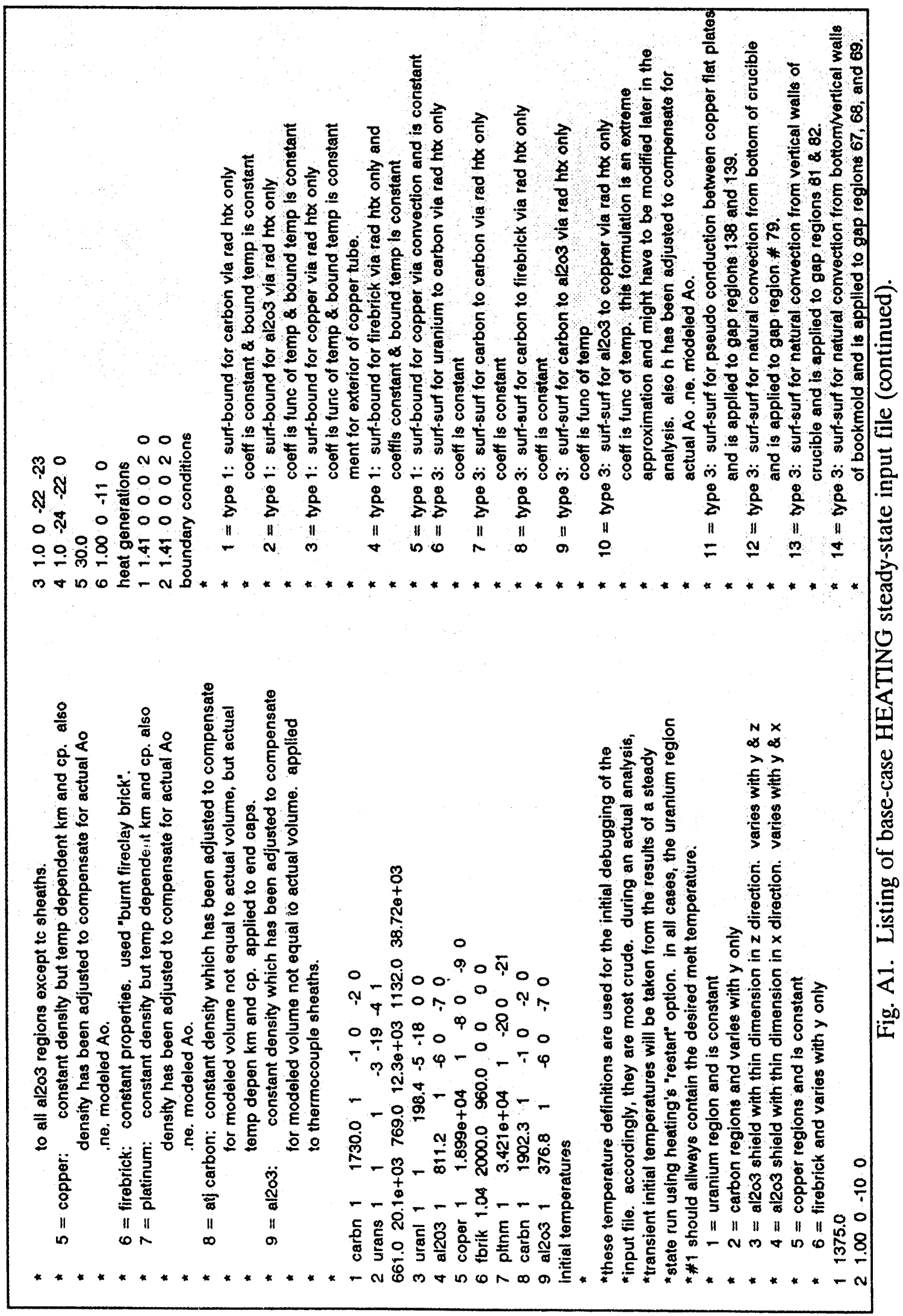




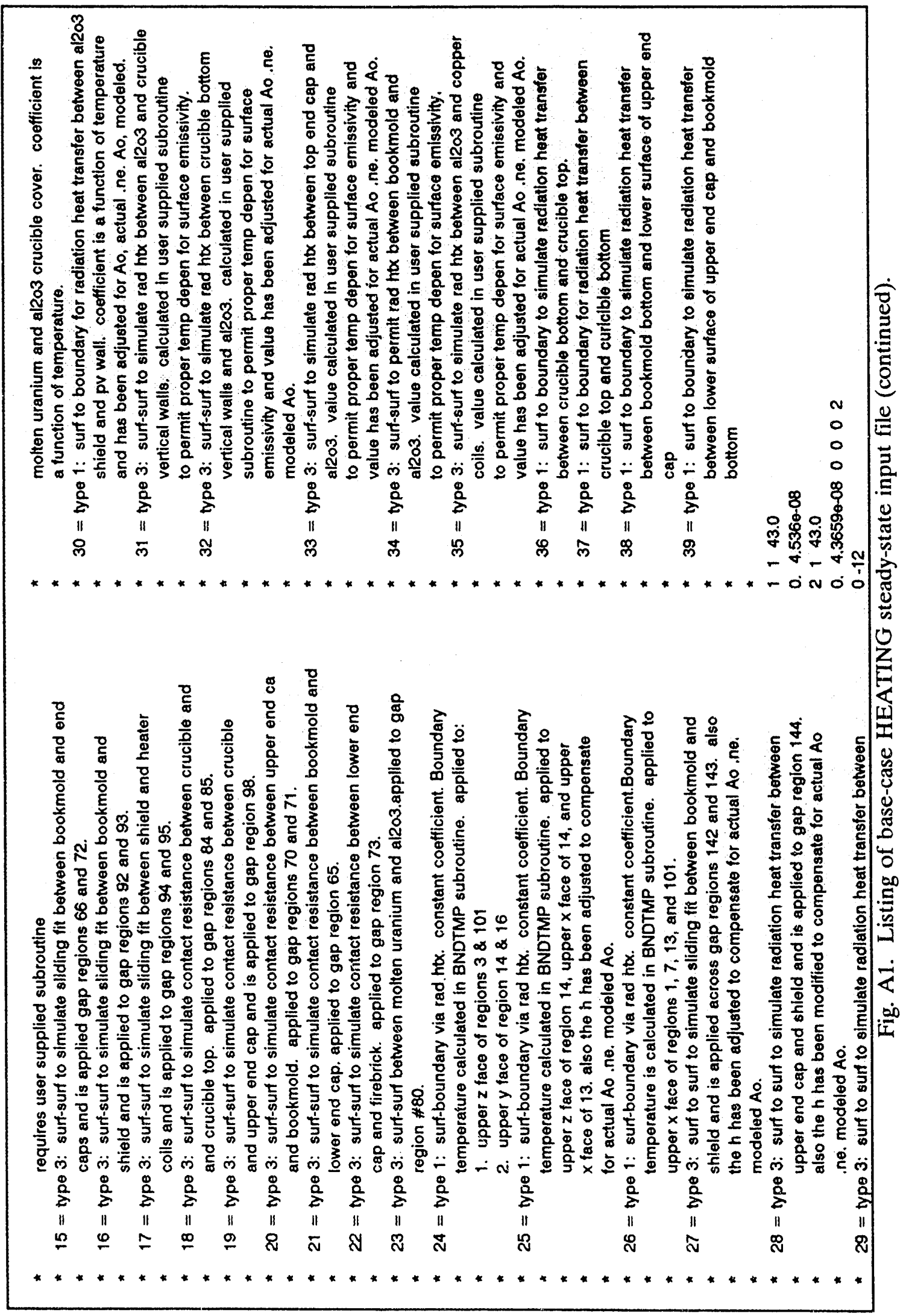




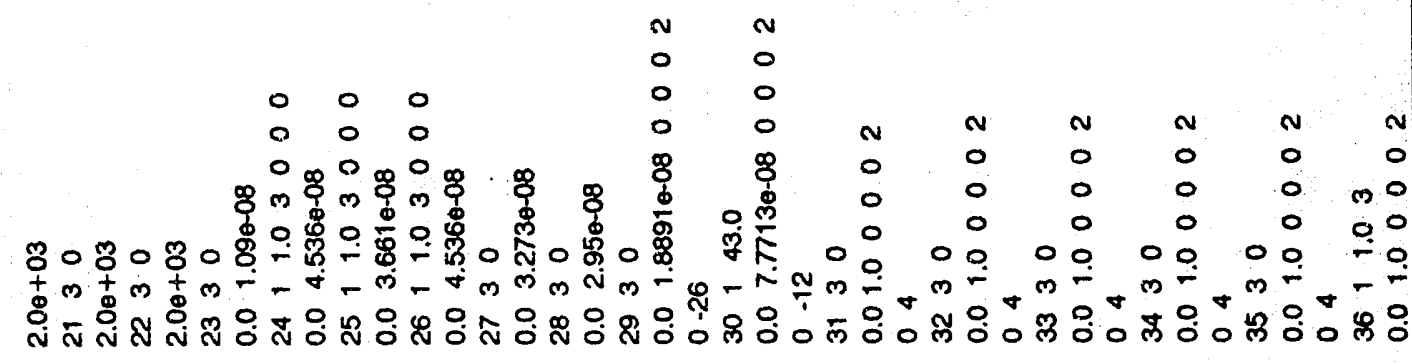

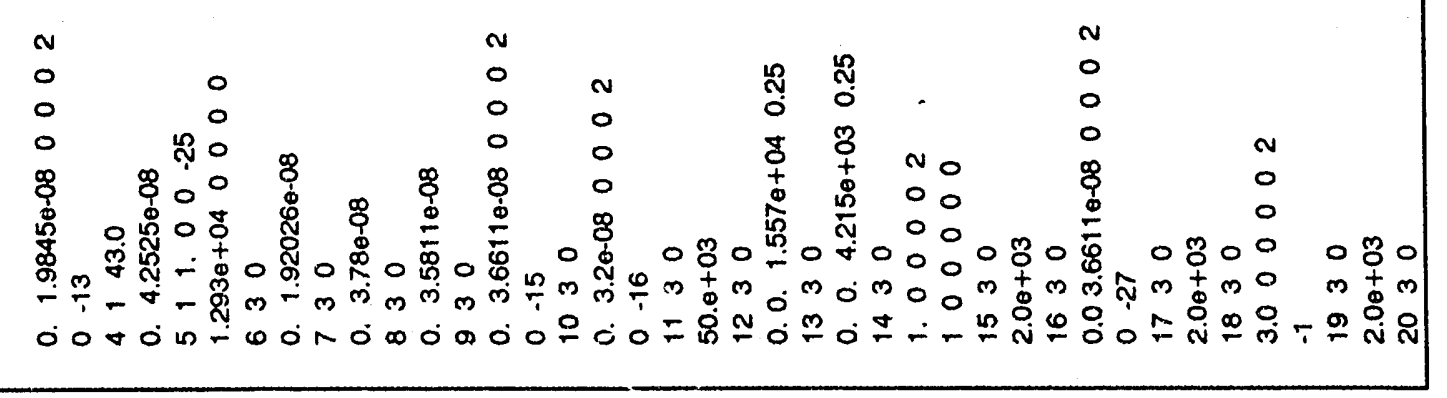




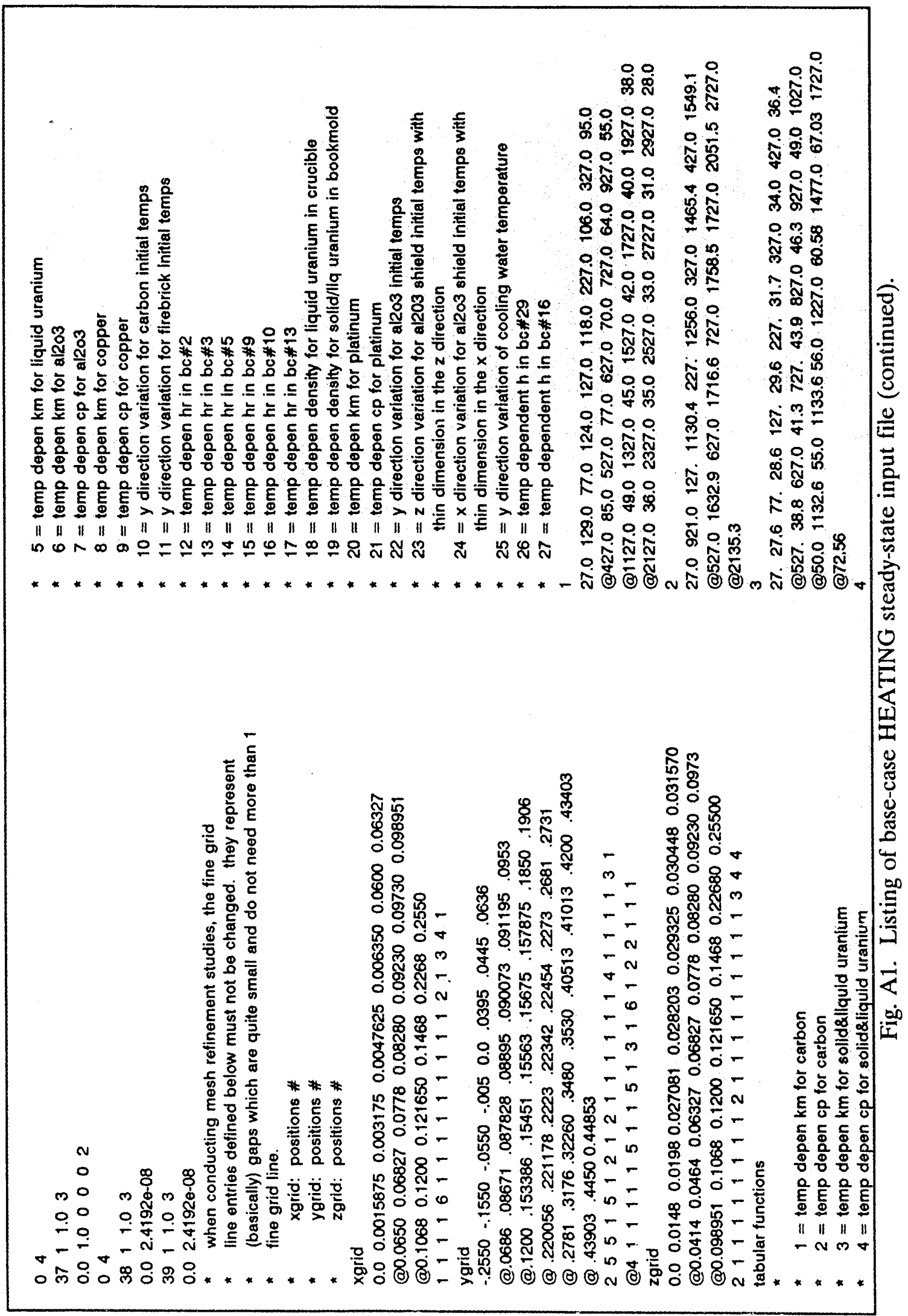




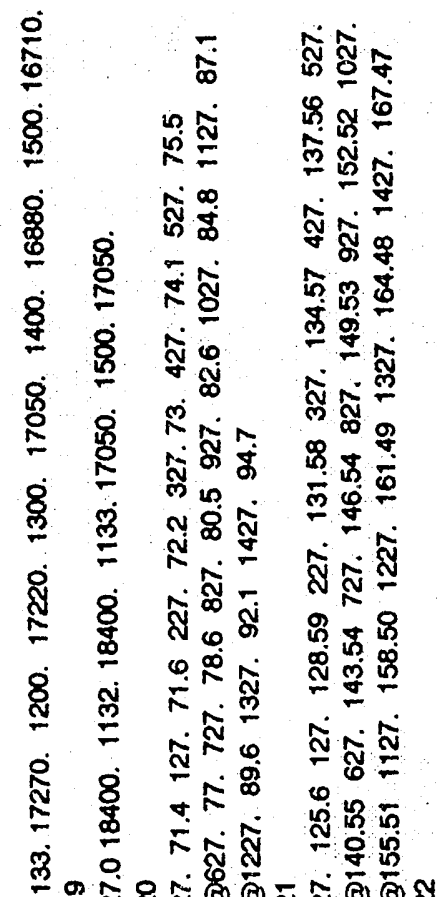

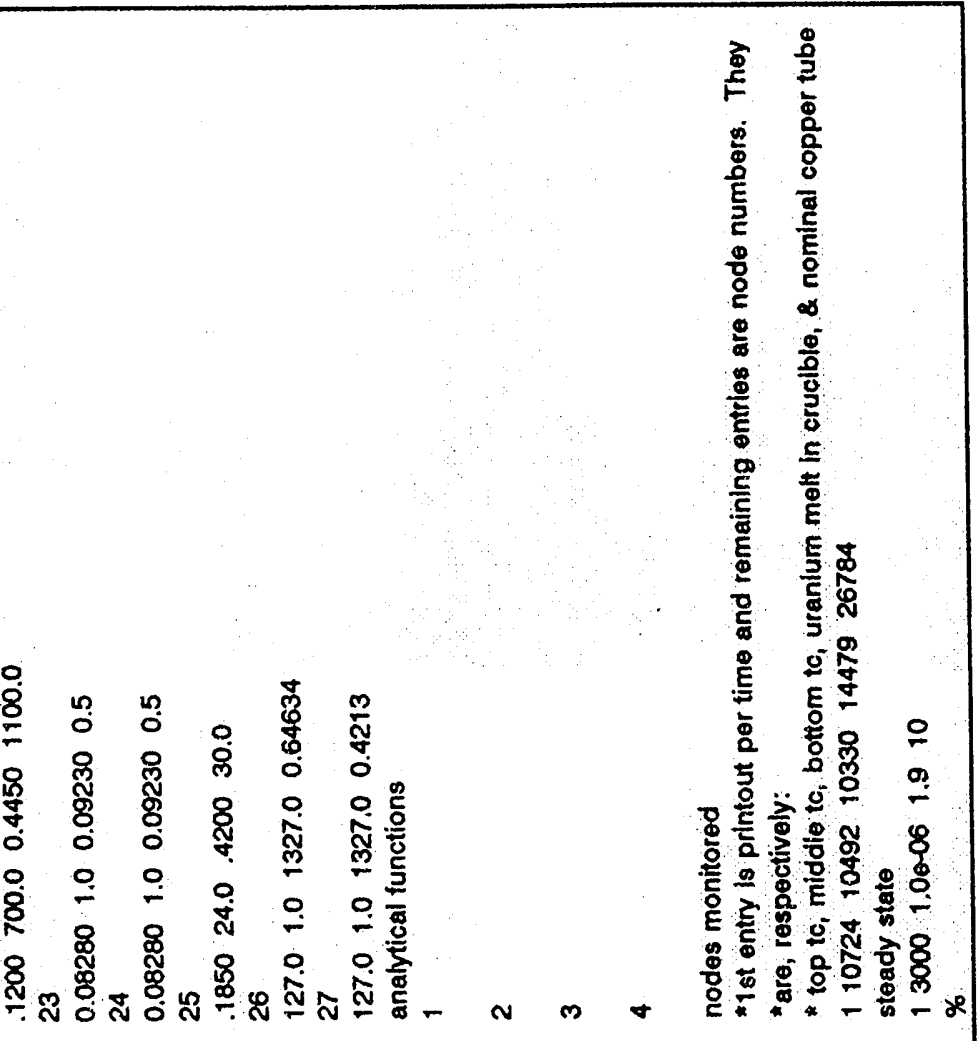

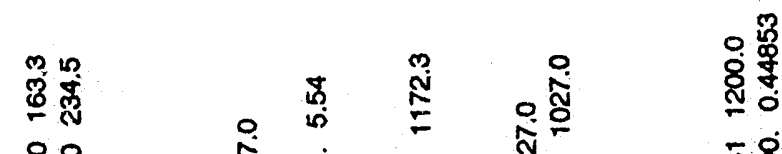

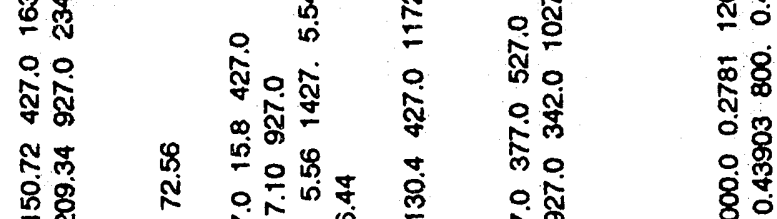

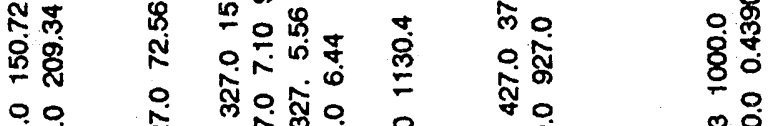

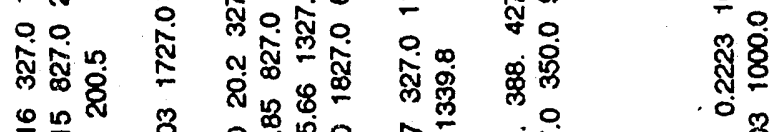

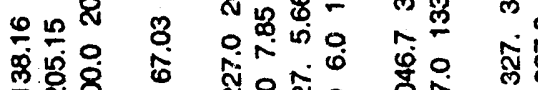

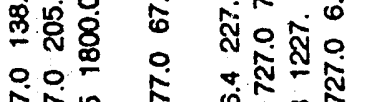

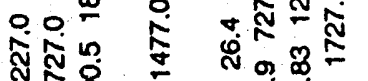

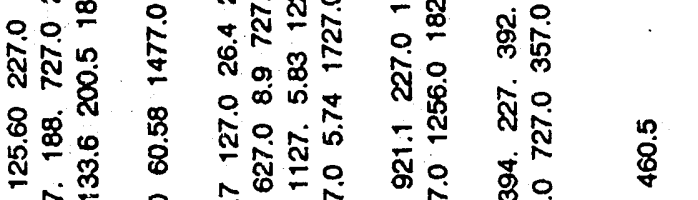

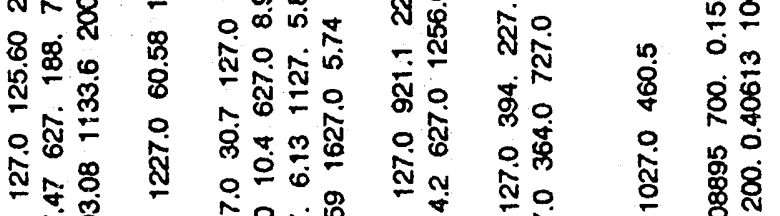

芯灾

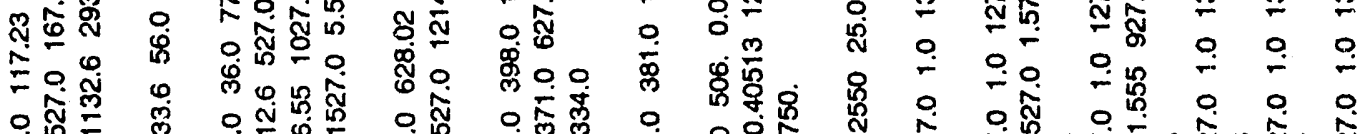

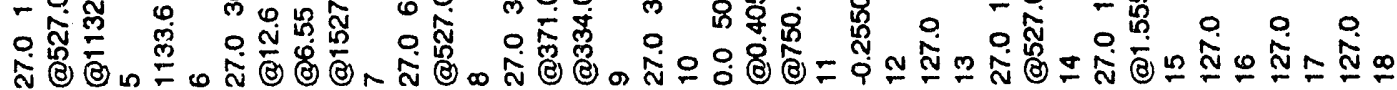




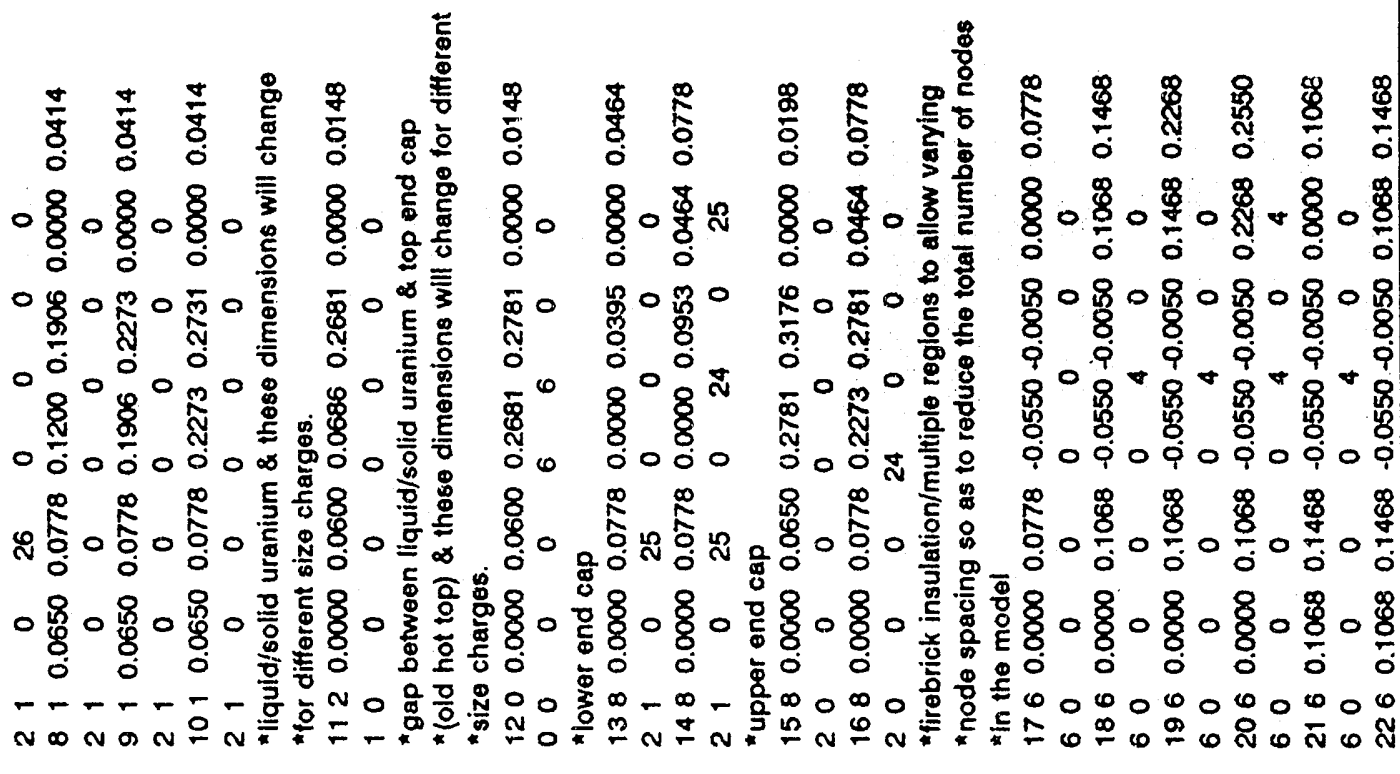

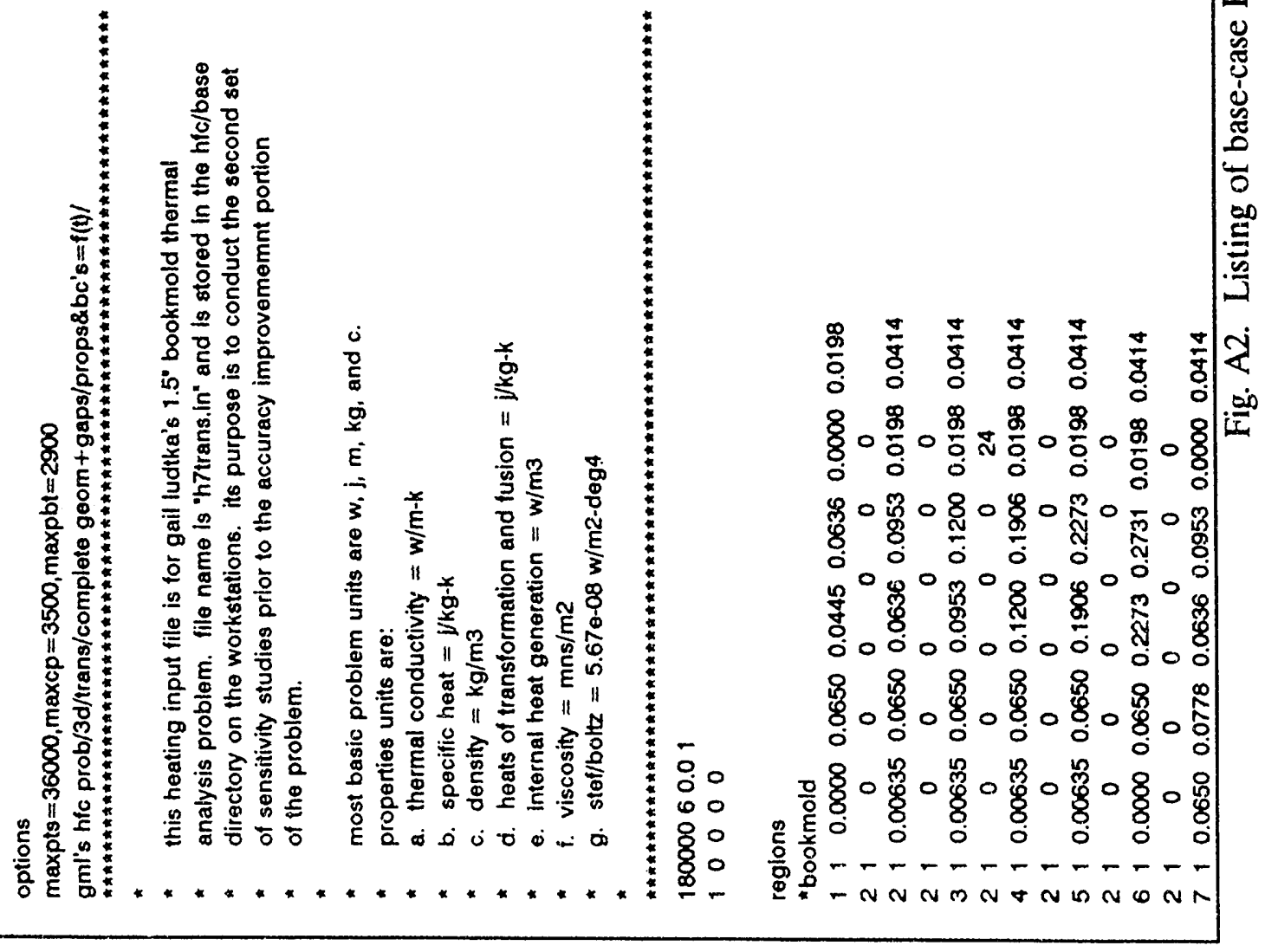


趂 总

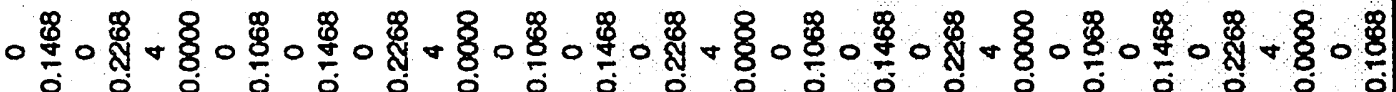

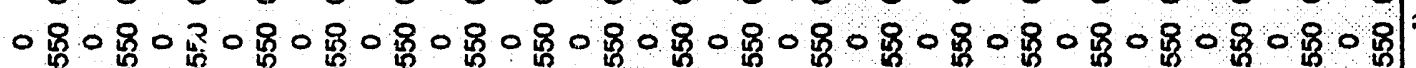

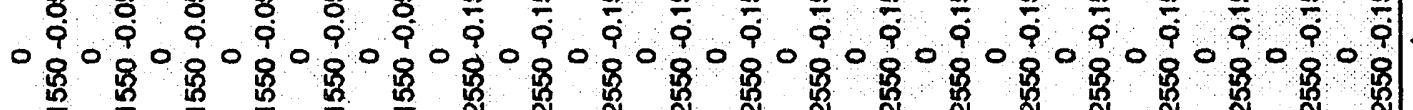
○

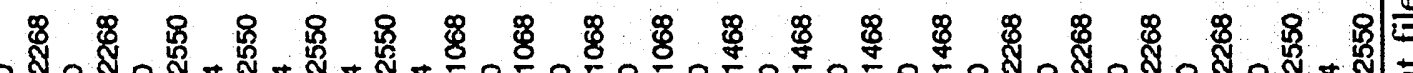

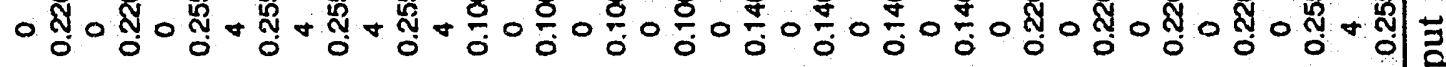

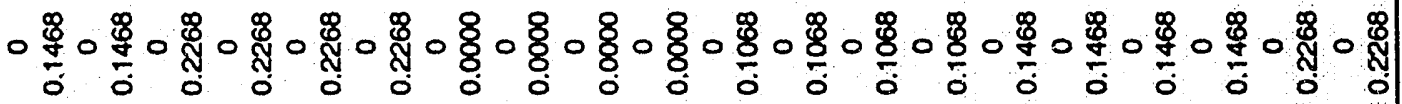
0000000000000000000000000000000000000000

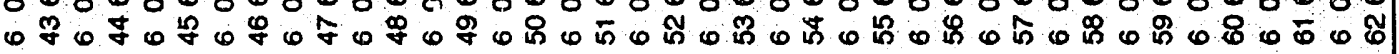
每

芯 员

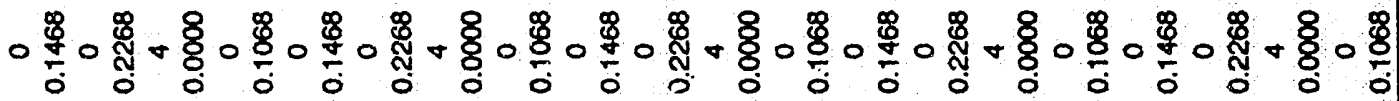

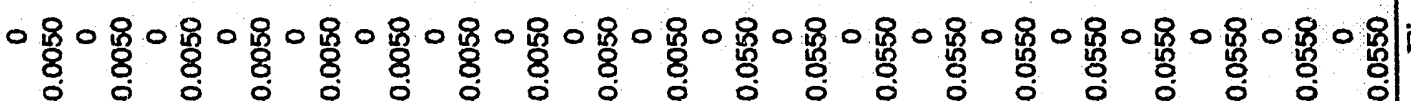

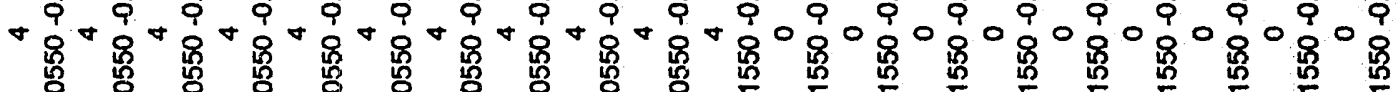

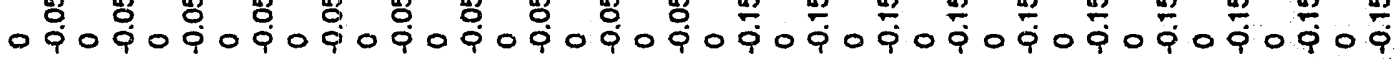

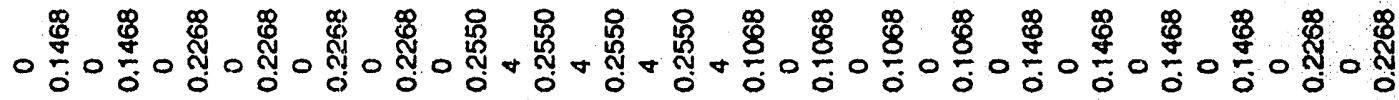

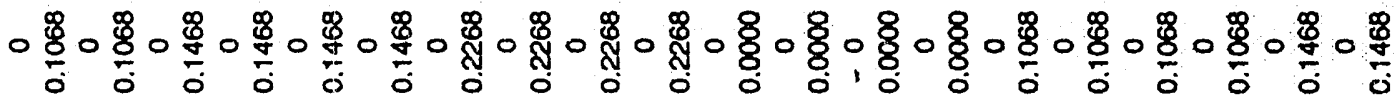
0000000000000000000000000000000000000000

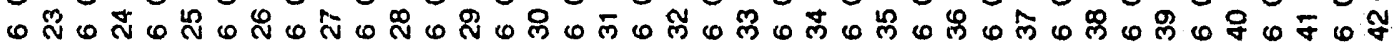




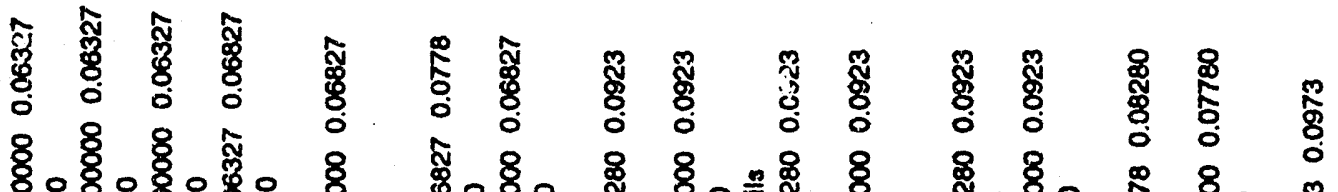

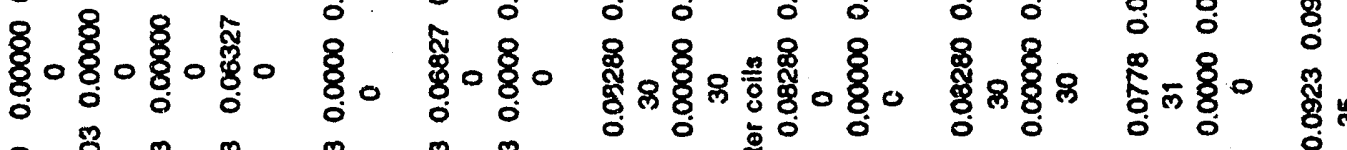

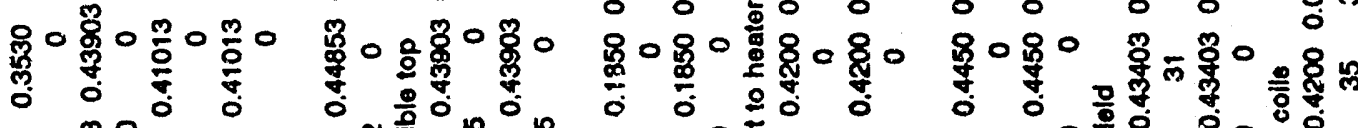

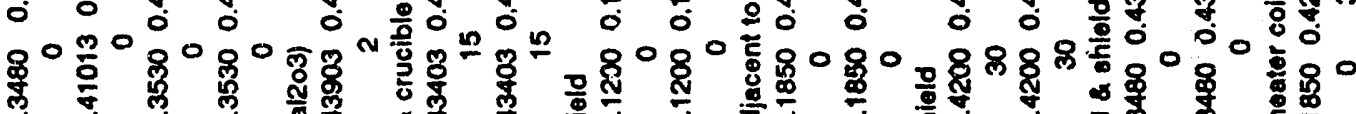

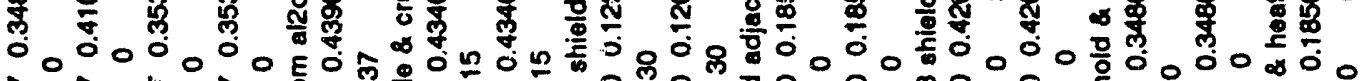

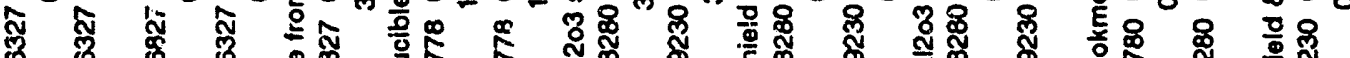

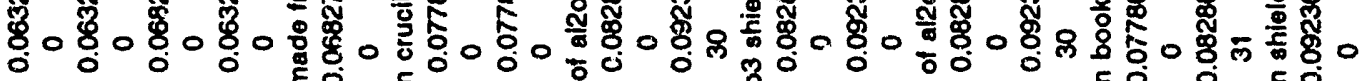
条 ०

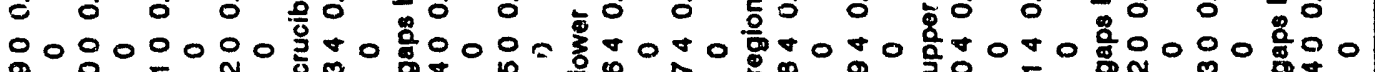

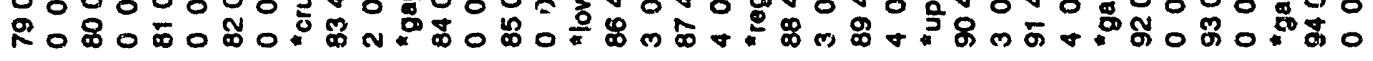

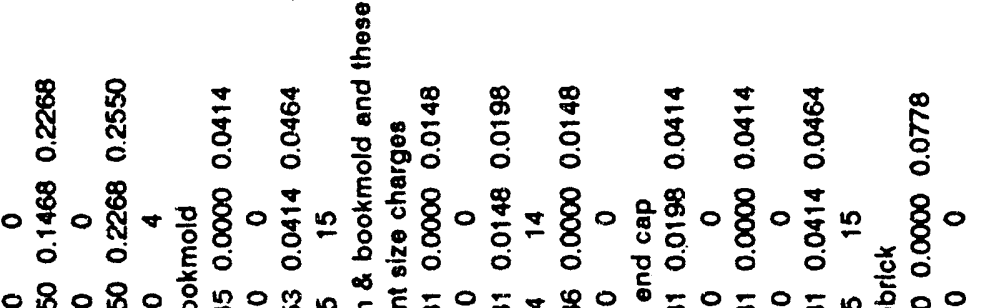

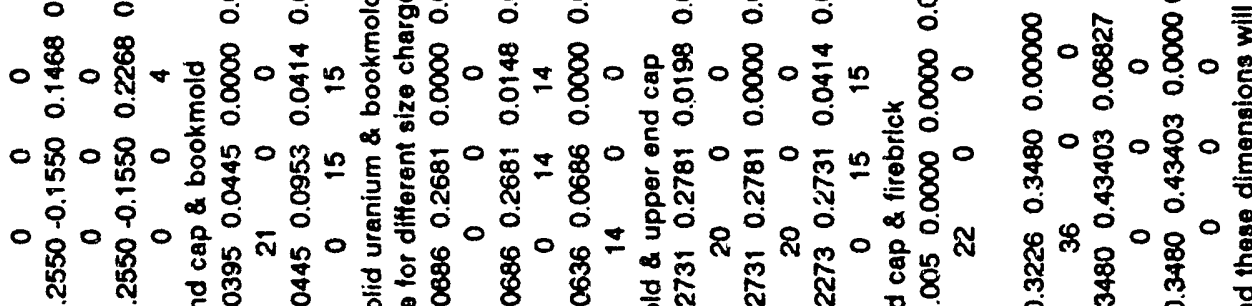

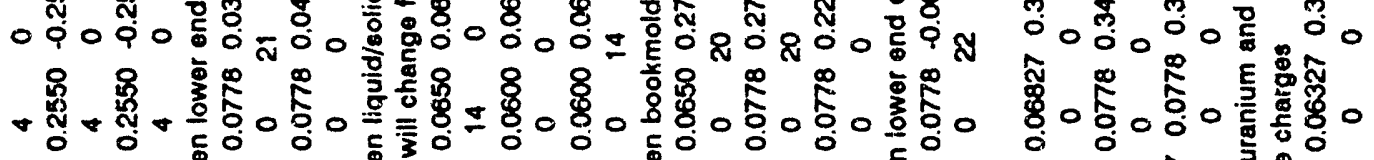

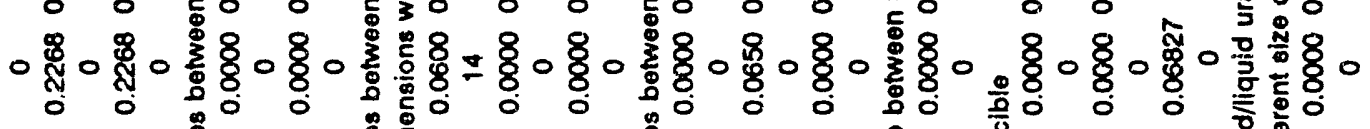

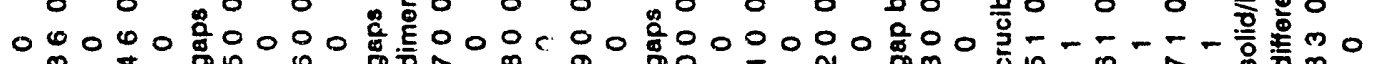
 


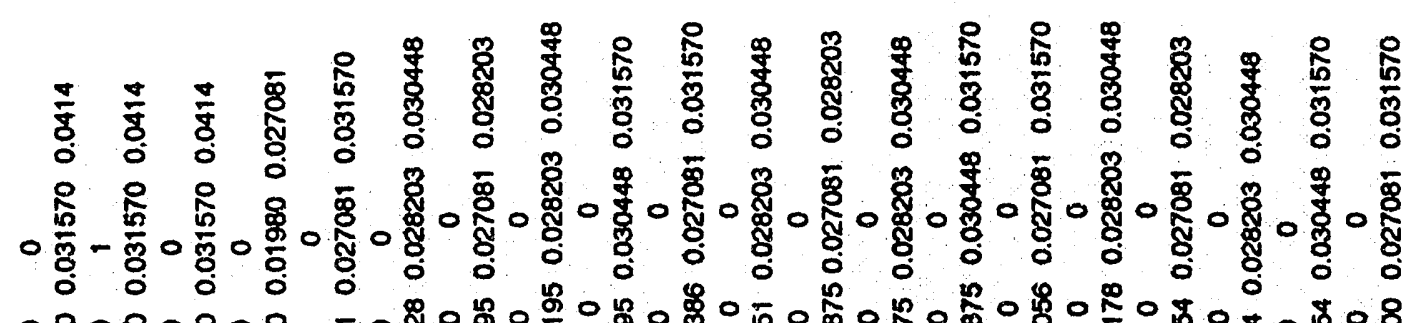

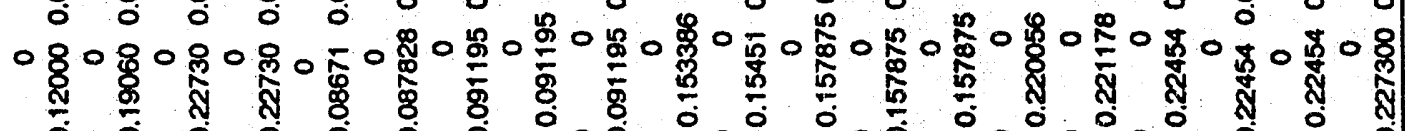

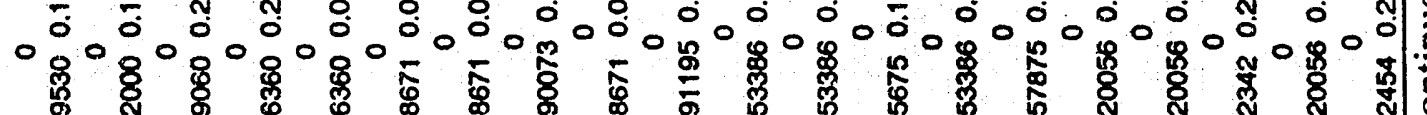

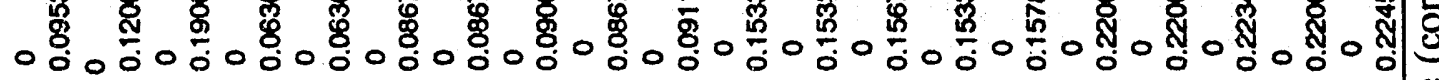

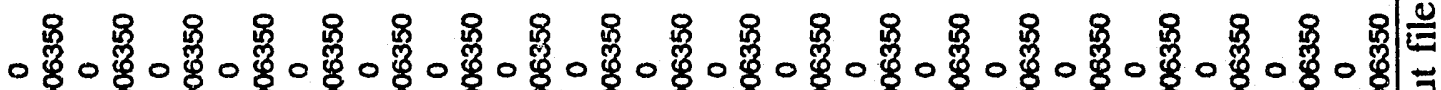

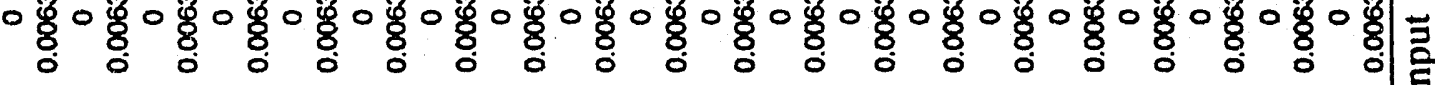

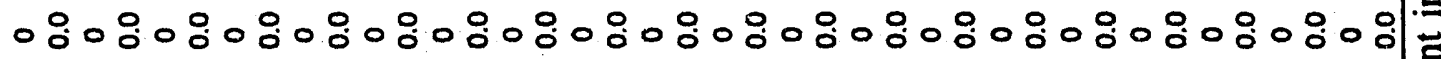

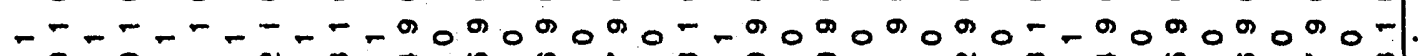
N

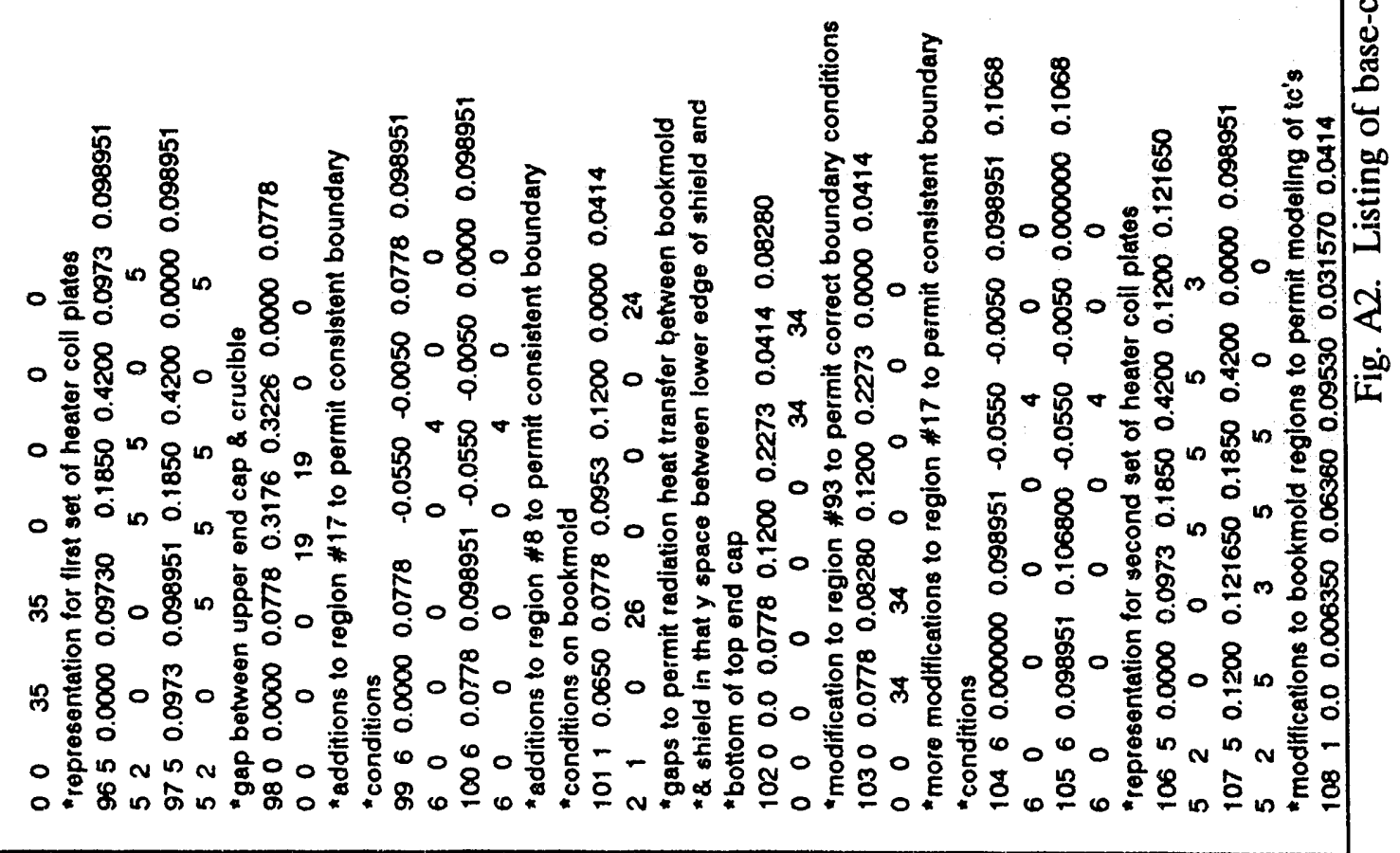




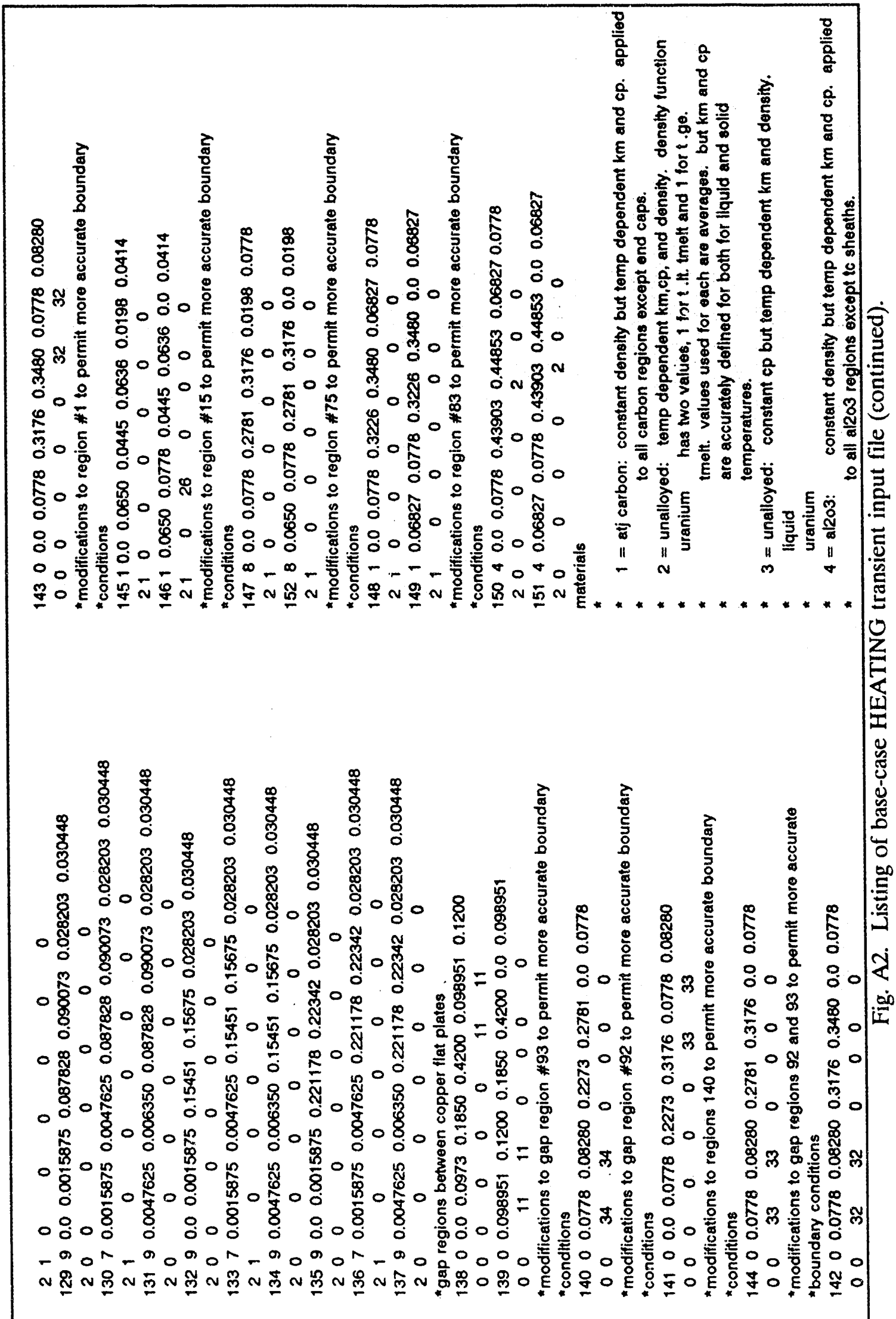




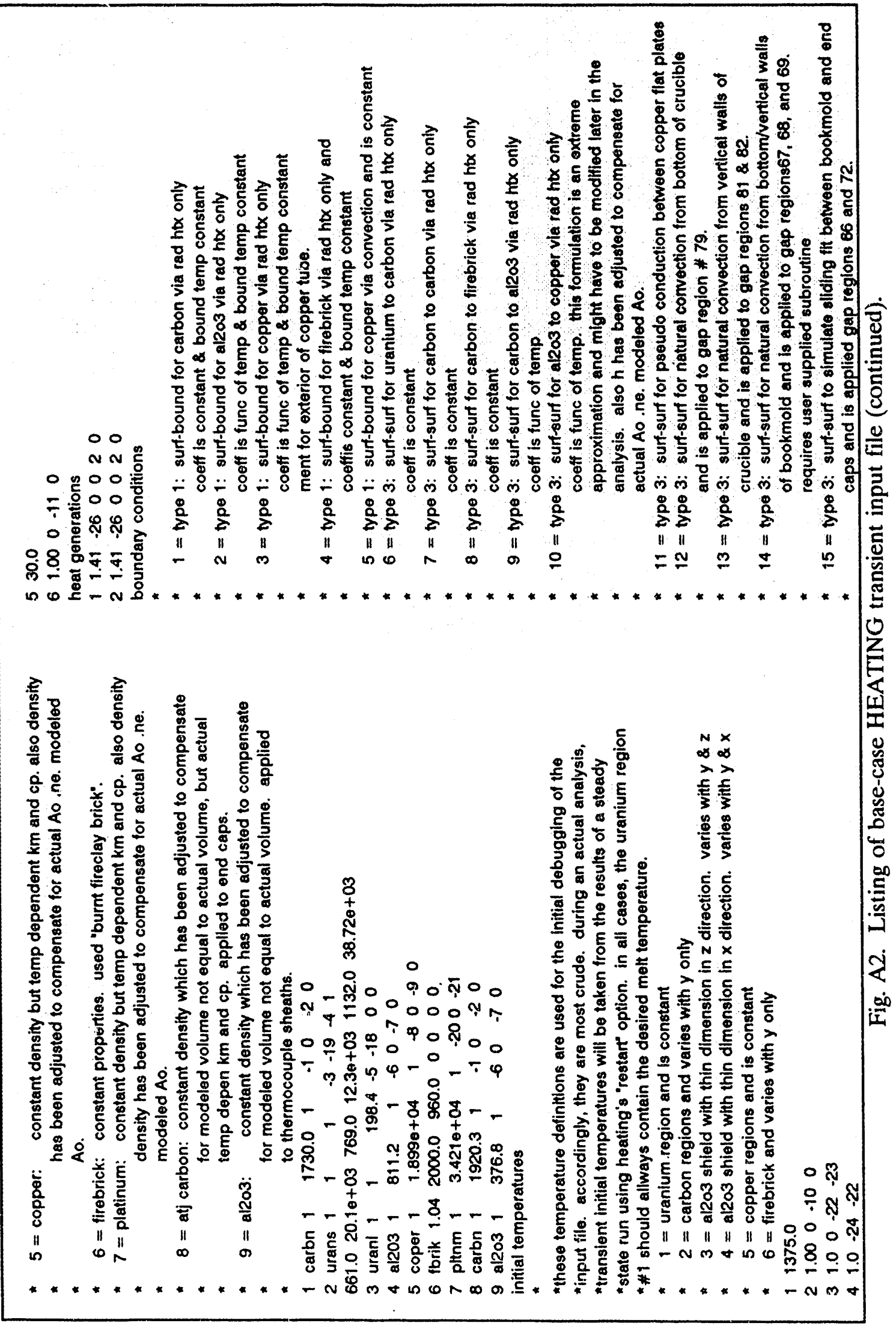




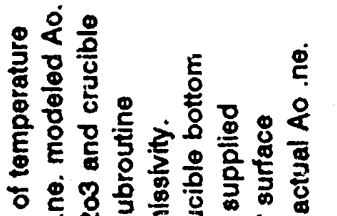

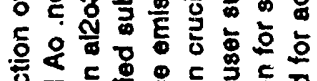

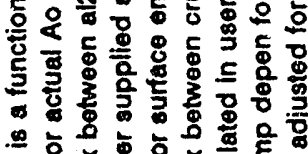

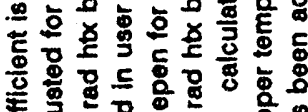

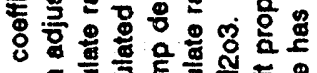

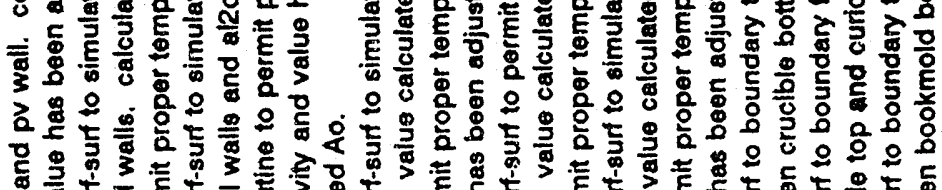

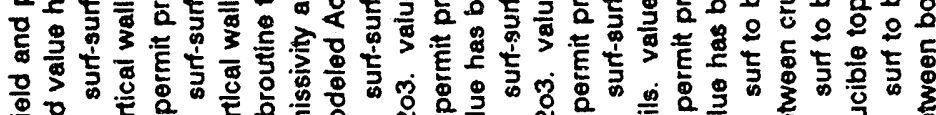

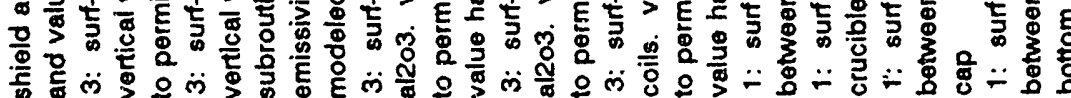

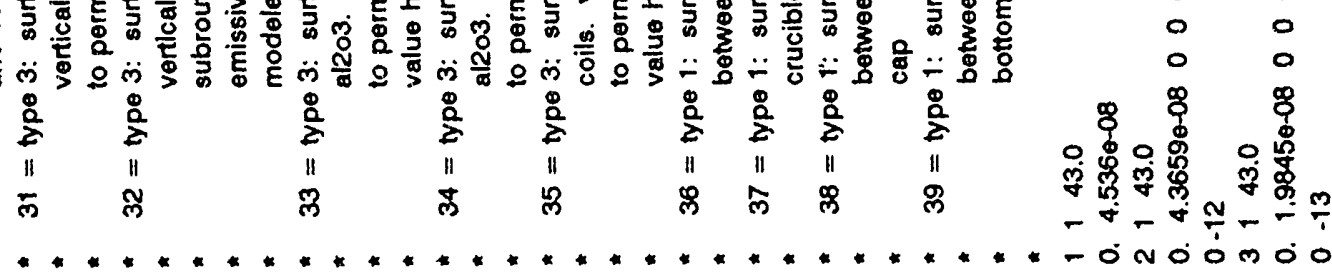

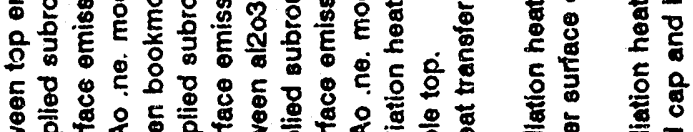

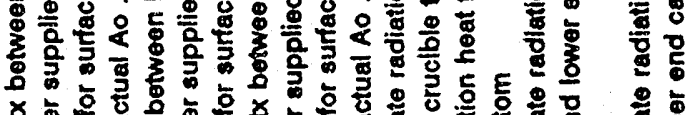

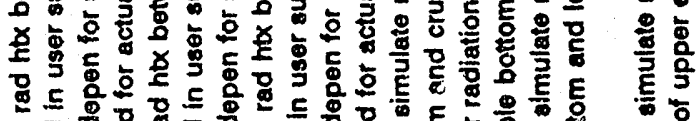

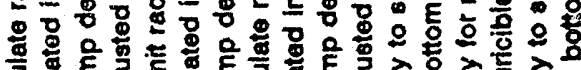

ํํㄹำ

응

量 N N

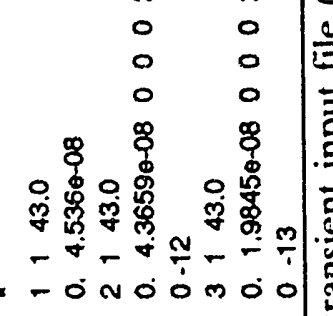

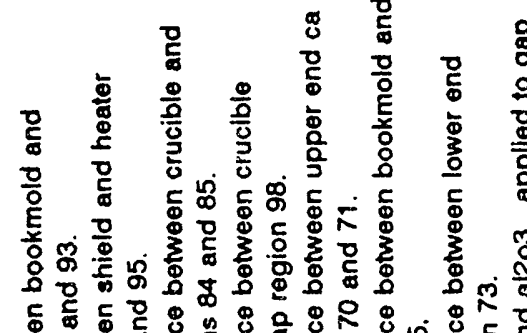

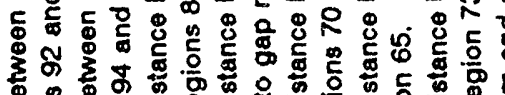

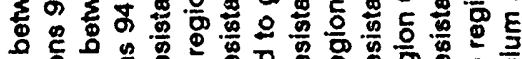

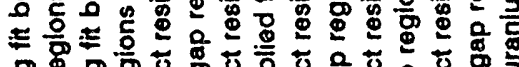

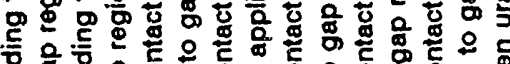

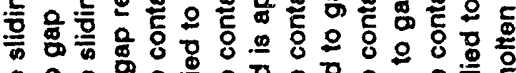

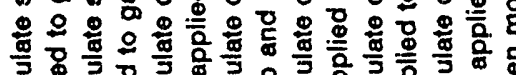

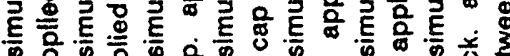

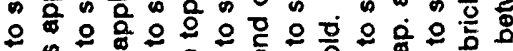

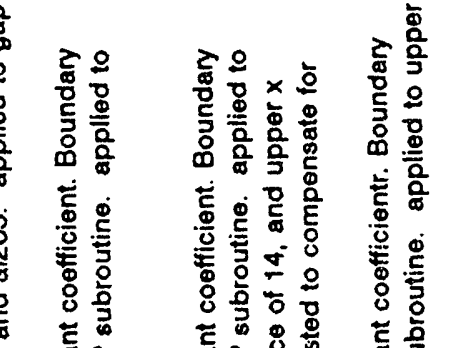

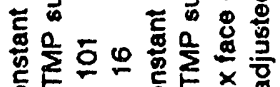

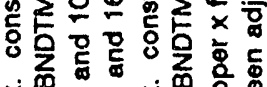

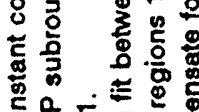

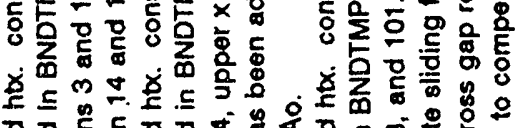

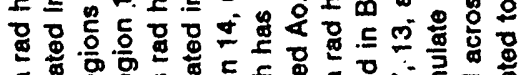

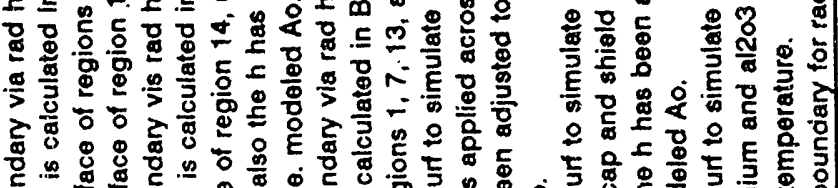

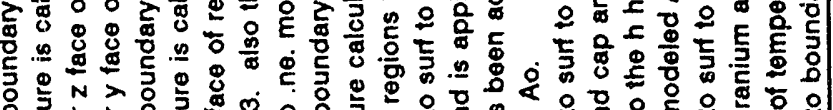

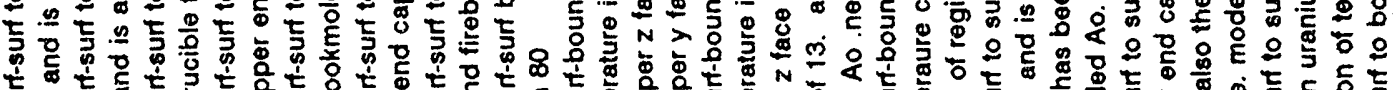

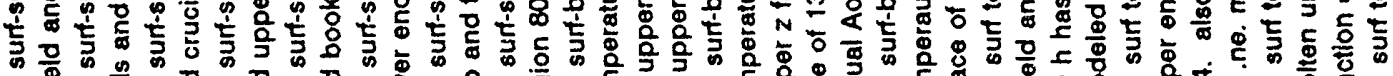

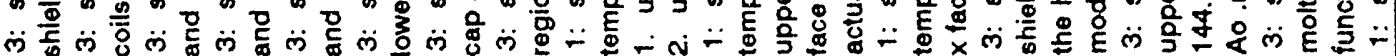

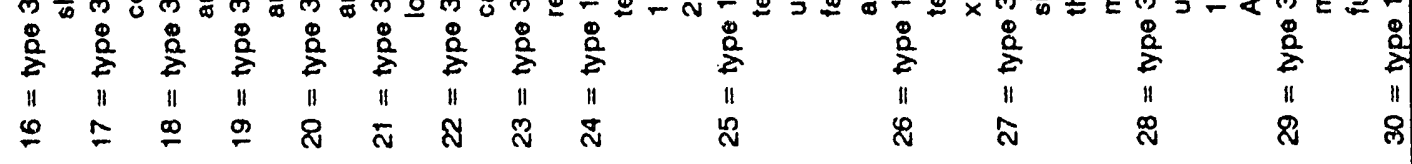




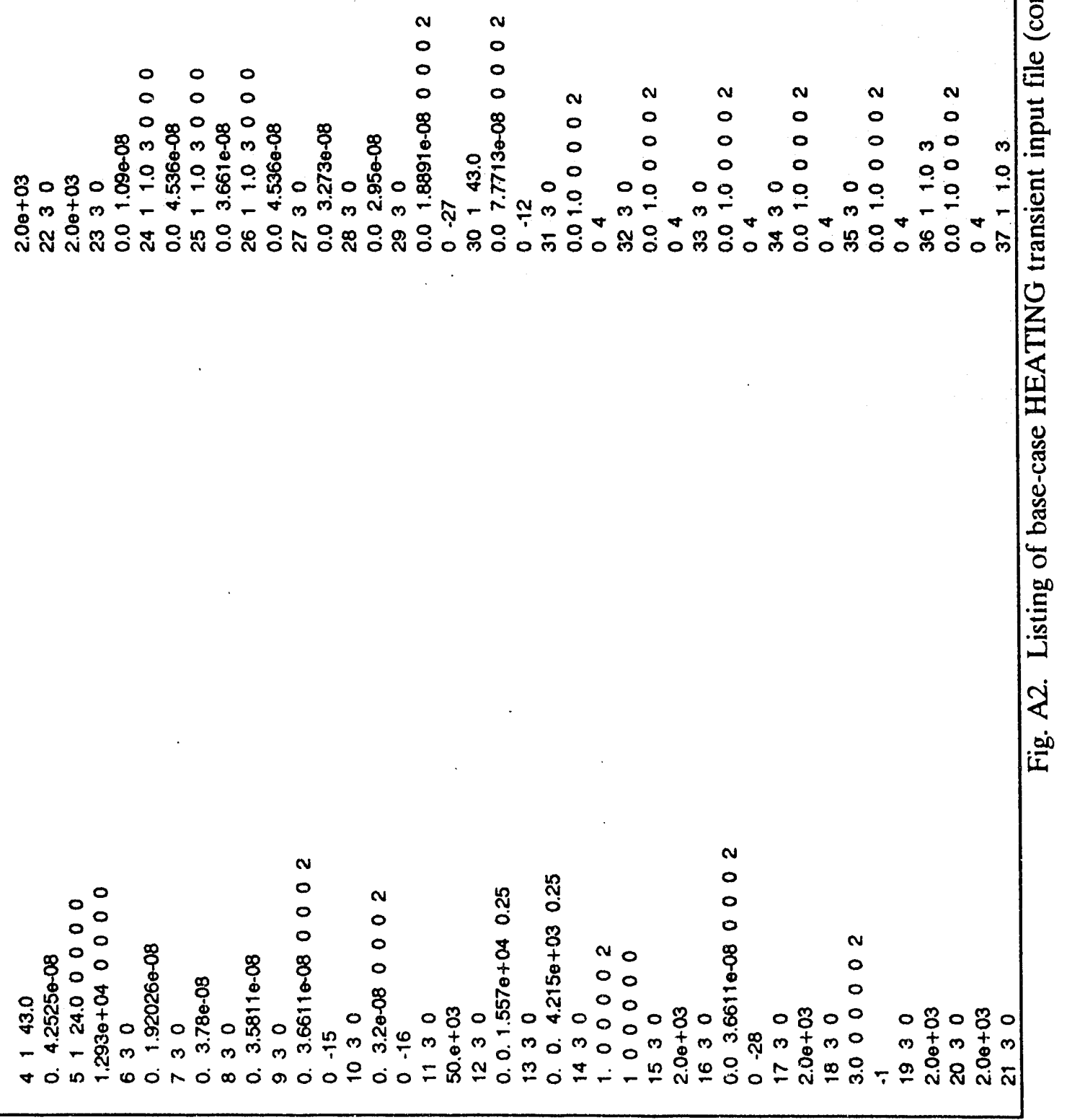




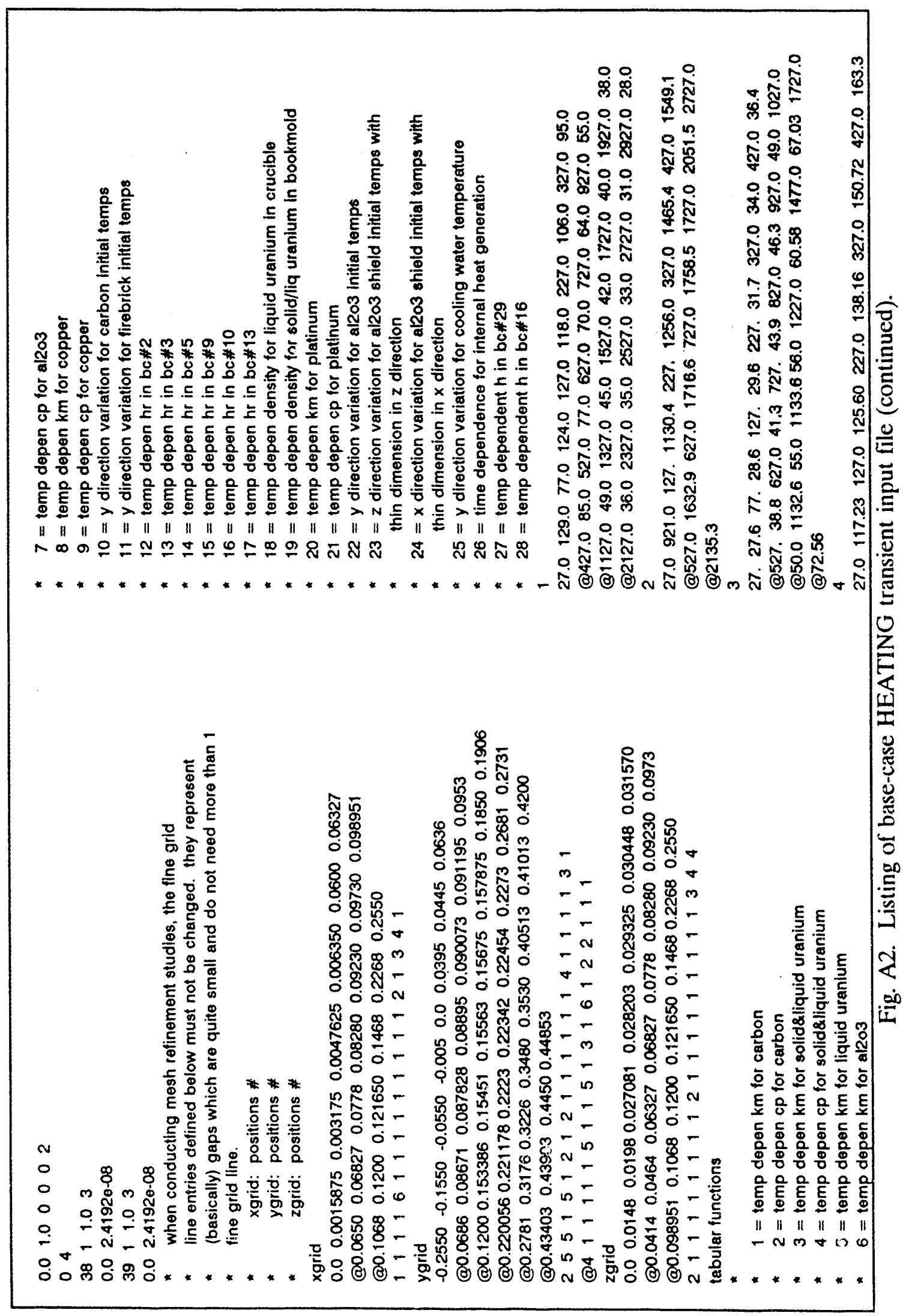




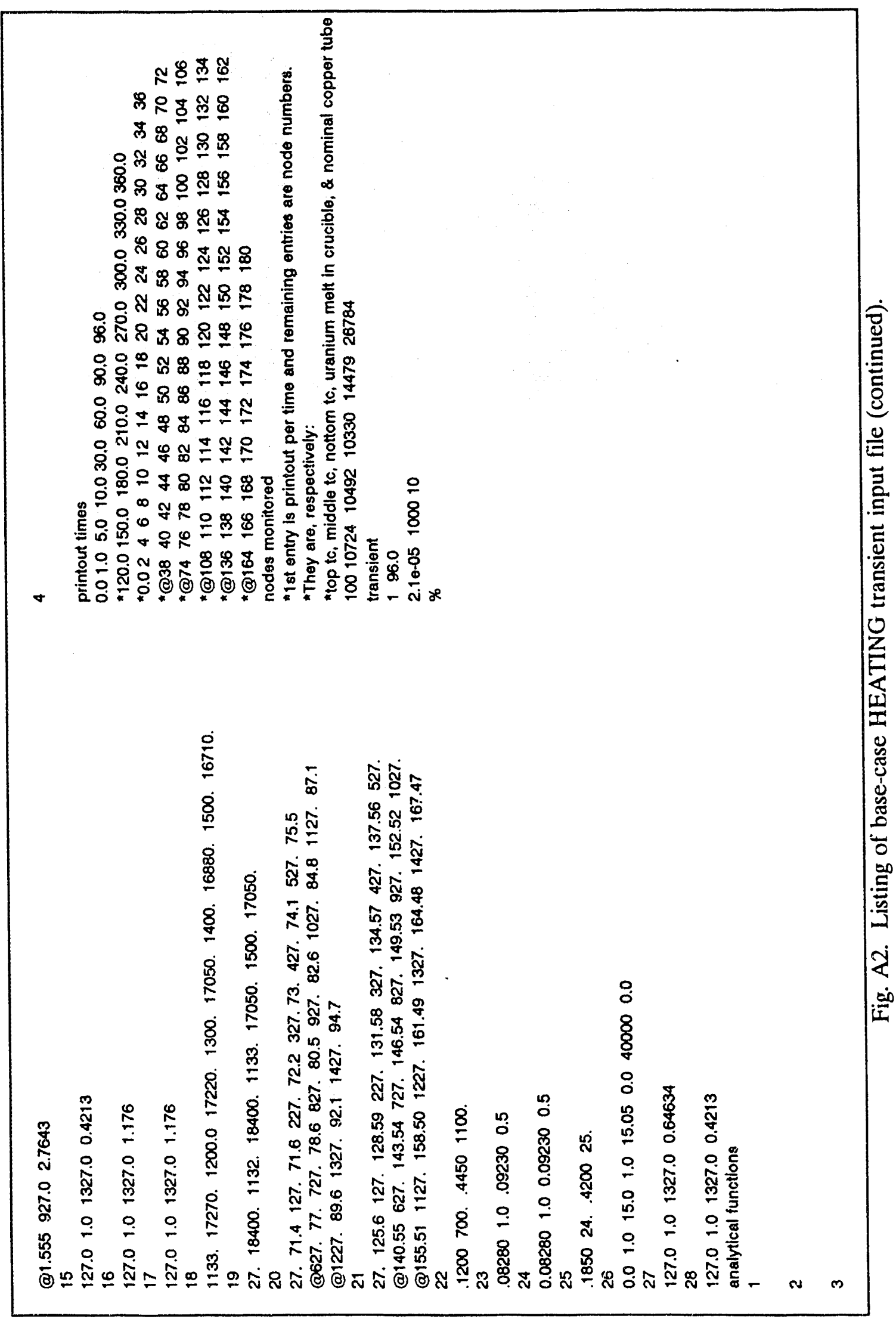




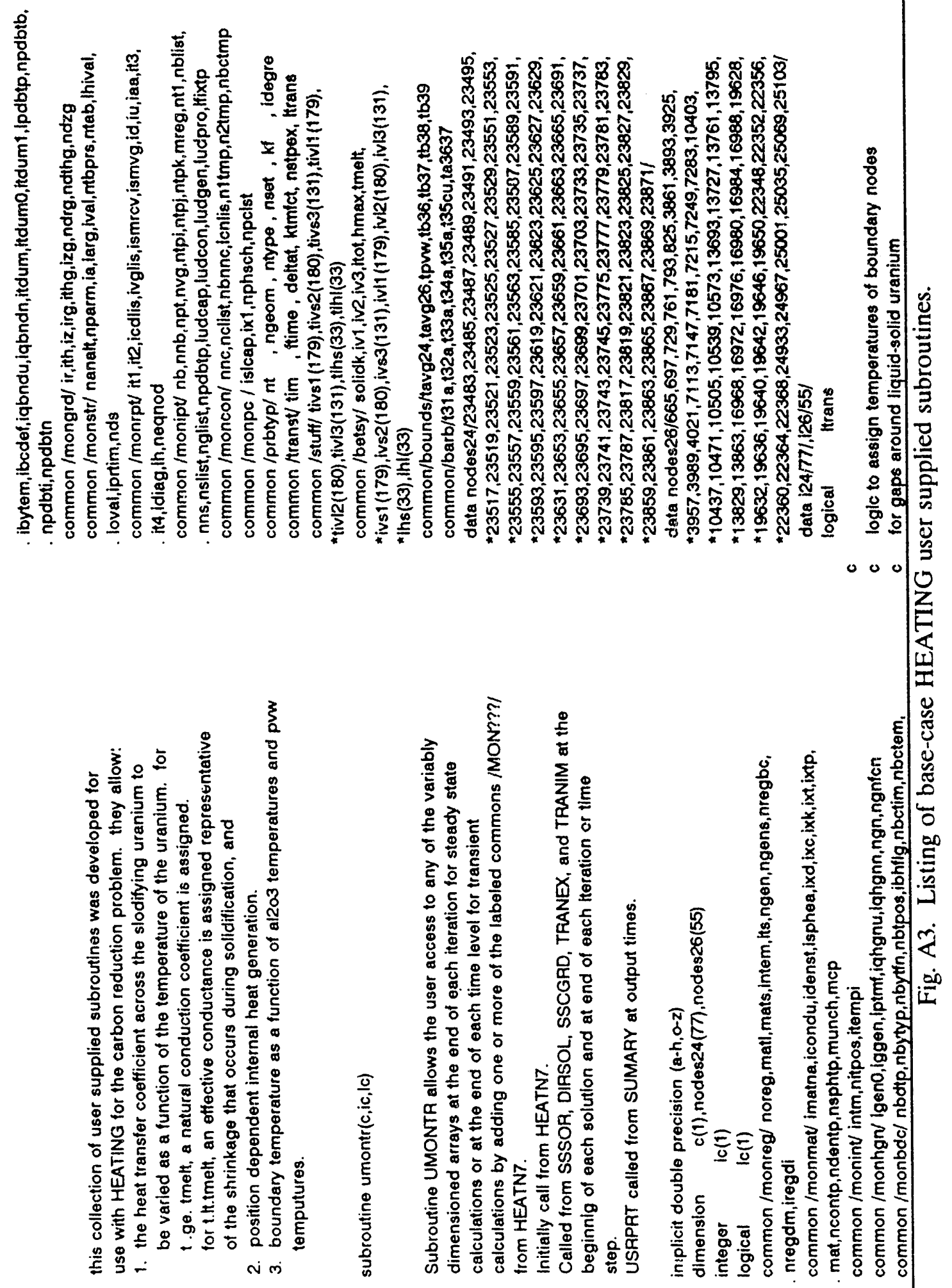




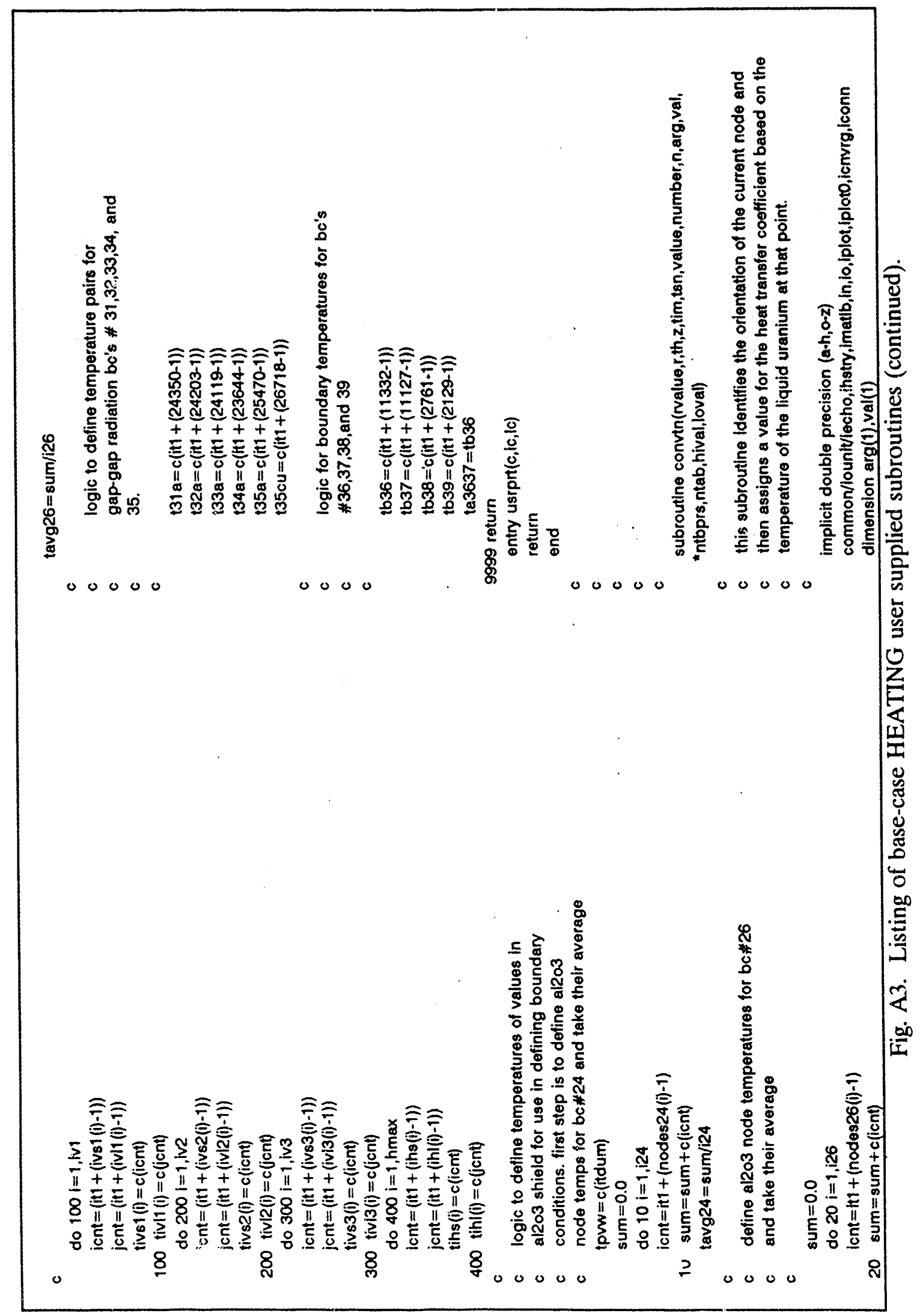




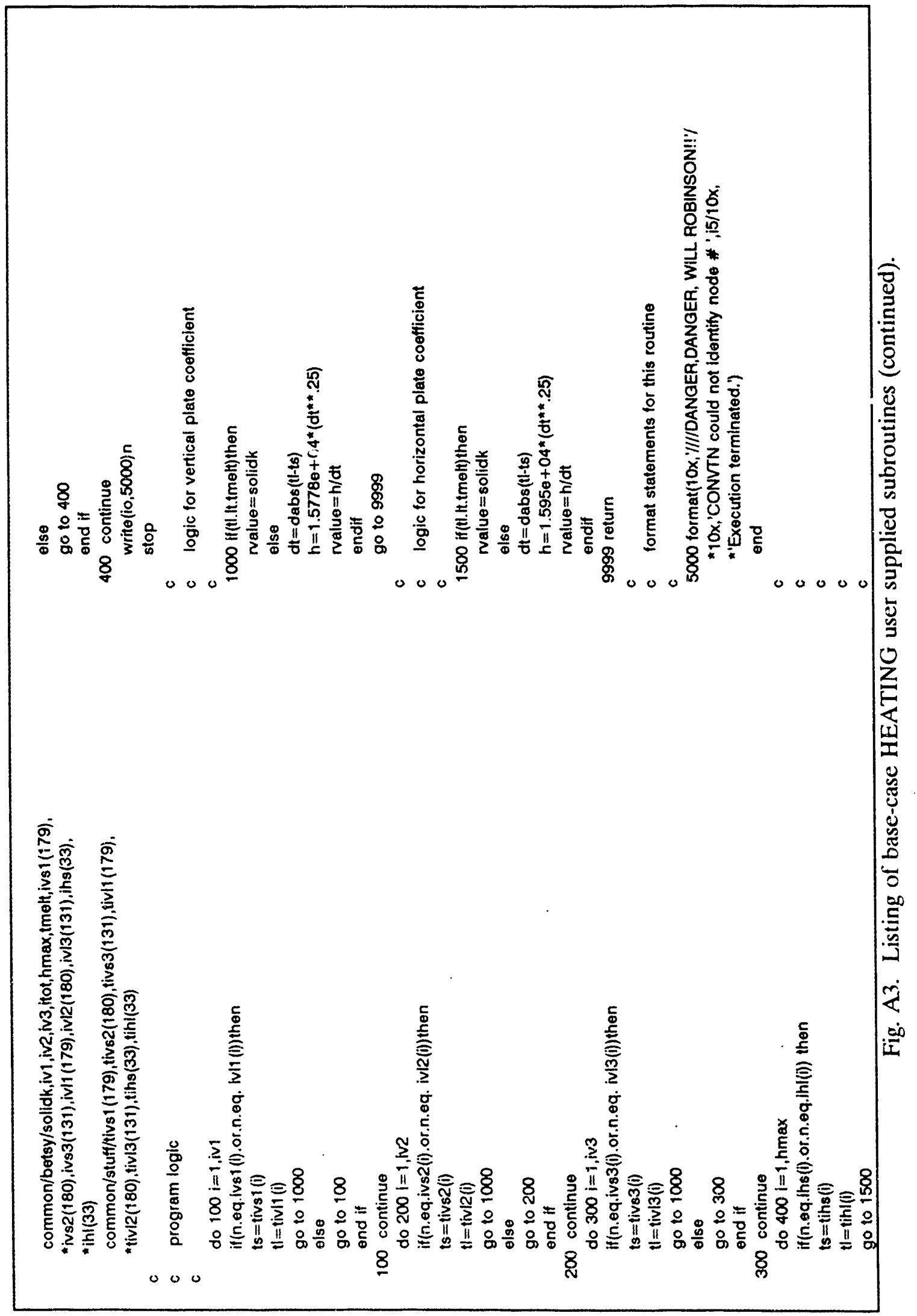




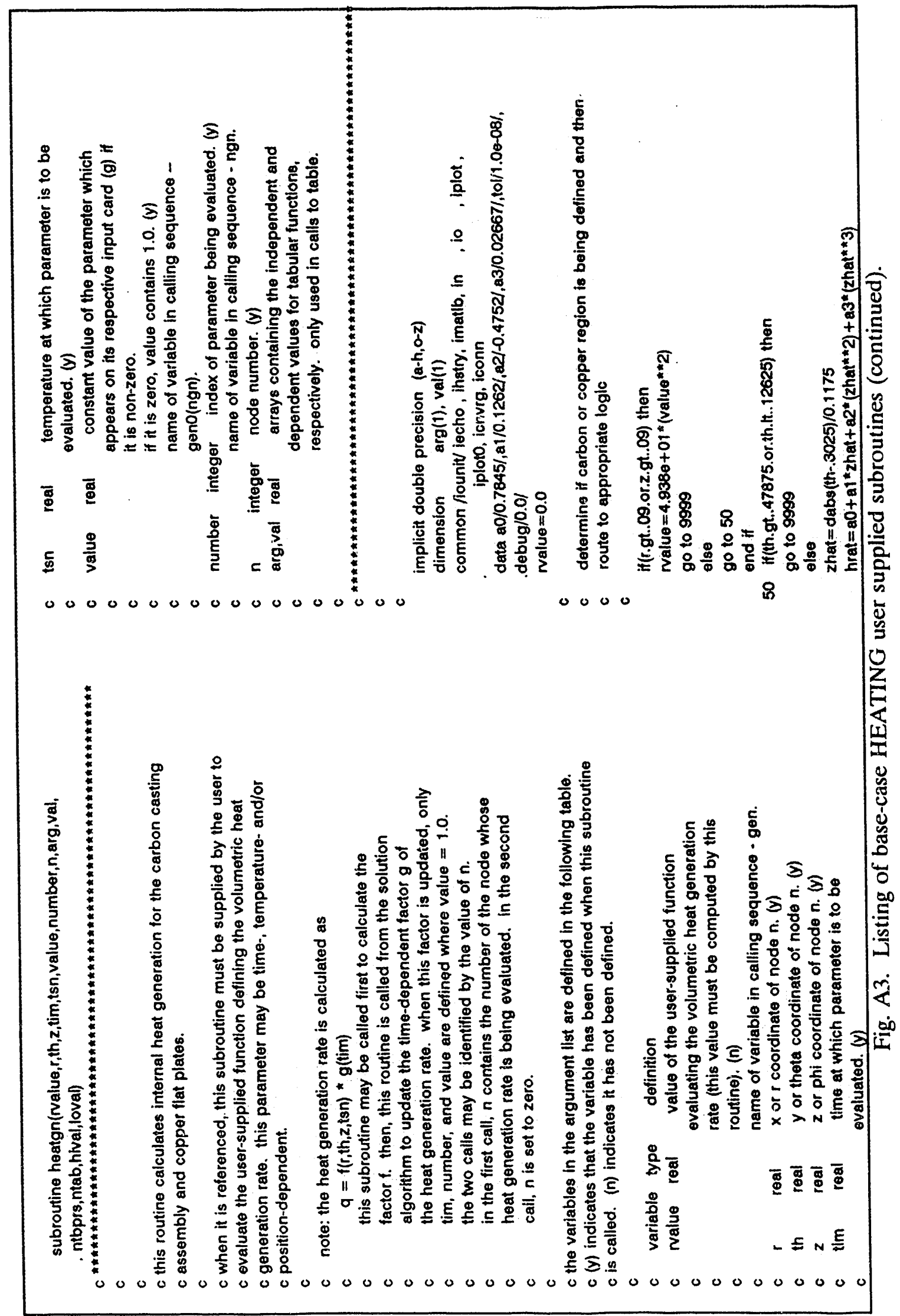




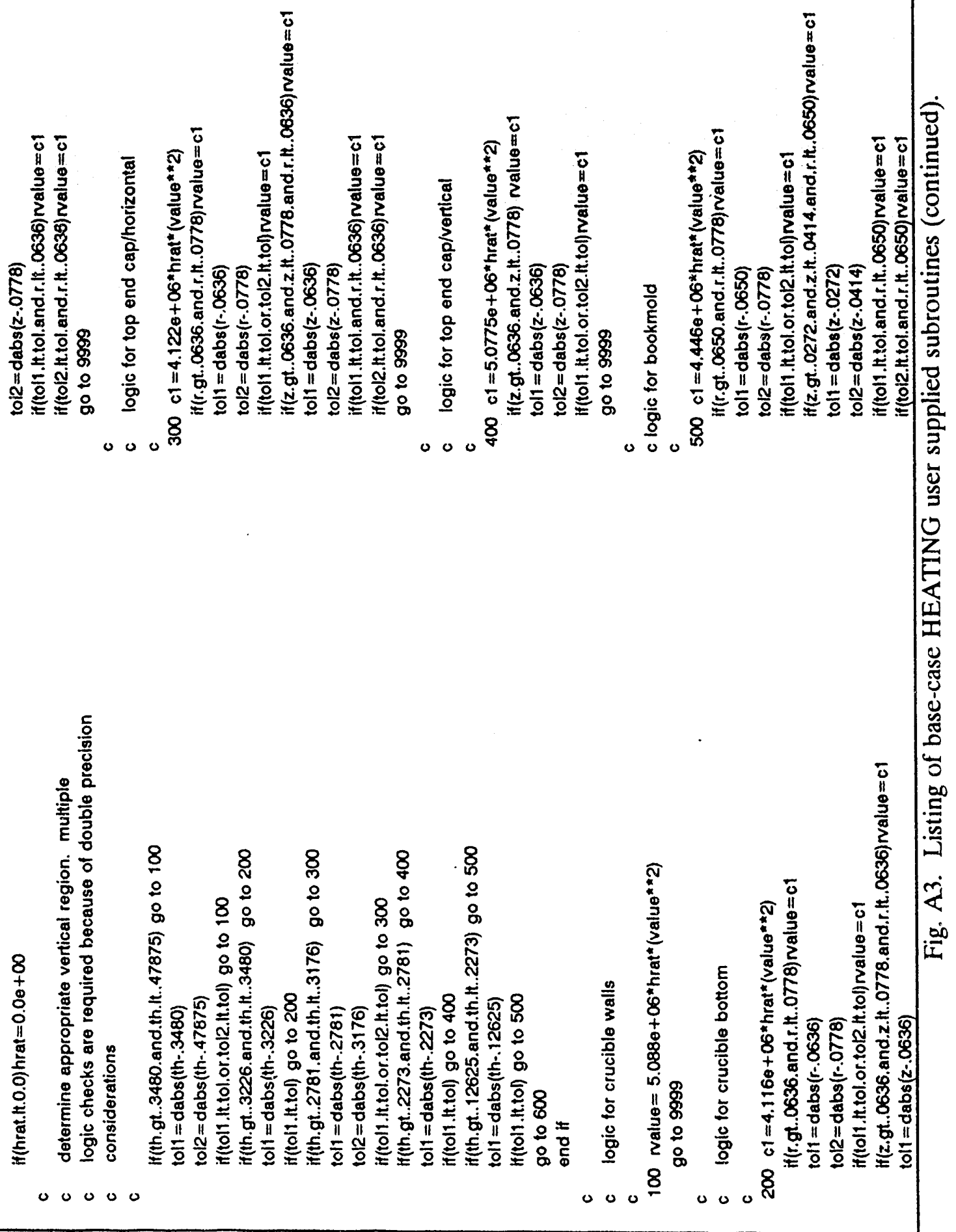




\section{芒送

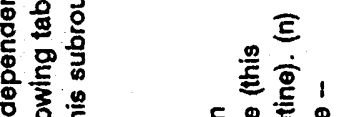

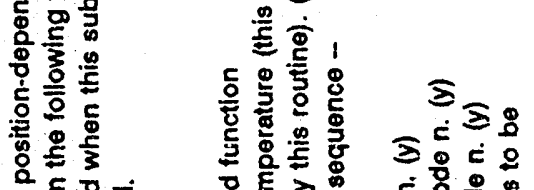

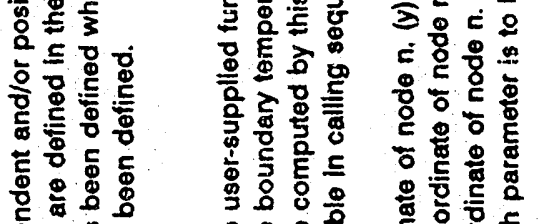

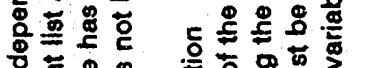

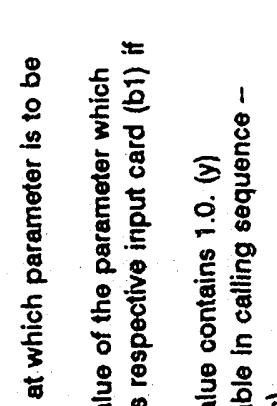

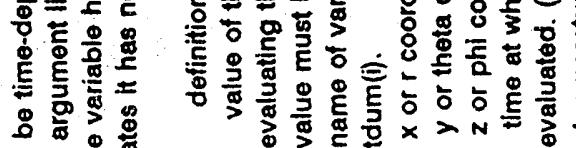

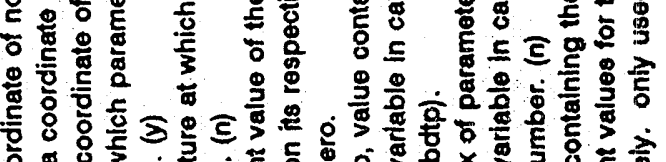

这

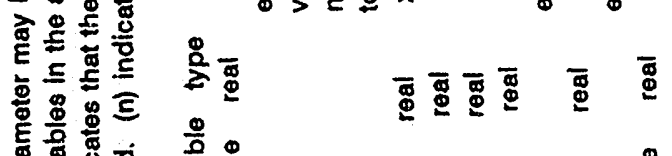

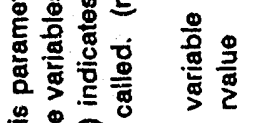

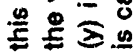

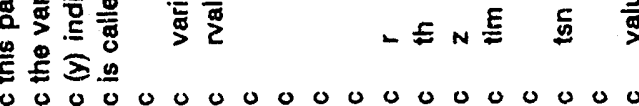

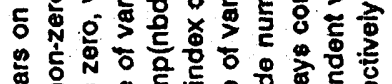

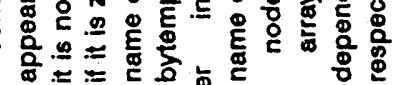

ळ

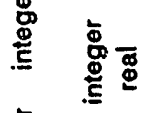

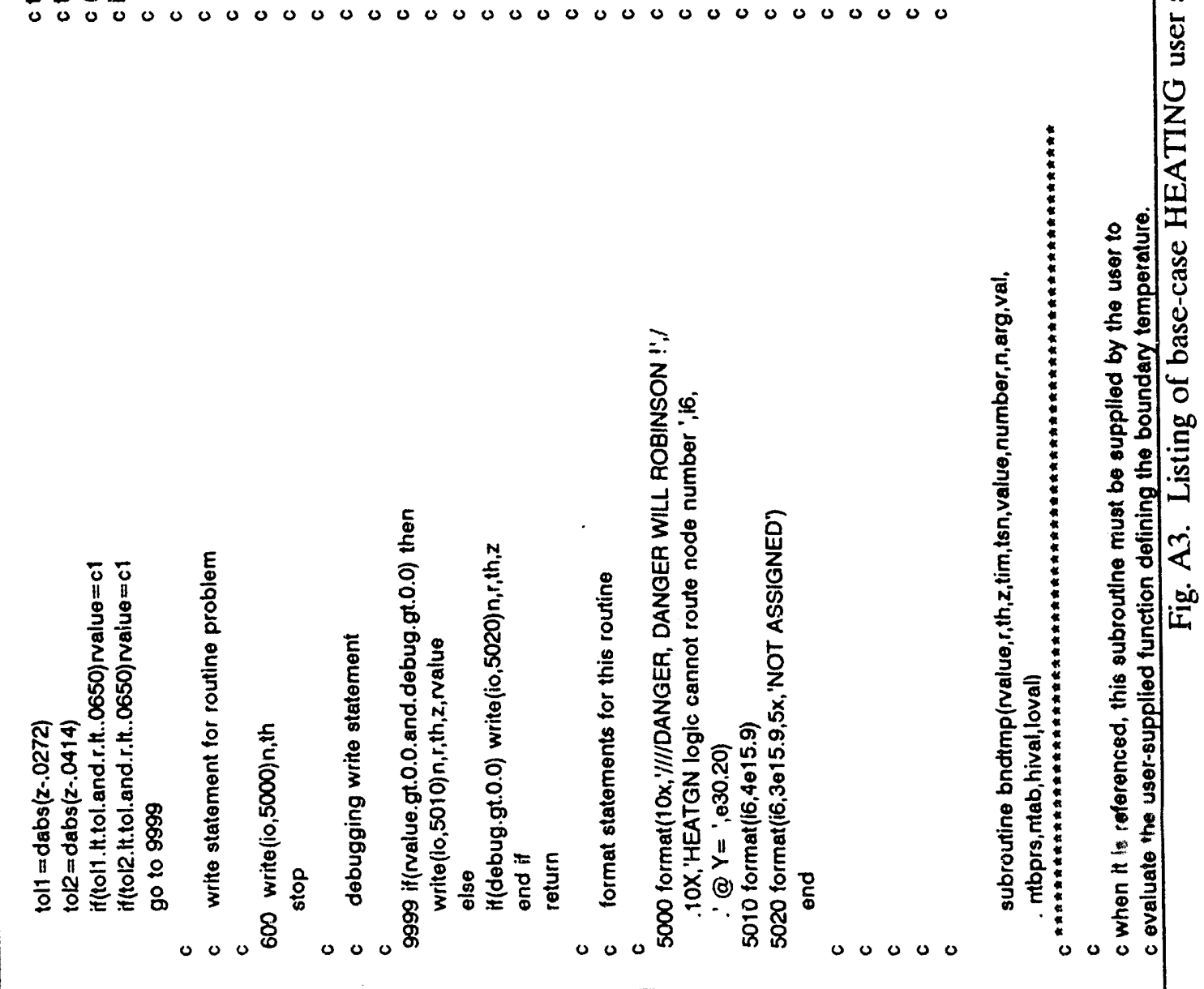




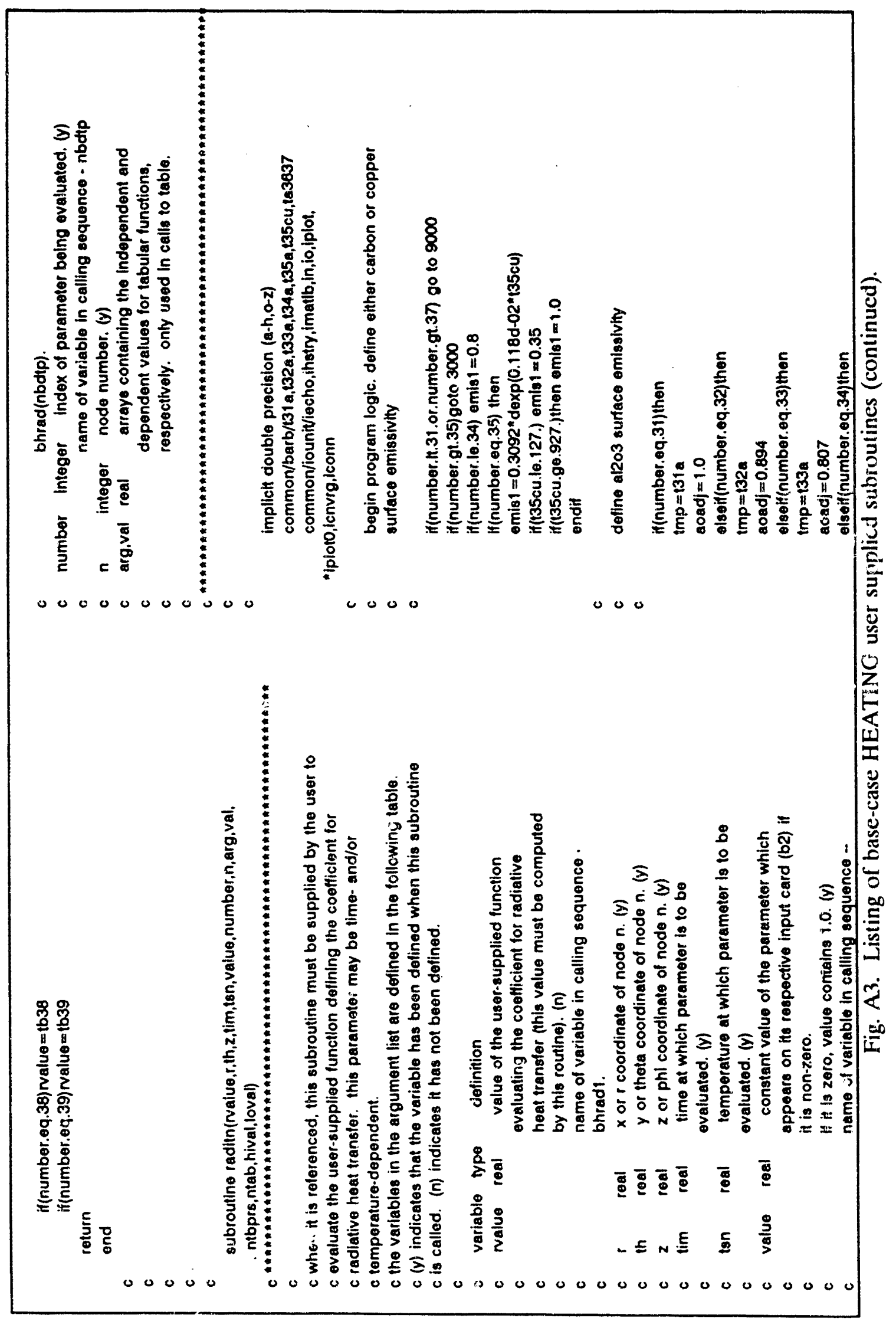




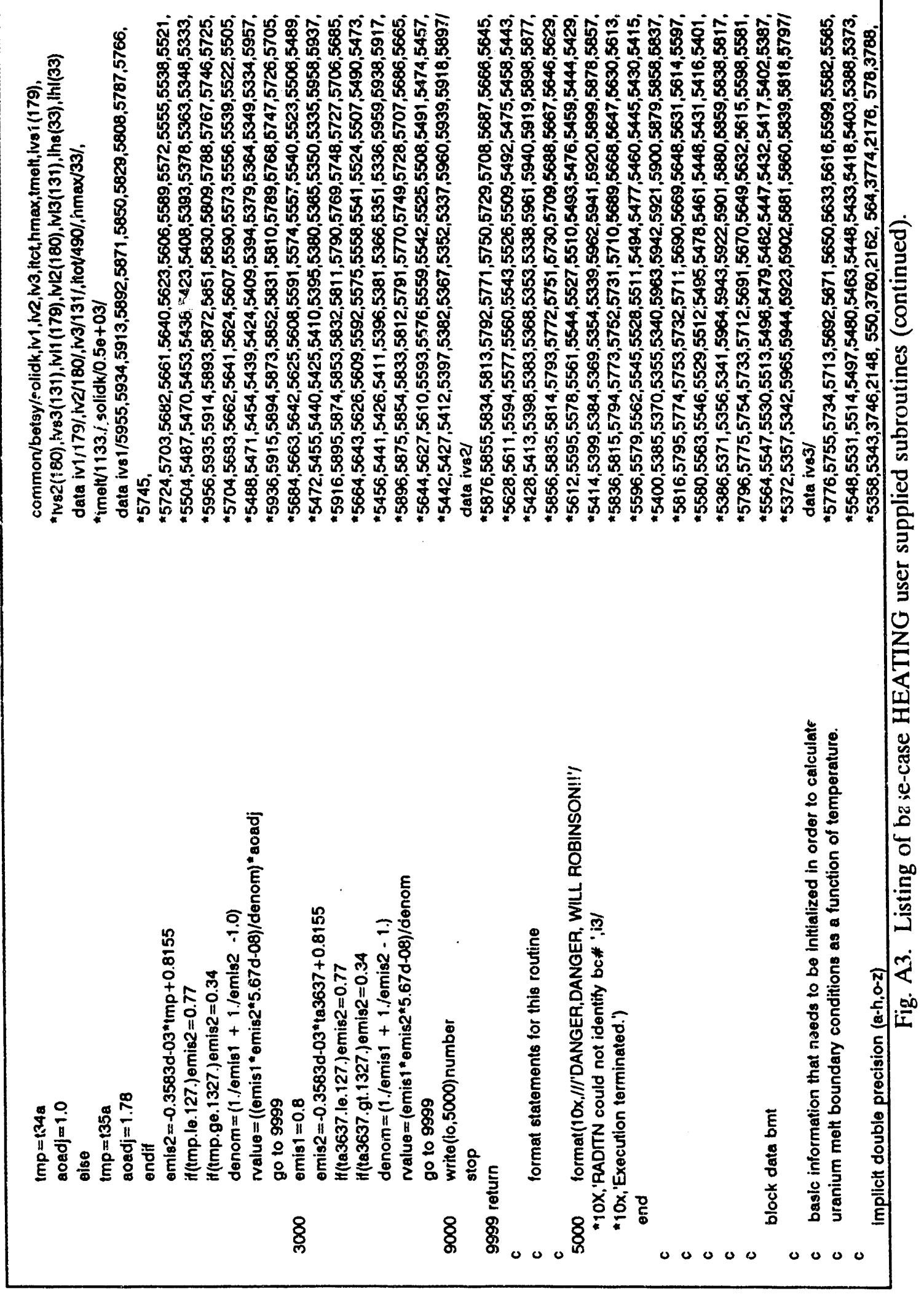




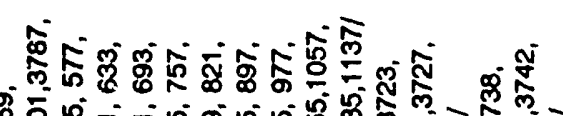

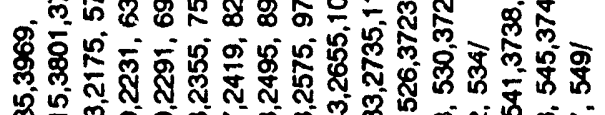

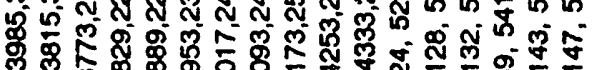

(1)

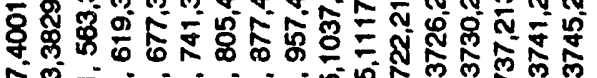

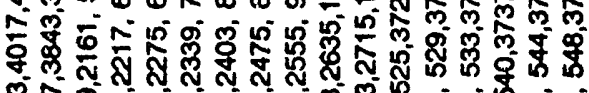

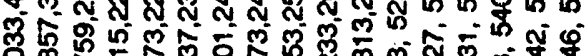

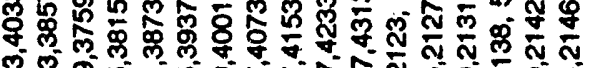

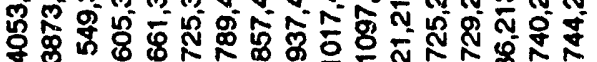

of os

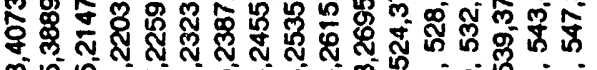

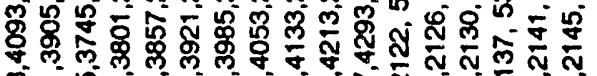

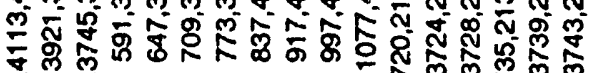

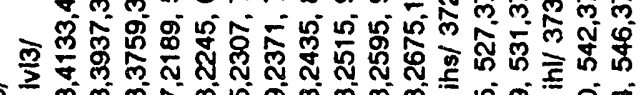

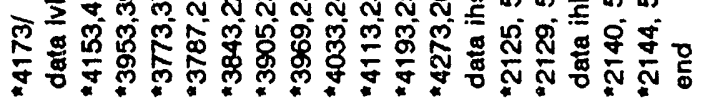

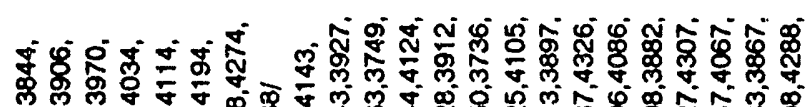

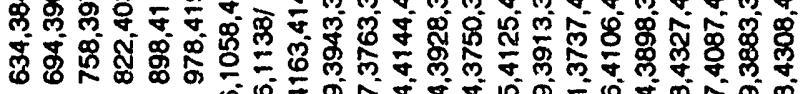

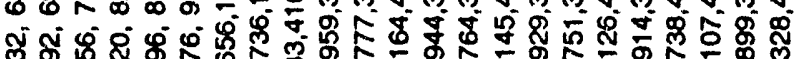

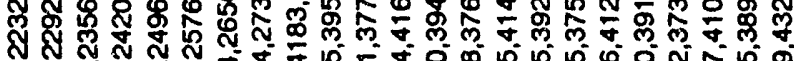

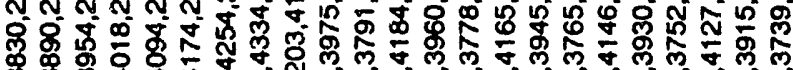

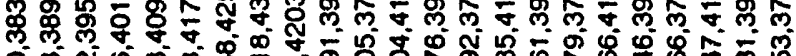

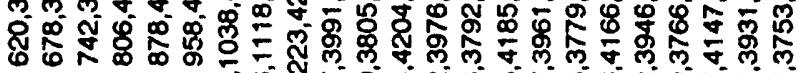
क 00

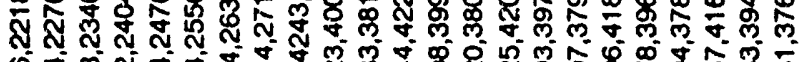

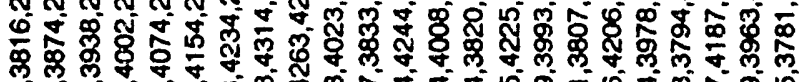

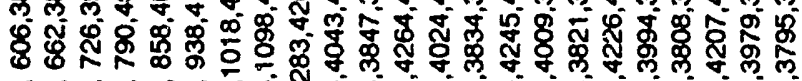

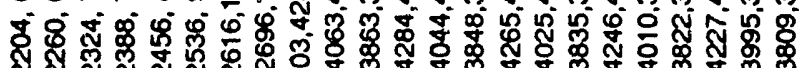
A

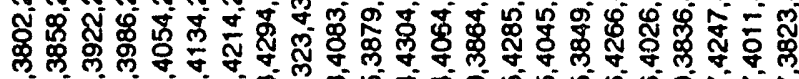

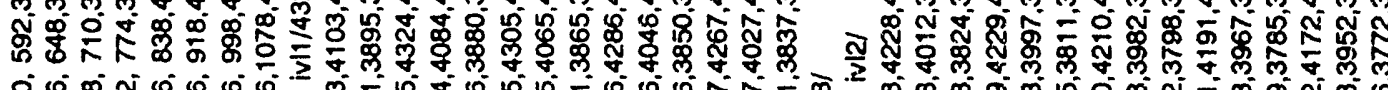

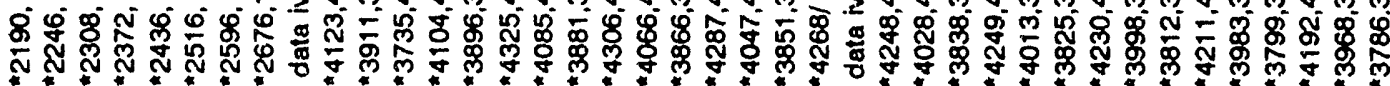

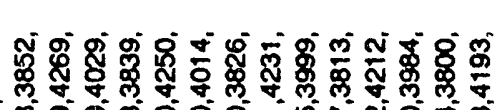

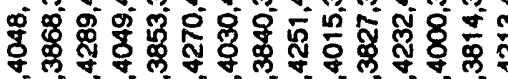
के 8 \%

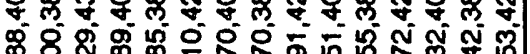

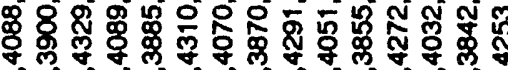

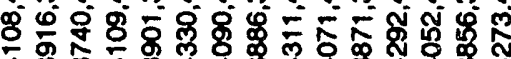

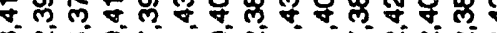

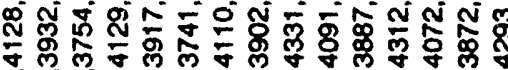

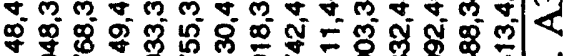
二

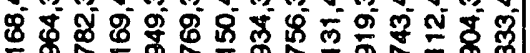
子

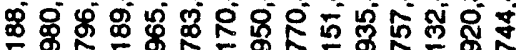
于 00 F

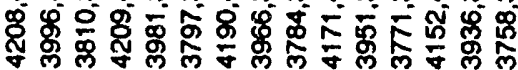

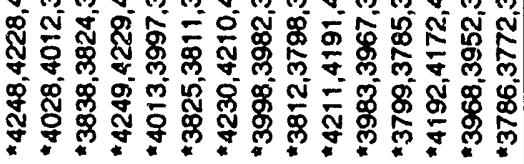




\section{INTERNAL DISTRIBUTION}

1. A. M. Ammons

2. R. L. Beatty

3. E. L. Bird

4. K. W. Childs

5. J. S. Crowell

6. G. E. Giles

7. J. R. Kirkpatrick

8. T. G. Kollie

9. D. J. Lott

10-13. G. Mackiewicz-Ludtka

14. G. M. Ludtka

15. W. G. Northcutt, Jr.

16. M. Olszewski

17. J. E. Park
18. S. H. Park

19. A. S. Quist

20. R. C. Riepe

21-22. C. H. Shappert

23-27. M. J. Taylor

28. J. J. Tomlinson

29. M. W. Wendel

30. G. E. Whitesides/R. P. Leinius/ Applied Technology Library

31. P. T. Williams

32. Applied Technology Library

33. Central Research Library

34. Laboratory Records

35. K-25 Site Records (RC)

\section{EXTERNAL DISTRIBUTION}

36-47. Office of Scientific and Technical Information, P.O. Box 62, Oak Ridge, TN 37831. 
DATE

FILMED

2122193 
